\title{
Acoustic Doppler Current Profiling from the JGOFS Arabian Sea Cruises Aboard the RV T. G. Thompson
}

\author{
TN047, May 3, 1995 - May 20, 1995

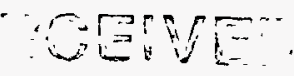 \\ TN048, June 21, 1995 - July 13, 1995 \\ TN049, July 17, 1995 - August 15, 1995 \\ TN050, August 18, 1995 - September 15, 1995

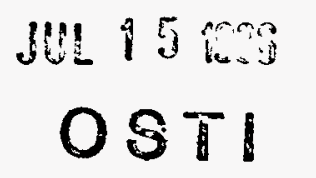

by

Hyun-Sook Kim, Charles N. Flagg, and Yan Shi

Oceanographic and Atmospheric Sciences Division

Brookhaven National Laboratory

Upton, NY 11973

June, 1996

DEPARTMENT OF APPLIED SCIENCE

BROOKHAVEN NATIONAL LABORATORY UPTON, LONG ISLAND, NEW YORK 11973 
DISCLAIMER

This report was prepared as an account of work sponsored by an agency of the United States Government. Neither the United States Government nor any agency thereof, nor any of their employees, nor any of their contractors, subcontractors, or their employees makes any warranty, express or implied, or assumes any legal liability or responsibility for the accuracy, completeness, or usefulness of any information, apparatus, product or process disclosed, or represents that its use would not infringe any privately owned rights. Reference herein to any specific commercial product, process, or service by trade name, trademark, manufacturer, or otherwise, does not necessarily constitute or imply its endorsement, recommendation, or favoring by the United States Government or any agency thereof. The views and opinions of authors expressed herein do not necessarily state or reflect those of the United States Government or any agency, contractor, or subcontractor thereof.

\section{Printed in the United States of America \\ Available From \\ National Technical Information Service}

U.S. Department of Commerce

5285 Port Royal Road

Springfield, VA 22161

NTIS price codes:

Printed Copy: A06; Microfiche Copy: A01 


\section{ACOUSTIC DOPPLER CURRENT PROFILING FROM THE JGOFS ARABIAN SEA CRUISES ABOARD THE RV T.G. THOMPSON}

TN047, May 3, 1995 - May 20, 1995

TNO48, June 21, 1995 - July 13, 1995

TN049, July 17, 1995 - August 15, 1995

TN050, August 18, 1995 - September 15, 1995

June 1996

Oceanographic and Atmospheric Sciences Division Department of Applied Science

Brookhaven National Laboratory Associated Universities, Inc. Upton, Long Island, New York 11973

Under Contract No. DE-AC02-76CH00016 with the UNITED STATES DEPARTMENT OF ENERGY 


\section{DISCLAIMER}

Portions of this document may be illegible in electronic image products. Images are produced from the best available original document. 


\section{Contents}

1 Introduction 3

2 ADCP Installation on the R/V Thompson 5

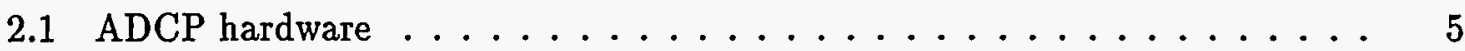

2.2 AutoADCP Data Acquisition System . . . . . . . . . . . 6

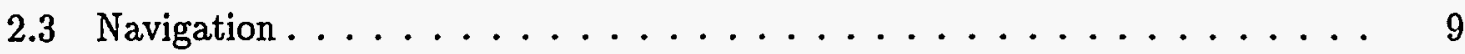

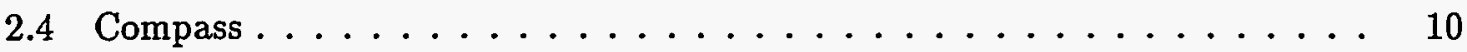

3 Data Processing and Analysis 11

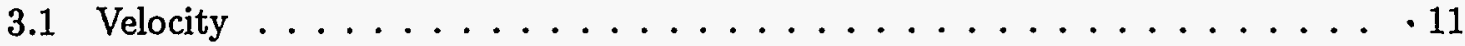

3.2 Acoustic Backscatter Intensity $\ldots \ldots \ldots \ldots \ldots \ldots$

4 Data Collection $\quad 22$

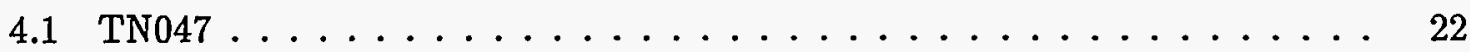

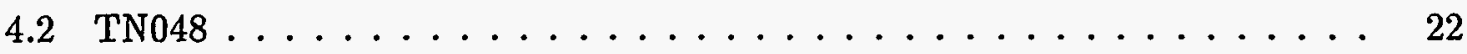

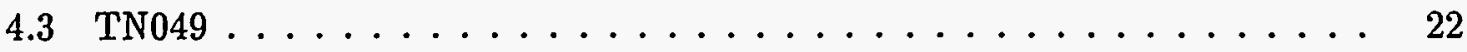

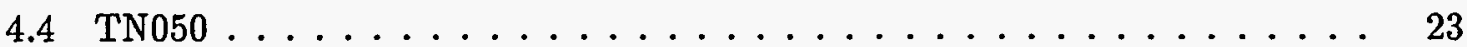

5 Profile Quality 28

6 Acknowledgments $\quad 35$

7 References $\quad 36$

8 Appendix A: List of Sections 42

9 Appendix B: Reference Layer Velocity $\quad 47$

10 Appendix C: Vector Plots and Contoured Sections 52 


\section{List of Figures}

1 Arabian Sea standard cruise track with the station locations, and an array. of current meter and sediment trap moorings. . . . . . . . . . . . 4

2 The ADCP regions of the Arabian Sea, Bay of Bengal, and western portion of the Indonesian Archipelago. $\ldots \ldots \ldots \ldots$

3 Scatter plot of the rms differences greater than $1.5 \mathrm{~dB} \ldots \ldots \ldots \ldots$

4 Scatter plot of the rms differences less than or equal to $1.5 \mathrm{~dB}$. . . . . . 21

5 Cruise track for TN047, Process cruise \#3. . . . . . . . . . . . . . 24

6 Cruise track for TN048, ONR/NRL SeaSoar cruise \#3. . . . . . . . 25

7 Cruise track for TN049, Process cruise \#4. . . . . . . . . . . . 26

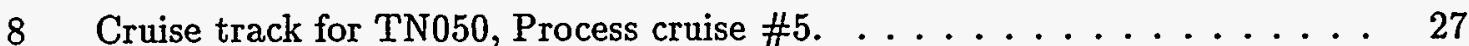

9 Diagnostic profiles for cruise TN049. . . . . . . . . . . . . 31

\section{List of Tables}

1 Cruise schedule for the U. S. JGOFS Arabian Sea Project. The bold-faced entries are the cruises covered by this data report. . . . . . . . . . 37

2 Listing of Arabian Sea regional ADCP configuration . . . . . . . . 38 


\section{Introduction}

Acoustic Doppler current profiler (ADCP) data is part of the core data for the U.S. JGOFS Arabian Sea project, along with hydrographic and nutrient data. Seventeen cruises are scheduled to take place between September 1994 and January 1996 on the R/V T.G. Thompson. They are numbered consecutively from the ship's commissioning with the first JGOFS cruise designated TN039. Table 1 lists start and end dates of each cruise with its mission.

All but the first cruise have been or will be staged from Muscat, Oman. Each cruise is scheduled for a duration of between two weeks and one month. Seven of the cruises, referred to as process cruises, follow a standard cruise track, taking hydrographic, chemical and biological measurements (see Figure 1). The rest of the cruises, which take place generally within the standard cruise region defined by a set track, are for the deployment and recovery of moored equipments and towing of a SeaSoar.

ADCP data are collected using an autonomous data acquisition system developed for ship-of-opportunity cruises, named the AutoADCP system. The system is an extension of RD instrument's DAS version 2.48 using enhancements made possible with "user-exit" programs. It makes it possible to collect ADCP data without the constant monitoring usually necessary and insures constant data coverage and uniform data quality.

This data report presents the ADCP data collection methods and results from the third group of four JGOFS Arabian Sea cruises, TN047 through TN050. This group includes three process cruises and one SeaSoar cruise (bold-faced entries in Table 1). The data were processed using the CODAS software, the single most widely used processing program for ship-mounted ADCP system, developed at the University of Hawaii for PC's or UNIX computers. All the ADCP data reside in the CODAS database at Brookhaven National Laboratory, and are generally available to JGOFS investigators through contact with the 


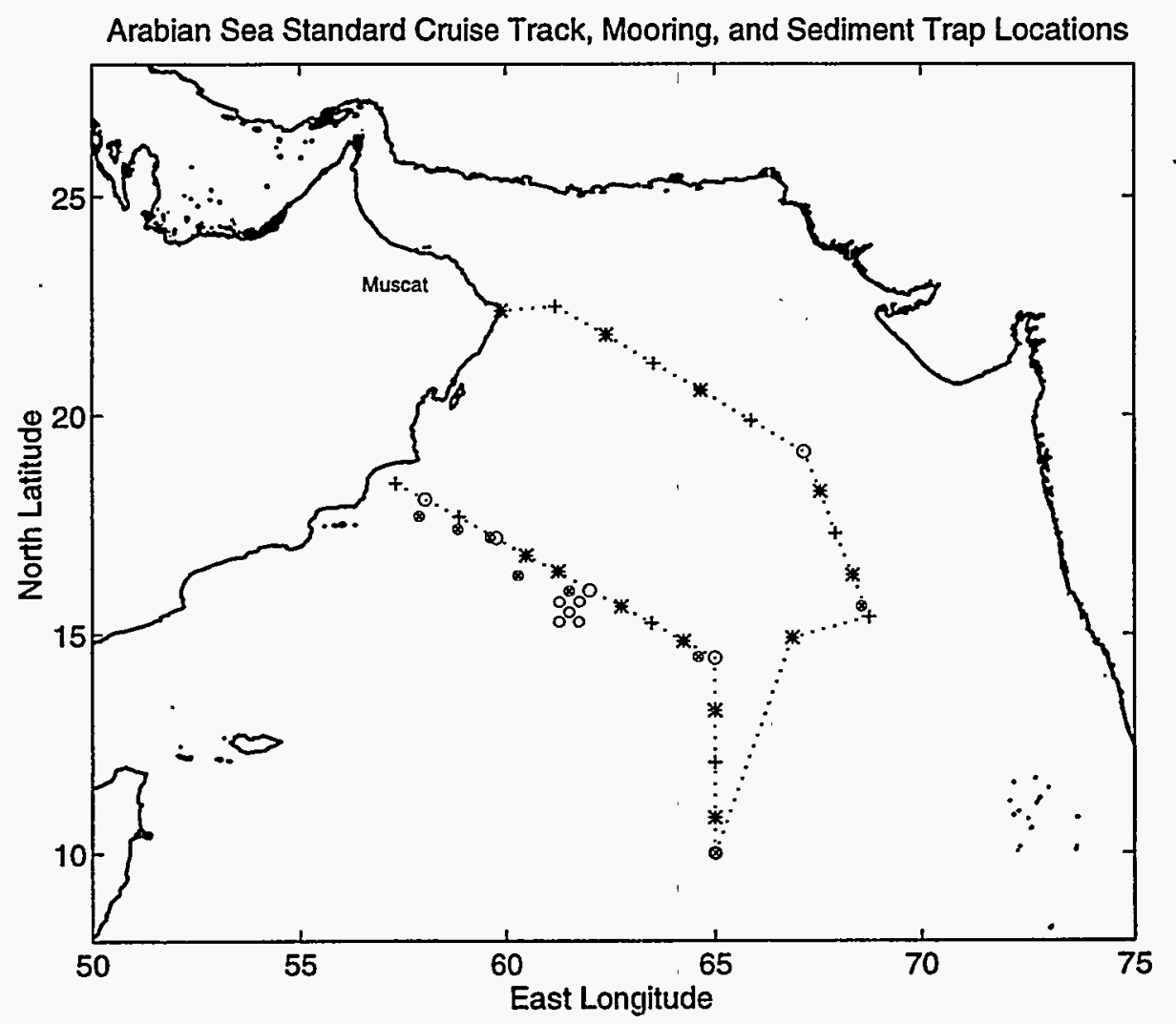

Figure 1: Arabian Sea standard cruise track with the station locations, and an array of current meter and sediment trap moorings: The $o,+$, and * indicate long, intermediate and hydrographic stations. The symbol of $\otimes$ designates sediment trap mooring. The o centered at $15.5^{\circ} \mathrm{N}, 61.5^{\circ} \mathrm{E}$ represent the locations of five long-term moorings. 
authors.

A description of ADCP hardware, the AutoADCP data acquisition system, and the collection of navigation and compass data on the Thompson is given in section 2 . Section 3 presents the processing and analysis of velocity and acoustic backscatter intensity data. Section 4 documents data collection for each cruise together with a cruise track. A diagnosis of profile quality is given in section 5 .

The ADCP data results from previous cruises are documented in two data reports; the data for cruises TN039 through TN042 is in Flagg and Shi (1995), and for cruises TN043 through TN046 is in Flagg, Kim and Shi (1995).

\section{ADCP Installation on the $\mathrm{R} / \mathrm{V}$ Thompson}

\subsection{ADCP hardware}

The ADCP used on the R/V Thompson is a $153.6 \mathrm{kHz}$ ADCP, model VM-150 manufactured by RD instruments at San Diego, CA, with a four-beam concave transducer (serial \# 127). The transducer is mounted in a faired transducer pod which protrudes below the hull of the Thompson by about two feet such that the depth of the transducer is nominally 5.9 meters (19 feet). The ADCP transducer is exposed directly to the sea. The transducer pod eliminates, or at least reduces the impact of bubble-sweep-down on the ADCP. Experience with this installation during the relatively calm conditions of the first eight cruises indicates that this is an excellent installation producing high quality data at all ship speeds. The ability to produce high quality data was tested during the JGOFS monsoon cruises in this data report, and the impact of high waves on ADCP performance is assessed below.

Installation of the ADCP deck unit was done on a computer rack above a sub-bottom depth sounder in the Thompson's computer lab. The deck unit was connected to the ship's 
uninterruptable power supply. The AC voltage going into the ADCP deck unit was measured to be 117 volts during the calibration and training cruise TN039. The temperature of the deck unit with the depth sounder operating was $30^{\circ}$ Celsius under the air-conditioned environment of the electronics lab. However, there were occasional large variations in temperature that may alter the operating environment of the deck unit.

On the R/V T.G. Thompson, the AutoADCP programs have been installed on two PC computers, both of which are connected by a Pathworks network to virtual disks on a DEC 5000-200 Unix workstation. In September 1994, one of the Thompson's PCs (a Delphi 286) was set up to collect the data, while a PC supplied by Brookhaven (a Dell 386) was used for real-time presentation of the results. The AutoADCP programs were installed on both computers so that the data collection could be switched to the Brookhaven PC if the primary PC suffered a failure.

Standard ADCP data is displayed on the Thompson's Delphi 286. The presentation consists of 5-minute ensemble averaged profiles of $U$ (zonal) and V (meridional) velocities, AGC (backscatter intensity) and percentage of good pings. In addition to the data gathering performed by the AutoADCP system, another set of programs was written in MATLAB to present ADCP data in real-time. These programs run on the second computer, the Dell 386, and make use of the networked virtual disk that is common with the AutoADCP system to access the most recent pingdata files. The real-time displays include vertical sections of $U$, $\mathrm{V}$ and range corrected backscatter intensity. The usual setup displays the last 12 hours of ADCP data, updating the display at 15 minute intervals.

\subsection{AutoADCP Data Acquisition System}

The AutoADCP system is a modified version of RD instrument's data acquisition system (DAS) version 2.48 for narrow-band ADCPs. The purpose of the modification is to 
ensure high quality data while minimizing interference with other program components. The system was initially developed in a collabration among Brookhaven National Laboratory, University of Rhode Island, and RD instruments. The program expands upon the standard DAS's capabilities to make it possible to automatically start and stop the collection of the data, and to change the configuration of the DAS depending upon the ship' s location. The AutoADCP system is also designed to make back-up copies of the pingdata files and provides a means of restarting the system if for any reason the DAS stops collecting data.

The major component of the system is a "user-exit" program named FLAG.EXE. This program is called up at the end of each ADCP ensemble, determines the ship's position, and compares it with pre-defined regions contained in the POSITION.DAT file as shown in Figure 2. When the ship leaves one region for another, the DAS's default configuration file, START.CNF, is updated, the computer reboots and the ADCP starts pinging using the new configuration. Most of the data in the program was obtained using the configuration for the northern Arabian Sea, ARABSEA.CNF. Table 2 presents the ARABSEA.CNF file.

Provision has also been made for a watchdog timer and automatic backup of pingdata files each time a file is filled. The utility of the AutoADCP DAS is that ensemble interval, number of bins, bin and pulse size, bottom tracking, and other configuration parameters can be controlled without an on-board operator monitoring the DAS's performance. This makes for a more consistent and robust data set.

In addition, the system includes the WOCE standard enhancements to the DAS with another "user-exit" program, UE4.EXE, which was developed by Eric Firing's group at the University of Hawaii. This program is designed to improve upon some features of RD instruments' ${ }^{\prime}$ DAS software. The most important element is that UE4 records the position of the ship precisely at either end of the ensemble. This allows a more accurate computation 


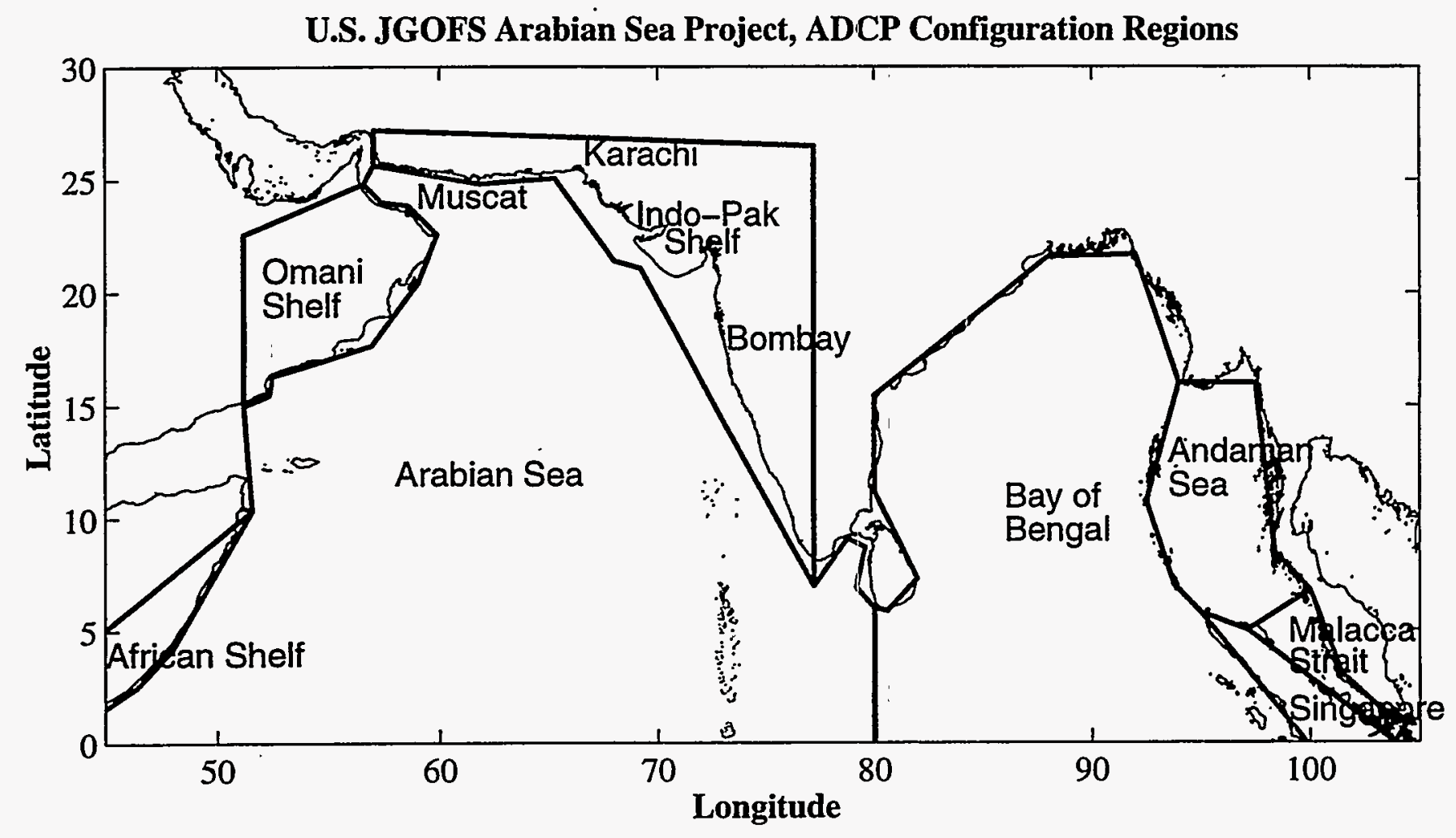

Figure 2: The ADCP regions of the Arabian Sea, Bay of Bengal, and western portion of the Indonesian Archipelago, which dictate control over the operation of the ADCP through the specification of the appropriate configuration file. The ADCP regions include possible ports of call and the continental shelves as well as the open ocean of the Arabian Sea and Bay of Bengal. 
of the ship's velocity during the ensemble. The UE4 program has been expanded recently so that it now works with the Ashtech GPS attitude sensor which uses phase differential GPS to determine the ship's heading. The Ashtech heading data is not only more accurate than the ship's gyro compass, but also immune to the latitudinal speed and turning errors that degrade gyros. However, because the Ashtech heading data can have gaps, the primary heading information for the ADCP remains the gyro compass. The recorded Ashtech heading data is used on a post-cruise basis to adjust the compass heading as needed.

A third user-exit program is AGCAVE.EXE, which modifies the way the DAS collects acoustic backscatter intensity data. Without the addition of this program, the DAS records the intensity data (which used to be called amplitude) as a single profile composed of the average of all four beams. This degrades the intensity data because, without calibration, the individual beams produce slightly different profiles. To address this problem and to allow for post-cruise calibration of the intensity data, AGCAVE.EXE was developed. The program forms ensemble averaged profiles for each beam and stores the results separately in the pingdata data file location nomally reserved for "last AGC".

These are the main components in the AutoADCP DAS so that it only requires an occasional check to ensure that the hardware is still functioning. At the end of each cruise the pingdata files were copied to a SyQuest removable hard disk and sent to Brookhaven National Laboratory for processing.

\subsection{Navigation}

Navigation information for the Thompson was provided by a GPS satellite navigation system. The intent was to use a P-code GPS receiver for the JGOFS cruises. However, permission to use the more accurate system was delayed and the $\mathrm{P}$-code receiver was not used during the first four cruises of the program (Flagg and Shi, 1995). The receiver was 
made operational in January, 1995 in preparation for cruise TN043. It worked successfully for cruise TN043 through the middle of cruise TN046, and then from cruises TN048 through TN050 (Appendix B). The improvement in the navigation quality due to the P-code receiver is significant and quite obvious during the processing of the ADCP data.

Relative accuracy of ensemble end-point positions using the degraded C/A GPS code had an rms value of about 33 meters for both latitude and logitude. The change in navigation quality is mostly visible in the initial estimates of the reference layer velocities where the P-code data had resulted in a factor of four to five reduction in the short-term variance, suggesting a similar reduction in rms short-term position accuracy. During the ADCP data processing, the navigation fixes are smoothed (Appendix B) to lessen the effects of the quasi-random navigation errors. With the P-code GPS receiver, the required smoothing to produce high quality results was significantly reduced.

The use of the P-code data was controlled by the UE4 user-exit program where the P-code data stream was set as the primary navigation source. The position data from the Ashtech receiver, when it was available, was used as a backup. The UE4 user-exit program reads the navigation data contained in the NEMA "GGA" message at the end of the ensemble and records the results in the "user buffer" area. With the P-code receiver in the system, the laptop computer used to reformat of the "GGA" message on the earlier cruises was no longer used. The UE4 program also maintained the PC clock to within 2 seconds of the GPS time provided in the GGA message.

\subsection{Compass}

The primary heading data for the ADCP was provided by the Thompson's gyro compass. Both the latitude and speed corrections for the compass were daily/regularly updated by bridge personnel depending upon the ship's activities (Bill Martin, personal communi- 
cation). When the ship stops on station, the gyro speed setting is apparently set to zero.

On cruise TN044 the compass was augmented with an Ashtech GPS attitude sensor which provided a data stream that could be used during post processing to reduce errors inherent to gyro compasses. The Ashtech was available for cruise TN044, but operated only for a day on TN045. It didn't function again until cruise TN049 where it worked throughout the cruise.

\section{Data Processing and Analysis}

Pingdata files from each cruise were shipped in binary format to Brookhaven National Laboratory. They were processed on a Silicon Graphics Indy (SGI) workstation by modified version of the CODAS (Common Oceanographic Data Access System) processing programs for the ship-mounted ADCP originally developed by the ADCP group at the University of Hawaii. These programs consist of two parts, a set of processing and data base programs called CODAS written in C, and a series of MATLAB analysis routines for post-processing and plotting ADCP velocity and backscatter data. The CODAS routines were expanded to handle the backscatter intensity data in keeping with the methods deleveloped by Flagg and Smith (1985) and Flagg et al. (1994). Detailed processing steps are as follows.

\subsection{Velocity}

The binary pingdata files were scanned to produce listings of the headers and ADCP configurations for each of the pingdata files, and to extract the GPS navigation data contained in the user-buffer area. Using the header listings as a guide to the appropriate ADCP profiles, the ADCP data in the pingdata files were separated into a CODAS data base for each cruise. Editing of the data started with a determination of parameters to flag complete or partial profiles. The basic editing parameter was the percent good determined by the 
ADCP and recorded along with the velocity data. The minimum percent good was set to 30 percent. Four other editing parameters were also used. The first was a bottom search criterion based on the difference between the minimum backscatter intensity and a subsequent maximum. Most of the JGOFS Arabian Sea cruise time was spent in waters considerably deeper than the ADCP's range, so this parameter was often ignored. In shallower water bottom tracking was used which also determined the bottom depth and that data was used to edit the ADCP profiles for bottom interference. The second flagging parameter was error velocity, the difference between vertical velocities calculated from opposite pairs of the four beams in the transducer. A third parameter was the variance of vertical velocity over the entire profile. The last editing parameter was the second order difference in the vertical (i.e., $\left.\partial^{2} / \partial z^{2}\right)$ of horizontal velocity components. Collectively, these parameters flag interference from the bottom, from instrumentation suspended from the ship, from large aggregations of fish or scatterers and other, possibly anomalous behavior.

Individual profiles of velocity and backscatter were examined visually and in light of the flagging parameters. Often they showed high variance of vertical velocity or false bottom indication which was due to diel vertical migration of euphausids and mictofids. Generally the profiles that showed this vertical migration were kept in the data set. One of the more notable features in data set was the drastic effect that diel migration had on the range of the ADCP. During daylight hours the plankton stayed at depth when the ADCP easily reached 350 to 400 meters. But during the night the plankton moved near the surface, and the range of the ADCP decreased to 200-250 meters. According to the results of a test run during cruise TN039, increasing the ADCP's acoustic output power at night (by increasing pulse length to $32 \mathrm{~m}$ ) resulted in no increase in range to any noticeable degree. Apparently, there were simply no scatterers left behind in the mad rush out of the low oxygen layer into the subsurface layer where the food (and predators) was. 
For calibration of the $\mathrm{ADCP}$ 's orientation and velocity, the heading offset and amplitude scale factor are required. In order to obtain values for these parameters, the primary source was bottom tracking data collected during $29 \mathrm{hrs}$ run-up the Malacca Straits at an average speed of $\sim 12$ knots $\left(6.75 \mathrm{~m} \mathrm{~s}^{-1}\right)$ on an average heading of $308^{\circ}$ during cruise TN039. Using a least-square-linear fitting of the ship's track determined from the bottom track velocities to that determined from the GPS positions, a heading offset and amplitude scale factor were found to be $1.53^{\circ}$ and 1.000 , respectively.

Subsequently, the ADCP calibration was checked using another bottom track run along the continental shelf south of Oman during cruise TN039 and water tracking during cruise TN041. From the three hour run along the Oman shelf where the ship was steaming at 4.4 knots on a heading of $261^{\circ}$, the rotation correction was $1.29^{\circ}$ while the scale factor was 1.006. The water tracking calibration from TN041 used about 85 right-angle turns produced during several rectilinear patterns made while the ship was making SeaBeam bottom surveys. The water track calibration resulted in a scale factor of 0.999 and rotation correction of $1.39^{\circ}$. While all the calibration runs yielded similar values, we have used the coefficients determined from the bottom track run-up the Malacca Straits since the section covered a long distance under nearly ideal conditions.

When the Ashtech attitude sensor functions, the ensemble averaged difference between the Ashtech heading data and the ship's compass is determined by the UE4 user-exit program, and recorded in the user buffer portion of the pingdata files. When the Ashtech data is available, the individual ensemble velocities are rotated before calibrating for the heading offset and amplitude factor. During cruise TN049, the mean offset between the Ashtech and the ship's compass was $-1.23^{\circ}$ with standard deviation of $\pm 1.56^{\circ}$.

This procedure corrects for the various compass errors, but leaves the ADCP heading data relative to new reference frame. It was therefore necessary to determine the angular 
offset of the Ashtech antennae relative to ADCP using the bottom tracking. Bottom track data from a 20 hour run near the end of cruise TN049 along the Oman shelf, resulted in an angular offset of $1.335^{\circ}$. The data from the cruise were then rotated by this amount. Note this correction and the mean difference between the compass and the Ashtech are nearly equal and of opposite sign.

Once the ADCP profiles were edited and the velocities scaled and rotated, the navigation data were combined with reference layer velocities to produce smoothed versions of the ship's track and absolute reference layer velocities. In deep water the reference layer spanned bins 5 to 20 (46 to 166 meters) while in the shallow waters of the Oman shelf the reference layer was defined as bins 3 to 8 ( 30 to 70 meters). The smoothing of the reference layer velocity was done using a Blackman window convolution filter (Bahr, Firing and Songnian, 1989) with a width of one hour. This filter has a half-power point at about 20 minutes corresponding to a distance of about $8 \mathrm{~km}$ at 13 knots. The smoothed reference layer velocity was then added to the ship's velocity relative to the reference layer to produce a smoothed version of the ship's actual velocity. The displacements calculated from the velocity were then fit to the position data to yield a smoothed cruise track. The smoothed velocities and position were then loaded into the data base. At this point in the processing the velocity data in the CODAS data base was ready to be extracted for plotting and analysis.

\subsection{Acoustic Backscatter Intensity}

Backscatter intensity data were recorded in terms of digital counts from each of the ADCP's four transducers. They were loaded into the CODAS data base directly from the pingdata files along with the velocity data. At the same time, two blank variables, CALIB_AMP and ZOOP_BIOMASS, were also loaded into the data base to make room for parameters to be filled in later. 
The first step in processsing backscatter intensity is calibrating the intensities from each beam and combining them to produce a single calibrated intensity profile for each ensemble. The calibration procedure is based upon the method outlined in RD instruments' technical bulletin ADCP-90-04 issued in December 1994, which attempts to determine the absolute value of the volume reverberation, Sv, for each depth bin.

The calibration equation for $\mathrm{Sv}$ for each beam is:

$$
\mathrm{Sv}=10 \log _{10}\left\{\frac{4.47 \times 10^{-20} K_{2} K_{s}\left(T_{x}+273\right)\left(10^{K_{c}\left(E-E_{r}\right) / 10}-1\right) R^{2}}{c L K_{1} 10^{-2 \alpha R / 10}}\right\}
$$

where the $K^{\prime}$ s are calibration coefficients, $c$ is the speed of sound at the transducer in $\mathrm{m} \mathrm{s}^{-1}$, $L$ is the pulse length in $\mathrm{m}, T_{x}$ is the transducer temperature in ${ }^{\circ} \mathrm{C}, \alpha$ is the sound absorption coefficient in $\mathrm{dB} \mathrm{m} \mathrm{m}^{-1}, R$ is the slant range in $\mathrm{m}, E_{r}$ is the intensity reference level, and $E$ is the echo intensity level. Both $E$ and $E_{r}$ are given in terms of counts. Two of the constants, $K_{1}$ and $K_{2}$ are determined by RD instruments during instrument checkout. $K_{1}$ is the power sent to the transducer and is given by:

$$
K_{1}=K_{1 c}\left(\frac{1.397 V_{s}-4.27}{37.14}\right)^{2}
$$

where $V_{s}$ is the measured rms AC voltage supplied to the deck unit (117 volts), and the values of $K_{1 c}$ supplied by RD instruments for the Thompson for beams 1 to 4 are:

\begin{tabular}{|l|l|}
\hline Beam & $K_{1 c}$ (Watts) \\
\hline 1 & 5.424 \\
2 & 5.647 \\
3 & 6.609 \\
4 & 6.172 \\
\hline
\end{tabular}

The system noise factors, $K_{2}$, also supplied by the manufacturer for the Thompson for beams 1 to 4 are: 


\begin{tabular}{|l|l|}
\hline Beam & $K_{2}$ \\
\hline 1 & 2.158 \\
2 & 2.244 \\
3 & 1.854 \\
4 & 2.183 \\
\hline
\end{tabular}

The conversion factor, $K_{c}$, from ADCP counts to measured intensity in $\mathrm{dB}$ is given by:

$$
K_{c}=\frac{127.3}{T_{e}+273}
$$

where $T_{e}$ is the temperature of the deck unit on the Thompson which was $30^{\circ} \mathrm{C}$ when measured. The reference thermal transducer noise, $E_{r}$, for the beams is given by:

$$
E_{r}=E_{r c}+\left(292+0.133 T_{e}\right)(1-a)+\left(273+0.1 T_{x}\right)(1-b)
$$

with

$$
a=\frac{T_{e}+273}{T_{e c}+273} ; \quad b=\frac{T_{x}+273}{T_{x c}+273}
$$

where $E_{r c}$ is the measured reference thermal noise, and $T_{e c}$ and $T_{x c}$ are the deck unit and transducer temperatures at the time when $E_{r c}$ was measured. For the Thompson data the values of $E_{r c}$ for each beam were taken to be the minimum backscatter counts recorded during the entire first cruise, minus one count to avoid numerical problems with calculating logarithms. $T_{e c}$ was taken to be $30^{\circ} \mathrm{C}$ while the values of $E_{r c}$ and $T_{x c}$ for the Thompson were:

\begin{tabular}{|l|l|l|}
\hline Beam & $E_{r c}$ (counts) & $T_{x c}\left({ }^{\circ} \mathrm{C}\right)$ \\
\hline 1 & 12 & 28.4 \\
2 & 15 & 28.1 \\
3 & 17 & 28.7 \\
4 & 16 & 27.2 \\
\hline
\end{tabular}


The absorption coefficient is given by Urick (1982) as:

$$
\alpha=\left\{1.86 \times 10^{2} S f_{t}\left(\frac{f^{2}}{f_{t}^{2}+f^{2}}\right)+2.68 \times 10^{-2}\left(\frac{f^{2}}{f_{t}}\right)\right\}\left\{\frac{1-6.54 \times 10^{-4} P}{914.4}\right\}
$$

where $P$ is the pressure in atmosphere, $f$ is the frequency of the ADCP which is $153.6 \mathrm{kHz}$ for the ADCP on the Thompson and

$$
f_{t}=21.9 \times 10^{6-1520 /\left(T_{x}+273\right)}
$$

The absorption coefficient for each bin is the average value between the transducer and the bin while the pressure term has a noticeable effect and needs to be included. The transducer temperature is clearly not the correct value to use in this calculation except near the transducer itself, but at this point we have not attempted to refine this value further by using CTD cast results.

This procedure brings the four acoustic beams into close, but not perfect agreement. Typically over the normal range of variablity, the beams might differ by one to two dB. As a result, we have taken an ad-hoc approach to ensure that over the length of a section or cruise all the beams will yield the same average backscatter profile. This secondary correction is done using the liner transformation:

$$
S_{v c}=a_{\circ}+a_{1} S_{v}
$$

where the scaling $a_{1}$ and offset $a_{\mathrm{o}}$ factors for each beam relative to the mean profile are determined by least squares.

In the past this had been a straight forward precedure, but in the Arabian Sea there was enough biological patchiness that when the ship was on station a single beam occasionally indicated substantially larger concentrations of scatters than the others. Under these circumstances, scatter plots of a single beam's return versus the average of all four beams showed enough scatter to adversely influence the least square calculations. To distinguish 
those profiles with large inter-beam variations, we calculated the rms difference of each profile relative to the mean from all four beams. An examination of the time dependence of the rms difference showed that high values were exclusively associated with periods when the ship was on station. The reverse was not necessarily the case. From this behavior we surmise that the distribution of plankton and/or fish can be patchy on the scale of one to two hundred meters. Thus when the ship is still, the anomalous scatters can remain within a beam for a significant portion of an ensemble and increase the recorded backscatter intensity. Figure 3 shows profiles of backscatter intensity differences between beam 1 and beam average when the rms intensity differences were greater than $1.5 \mathrm{~dB}$. (This plot was generated before the secondary corrections were applied which leads to a positive mean offset.) The figure shows that the large beam discrepancies were majorily confined to the ADCP's mid-range between bins 12 to 32 . These bins correspond to depths of 114 and 274 meters spanning the thermocline in the Arabian Sea and the depths over which the oxygen concentrations decrease to very small values. It would appear that there are individual large fish, schools of smaller fish, or plankton patches that tend to congregate in and just above the thermocline perhaps waiting to feed on the upward migrating meso-planktonic euphausids and mictophids.

We thus edited the profiles and include only those whose rms intensity differences were less than or equal to $1.5 \mathrm{~dB}$. The secondary correction factors, determined using an edited set of profiles from the calibration and training cruise were:

\begin{tabular}{|c|r|c|}
\hline Beam & $a_{\mathrm{o}}(\mathrm{dB})$ & $a_{1}$ \\
\hline 1 & -1.6387 & 0.9991 \\
2 & -0.2789 & 0.9983 \\
3 & 0.9646 & 0.9954 \\
4 & -0.0794 & 0.9926 \\
\hline
\end{tabular}


During the processing, the ensemble averaged backscatter profiles are combined to form a single profile for each ensemble. For those ensembles where the rms differences relative to the mean are greater than $1.5 \mathrm{~dB}$, indicating contamination from anomalous scatters densities, the average profiles are set to nulls. Backscatter differences of a single beam from the mean profiles is shown in Figure 4, which is obtained after secondary correction is applied. Note the change in the scale of the abscissa relative to Figure 3. 


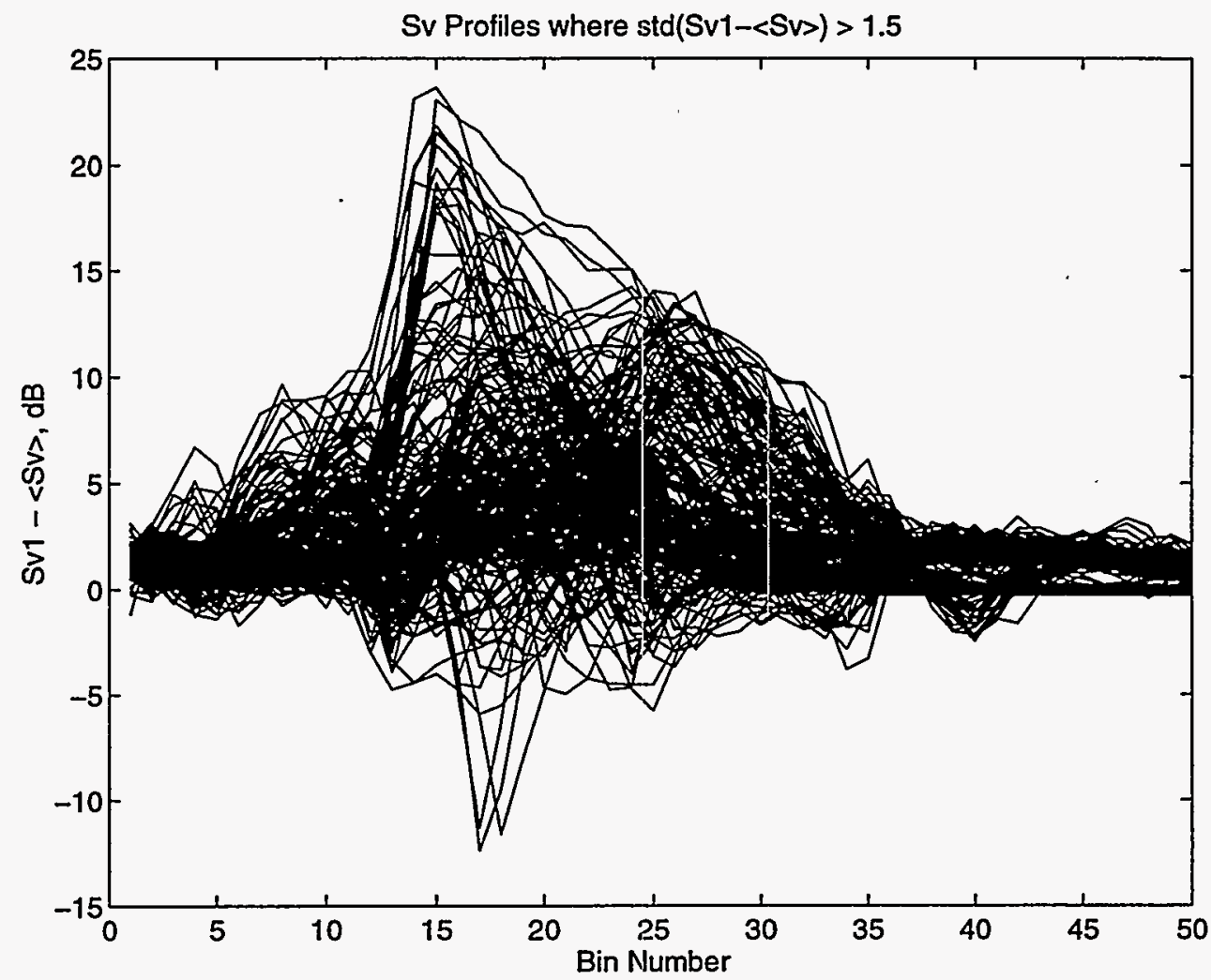

Figure 3: Scatter plot of the rms differences greater than 1.5 dB: They are the differences between the partially calibrated backscatter intensity from Beam \#1 and the mean intensity of all four beams from cruise TN039. The occurrence of the relatively large difference is restricted to periods when the ship is on station. It appears to reflect inhomogeneities in the small-scale distribution of fish and/or plankton. The bin length is 8 meters and the first bin is centered at a depth of approximately 22 meters. 


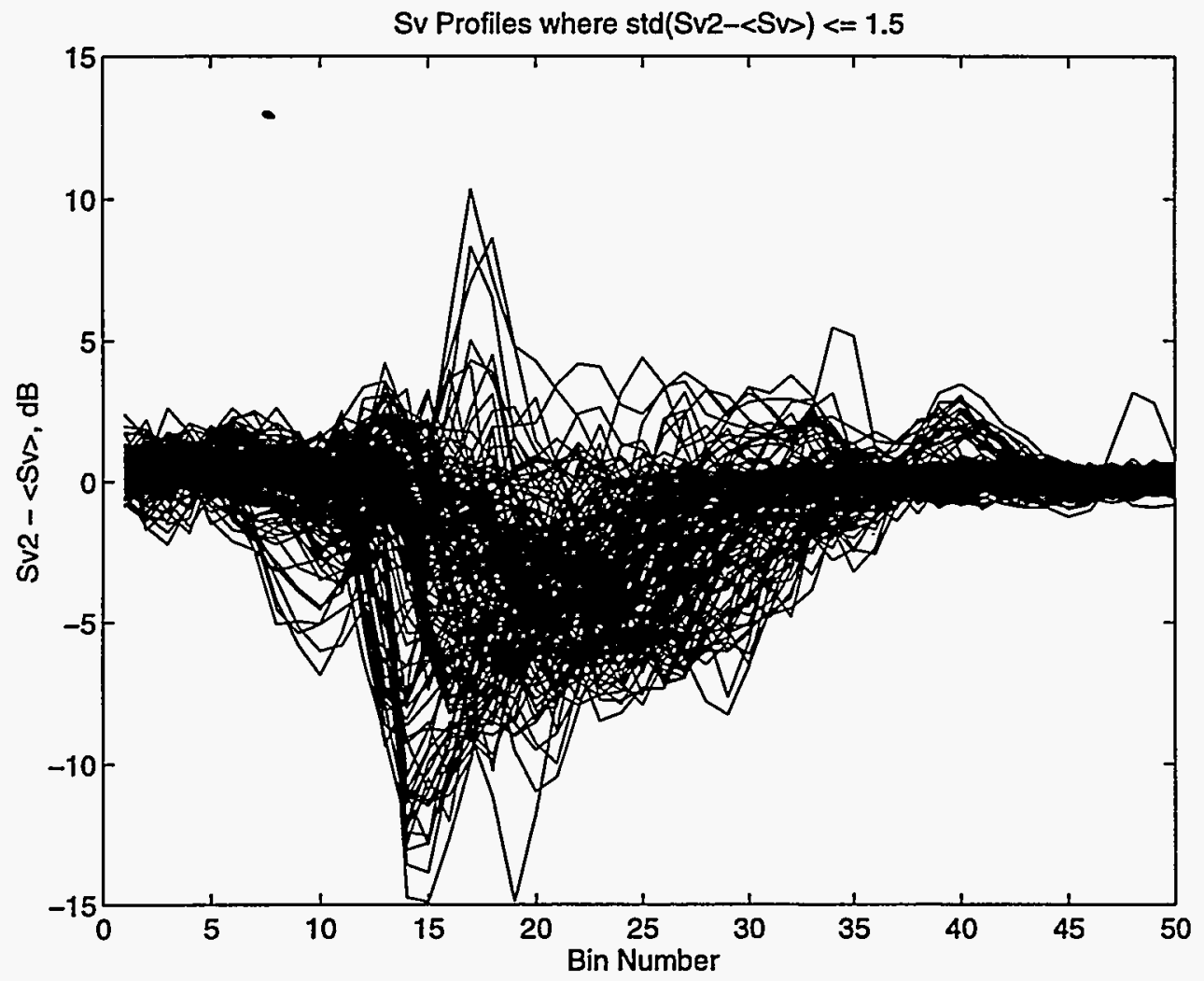

Figure 4: Scatter plot of the rms differences less than or equal to $1.5 \mathrm{~dB}$. The data were taken from cruise TN039. 


\section{Data Collection}

\section{$4.1 \quad$ TN047}

The third process cruise, which took place during the pre-summer monsoon period, was for the purpose of turning around the sediment trap moorings and taking sediment cores under the upwelling area off southern Oman. The duration of the cruise was 18 days from May 3 through May 20, 1995. The cruise track was slightly different from the standard one (Figure 5), proceeding directly to the mooring sites hence northwestward to the coast. Jack Dymond and Warren Prell were co-chief scientists during this cruise, while Bill Martin monitored the AutoADCP system.

\section{$4.2 \quad$ TN048}

This cruise was the third of the ONR/NRL SeaSoar cruises, starting on June 21 and ending July 13, 1995 in the southwest monsoon. The P-code GPS receiver was up running for better navigation data. Ken Brink was the chief scientist for the cruise. As before the cruise track consisted of two "radiator" seasoar surveys along the main transect and a "bowtie" around the long-term moorings. There was also an abreviated radiator pattern near the coast and a series of hydrographic stations to investigate a large filament observed near the shelf break.

\section{$4.3 \quad$ TN049}

TN049 was the fourth process cruise and was also conducted during the SW monsoon. The cruise followed the standard track line, leaving Muscat on July 17 and returning on August 15, 1995. Richard Barber was the chief scientist and Mike Grogan helped monitor the ADCP and Ashtech unit. During this cruise, the Ashtech receiver functioned intermittantly. In the gaps, the velocities were rotated by the average Ashtech heading offset. The 
P-code receiver functioned thoughout the cruise.

\subsection{TN050}

The fifth process cruise took place from August 18 through September 15, 1995 at the end of the SW monsoon with Sharon Smith as the chief scientist and Bill Martin responsible for the ADCP. The P-code receiver worked throughout the cruise while the Ashtech receiver did not. 


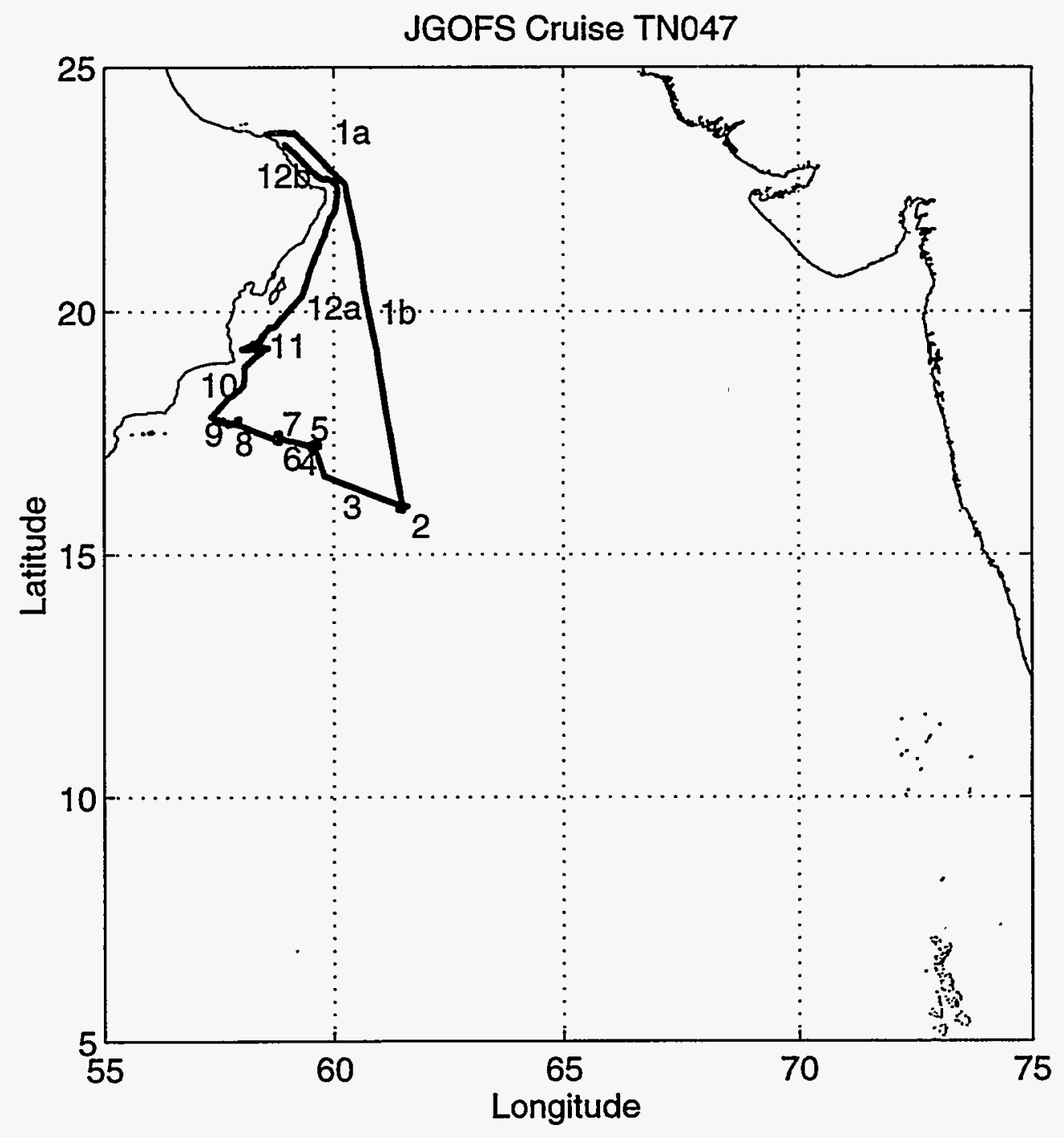

Figure 5: Cruise track for TN047, Process cruise \#3. Numbers along the track represent sections and stations used later for vectors and contour plots in Appendix C. 


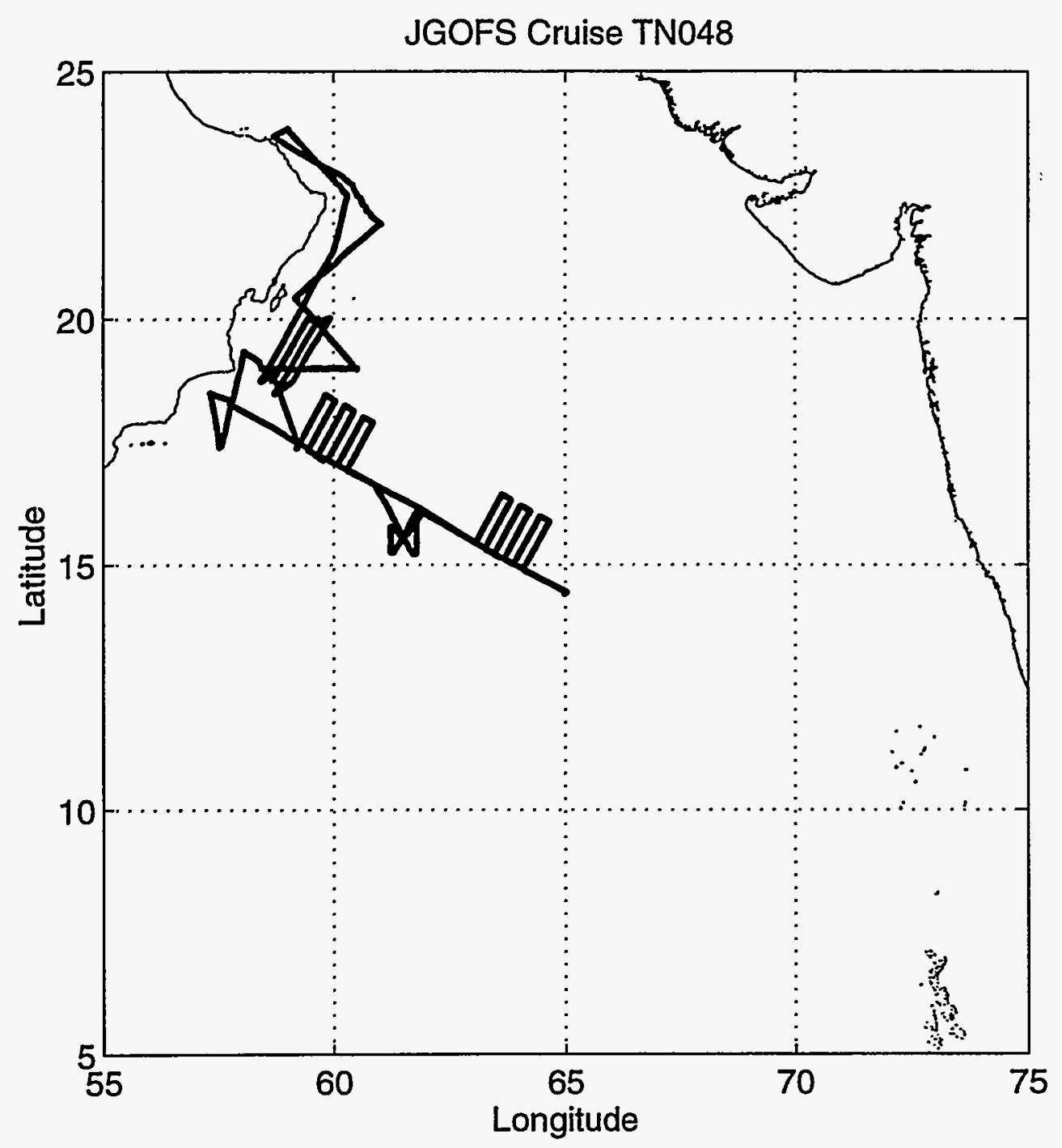

Figure 6: Cruise track for TN048, the 3rd ONR/NRL SeaSoar cruise. Duration of this cruise is three weeks. 


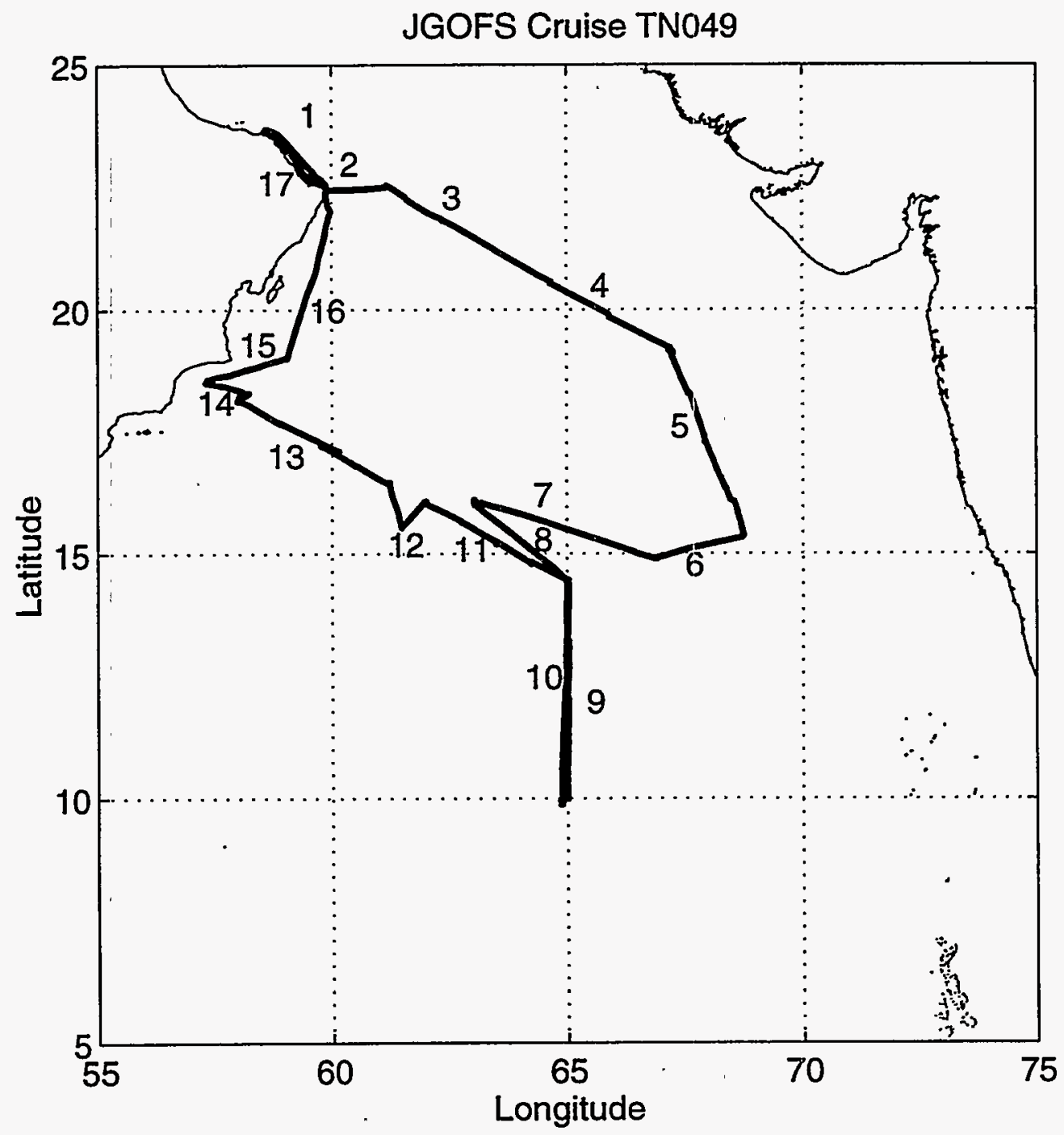

Figure 7: Cruise track for TN049, following the standard cruise track. 


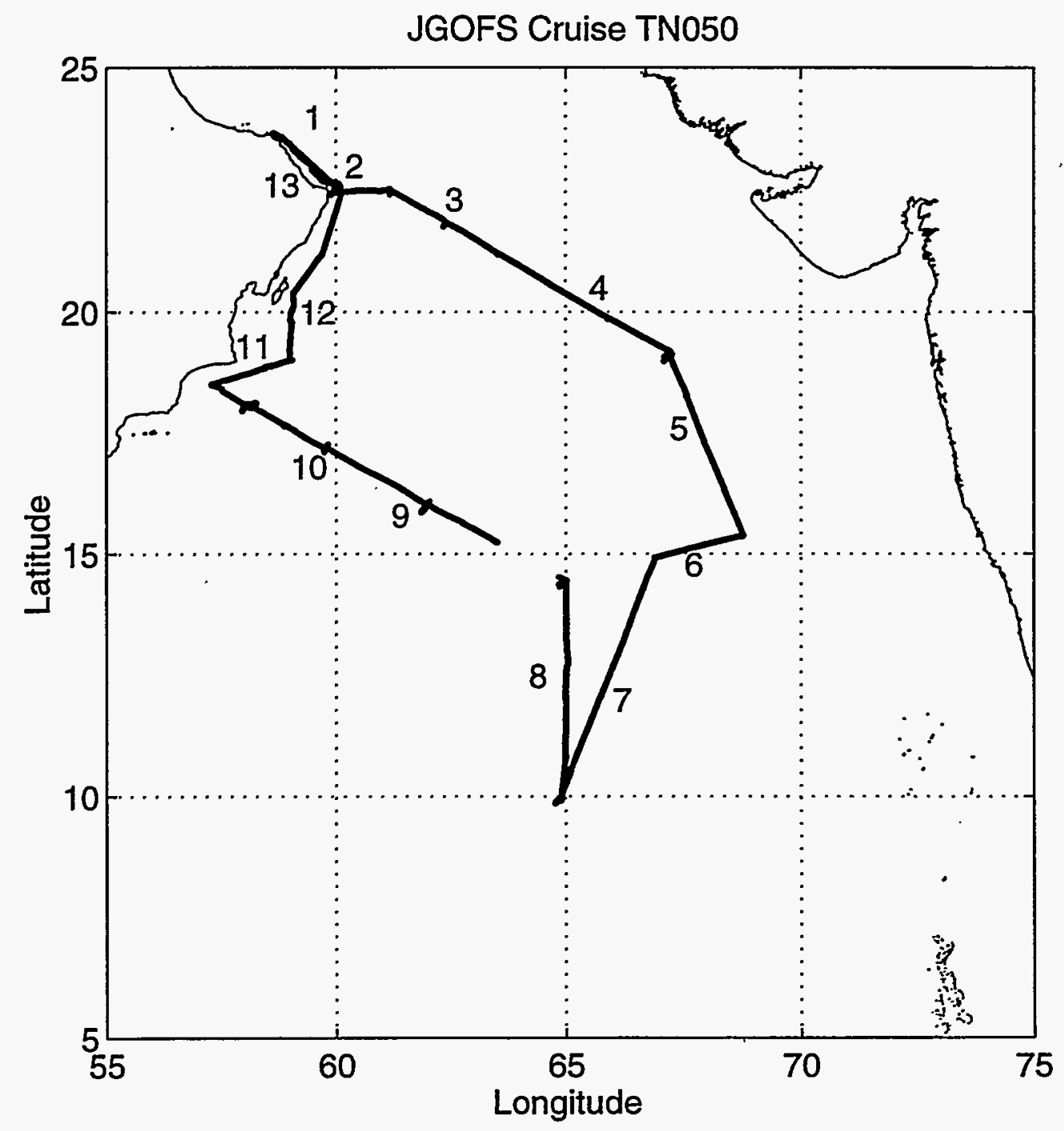

Figure 8: Cruise track for TN050, the 5th process cruise. 


\section{Profile Quality}

In processing the ADCP data, a set of diagnostic products is routinely produced. Typically, each cruise is broken into sections along the track or subsections of special interest. The diagnostic products include separate underway and on-station profiles of averages and standard deviations of horizontal velocity shears (first differences in the vertical), vertical velocity, error velocity, backscatter intensity, and percent good, based upon the ensemble data.

Figure 9 shows results of the quality analysis of the data collected during cruise TN049 along the standard track (Figure 7) in the SW monsoon. Cruise TN049 is of special interest, because both the P-code GPS receiver and Ashtech attitude sensor were available. Hence the data set should be of the highest quality possible with current technology. For the statistical results in Figure 9, 4700 ensembles were extracted while the ship was on station $\left(<2.5 \mathrm{~m} \mathrm{~s}^{-1}\right)$ and 2330 ensembles when the ship was underway $\left(>5.0 \mathrm{~m} \mathrm{~s}^{-1}\right)$.

The first difference/vertical shear diagnostics shown in Figure $9 \mathrm{a}$ and $9 \mathrm{~b}$ are intended to illustrate the portions of the profile affected by misalignments of the tracking filters near the surface, in regions of high shear, or in regions of low return signal. The shears were significant only in the upper 100 meters or so, where the maximum values approached 0.5 $\mathrm{cm} \mathrm{s}^{-1}$. The standard deviation of the shear was relatively higher between the first and second bins, below 150 meters when underway, and near the extreme range of the ADCP below 360 meters. The maximum shears generally encountered were well below the limit of the velocity tracking capability of the tracking filter $\left(\sim 2.0 \mathrm{~cm} \mathrm{~s}^{-1}\right)$ and therefore it should not pose any problem. The higher standard deviations near the surface may reflect the often encountered difficulties with the first bin where signal-to-noise may decrease (note increase in backscatter intensity in Figure 9e) and spectral width increase, Figure 9f, such that the ping-to-ping first bin tracking control may be less than optimal. The " $\mathrm{E}$ " command used 
the results from depth cells 2 to 5 from the previous ping to determine the initial position of tracking filter during these cruises. In highly sheared near surface conditions, as might be encountered during extreme wind forcing of the SW monsoon, it is quite possible that there was some skew bias introduced by a misaligned tracking filter. The cause for the increased shear standard deviation below 150 meters while underway is unclear. In the lowest 50 meters of the profile where the shear standard deviation is increased substantially appears to reflect noise bias. This should not impact the data products because the percent good over that portion of the profile was well below the acceptance level of 30 percent.

The vertical and error velocities are expected to be fairly small, and significant values would indicate misalignment of the transducers either relative to the vertical or between themselves. The notable features of the average vertical velocity profile, Figure $9 \mathrm{c}$, are the uniformity with depth below 50 meters, the $\sim 3 \mathrm{~cm} \mathrm{~s}^{-1}$ difference between underway and on-station profiles suggest that the ship (actually the ADCP transducer) was out of trim by about 0.3 degrees, a remarkably small value. The negative near surface values while underway suggest that the passage of the ship through the water is forcing downward water motion in the vicinity of the transducer. The impact of this on the horizontal velocities is unclear. The error velocities on this cruise, Figure 9d, were less than we've seen in some of the previous cruises. The underway values were about $1 \mathrm{~cm} \mathrm{~s}^{-1}$ higher than those from on-station periods. It suggests that there may have been less than 0.1 degrees misalignment of beams 1 and 3 relative to beams 2 and 4 . Why the on-station error velocity increases with depth is unclear; this behavior was not evident in some of the earlier cruises.

The average backscatter intensity (aka amplitude) profiles are presented in Figure $9 \mathrm{e}$ in terms of digital counts for both underway and on-station conditions. Figure 9e shows the usual large decrease with depth. These averaged profiles are not filtered using a percent good criterion and include all ensembles selected for this section. Without range correction, the 
backscatter intensity profiles accentuate the upper water column. The standard deviation profiles indicate maximum variabilty between 100 and $300 \mathrm{~m}$, reflecting the planktonic diel migration under which a large proportion of the plankton rises from their daytime depths around 300 meters to upper 100 meters during the night.

The percent good profiles of Figure $9 \mathrm{~g}$ indicates that highly reliable data covered the upper 175 meters. Below that, the range is subject to the effects of diel migration. During the night the effective range of the ADCP in the northern Arabian Sea was generally not more than 250 meters. From experiments on earlier cruises doubling the pulse lengths to 32 meters had no measurable effect. 

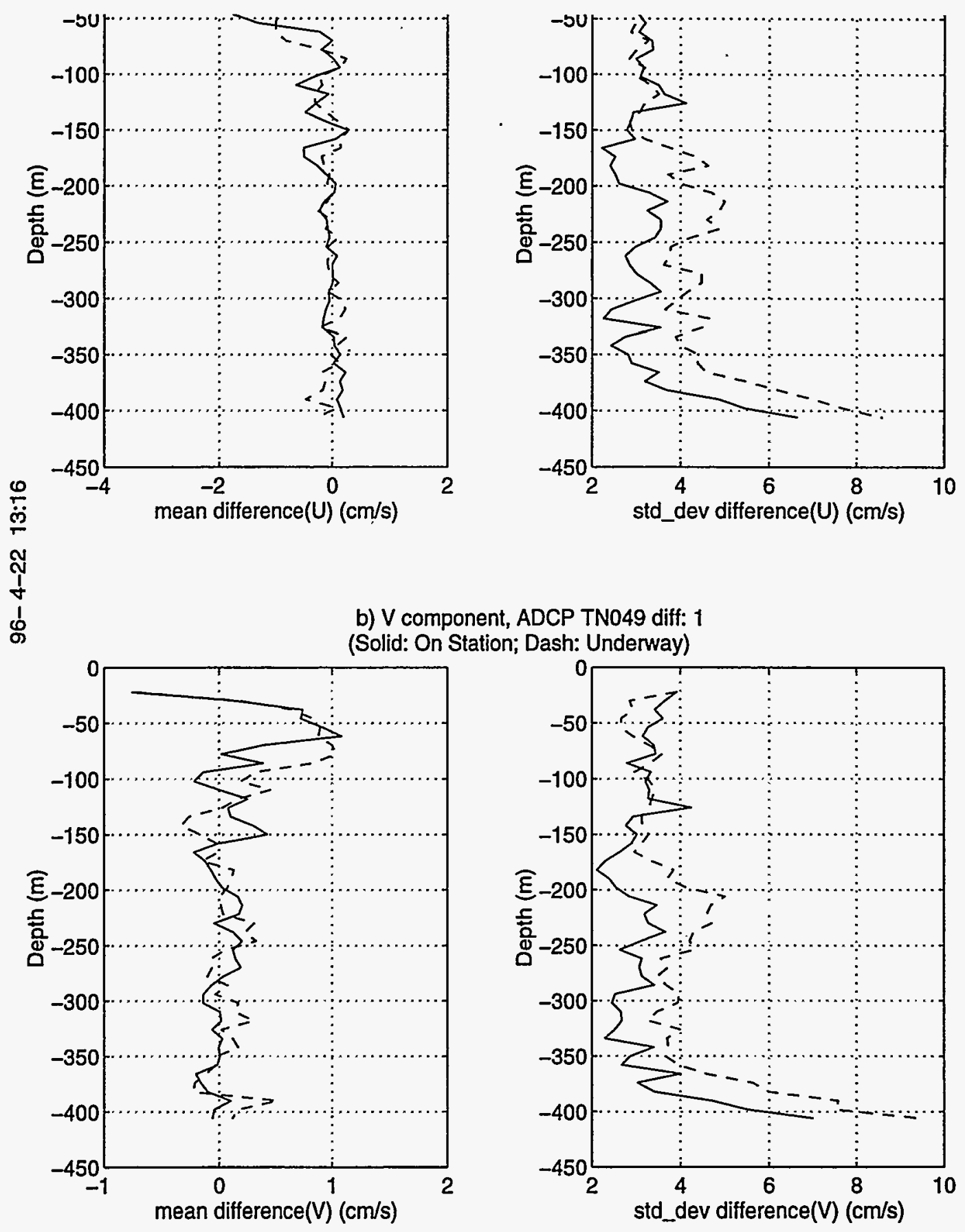

b) V component, ADCP TN049 diff: 1 (Solid: On Station; Dash: Underway)

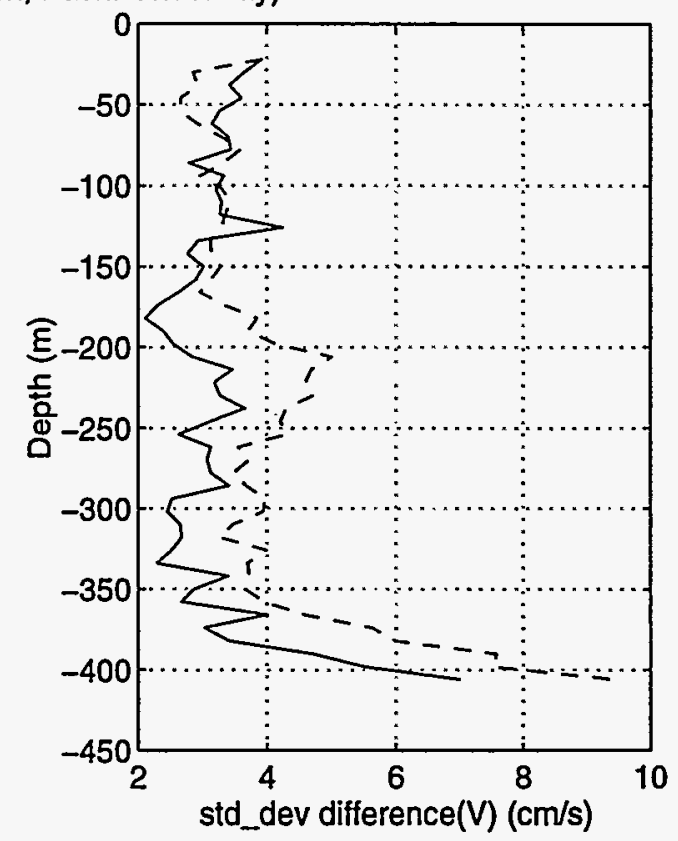

Figure 9: Diagnostic profiles of ensemble averaged a) zonal vertical shear, b) meridional verical shear, c) vertical velocity, d) error velocity, e) backscatter intensity, f) spectral width, g) percent good for underway and on-station ADCP data taken along the standard cruise track for TN049. 
c) W component, ADCP TN049

(Solid: On Station; Dash: Underway)
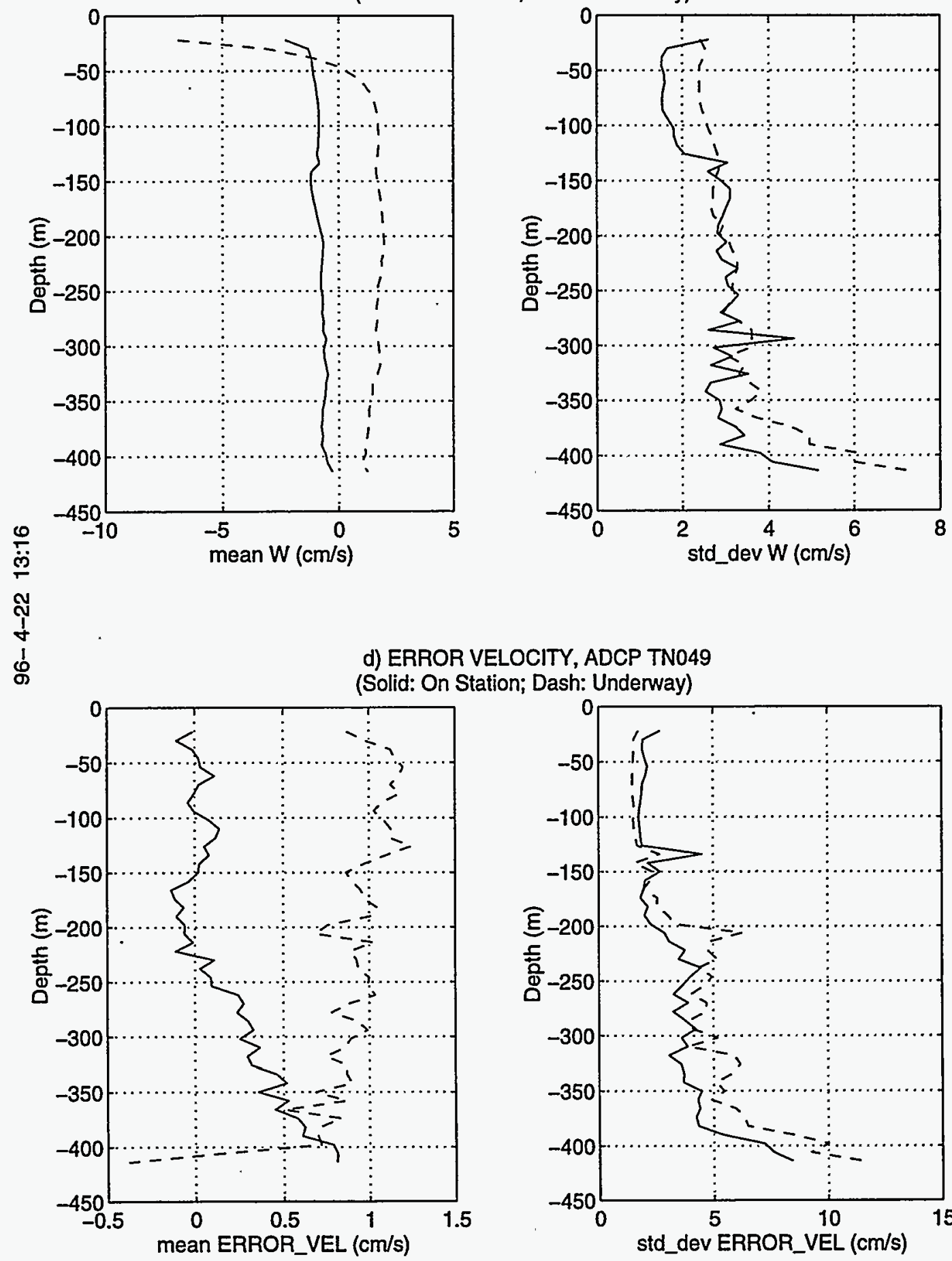

d) ERROR VELOCITY, ADCP TN049

(Solid: On Station; Dash: Underway)

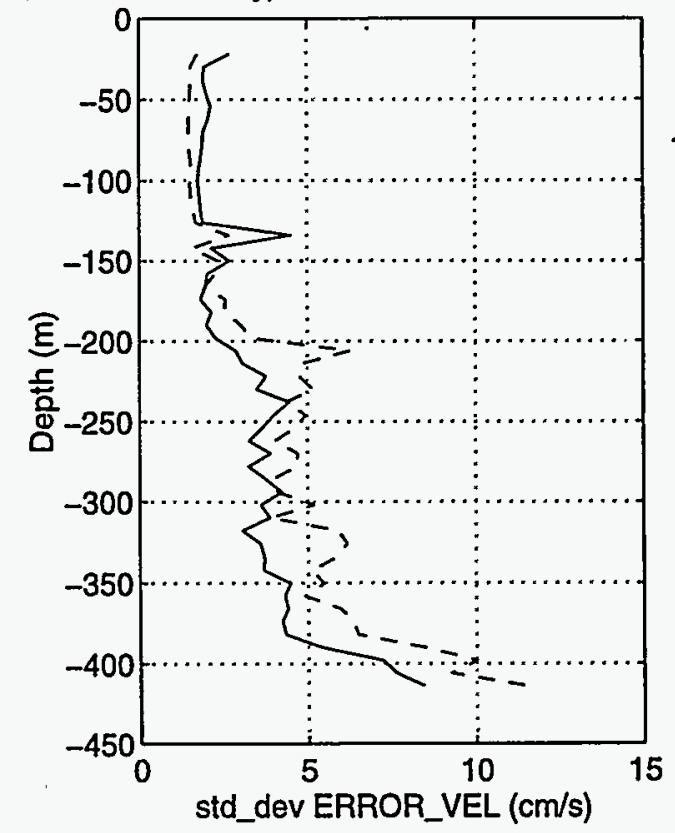


e) AMPLITUDE, ADCP TN049

(Solid: On Station; Dash: Underway)
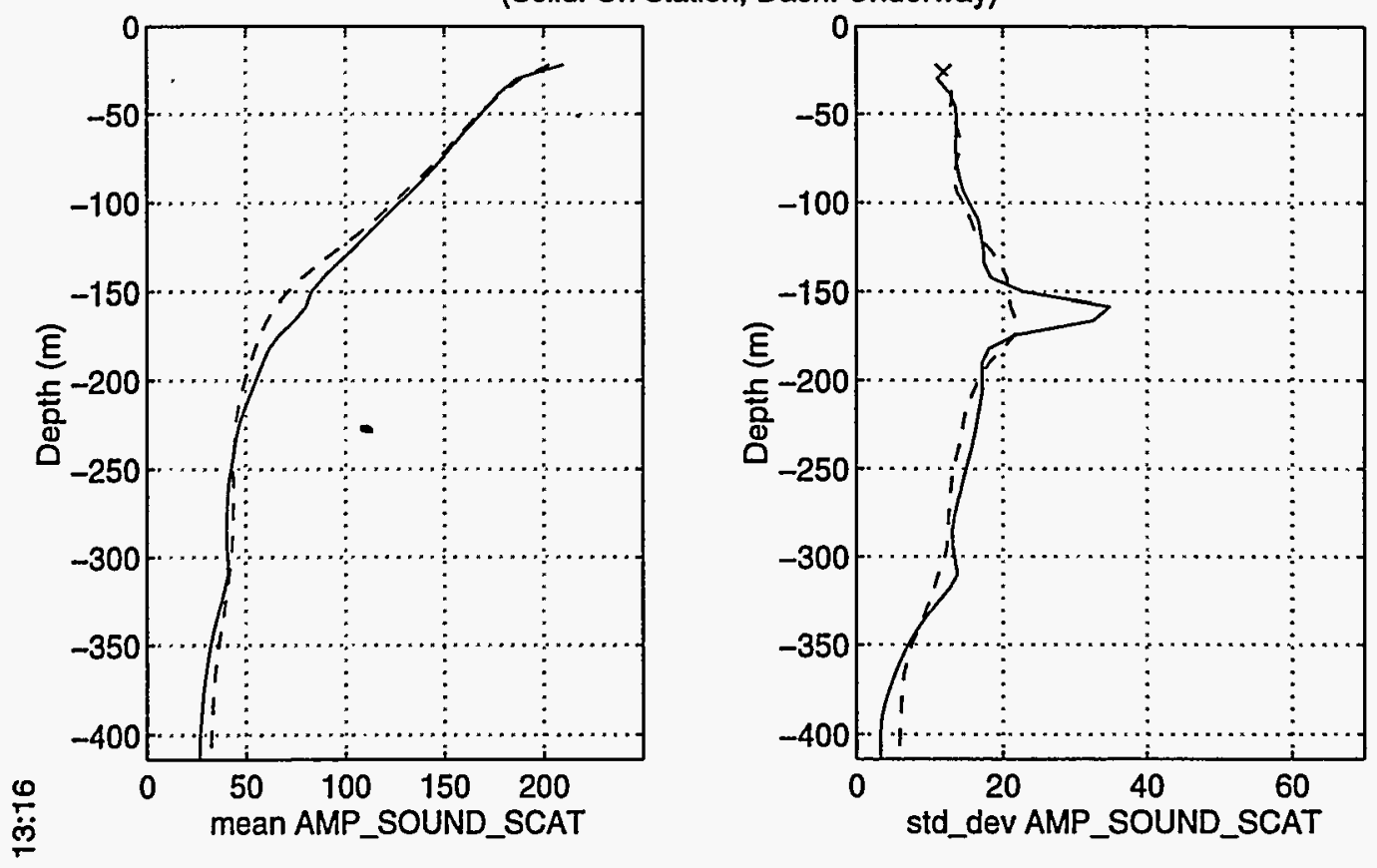

ฟิ
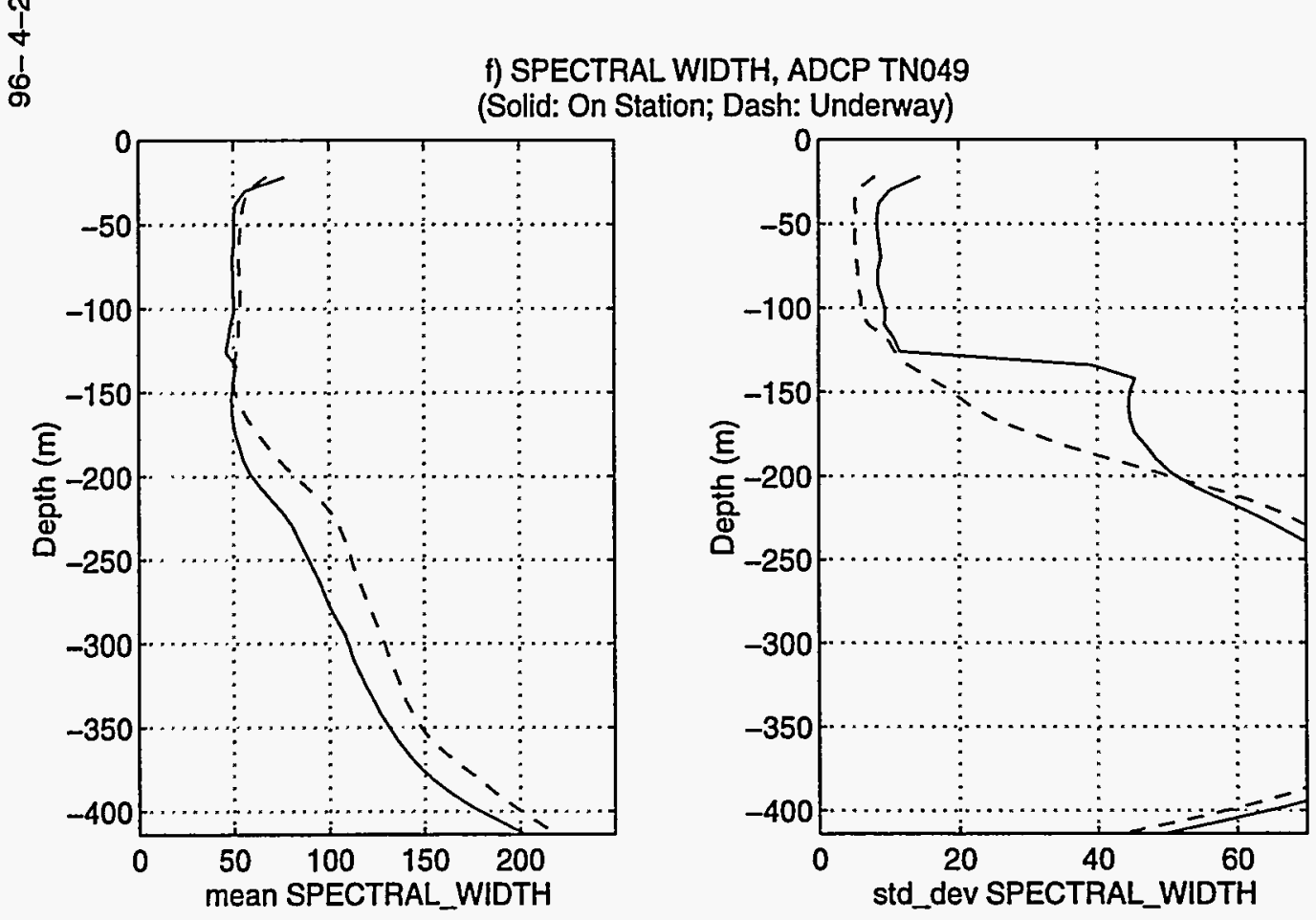


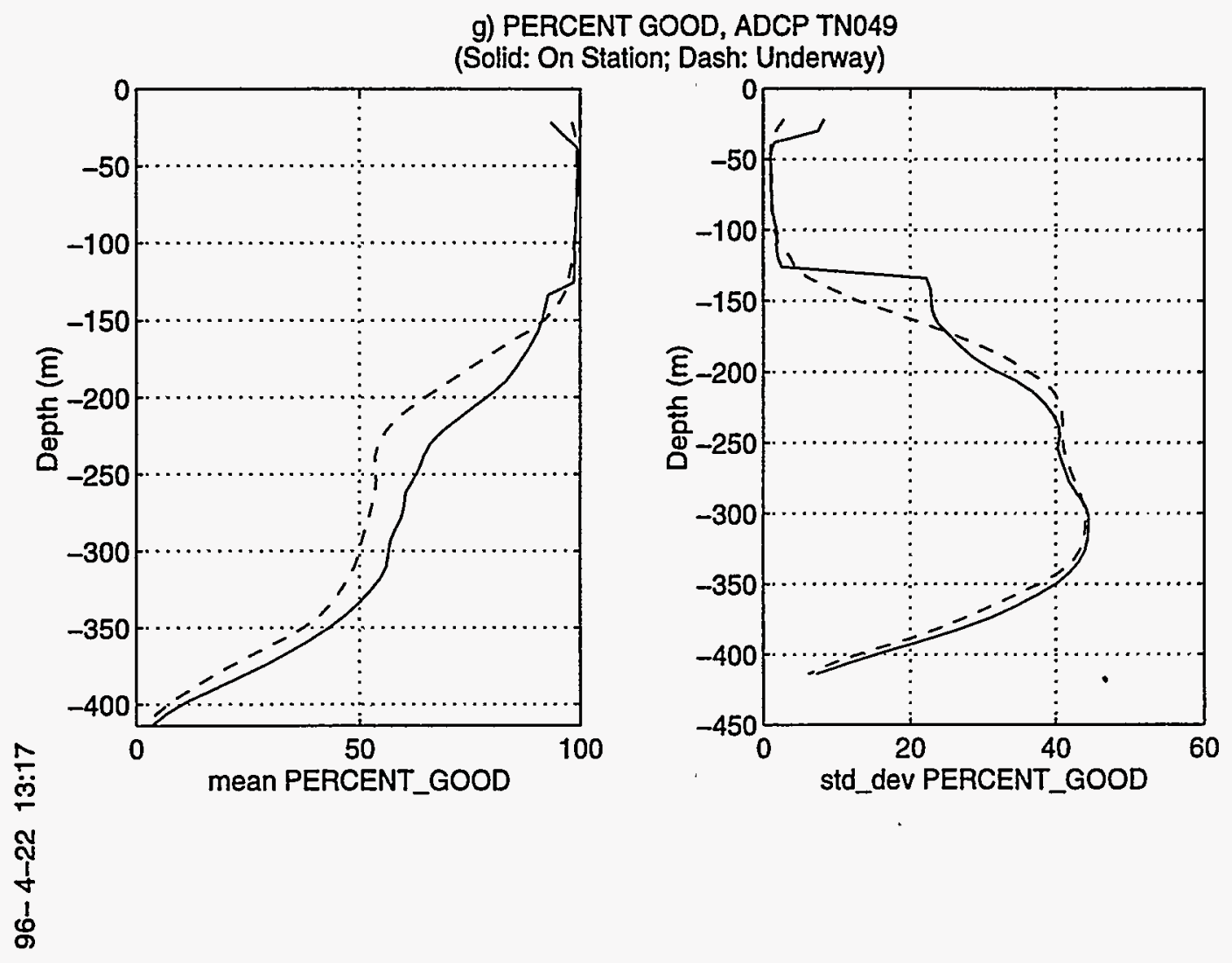




\section{Acknowledgments}

We would like to express our appreciation for the assistance of George White, Mike Realander, Bill Martin, Mike Grogran, William Peterson and the Thompson's crew in the initial set-up the ADCP system and in the continuing data collection. We also received significant help from Eric Firing and Frank Bahr at early stage in the program, especially Frank Bahr who has checked on the AutoADCP system and helped the Ashtech receiver available during his cruises. Eric Firing and Julie Renanda were also very helpful for the installation of the CODAS processing system on our UNIX computer. 


\section{References}

Bahr, F., E. Firing and Songnian, 1989.

Firing, E., J. Ranada and P. Caldwell, 1995. Processing ADCP data with the CODAS software System. Version 3.1. Joint Institute for Marine and Atmospheric Research, University of Hawaii, 212pp.

Flagg, C. N., H.-S. Kim and Y. Shi, 1995. Acoustic Doppler Profiling from the JGOFS Arabian Sea Cruises Aboard the RV T. G. Thompson, TN043 through TN046. Brookhaven National Laboratory Data Report, BNL-62352, 231pp.

Flagg, C. N., and Y. Shi, 1995. Acoustic Doppler Profiling from the JGOFS Arabian Sea Cruises Aboard the RV T. G. Thompson, TN039 through TN042. Brookhaven National Laboratory Data Report, BNL-61633, 153pp.

Flagg, C. N., and S. L. Smith, 1985. On the use of the ascoutic doppler current profiler to measure zooplankton abundance. Deep-Sea Research, 36, 455-474.

Flagg, C. N., C. D. Wirick, and S. L. Smith, 1994. The interaction of phytoplankton, zooplankton, and currents from 15 moths of continuous data from the Mid-Atlantic Bight. Deep-Sea Research, Part II, 41, 411-436.

Urick, R. J., 1982. Sound propagation in the Sea. Peninsula Publishing, Los Altos, California, 207pp. 
Table 1: Cruise schedule for the U. S. JGOFS Arabian Sea Project. The bold-faced entries are the cruises covered by this data report.

\begin{tabular}{|l|l|l|l|l|}
\hline Cruise ID & Start Date & End Date & Chief Sci. & Purpose \\
\hline TN039 & $09 / 20 / 94$ & $10 / 07 / 94$ & L. Codispoti & Calibration and training \\
TN040 & $10 / 11 / 94$ & $10 / 25 / 94$ & C. Erickson & Mooring deployment \\
TN041 & $10 / 28 / 94$ & $11 / 21 / 94$ & S. Honjo & Sediment trap and coring \\
TN042 & $11 / 28 / 94$ & $12 / 17 / 94$ & D. Young & SeaSoar survey \#1 \\
TN043 & $01 / 08 / 95$ & $02 / 04 / 95$ & M. Roman & Process cruise \#1 \\
TN044 & $02 / 08 / 95$ & $02 / 25 / 95$ & K. Brink & SeaSoar survey \#2 \\
TN045 & $03 / 14 / 95$ & $04 / 10 / 95$ & J. Marra & Process cruise \#2 \\
TN046 & $04 / 14 / 95$ & $04 / 29 / 95$ & R. Weller & Mooring turn-around \\
TN047 & $\mathbf{0 5 / 0 3 / 9 5}$ & $\mathbf{0 5 / 2 0 / 9 5}$ & J. Dymond & Process cruise \#3 \\
TN048 & $\mathbf{0 6 / 2 1 / 9 5}$ & $\mathbf{0 7 / 1 3 / 9 5}$ & K. Brink & SeaSoar survey \#3 \\
TN049 & $\mathbf{0 7 / 1 7 / 9 5}$ & $\mathbf{0 8 / 1 5 / 9 5}$ & R. Barber & Process cruise \#4 \\
TN050 & $\mathbf{0 8 / 1 8 / 9 5}$ & $\mathbf{0 9 / 1 5 / 9 5}$ & S. Smith & Process cruise \#5 \\
TN051 & $\mathbf{0 9 / 1 8 / 9 5}$ & $10 / 09 / 95$ & R. Arnone & Searsoar survey \#4 \\
TN052 & $10 / 14 / 95$ & $10 / 25 / 95$ & D. Rudnick & Mooring retrieval \\
TN053 & $10 / 29 / 95$ & $11 / 26 / 95$ & B. Balch & Process cruise \#6 \\
TN054 & $11 / 30 / 95$ & $12 / 27 / 95$ & W. Gardner & Process cruise \#7 \\
TN055 & $12 / 31 / 95$ & $01 / 15 / 96$ & W. Prell & Sediment trap retrieval \\
\hline
\end{tabular}


Table 2: Listing of the Arabian Sea regional ADCP configuration used for the deep water portion of the U. S. JGOFS Project.

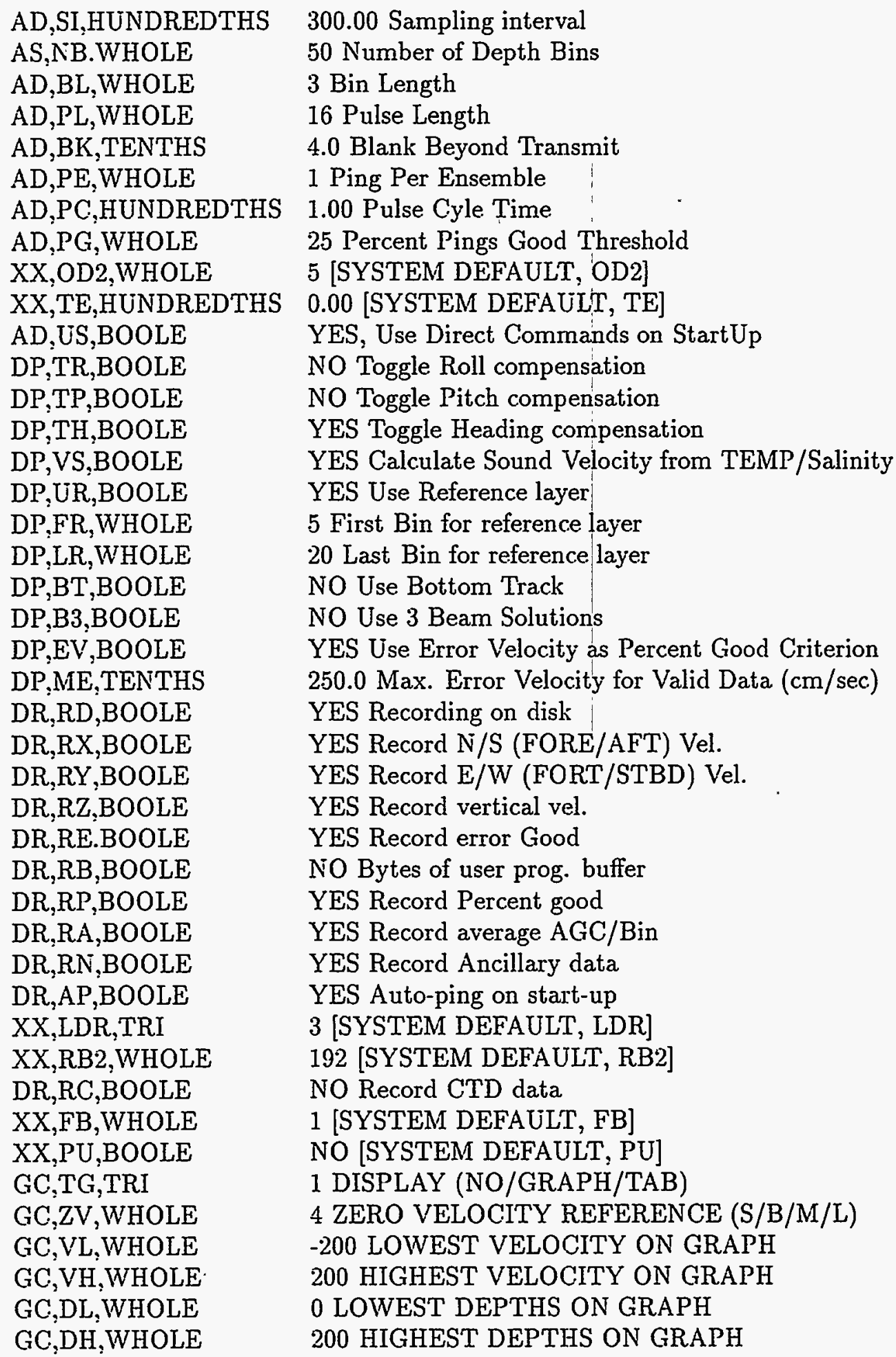


GC,SW,WHOLE GC,MP,WHOLE SG,PNS,BOOLE SG,PEW,BOOLE SG,PVT,BOOLE SG,PEV,BOOLE SG,PPE,BOOLE SG,PMD,BOOLE SG,PSW,BOOLE SG,PAV,BOOLE SG,PPG,BOOLE SG,PD1,BOOLE SG,PD2,BOOLE SG,PD3,BOOLE SG,PD4,BOOLE SG,PW1,BOOLE SG,PW2,BOOLE SG,PW3,BOOLE SG,PW4,BOOLE SG,PA1,BOOLE SG,PA2,BOOLE SG,PA3,BOOLE SG,PA4,BOOLE SG,PP3,BOOLE SS,OD, WHOLE SS,OH,TENTHS SS,OP,TENTHS SS,ZR,TENTHS SS,OT,HUNDREDTHS SS,ST,HUNDREDTHS SS,SL,HUNDREDTHS SS,UD,BOOLE SS,CV,BOOLE SS,MA,TENTHS SS,SS,HUNDREDTHS $\mathrm{XX}, \mathrm{GP}, \mathrm{BOOLE}$ $X X, D D, T E N T H S$ XX,PT,BOOLE $\mathrm{XX}, \mathrm{TU}, \mathrm{TRI}$ TB,FP,WHOLE TB,LP,WHOLE TB,SK,WHOLE TB,DT,WHOLE DU,TD,BOOLE XX,PN,WHOLE
YES Set Depths Window to include all bins 25 MINIMUM PERCENT GOOD TO PLOT YES Plot North/South Vel. YES Plot East/West Vel. NO Plot Vertical Vel.

NO Plot Error Vel.

NO Plot Percent Error

NO Plot Mag and Dir NO Plot Average SP. W.

- YES Plot Average AGC YES Plot Percent Good NO Plot Doppler 1 NO Plot Doppler 2 NO Plot Doppler 3 NO Plot Doppler 4 NO Plot SP. W. 1 NO Plot SP. W. 2 NO Plot SP. W. 3 NO Plot SP. W. 4 NO Plot AGC 1 NO Plot AGC 2 NO Plot AGC 3 NO Plot AGC 4

NO Plot 3-Beam Solution

0 Offset for Depth -90.0 Offset for Heading 0.0 Offset for Pitch 0.0 Offset for Roll 45.00 Offset for Temp 50.00 Scale for Temp 36.00 Salinity (PPT) YES Toggle UP/DOWN NO Toggle Concave/Convex transducer head 30.0 Mounting angle for transducers 1500.00 Speed of Sound $(\mathrm{m} / \mathrm{sec})$ YES [SYSTEM DEFAULT, GP] 1.0 [SYSTEM DEFAULT, DD] NO [SYSTEM DEFAULT, PT] 2 [SYSTEM DEFAULT, TU] 1 FIRST BIN TO PRINT 64 LAST BIN TO PRINT 6 Skip interval between bins YES Diagnostic TAB mode NO Toggle use of dummy data 0 [SYSTEM DEFAULT, PN] 
DR,SD, WHOLE

DR,PD, WHOLE DP,PX,BOOLE

SS,LC,TENTHS

SS,NW,TENTHS

GC,GM,TRI

$A D, P S, B O O L E$

XX,LNN,BOOLE

$\mathrm{XX}, \mathrm{BM}, \mathrm{BOOLE}$

XX,RSD,BOOLE

XX,DRV,WHOLE

XX,PBD, WHOLE

TB,RS,BOOLE

UX,EE,BOOLE

SS,VSC,TRI

AD,DM,BOOLE

TB,SC,BOOLE

AD,CW,BOOLE

$\mathrm{DR}, \mathrm{RW}, \mathrm{BOOLE}$

DR,RRD,BOOLE

DR,RRA,BOOLE

DR,RRW,BOOLE

DR,R3,BOOLE

DR,RBS,BOOLE

XX,STD,BOOLE

LR,HB,HUNDREDTHS

SL, 1,ARRAY5

SL, 2,ARRAY 5

SL, 3,ARRAY 5

SL, 4, ARRAY 5

SL,5,ARRAY5

SL,6,ARRAY5

DU,1,ARRA6

DU,2,ARRA6

DU,3,ARRA6

DU,4,ARRA6

DU,5,ARRA6

DU,6,ARRA6

DU,7,ARRA6

DU,8,ARRA6

DU,9,ARRA6

DU, 10,ARRA6

DC, 1, SPECIAL

DC,2,SPECIAL
4 Second recording drive

3 First recording drive $(1=\mathrm{A}: 2=\mathrm{B} \ldots)$

NO Profiler does XYZE transform

5.0 Limit of Knots change

0.5 Weight of new knots of value

2 Graphic Control $0=$ lo res, $1=$ hi res, $2=$ enhanced

NO YES=SERIAL/NO=PARALLEL Profiler Link

YES [SYSTEM DEFAULT, LNN]

YES [SYSTEM DEFAULT, BM]

NO Record Standard Deviation of Velocities per Bin

0 [SYSTEM DEFAULT, DRV]

3 [SYSTEM DEFAULT, PBD]

NO HSOW RHPT STATISTIC

YES Enable Exit to External Program

0 Velocity scale adjustment

NO USE DMA

NO SHOW CTD DATA

YES Collect spectral width

YES Record average SP. W. /Bin

NO Record last raw dopplers

YES Record last raw AGC

NO Record last SP. W.

NO Record average 3-beam solutions

YES Record beam statistic

NO [SYSTEM DEFAULT, STD]

0.00 Heading Bias

018 NONE 19200 PROFILER

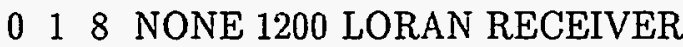

$\begin{array}{lll}0 & 1 & 8 \\ 0\end{array}$

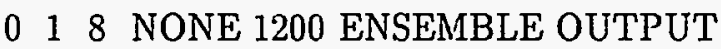

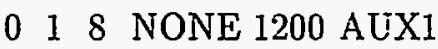

018 NONE 1200 AUX2

100.00100 .0060 .000 .000 .00 YES D1

$-100.00-100.0060 .000 .000 .00$ YES D2

200.00200 .0060 .000 .000 .00 YES D3

$-200.00-200.0060 .000 .000 .00$ YES D4

200.0019 .0060 .000 .000 .00 YES AGC

0.000 .0060 .000 .000 .00 NO SP. W.

0.000 .0060 .000 .000 .00 NO ROLL

0.000 .0060 .000 .000 .00 NO PITCH

0.000 .0060 .000 .000 .00 NO HEADING

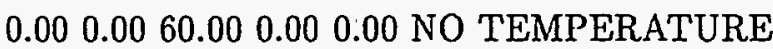

"FH00001" MACRO 1

"CF64" MACRO 2 
DC,3,SPECIAL "E0004020099" MACRO 3

DC,4,SPECIAL "B0009001" MACRO 4

CI,1,SPECIAL "Arabian Sea" CRUISE ID GOES HERE

LR,1,SPECIAL “ " LORAN FILE NAME GOES HERE 


\section{Appendix A. List of Sections}

Each cruise is divided into sections and stations, to form either nearly linear transects or coverage over some localized area. In this section, we list the start date, stop date, and the begining and end positions of each section. 
Section List for TN047

\begin{tabular}{|c|c|c|c|c|c|c|c|c|}
\hline \multirow{3}{*}{$\begin{array}{l}\mathrm{Sec} \\
1\end{array}$} & \multicolumn{4}{|c|}{ Start } & \multicolumn{4}{|c|}{ End } \\
\hline & \multicolumn{2}{|c|}{ Date } & Year Day & (Lat,Lon) & \multicolumn{2}{|c|}{ Date } & Year Day & (Lat,Lon) \\
\hline & $95 / 05 / 03$ & 03:47:39 & 122.158 & $(23.655,58.615)$ & $95 / 05 / 05$ & $02: 34: 54$ & 124.108 & $(15.971,61.501)$ \\
\hline la & $95 / 05 / 03$ & 03:47:39 & 122.158 & $(23.655,58.615)$ & $95 / 05 / 03$ & $18: 43: 26$ & 780 & $(22.272,60.312)$ \\
\hline & $95 / 05 / 03$ & $18: 48: 26$ & 122. & $(22$. & $95 / 05 / 05$ & 64 & 88 & \\
\hline & $95 /$ & & 1 & & 107 & & & \\
\hline & $/ 07$ & $: 54$ & & & $5 / 07$ & & & \\
\hline & $95 / c$ & 20: & 17 & & $95 / 05 / 07$ & & & $96)$ \\
\hline & $95 /$ & $23:$ & 126 & & 110 & & & \\
\hline & & 10: & 12 & & & & & \\
\hline & 10 & 19: & 12 & & 12 & & & 94) \\
\hline & $95 /$ & & & & & & & 156) \\
\hline & $95 / 05 / 13$ & $00:$ & & & & & & 357) \\
\hline & 115 & 23: & & & & & & \\
\hline 1 & $95 / C$ & & & & & & & 47) \\
\hline & $95 / 05 / 19$ & $06: 14: 24$ & & & & & & 994) \\
\hline $12 \mathrm{a}$ & $95 / 05 / 19$ & $06: 14: 24$ & 138.260 & $(19$ & $95 / 05 / 20$ & $09: 29: 02$ & 139.395 & $(22.452,6$ \\
\hline $12 \mathrm{~b}$ & $95 / 05 / 20$ & 09:34:02 & 139.399 & $(22.464,60.085)$ & $95 / 05 / 20$ & 23:34:00 & 139.982 & $(23.375,58.994)$ \\
\hline
\end{tabular}


Section List for TN048

\begin{tabular}{|c|c|c|c|c|c|c|c|c|}
\hline \multirow{3}{*}{$\begin{array}{l}\text { Sec } \\
1\end{array}$} & \multicolumn{4}{|c|}{ Start } & \multicolumn{4}{|c|}{ End } \\
\hline & \multicolumn{2}{|c|}{ Date } & Year Day & (Lat,Lon) & \multicolumn{2}{|c|}{ Date } & 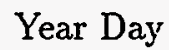 & (Lat,Lon) \\
\hline & $95 / 06 / 21$ & $05: 52: 34$ & 171.245 & $(23.713,58.731)$ & $95 / 06 / 21$ & $23: 04: 57$ & 171.962 & $(22.494,60.291$ \\
\hline 2 & $95 / 06 / 21$ & $23: 09: 57$ & 171.965 & $(22.486,60.295)$ & $95 / 06 / 23$ & 08:49:58 & 173.368 & $(18.739,58.42:$ \\
\hline 3 & $95 / 06 / 23$ & $08: 54: 58$ & 173.372 & $(18.746,58.436)$ & $95 / 06 / 26$ & $13: 59: 59$ & 176.583 & $\left(18.751,58.63^{\prime}\right.$ \\
\hline 4 & $95 / 06 / 26$ & $14: 04: 59$ & 176.587 & $(18.750,58.638)$ & $95 / 06 / 27$ & $01: 14: 59$ & 177.056 & $(17.392,59.18 !$ \\
\hline 5 & $95 / 06 / 27$ & $01: 19: 59$ & 177.056 & $(17.392,59.188)$ & $95 / 06 / 29$ & $13: 53: 15$ & 179.579 & $(16.929$ \\
\hline 6 & $95 / 06 / 29$ & $13: 58: 15$ & 179.582 & .293) & $6 / 30$ & $: 17$ & 180.079 & $.83:$ \\
\hline 7 & $95 / 06 / 30$ & 01:58:15 & 180.082 & $(16.154,61.830)$ & $95 / 07 / 01$ & 02:48:15 & 181.117 & $67,61.81$ ، \\
\hline 8 & $95 / 07 / 01$ & $02: 53: 14$ & 181.120 & $(16.164,61.855)$ & $95 / 07 / 01$ & $12: 48: 15$ & 181.534 & $3.06 !$ \\
\hline 9 & $95 / 07 / 01$ & $12: 53: 15$ & 181.537 & $(15.450,63.077)$ & $95 / 07 / 03$ & $22: 56: 23$ & 183.956 & $\left(11.906,64.09^{\prime}\right.$ \\
\hline 10 & $95 / 07 / 03$ & $23: 01: 23$ & 183.959 & $(14.893,64.098)$ & $95 / 07 / 04$ & $06: 16: 23$ & 184.261 & $\left(14.435,65.00^{\circ}\right.$ \\
\hline 11 & $95 / 07 / 04$ & $06: 21: 23$ & 184.265 & $(14.430,6$ & $95 / 07 / 06$ & $01: 11: 23$ & 186.070 & $(16.511,61.46$ \\
\hline 12 & $95 / 07 / 06$ & $01: 46: 23$ & 186.074 & (15.510, & $95 / 07 / 08$ & $0: 18$ & 188.063 & 7.30: \\
\hline 13 & $95 / 07 / 08$ & $01: 35: 18$ & 188.066 & $(18.500,57.304)$ & $95 / 07 / 09$ & $07: 39: 59$ & 189.319 & $(19.341,58.03 !$ \\
\hline 14 & $95 / 07 / 09$ & $07: 44: 58$ & 189.323 & $(19.338,58.041)$ & $95 / 07 / 10$ & $12: 55: 46$ & 190.539 & $(18.999,60.50 !$ \\
\hline 15 & $95 / 07 / 10$ & $13: 00: 46$ & 190.542 & $.505)$ & $95 / 07 / 11$ & $06: 05: 44$ & 191.254 & $(20.425,59.15$ \\
\hline 16 & $95 / 07 / 11$ & $06: 10: 45$ & 191.257 & $(20.430,59.163)$ & $95 / 07 / 11$ & $22: 50: 44$ & 191.952 & $(21.913,61.02$ \\
\hline 17 & $95 / 07 / 11$ & $22: 55: 45$ & 191.955 & $(21.915,61.018)$ & $95 / 07 / 13$ & $01: 35: 45$ & 193.066 & $(23.676,58.671$ \\
\hline
\end{tabular}


Section List for TN049

\begin{tabular}{lllllllll}
\multicolumn{1}{c}{ Sec } & \multicolumn{9}{c}{ Start } & \multicolumn{3}{c}{ End } \\
1 & $95 / 07 / 17$ & $16: 29: 22$ & 197.687 & $(23.660,58.620)$ & $95 / 07 / 18$ & $02: 31: 48$ & 198.105 & $(22.387,59.884)$ \\
2 & $95 / 07 / 18$ & $05: 34: 36$ & 198.232 & $(22.440,59.915)$ & $95 / 07 / 18$ & $11: 09: 55$ & 198.465 & $(22.500,61.163)$ \\
3 & $95 / 07 / 18$ & $17: 34: 36$ & 198.732 & $(22.524,61.236)$ & $95 / 07 / 19$ & $11: 34: 56$ & 199.482 & $(21.190,63.541)$ \\
1 & $95 / 07 / 19$ & $17: 29: 36$ & 199.729 & $(21.160,63.604)$ & $95 / 07 / 21$ & $02: 29: 36$ & 201.104 & $(19.201,67.170)$ \\
5 & $95 / 07 / 23$ & $08: 54: 36$ & 203.371 & $(19.133,67.184)$ & $95 / 07 / 24$ & $23: 29: 56$ & 204.979 & $(15.391,68.749)$ \\
6 & $95 / 07 / 25$ & $08: 29: 35$ & 205.353 & $(15.314,68.679)$ & $95 / 07 / 25$ & $18: 28: 15$ & 205.769 & $(14.918,66.887)$ \\
7 & $95 / 07 / 26$ & $00: 22: 55$ & 206.016 & $(14.902,66.846)$ & $95 / 07 / 27$ & $05: 02: 54$ & 207.210 & $(15.963,63.109)$ \\
8 & $95 / 07 / 27$ & $05: 02: 54$ & 207.210 & $(15.952,63.124)$ & $95 / 07 / 27$ & $16: 03: 14$ & 207.668 & $(14.467,64.985)$ \\
9 & $95 / 07 / 28$ & $15: 36: 04$ & 208.650 & $(14.434,65.029)$ & $95 / 07 / 30$ & $07: 14: 41$ & 210.301 & $(19.162,67.157)$ \\
10 & $95 / 08 / 01$ & $02: 19: 21$ & 212.096 & $(10.008,64.893)$ & $95 / 08 / 01$ & $23: 39: 42$ & 212.985 & $(14.444,65.001)$ \\
11 & $95 / 08 / 02$ & $08: 29: 21$ & 213.353 & $(14.480,64.950)$ & $95 / 08 / 03$ & $19: 29: 41$ & 214.812 & $(16.031,62.005)$ \\
12 & $95 / 08 / 05$ & $07: 44: 21$ & 216.322 & $(15.572,61.500)$ & $95 / 08 / 05$ & $12: 29: 42$ & 216.520 & $(16.418,61.250)$ \\
13 & $95 / 08 / 05$ & $18: 49: 22$ & 216.784 & $(16.408,61.229)$ & $95 / 08 / 09$ & $10: 59: 41$ & 220.457 & $(18.126,58.013)$ \\
14 & $95 / 08 / 11$ & $14: 59: 21$ & 222.624 & $(18.329,58.029)$ & $95 / 08 / 11$ & $18: 20: 27$ & 222.764 & $(18.492,57.330)$ \\
15 & $95 / 08 / 12$ & $15: 18: 16$ & 223.637 & $(18.569,57.386)$ & $95 / 08 / 13$ & $00: 49: 22$ & 224.034 & $(18.996,58.988)$ \\
16 & $95 / 08 / 13$ & $04: 39: 23$ & 224.193 & $(18.996,59.027)$ & $95 / 08 / 14$ & $02: 44: 14$ & 225.114 & $(22.016,59.976)$ \\
17 & $95 / 08 / 14$ & $02: 44: 14$ & 225.114 & $(22.016,59.976)$ & $95 / 08 / 15$ & $03: 48: 03$ & 226.158 & $(23.644,58.578)$
\end{tabular}


Section List for TN050

\begin{tabular}{lllllllll} 
& \multicolumn{9}{c}{ Start } & \multicolumn{3}{c}{ End } \\
Sec & \multicolumn{2}{c}{ Date } & Year Day & (Lat,Lon) & \multicolumn{2}{c}{ Date } & Year Day & (Lat,Lon) \\
1 & $95 / 08 / 18$ & $04: 50: 46$ & 229.201 & $(23.65158 .617)$ & $95 / 08 / 18$ & $15: 26: 32$ & 229.643 & $(22.23759 .88$ \\
2 & $95 / 08 / 18$ & $15: 31: 32$ & 229.646 & $(22.39059 .883)$ & $95 / 08 / 18$ & $20: 31: 32$ & 229.855 & $(22.40959 .88$ \\
2 & $95 / 08 / 18$ & $20: 36: 31$ & 229.858 & $(22.41959 .895)$ & $95 / 09 / 20$ & $09: 06: 33$ & 231.379 & $(21.73862 .35$ \\
3 & $95 / 08 / 20$ & $09: 16: 32$ & 231.386 & $(21.73962 .360)$ & $95 / 08 / 21$ & $22: 54: 40$ & 232.954 & $(19.89865 .85$ \\
4 & $95 / 08 / 21$ & $22: 59: 49$ & 232.958 & $(19.89365 .861)$ & $95 / 08 / 23$ & $13: 54: 40$ & 234.579 & $(19.07667 .09$. \\
5 & $95 / 08 / 23$ & $13: 59: 39$ & 234.583 & $(19.07567 .093)$ & $95 / 08 / 26$ & $08: 32: 49$ & 237.356 & $(15.37868 .76$ \\
6 & $95 / 08 / 26$ & $08: 37: 50$ & 237.359 & $(15.37768 .758)$ & $95 / 08 / 27$ & $01: 27: 49$ & 238.060 & $(14.90566 .88$ \\
7 & $95 / 08 / 27$ & $01: 32: 50$ & 238.064 & $(14.90366 .884)$ & $95 / 08 / 30$ & $06: 46: 02$ & 241.281 & $(9.96664 .898$ \\
8 & $95 / 08 / 30$ & $06: 51: 01$ & 241.285 & $(9.96664 .898)$ & $95 / 09 / 02$ & $19: 19: 11$ & 244.804 & $(14.44465 .00$ \\
9 & $95 / 09 / 02$ & $19: 24: 09$ & 244.808 & $(14.44464 .999)$ & $95 / 09 / 08$ & $15: 06: 50$ & 250.629 & $(17.40259 .77$. \\
10 & $95 / 09 / 08$ & $15: 11: 50$ & 250.633 & $(17.14059 .776)$ & $95 / 09 / 12$ & $15: 30: 49$ & 254.646 & $(18.50757 .31$ \\
11 & $95 / 09 / 12$ & $15: 35: 49$ & 254.649 & $(18.50757 .318)$ & $95 / 09 / 13$ & $08: 34: 42$ & 255.357 & $(19.00258 .99$ \\
12 & $95 / 09 / 13$ & $08: 39: 43$ & 255.360 & $(19.01358 .996)$ & $95 / 09 / 14$ & $09: 44: 19$ & 256.405 & $(22.64159 .98$ \\
13 & $95 / 09 / 14$ & $09: 49: 20$ & 256.409 & $(22.64159 .971)$ & $95 / 09 / 15$ & $01: 20: 48$ & 257.056 & $(23.58058 .81$
\end{tabular}




\section{Appendix B. Reference Layer Velocity}

This section shows zonal (U) and meridional (V) velocities for reference layer, together with navigation data (longitude and latitude), for each cruise. In each plot, $\mathrm{x}$-axis represents duration of cruise in yearday. 

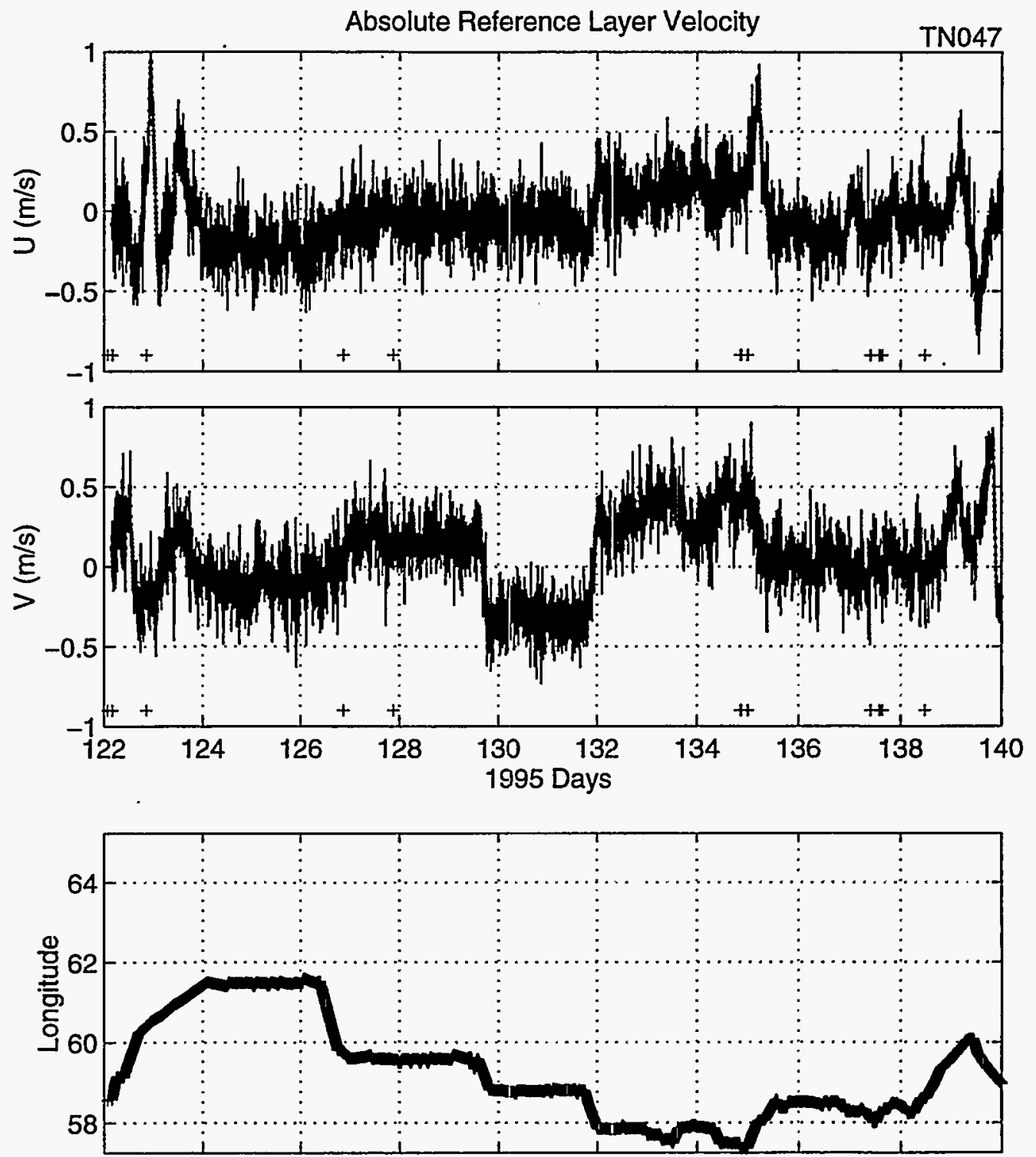

8
0
0
10
1
1
1
1
2

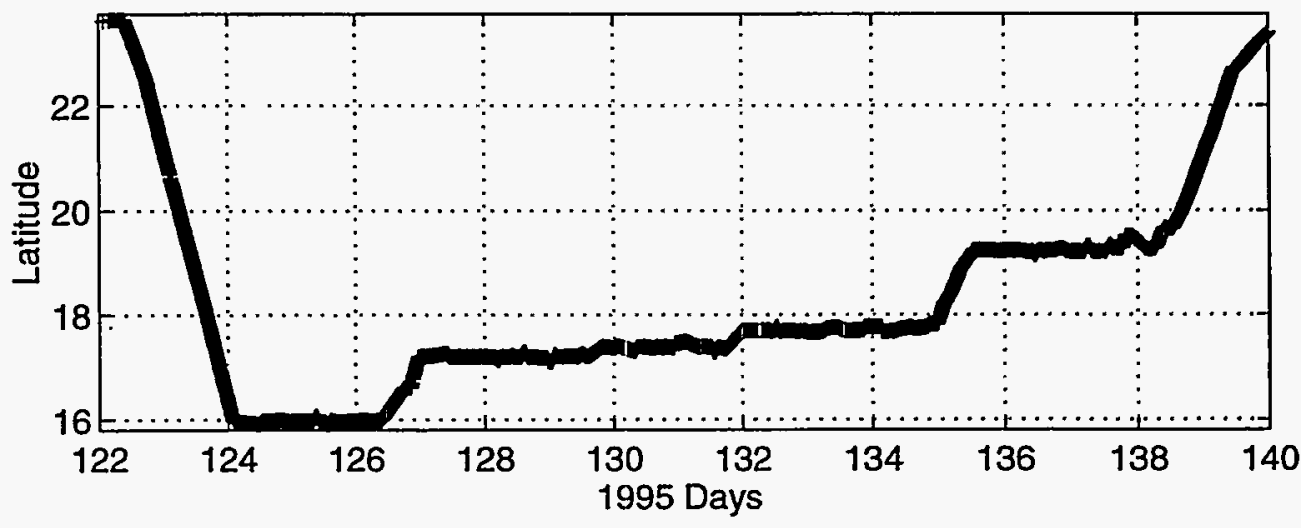



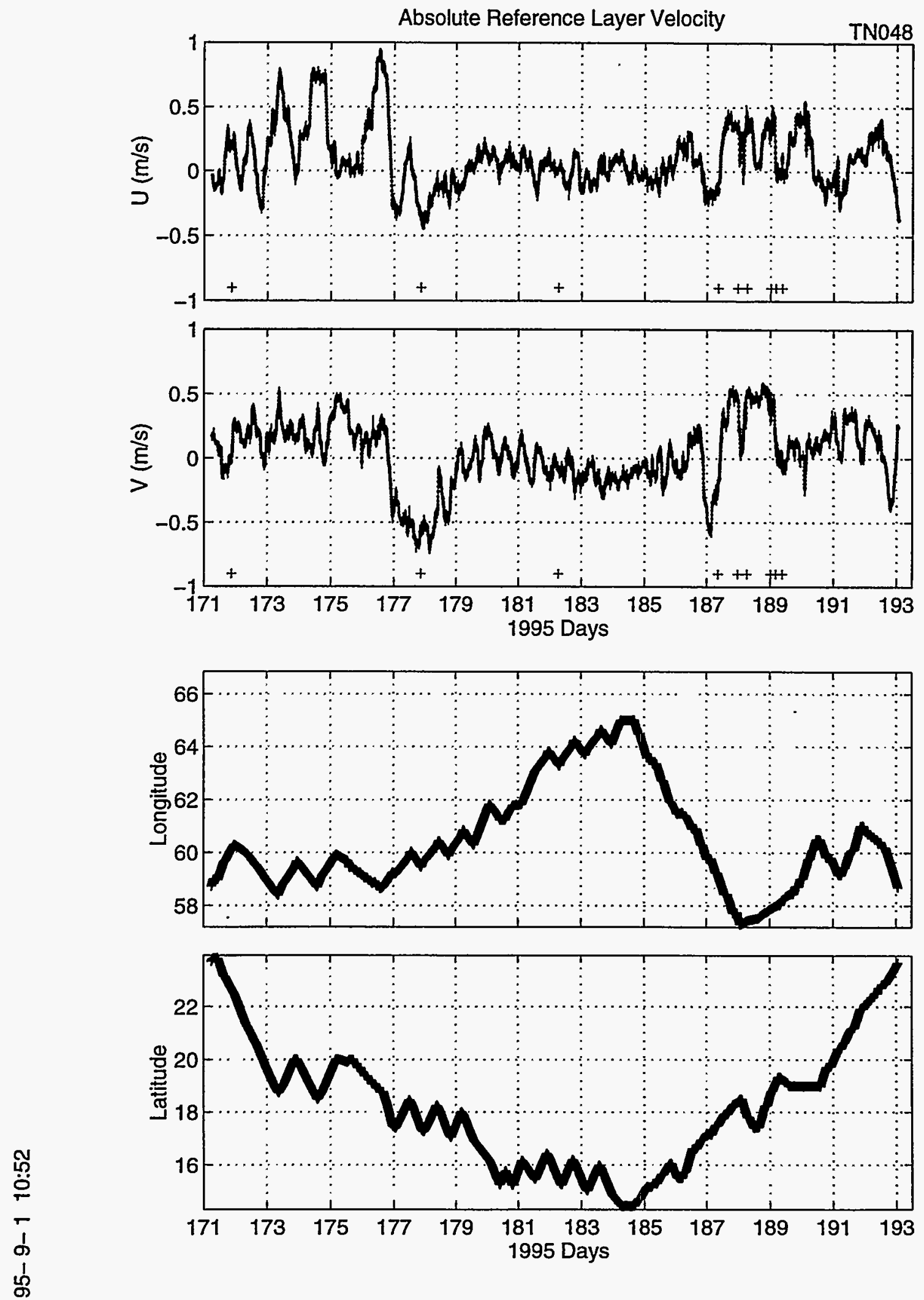

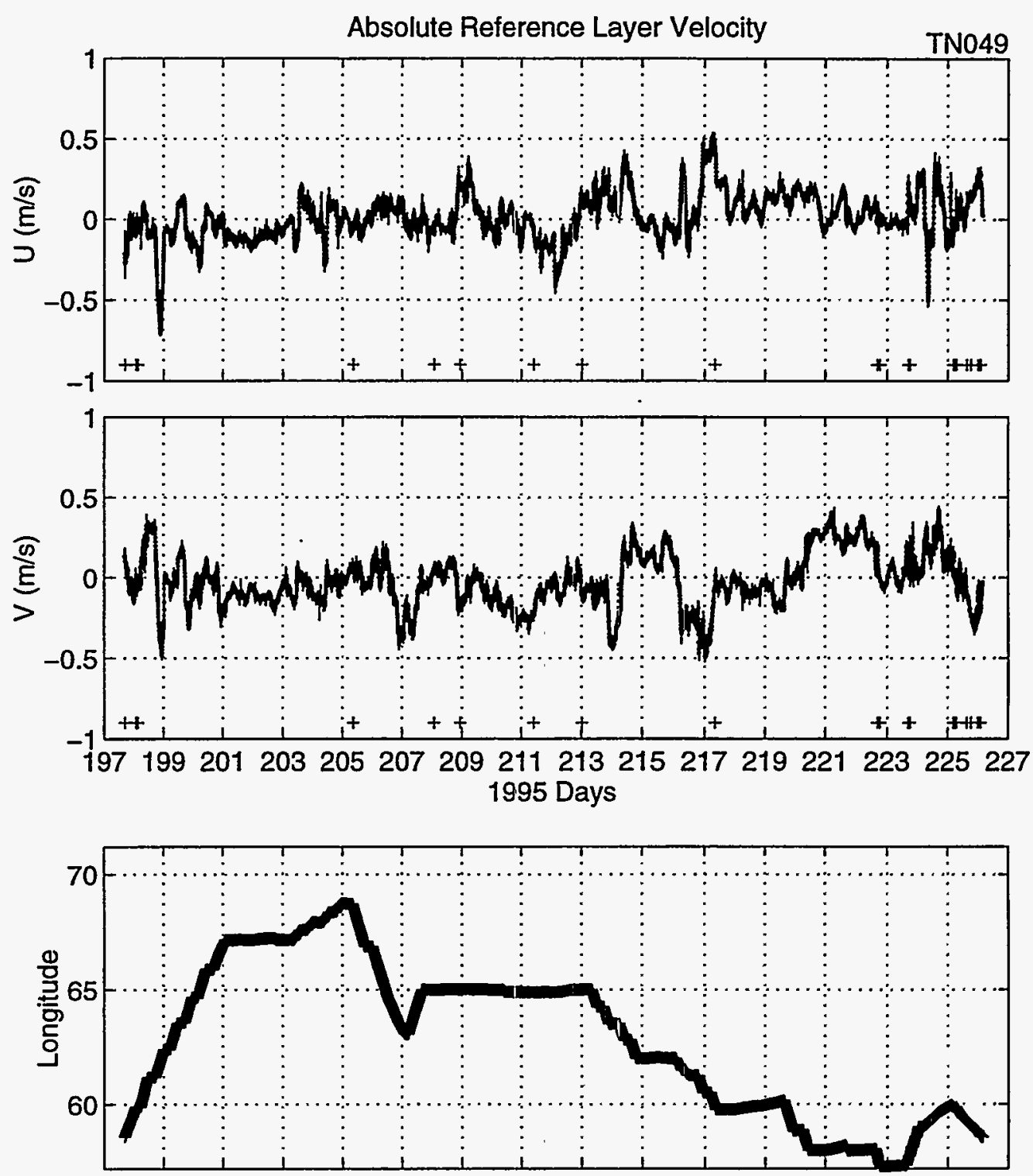

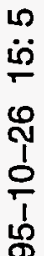

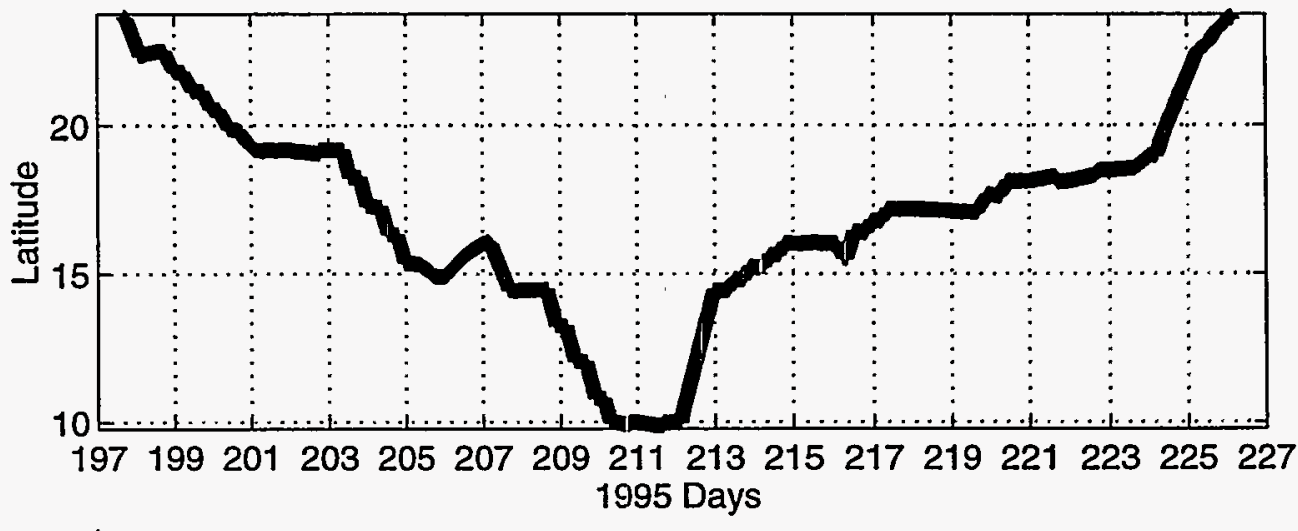



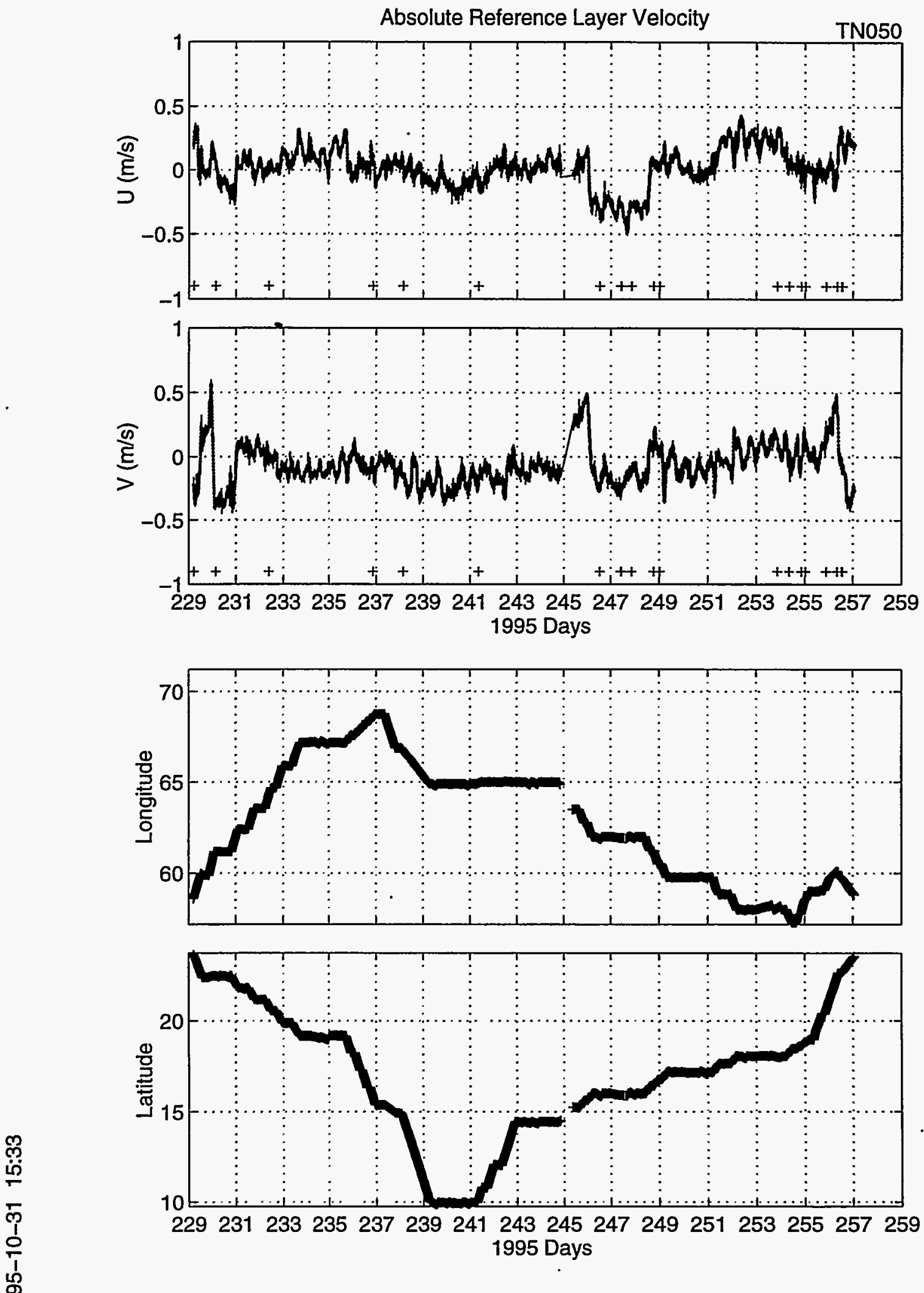


\section{Appendix C. Vector Plots and Contoured Sections}

This section presents vector plots and contoured $U, V$ and backscatter plots for individual sections on each cruise. Vector plots include currents at four layers, each of which is averaged between $20-50 \mathrm{~m}, 50-100 \mathrm{~m}, 100-200 \mathrm{~m}$, and $200-300 \mathrm{~m}$, respectively. 


\section{TN047}




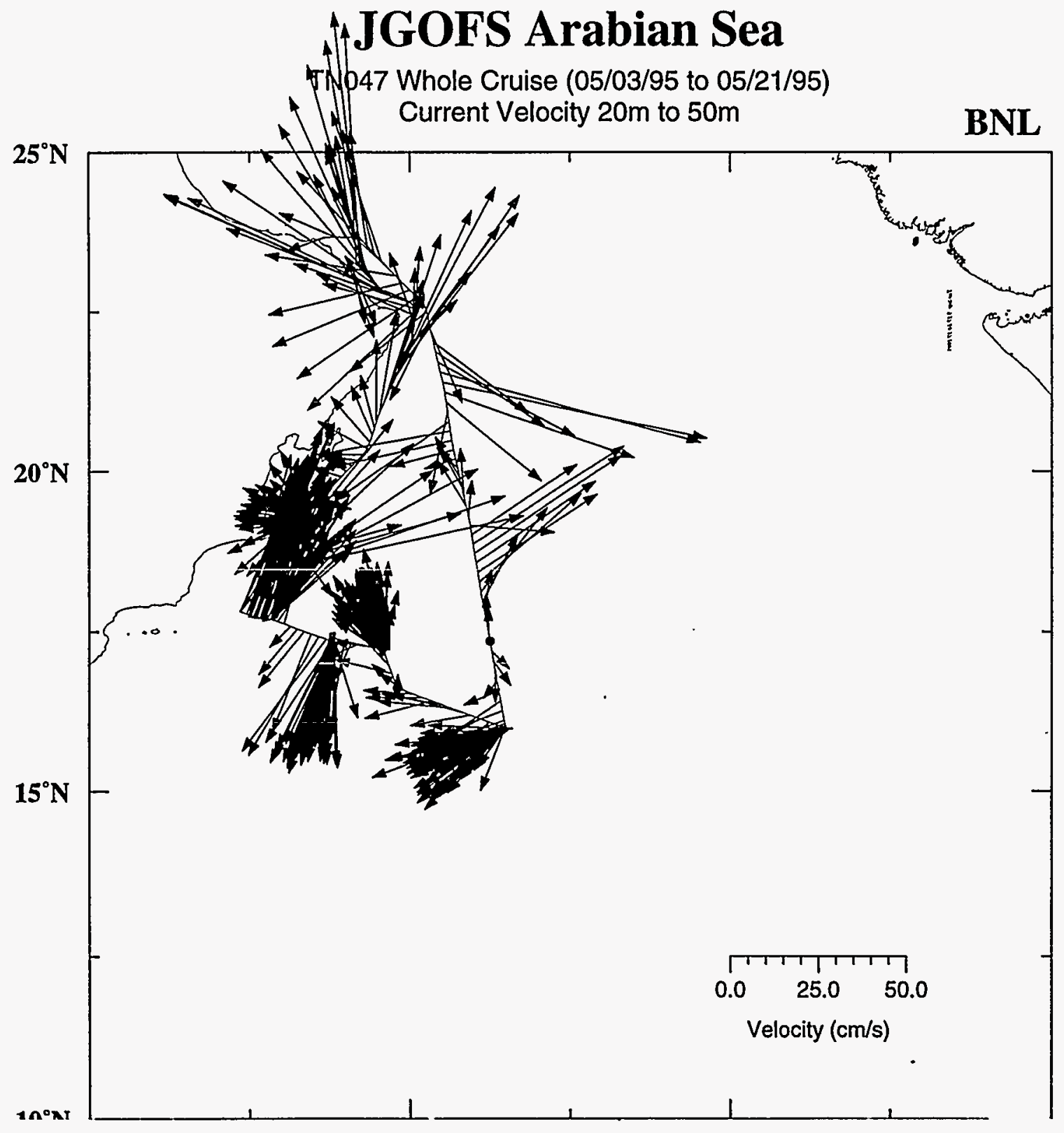




\section{JGOFS Arabian Sea}

TN047 Whole Cruise (05/03/95 to 05/21/95)

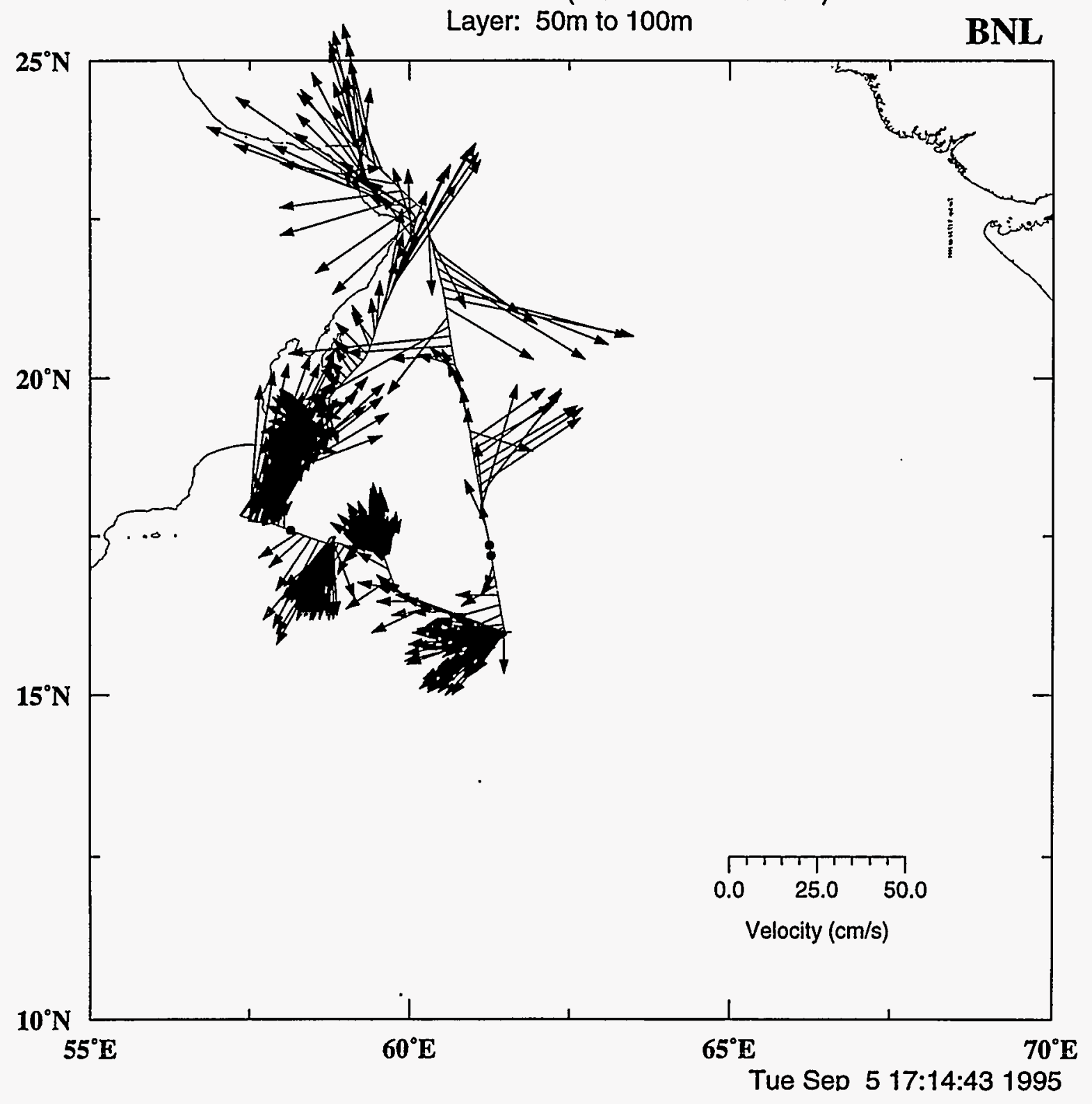




\section{JGOFS Arabian Sea}

TN047 Whole Cruise (05/03/95 to 05/21/95)

Layer: $100 \mathrm{~m}$ to $200 \mathrm{~m}$

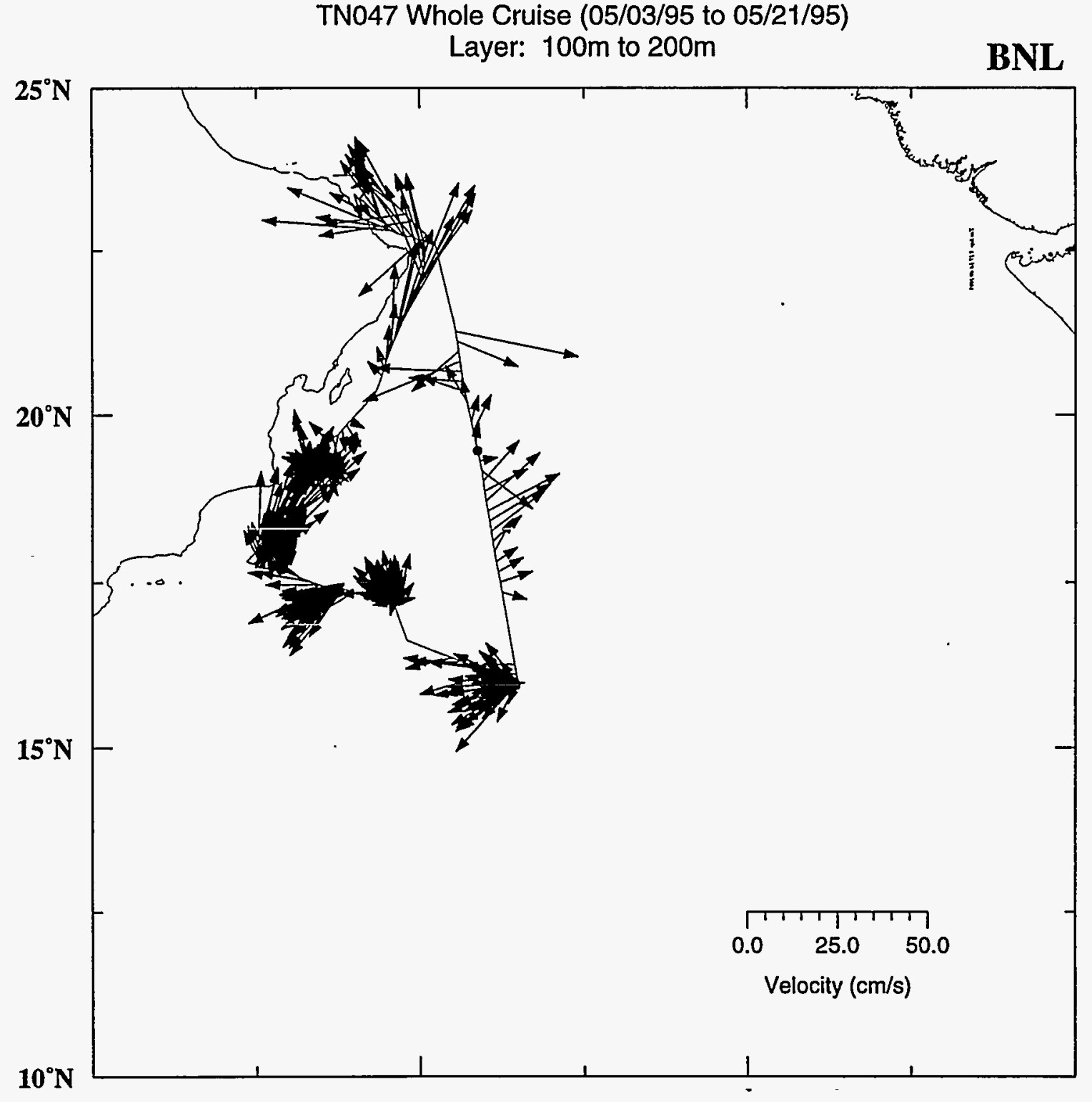


JGOFS Arabian Sea

TN047 Whole Cruise (05/03/95 to 05/21/95)

Layer: $200 \mathrm{~m}$ to $300 \mathrm{~m}$

BNL

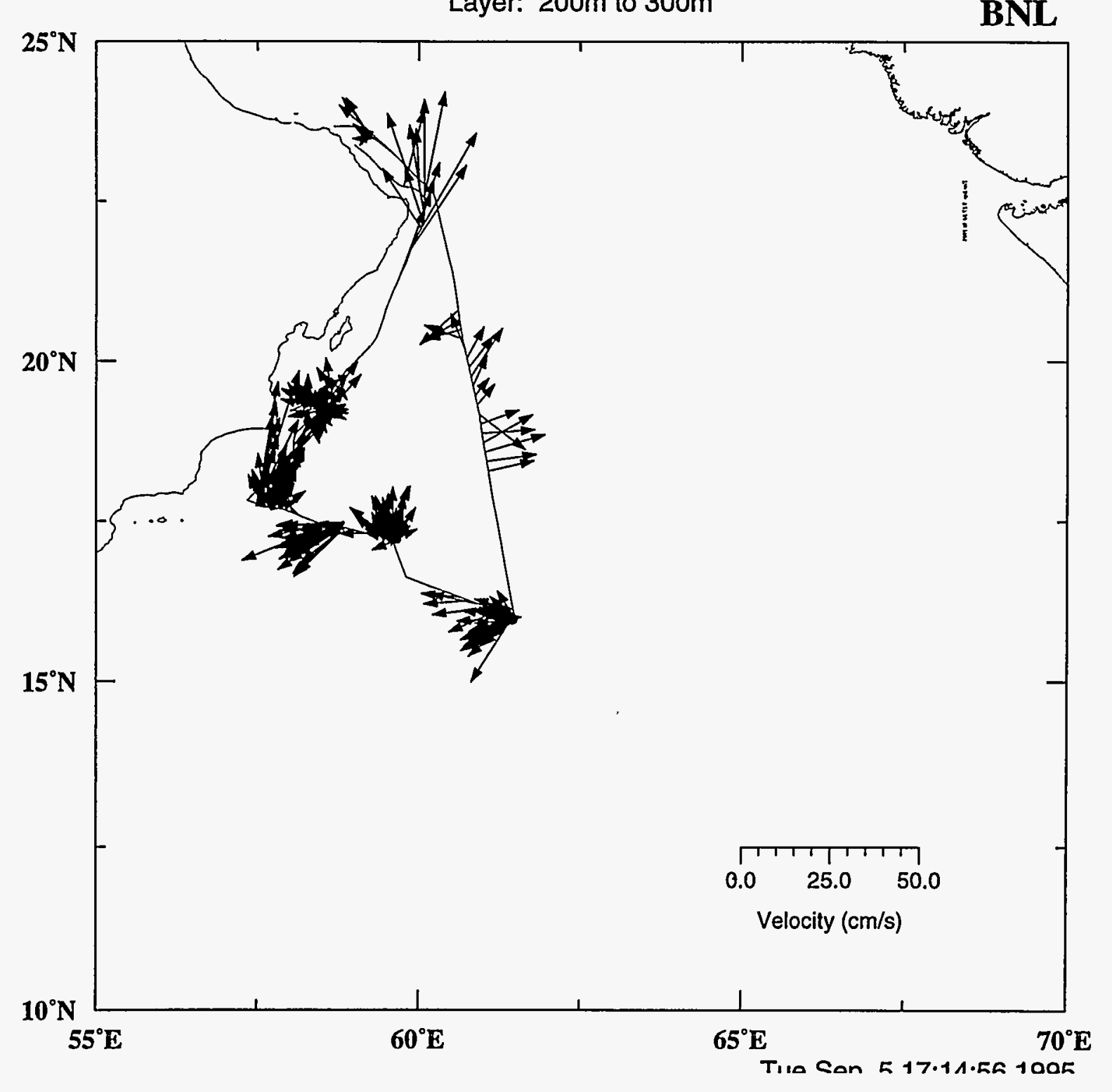


JGOFS Arabian Sea

TN047 Section 3,4,6,8 (05/07/95 to 05/13/95)

Current Velocity $20 \mathrm{~m}$ to $50 \mathrm{~m}$

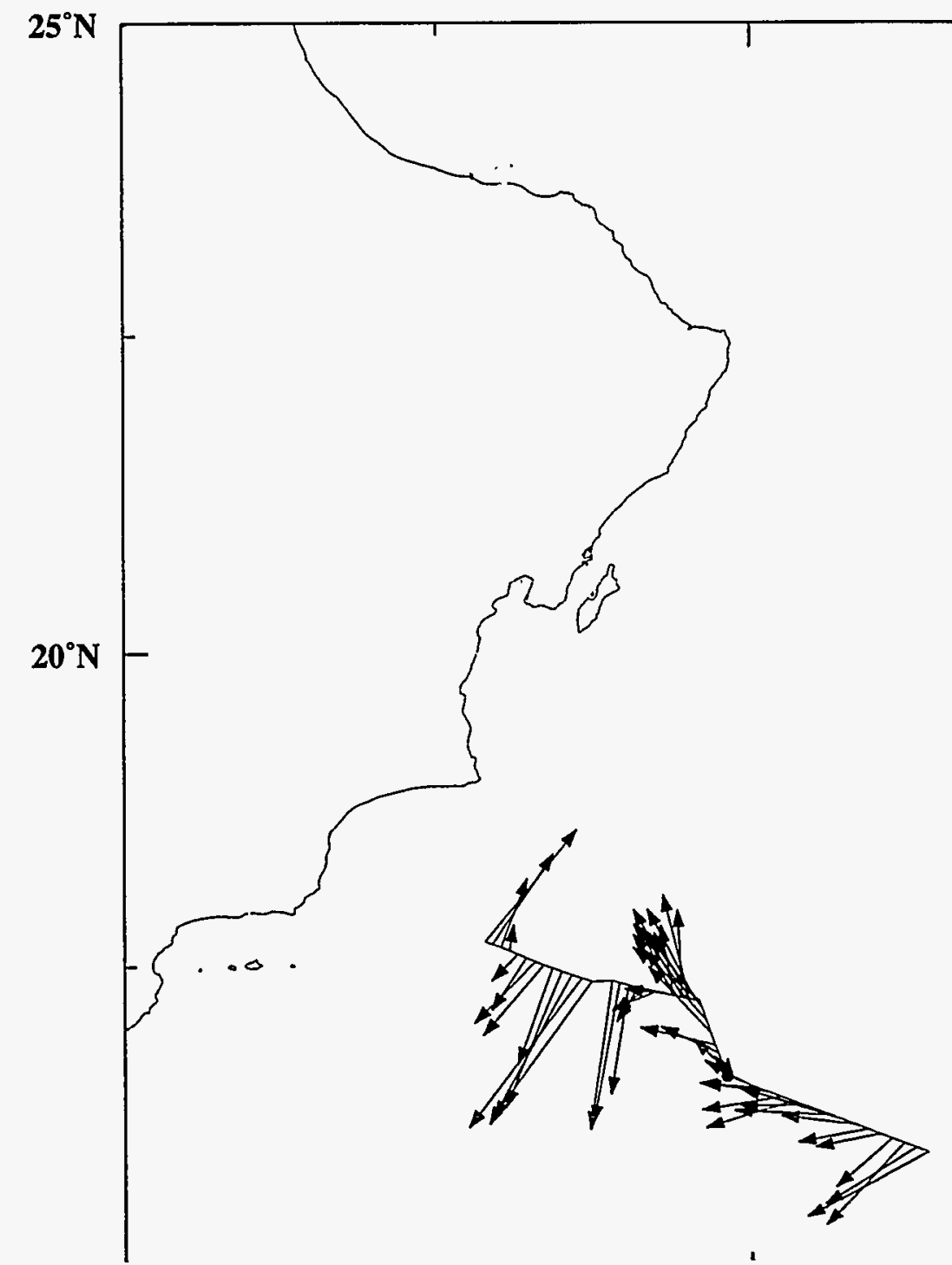

BNL

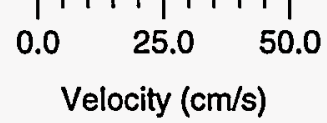




\section{JGOFS Arabian Sea}

TN047 Section 3,4,6,8 (05/07/95 to 05/13/95)

Layer: $50 \mathrm{~m}$ to $100 \mathrm{~m}$

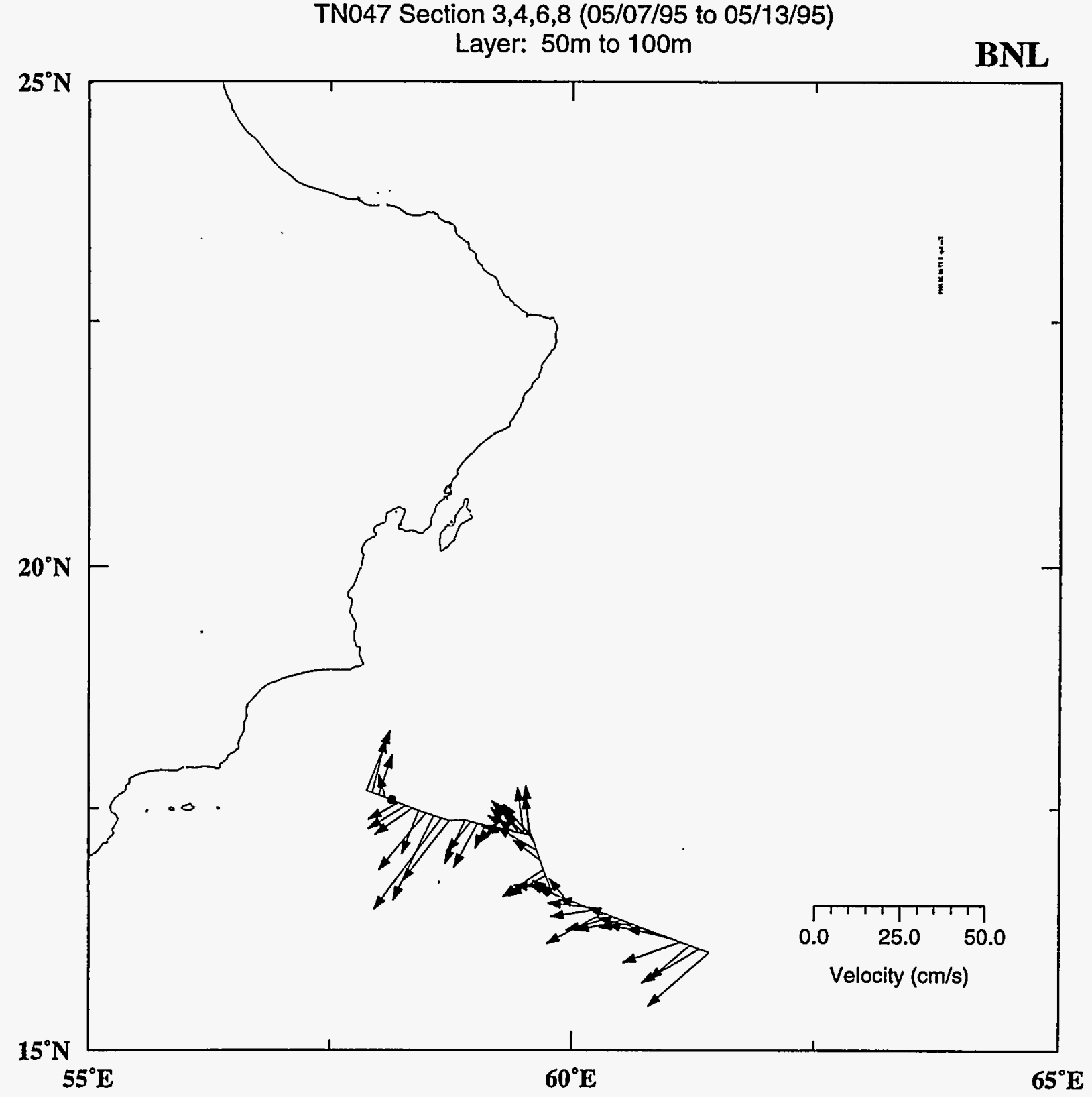




\section{JGOFS Arabian Sea}

TN047 Section 3,4,6,8 (05/07/95 to 05/13/95) Layer: $100 \mathrm{~m}$ to $200 \mathrm{~m}$

BNL

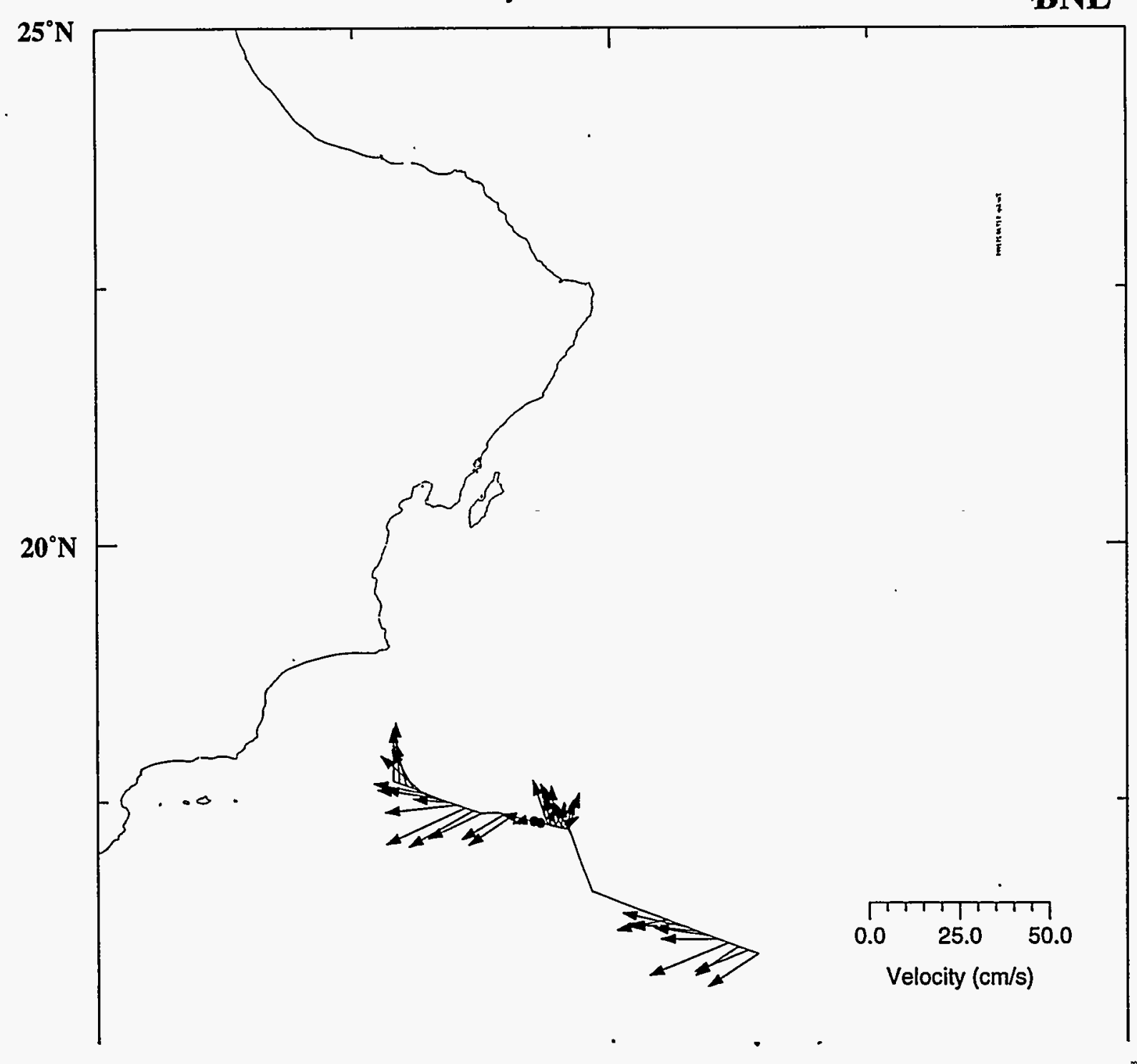




\section{JGOFS Arabian Sea}

TN047 Section 3,4,6,8 (05/07/95 to 05/13/95) Layer: $200 \mathrm{~m}$ to $300 \mathrm{~m}$

BNL

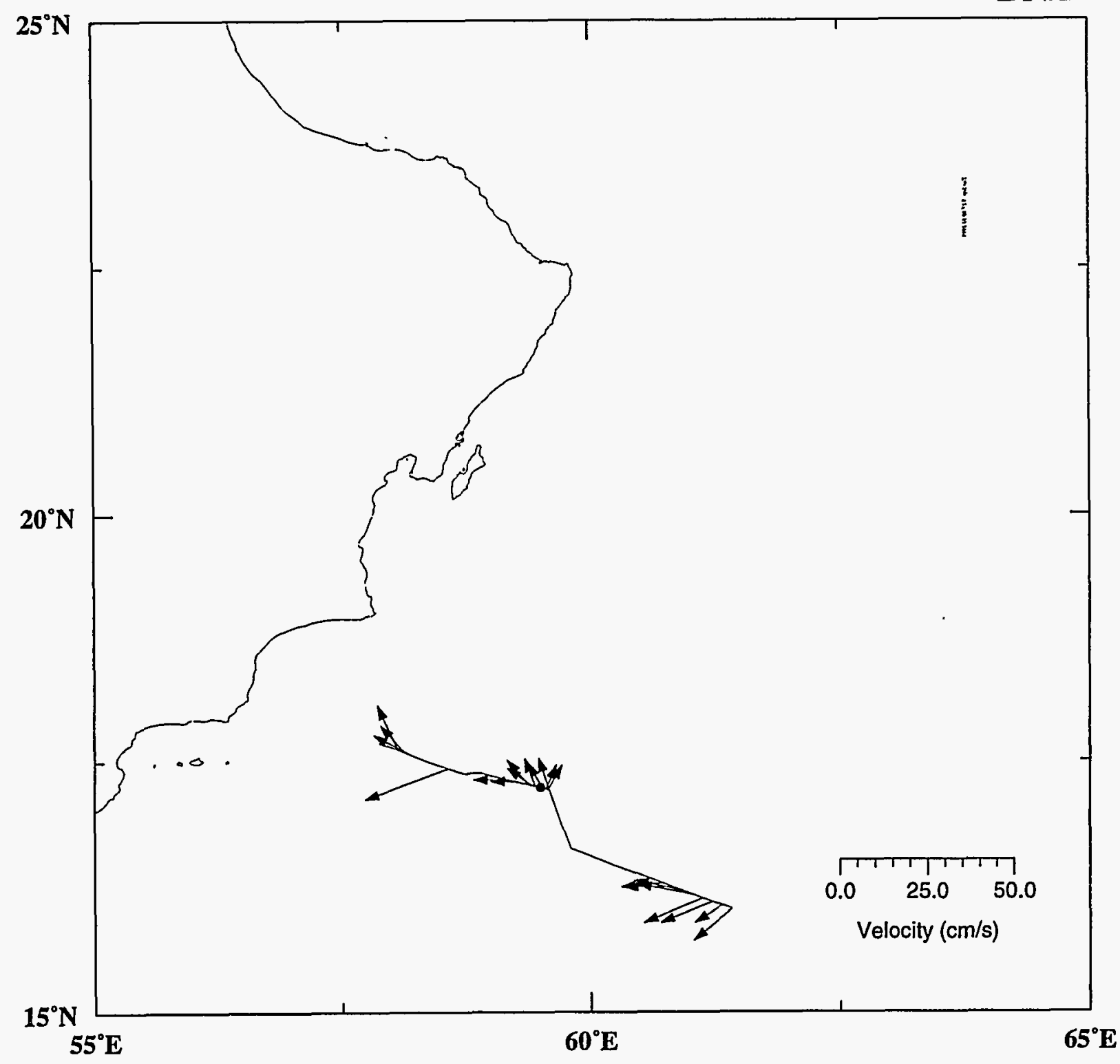


JGOFS Arabian Sea

TN047 Section 10,12 (05/15/95 to 05/21/95)

Currept Velocity $20 \mathrm{~m}$ to $50 \mathrm{~m}$

BNL

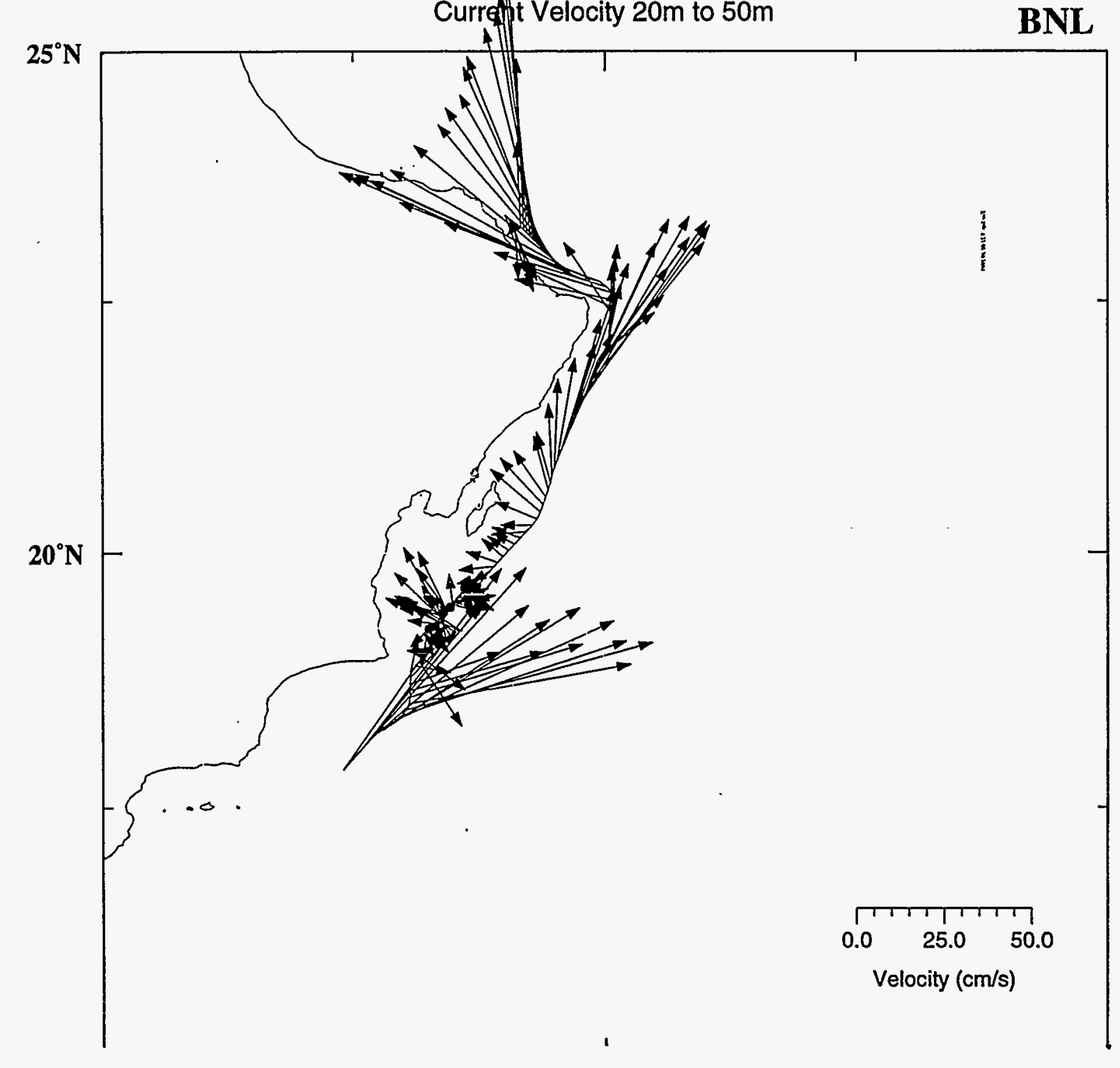


JGOFS Arabian Sea

TN047 Section 10,12 (05/15/95 to 05/21/95) Layer: $50 \mathrm{~m}$ to $100 \mathrm{~m}$

BNL

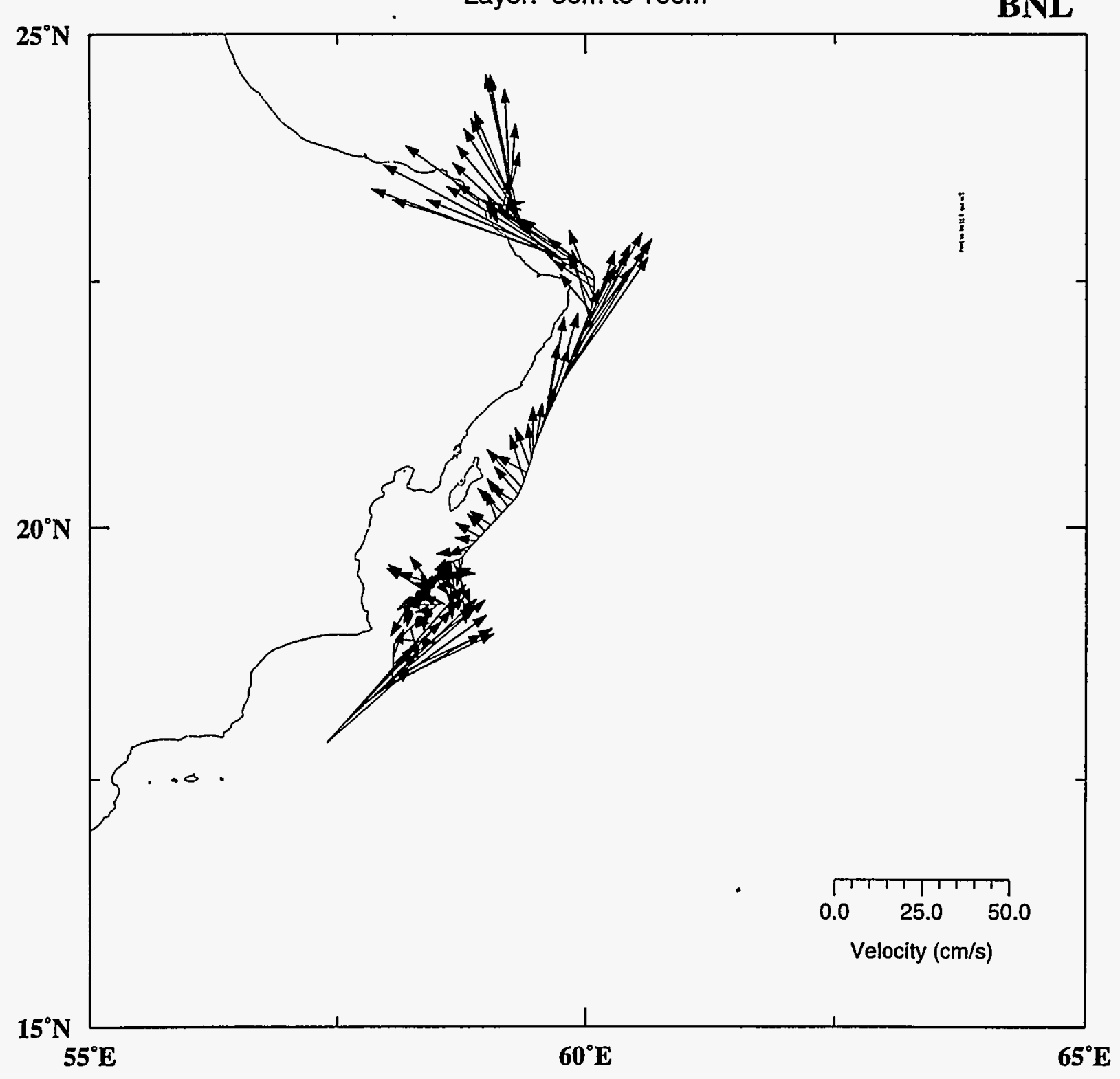




\section{JGOFS Arabian Sea}

TN047 Section 10,12 (05/15/95 to 05/21/95) Layer: $100 \mathrm{~m}$ to $200 \mathrm{~m}$

BNL

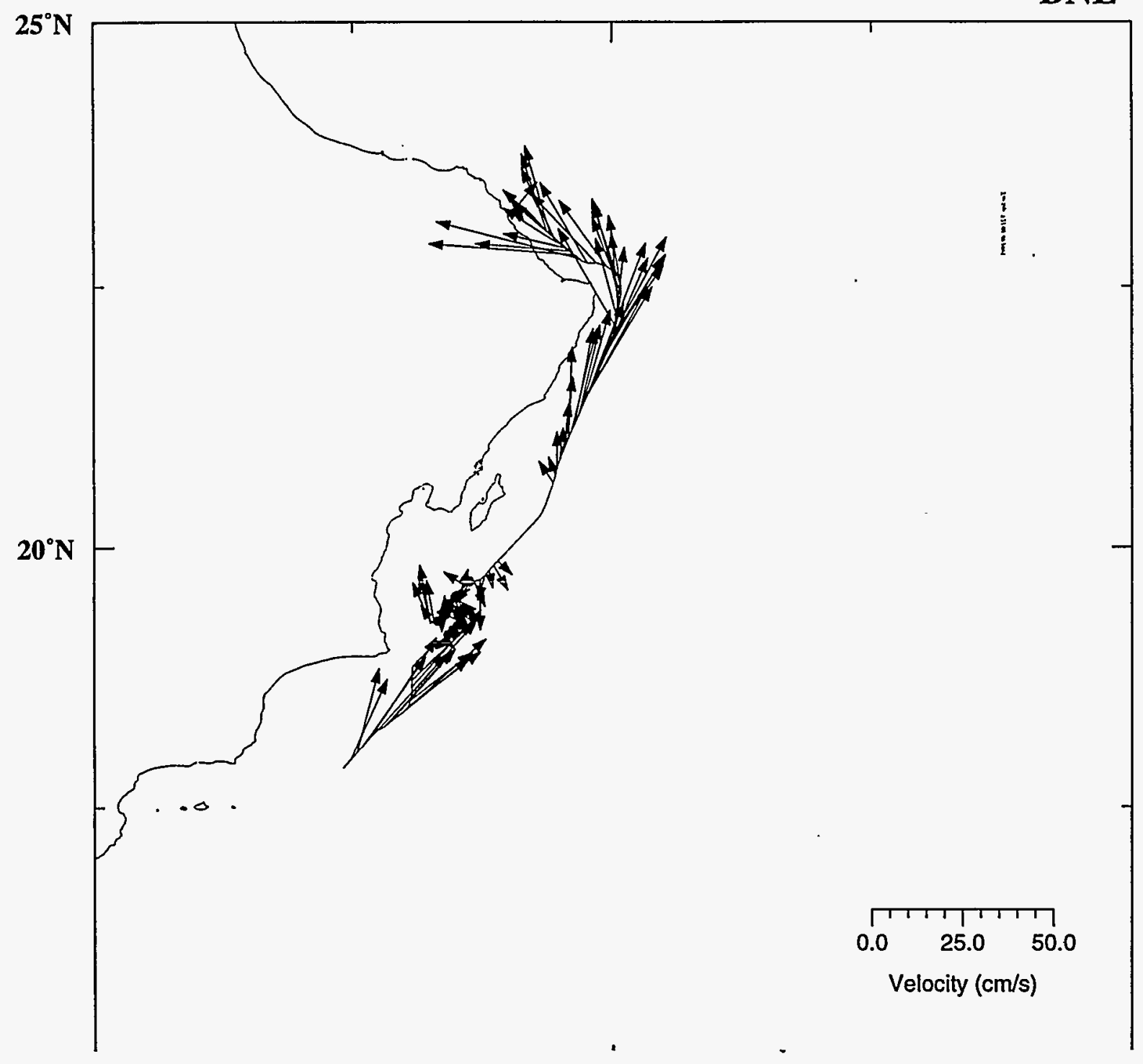




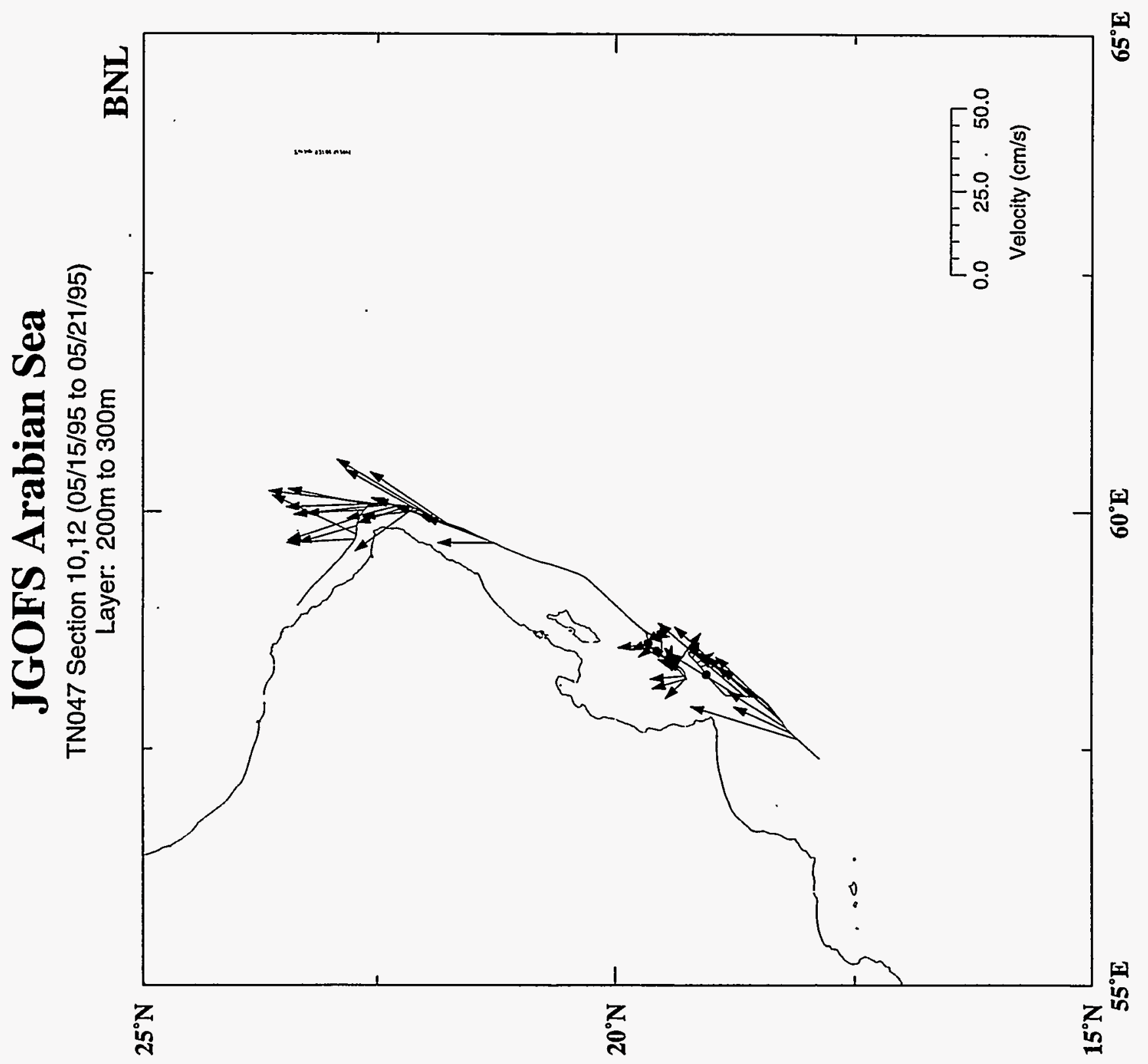




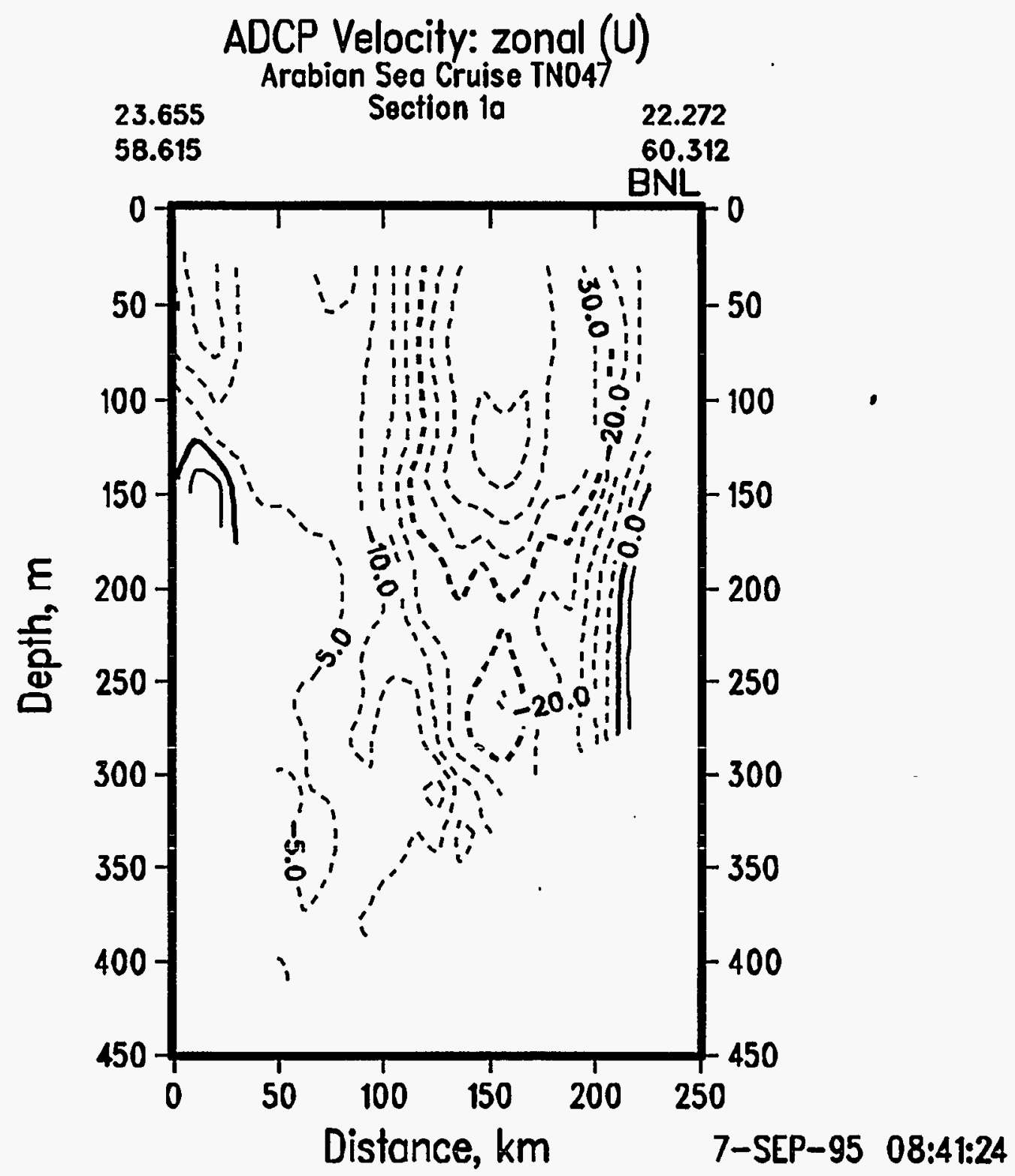




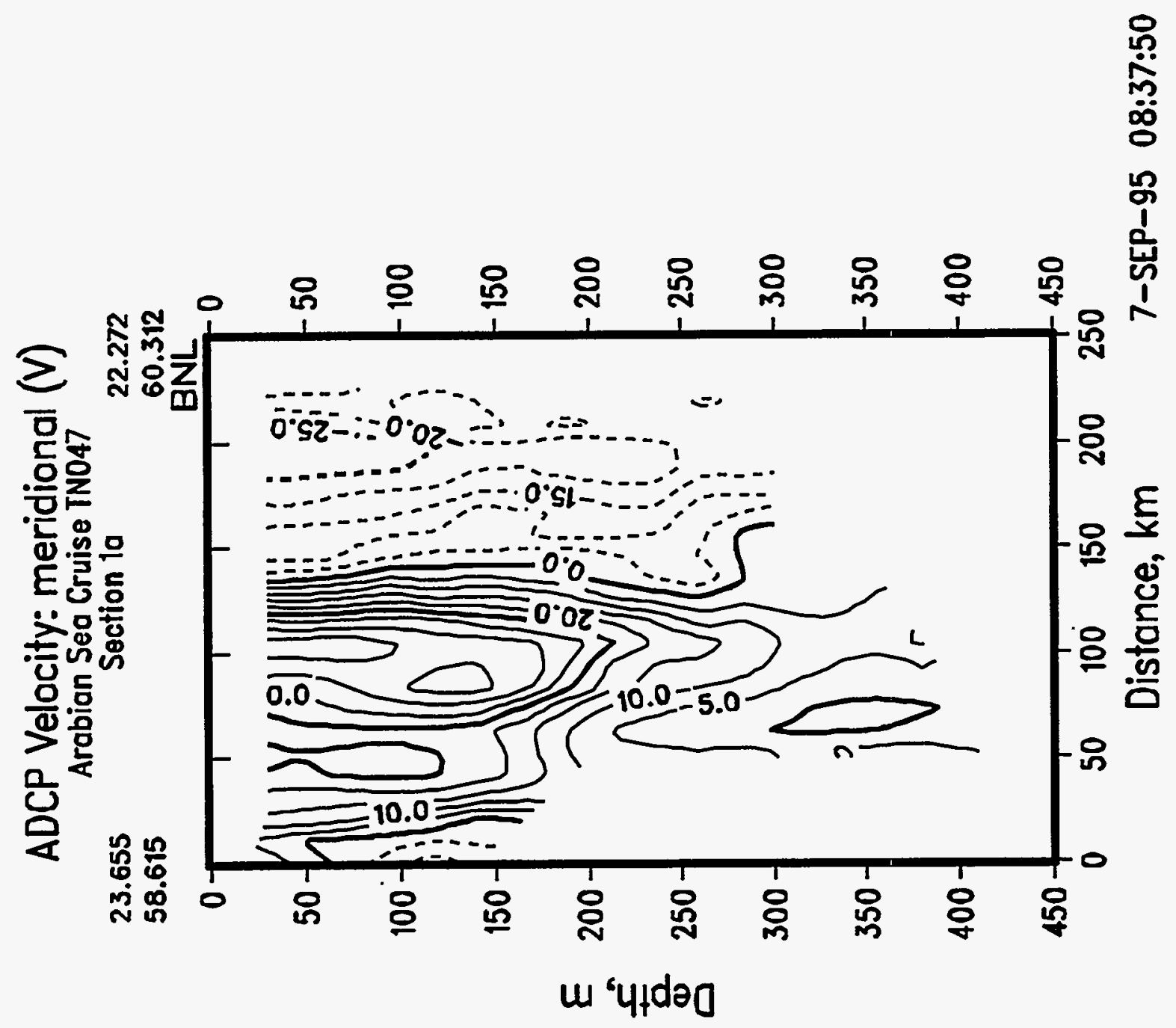




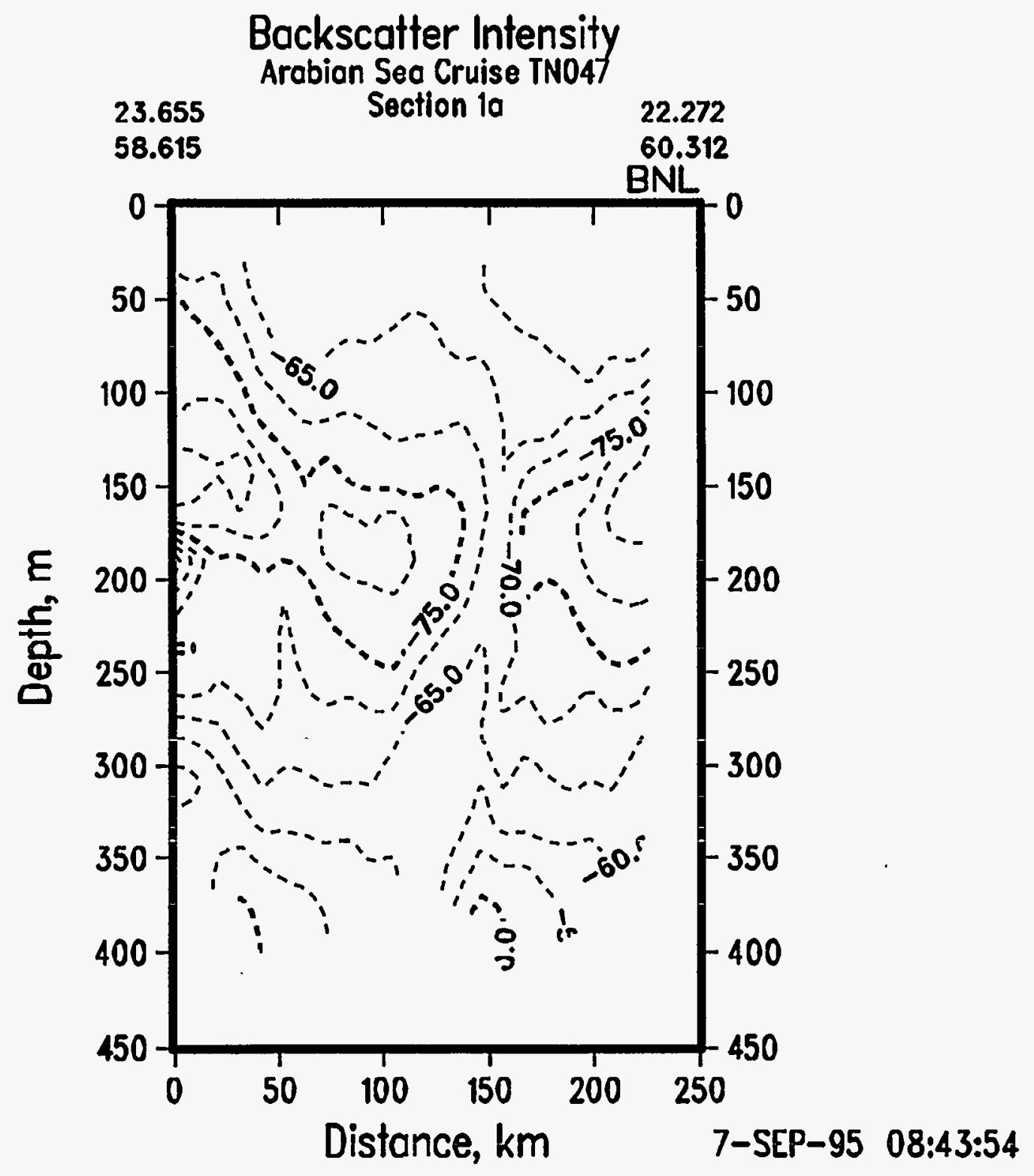




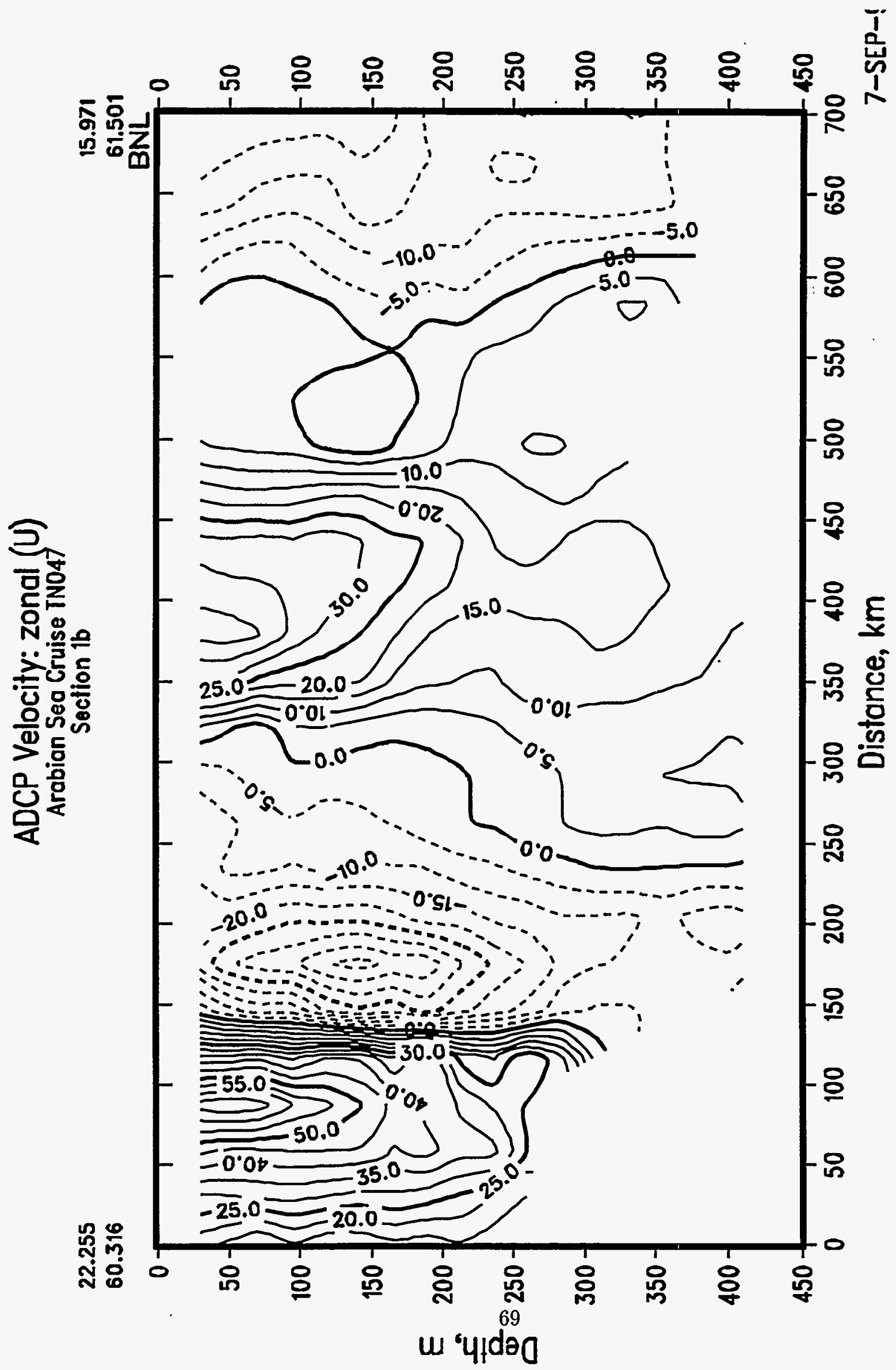




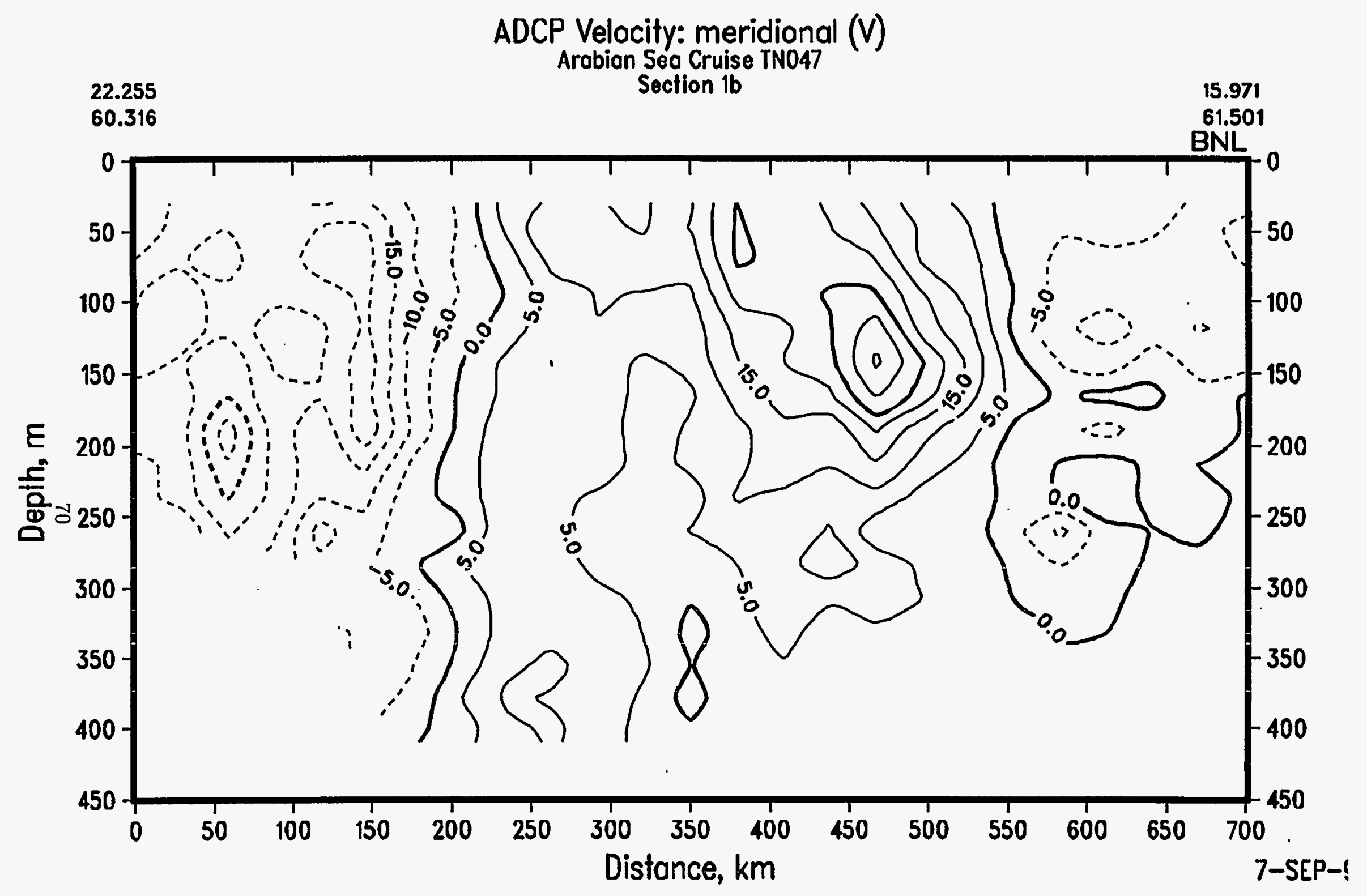




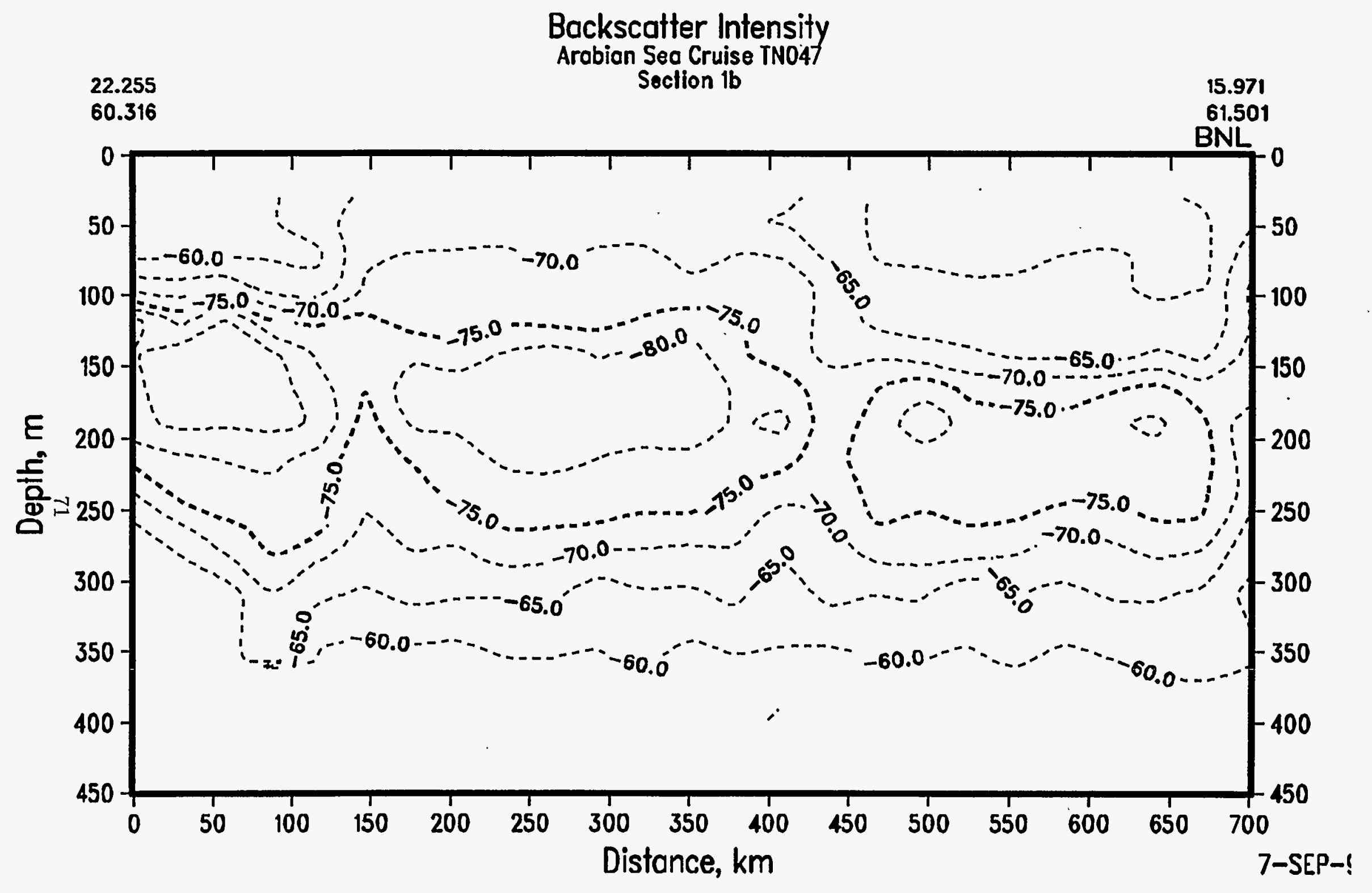




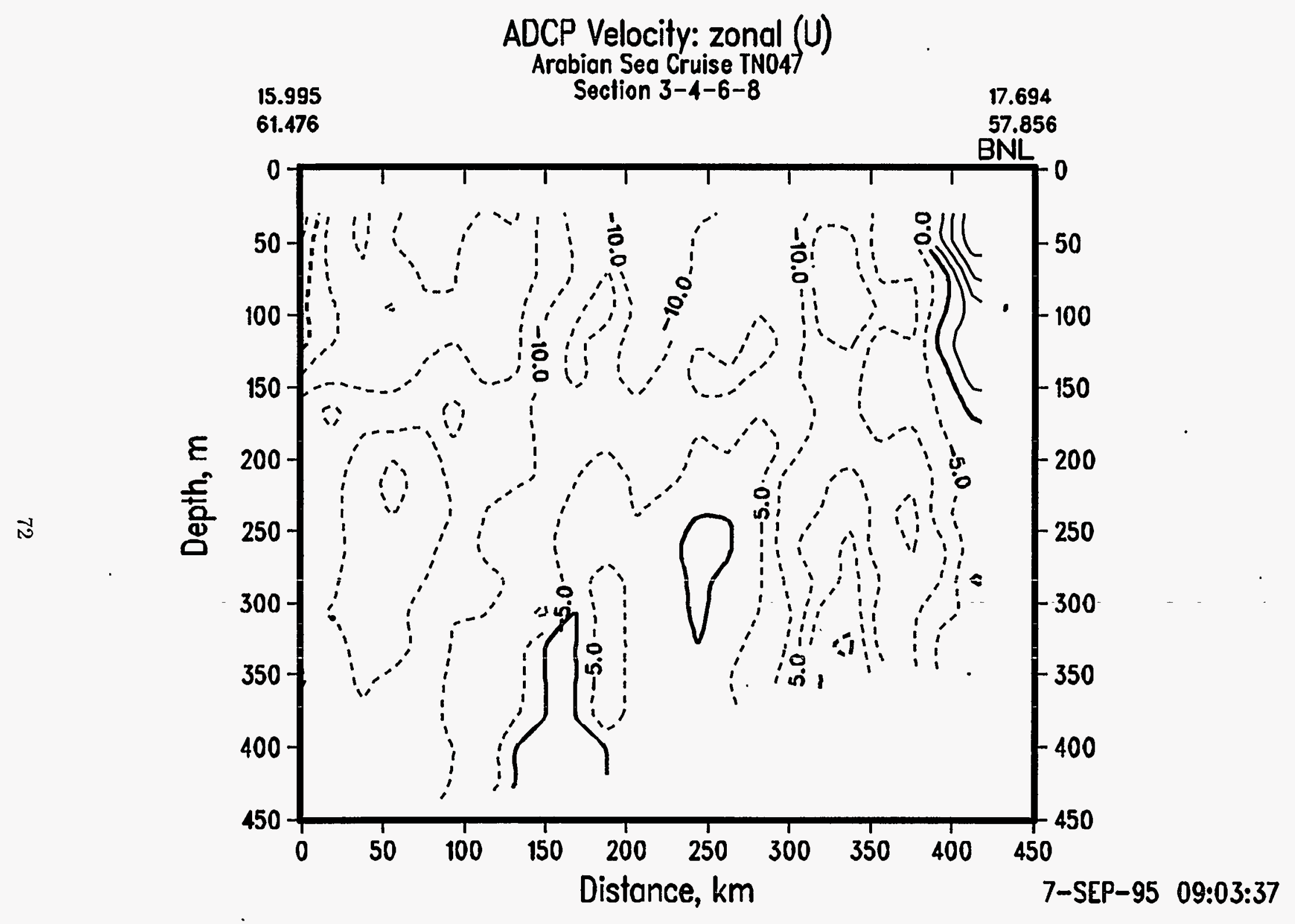




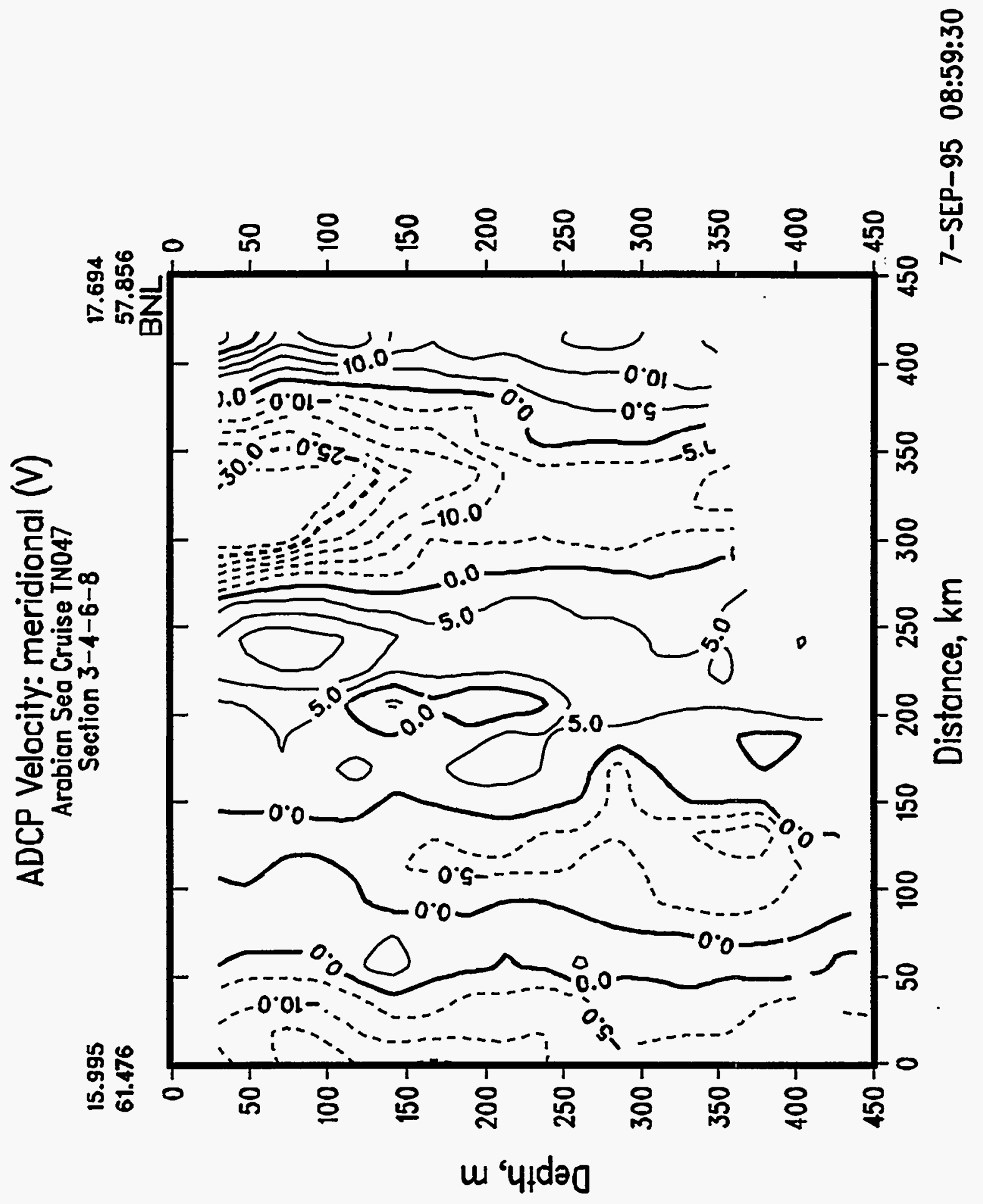




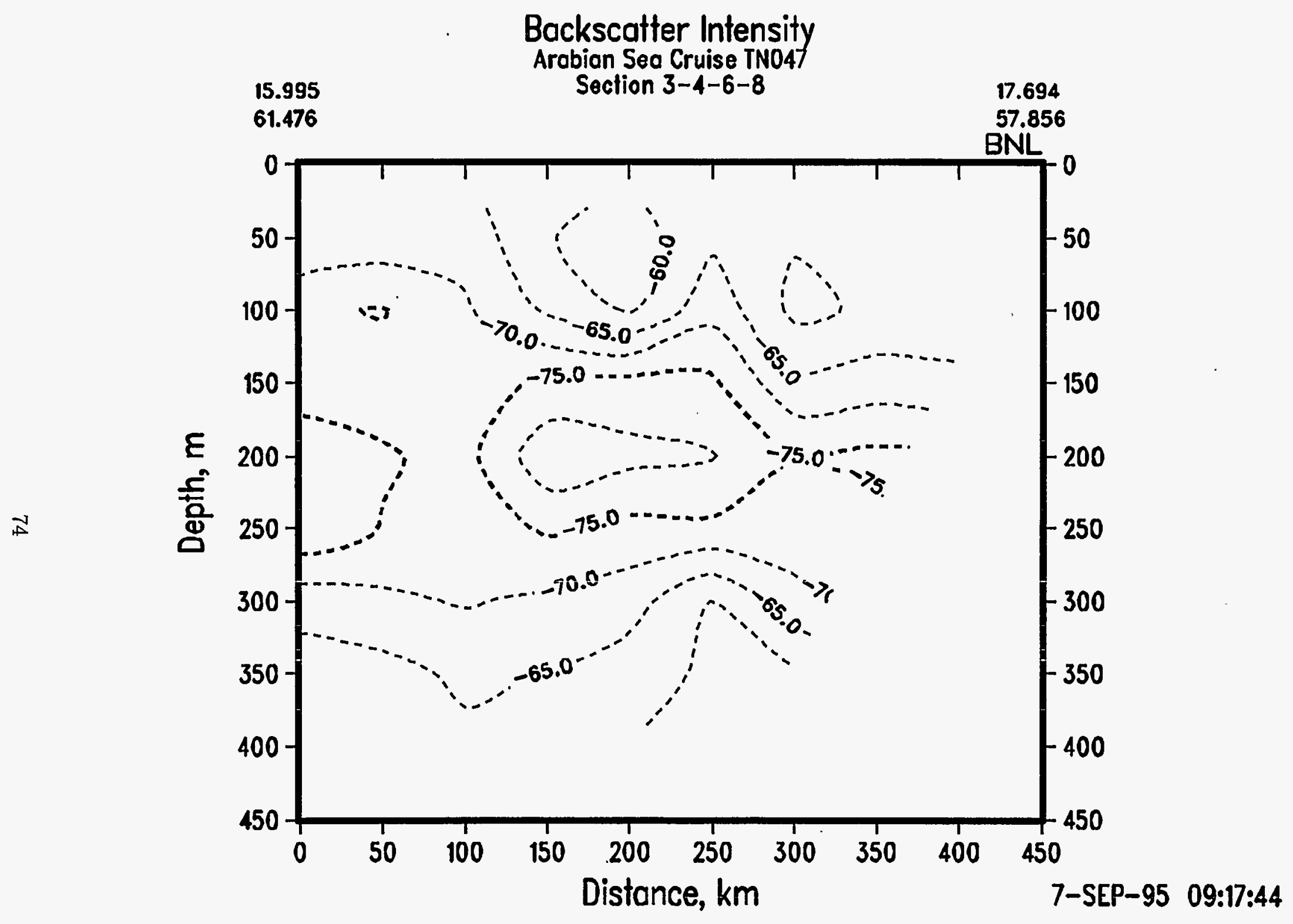




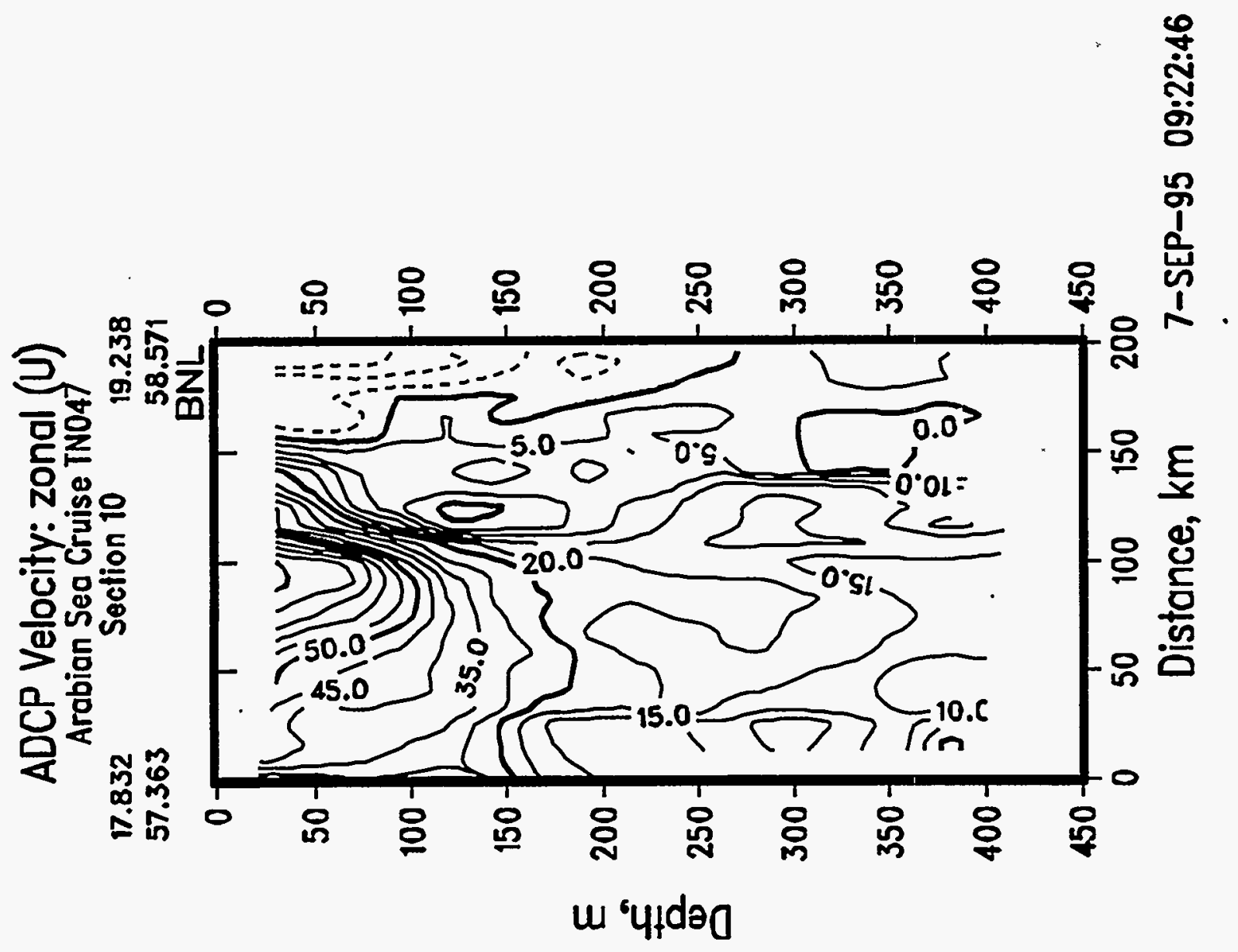




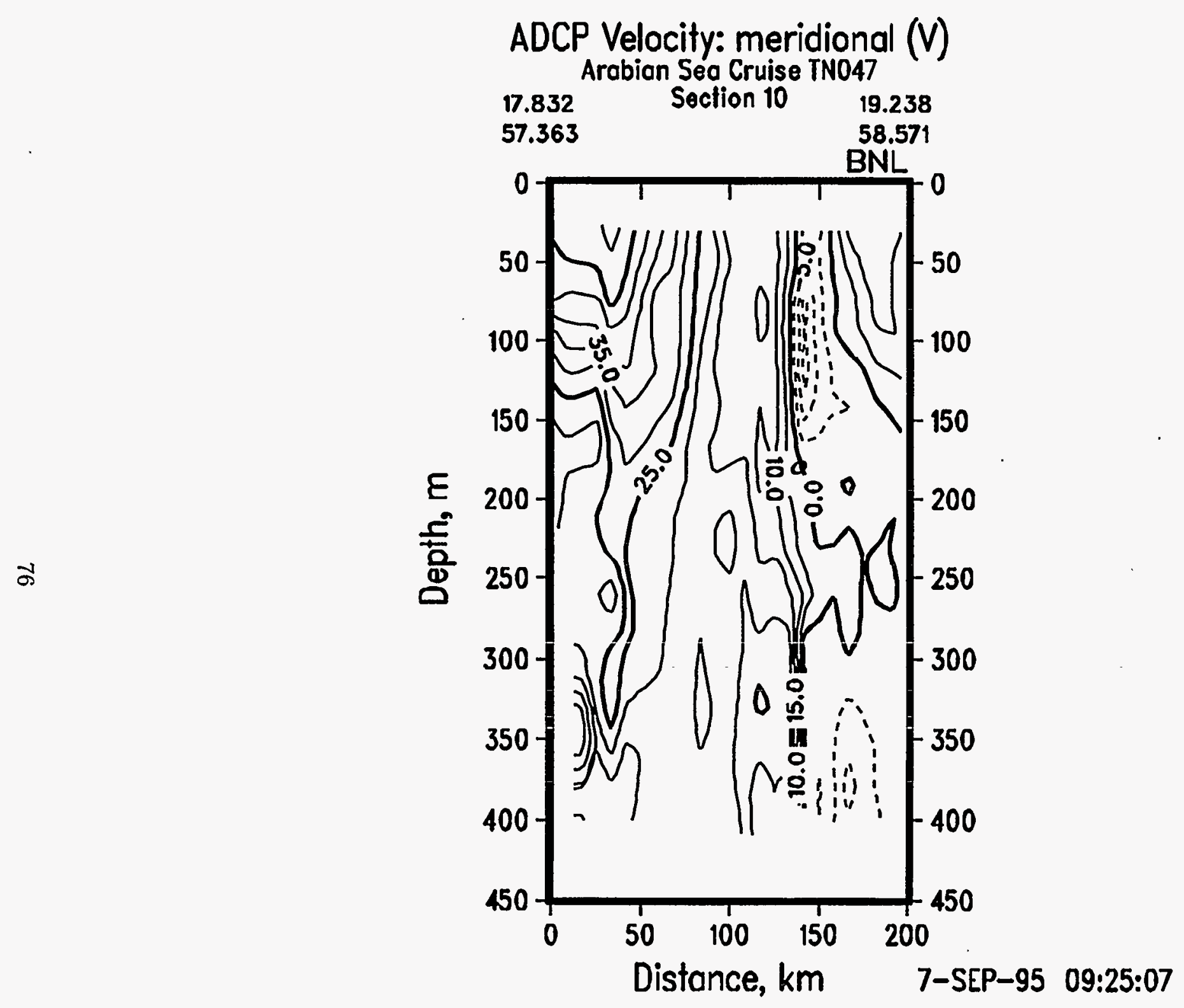




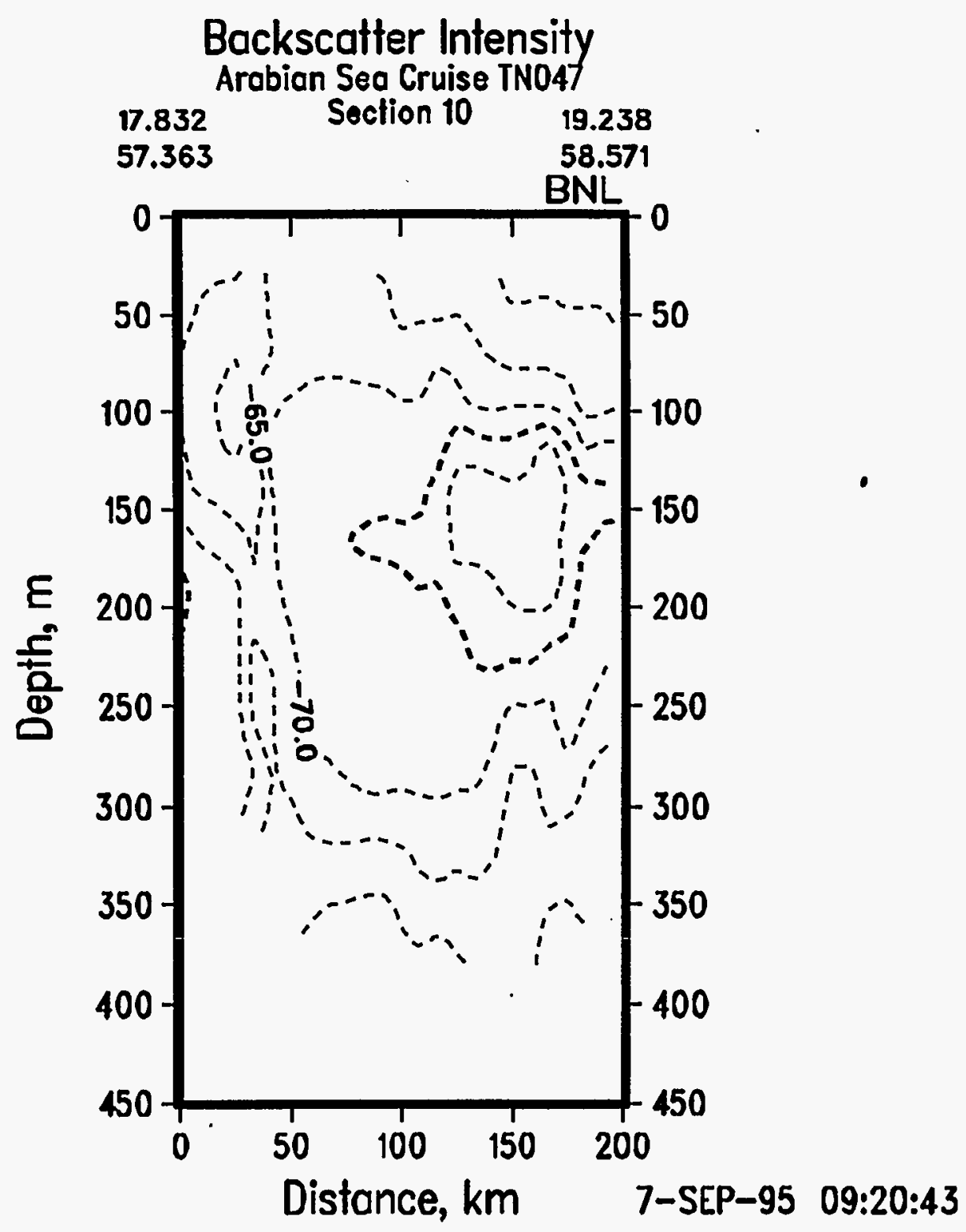




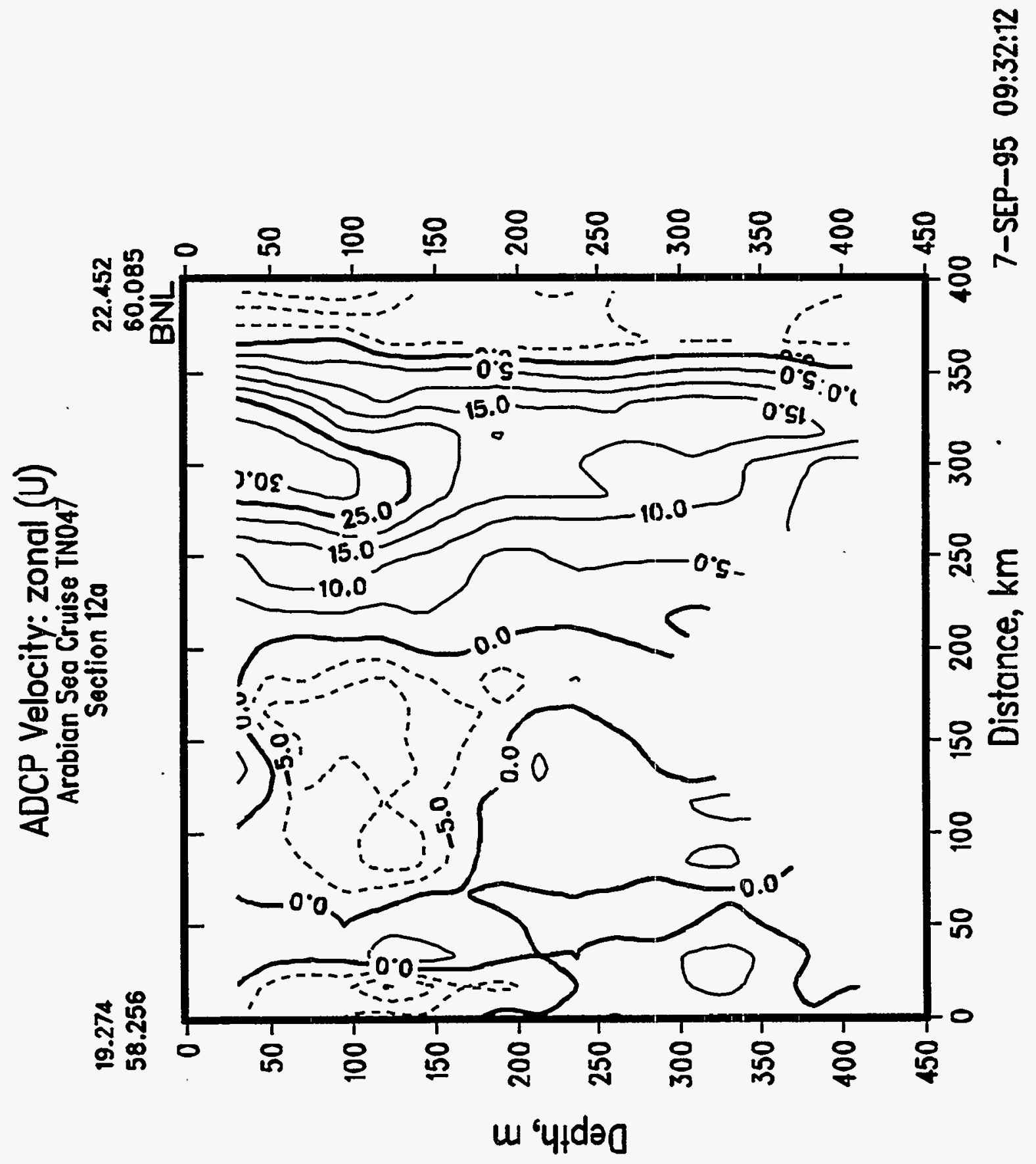




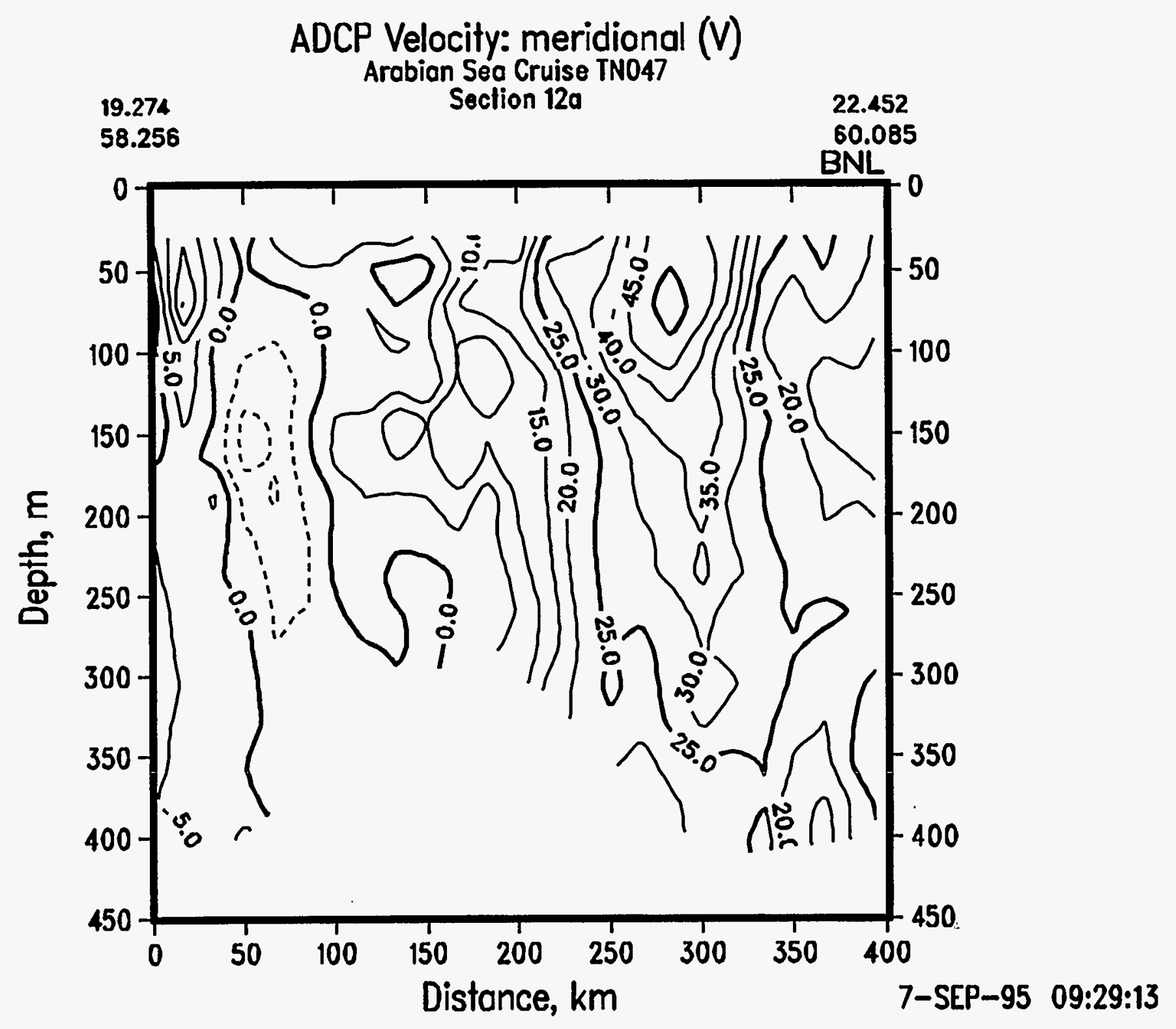




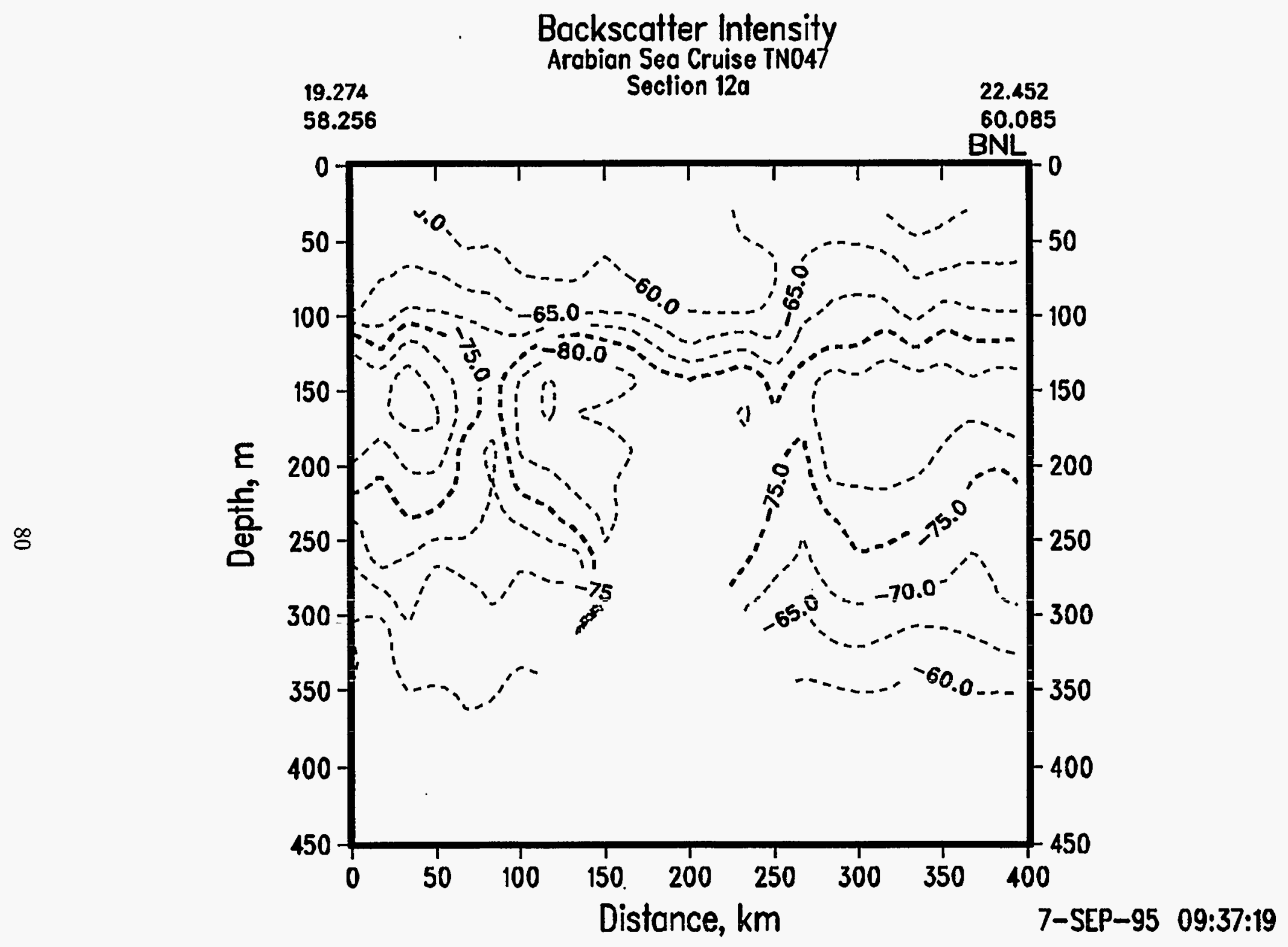




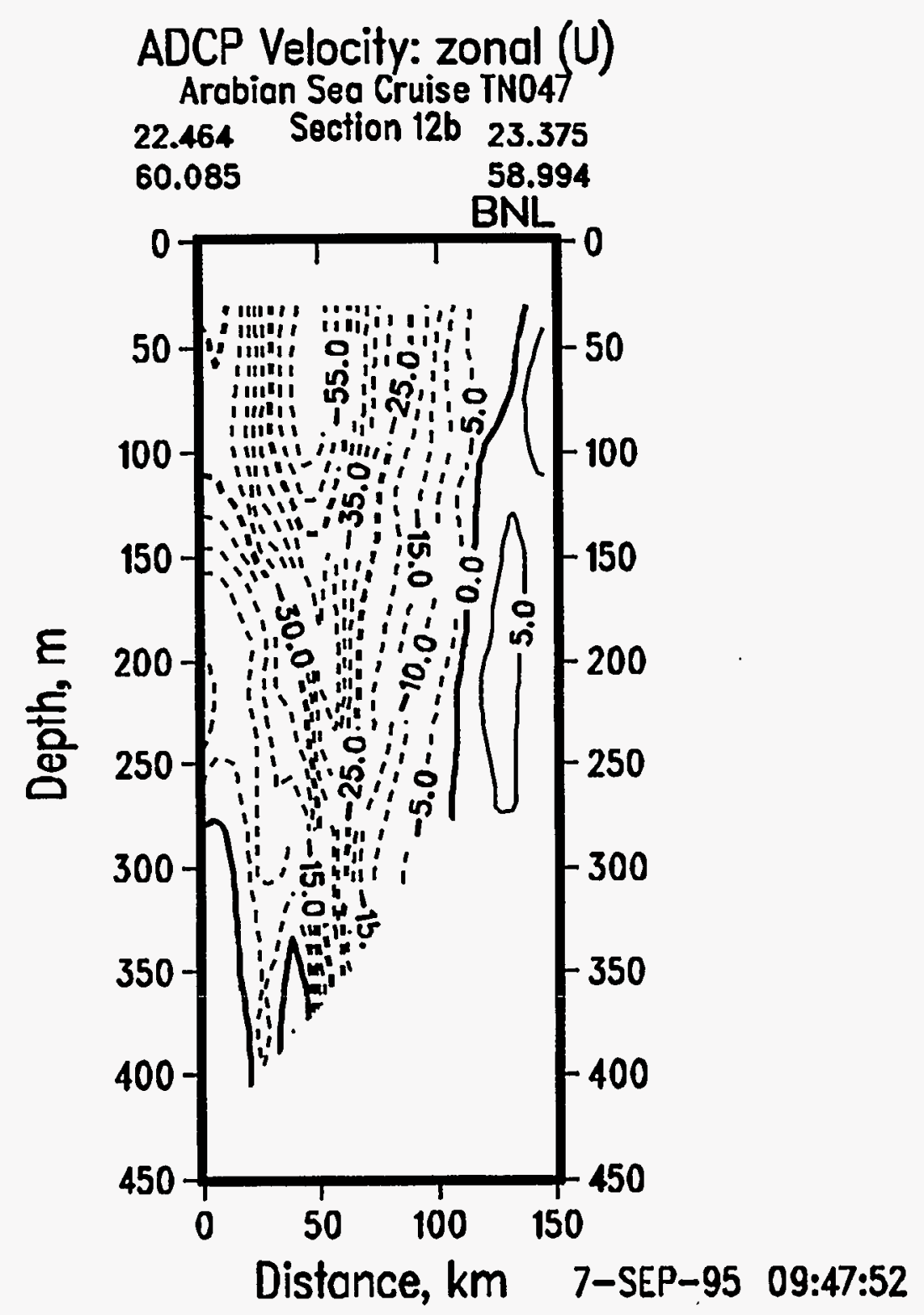




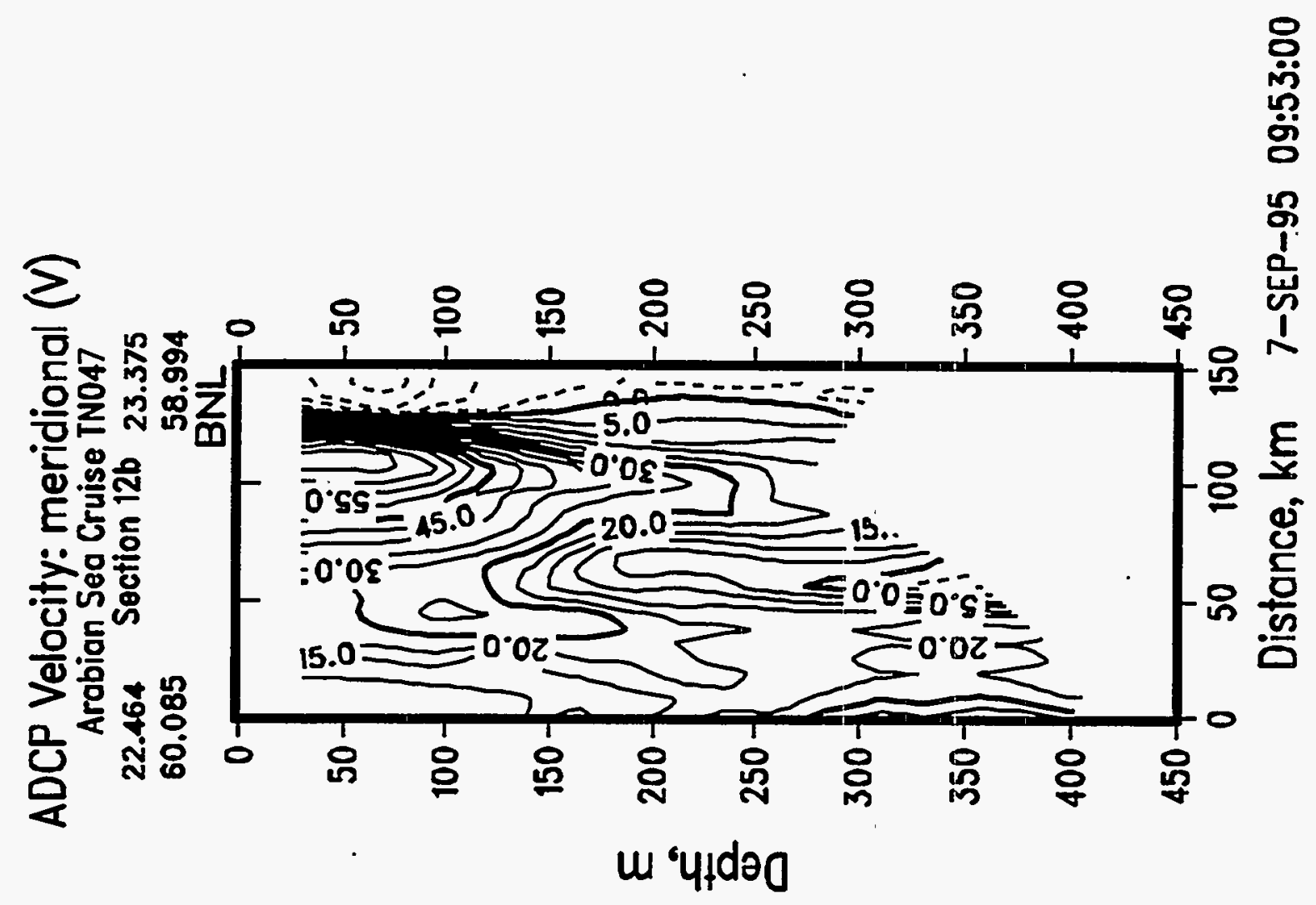




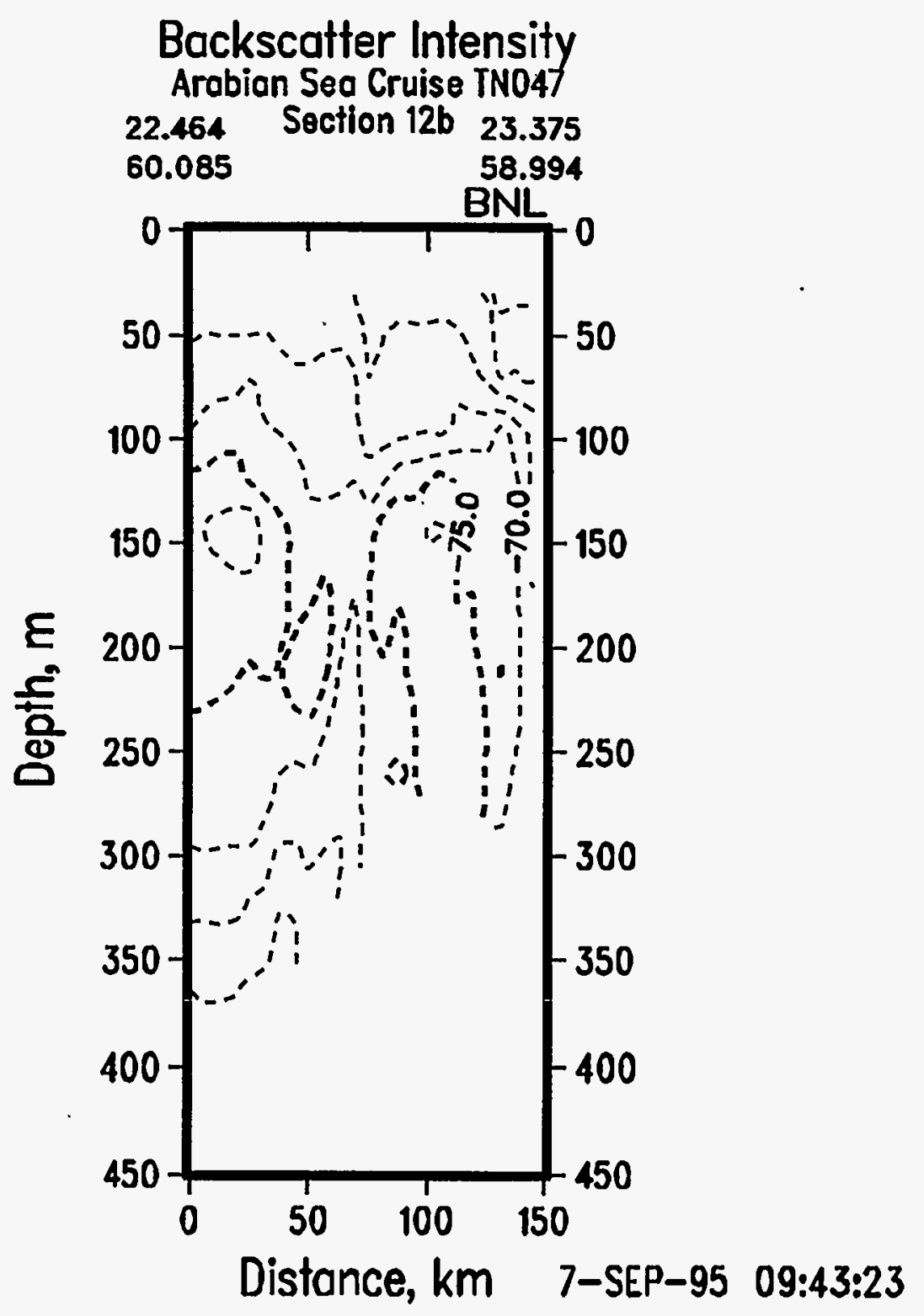


TN048 


\section{JGOFS Arabian Sea}

TN048 First Half Cruise (06/21/95 to 07/04/95)

Current Velocity $20 \mathrm{~m}$ to $50 \mathrm{~m}$

BNL

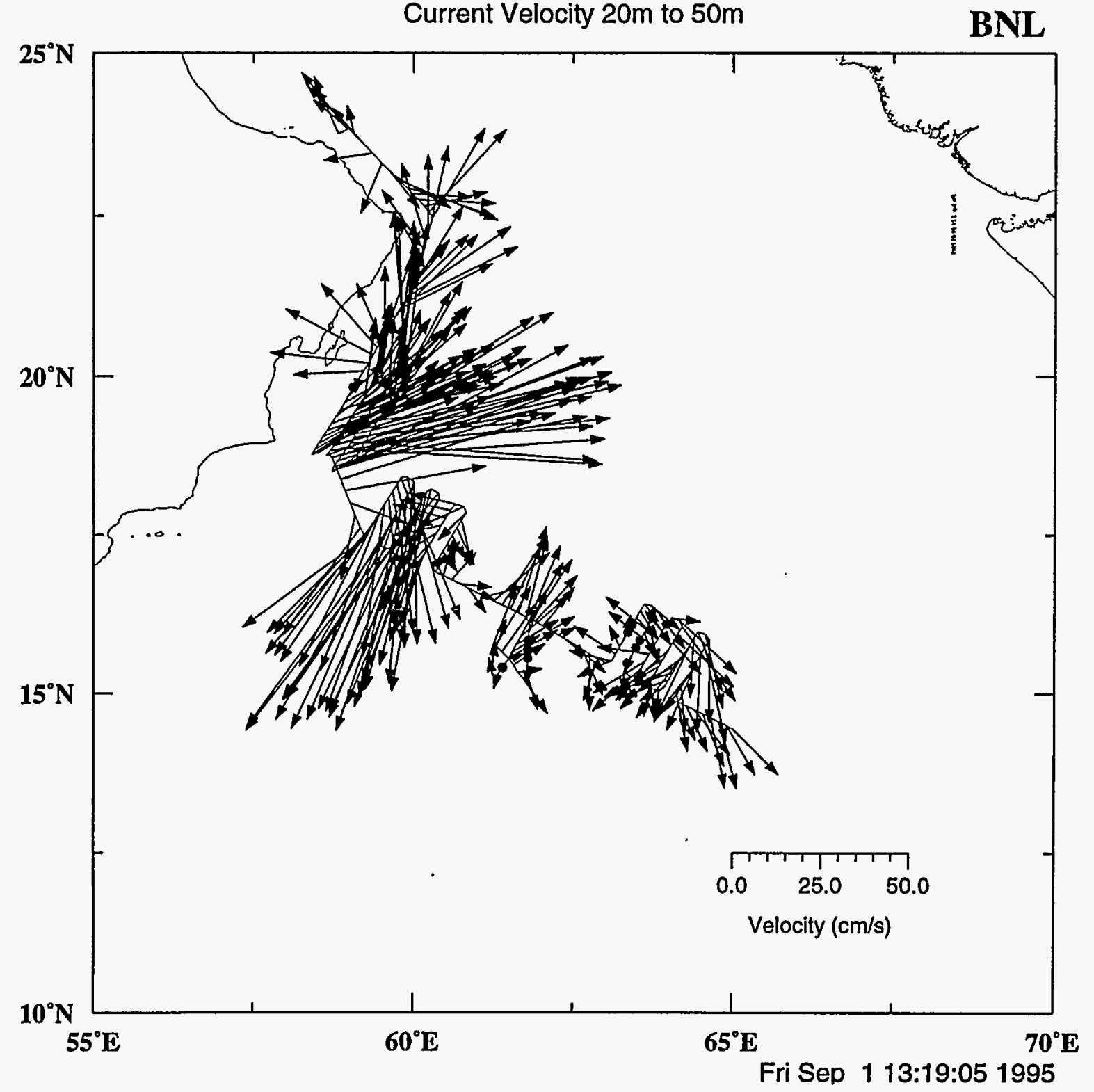




\section{JGOFS Arabian Sea}

TN048 First Half Cruise (06/21/95 to 07/04/95)

Layer: $50 \mathrm{~m}$ to $100 \mathrm{~m}$

BNL

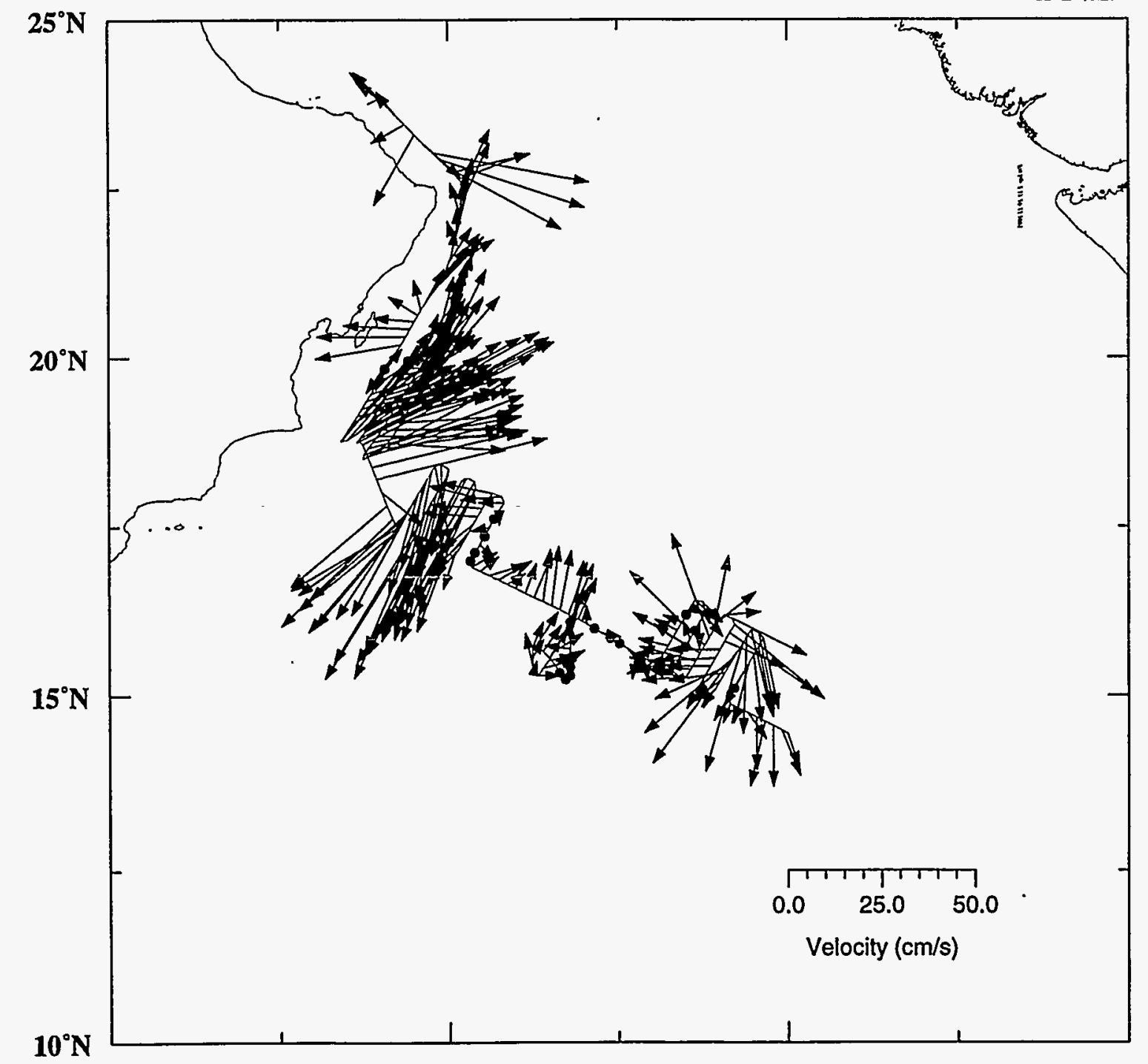


JGOFS Arabian Sea

TN048 First Half Cruise (06/21/95 to 07/04/95) Layer: $100 \mathrm{~m}$ to $200 \mathrm{~m}$ BNL

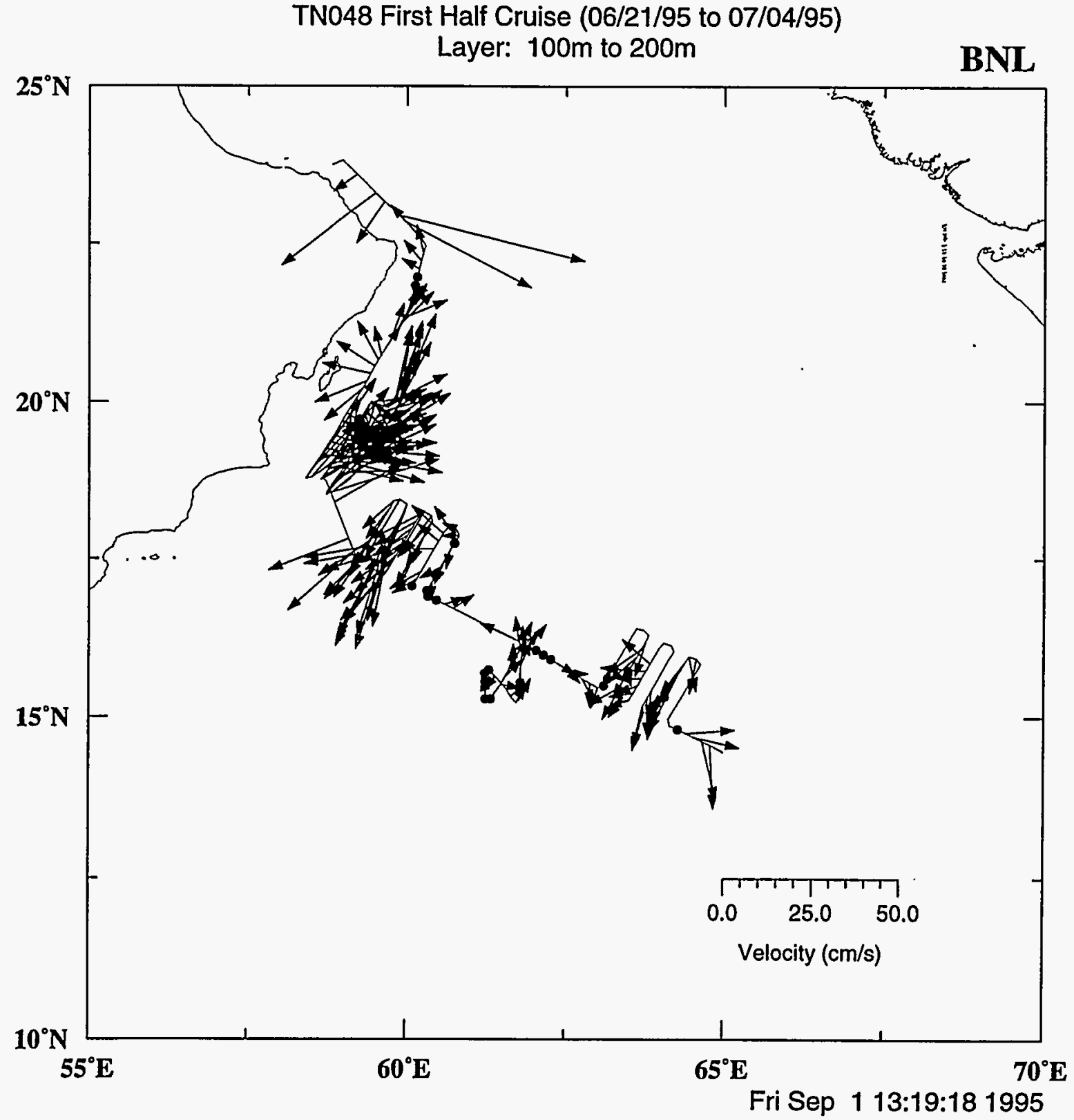


JGOFS Arabian Sea

TN048 First Half Cruise (06/21/95 to 07/04/95)

Layer: $200 \mathrm{~m}$ to $300 \mathrm{~m}$

BNL

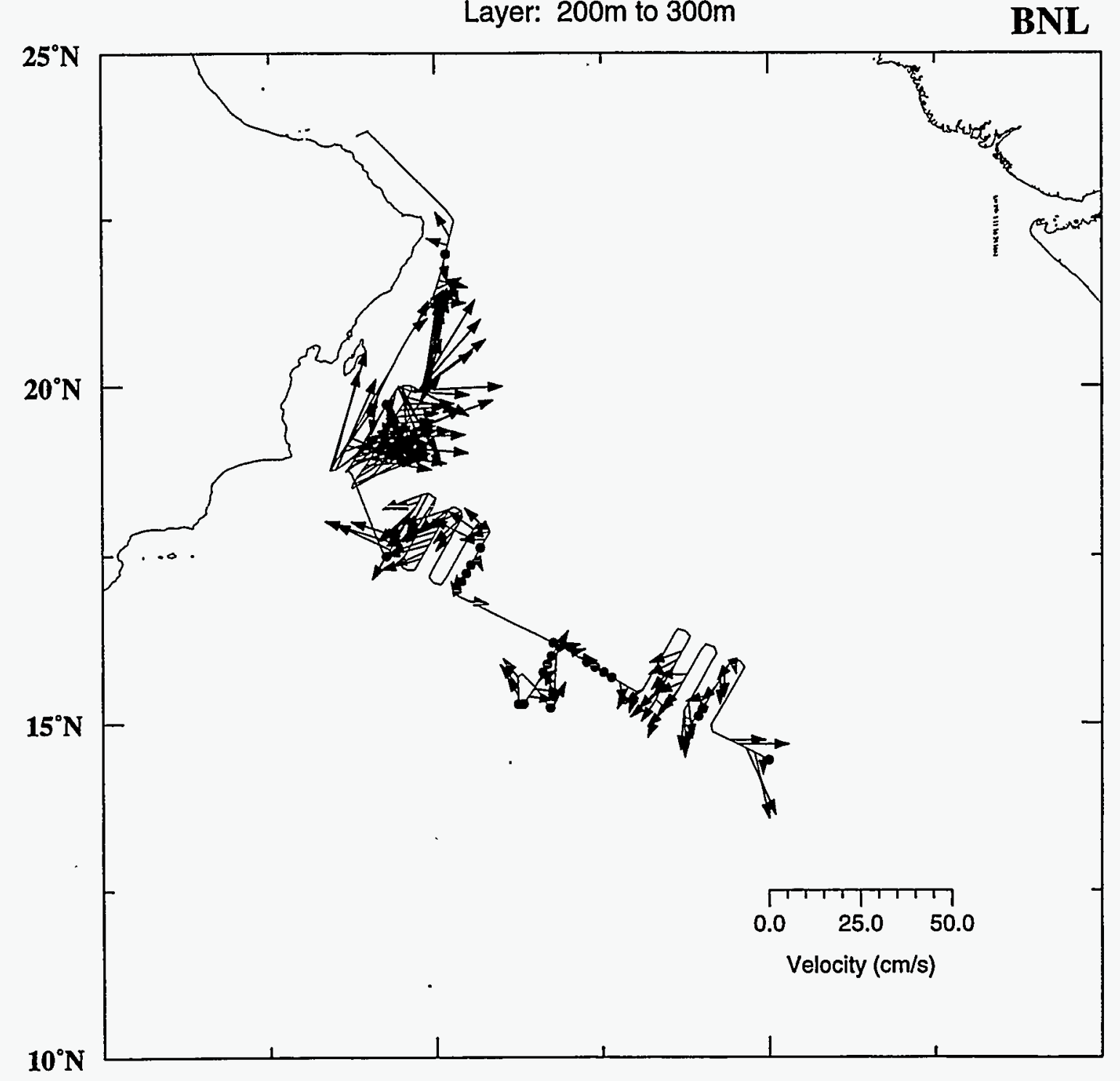




\section{JGOFS Arabian Sea}

TN048 Second Half Cruise (07/04/95 to 07/13/95) Current Velocity $20 \mathrm{~m}$ to $50 \mathrm{~m}$

BNL

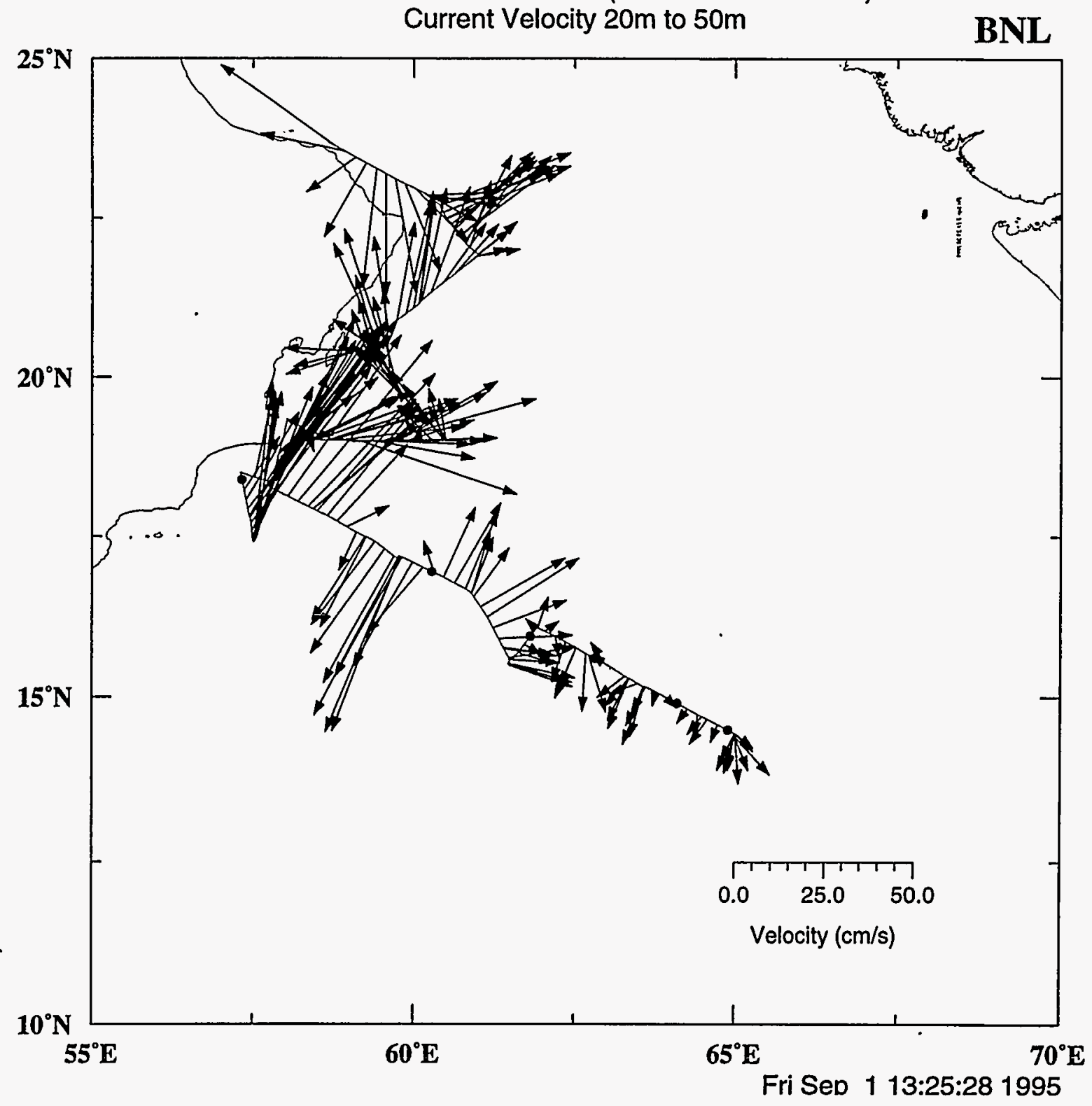




\section{JGOFS Arabian Sea}

TN048 Second Half Cruise (07/04/95 to 07/13/95) Layer: $50 \mathrm{~m}$ to $100 \mathrm{~m}$

BNL

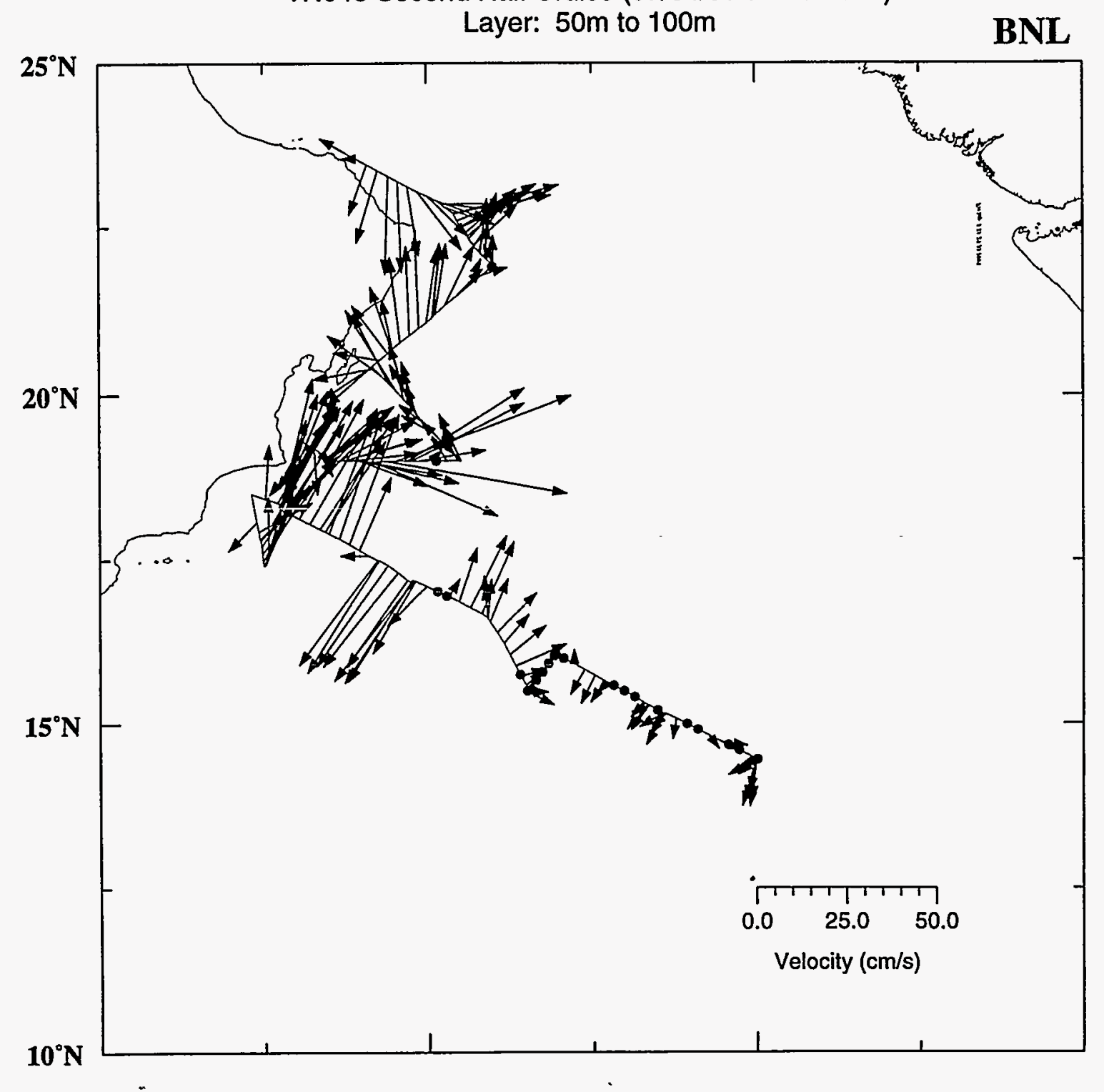




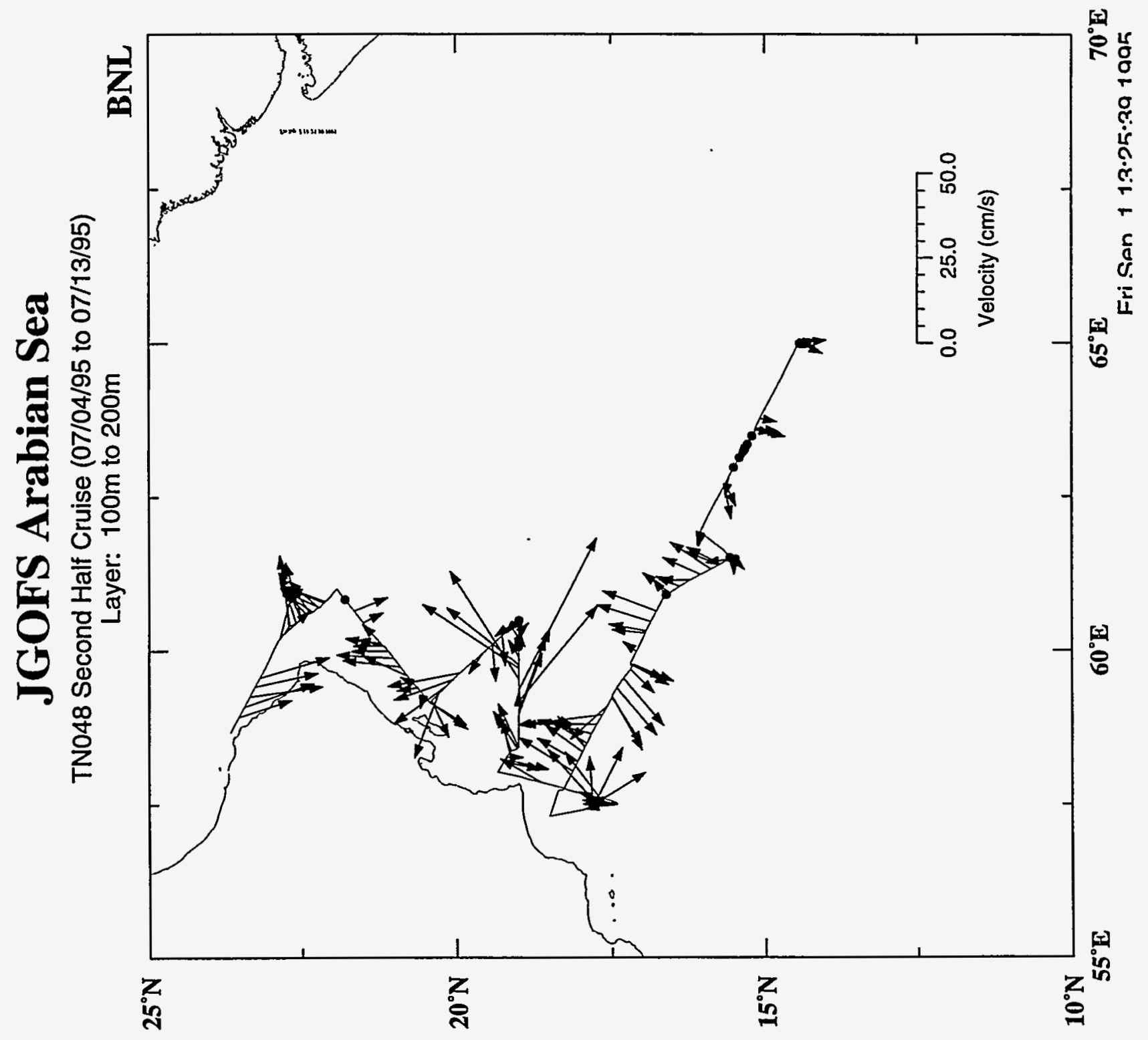




\section{JGOFS Arabian Sea}

TN048 Second Half Cruise (07/04/95 to 07/13/95)

Layer: $200 \mathrm{~m}$ to $300 \mathrm{~m}$

BNL

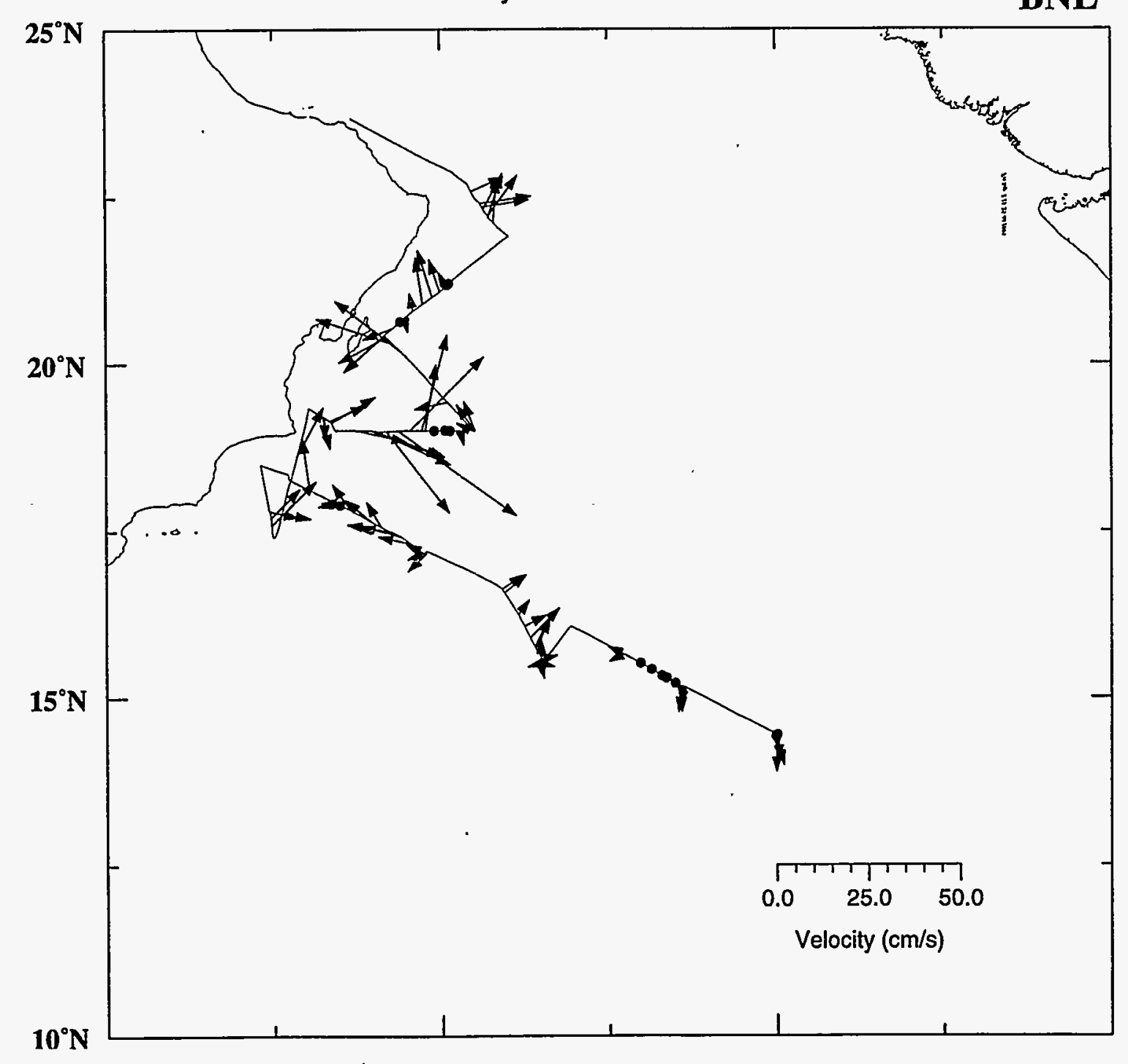




\section{JGOFS Arabian Sea}

TN048 Section 3 (06/23/95 to 06/26/95)

Current Velocity $20 \mathrm{~m}$ to $50 \mathrm{~m}$

BNL

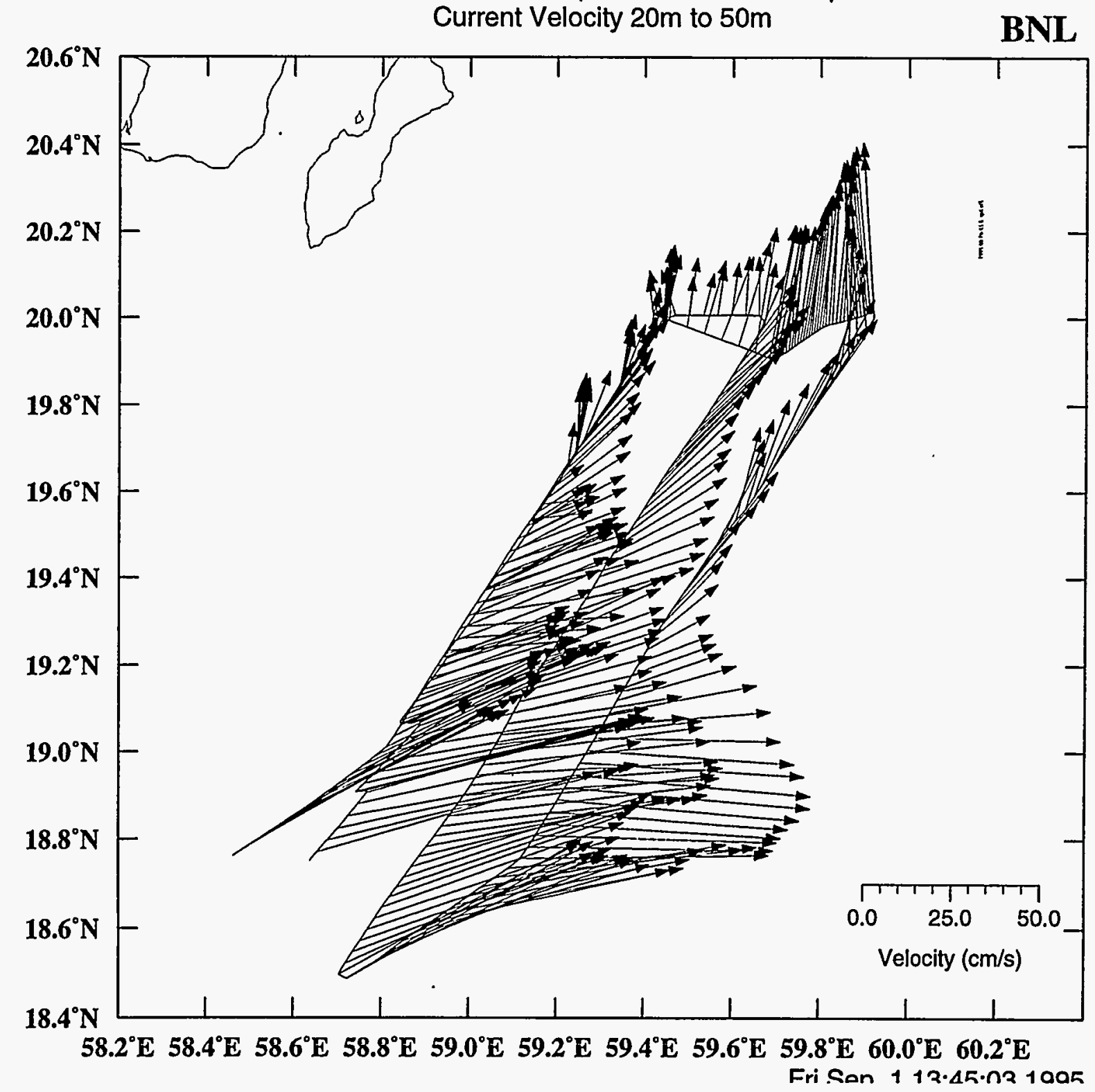




\section{JGOFS Arabian Sea}

TN048 Section 3 (06/23/95 to 06/26/95)

Layer: $50 \mathrm{~m}$ to $100 \mathrm{~m}$

BNL

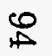

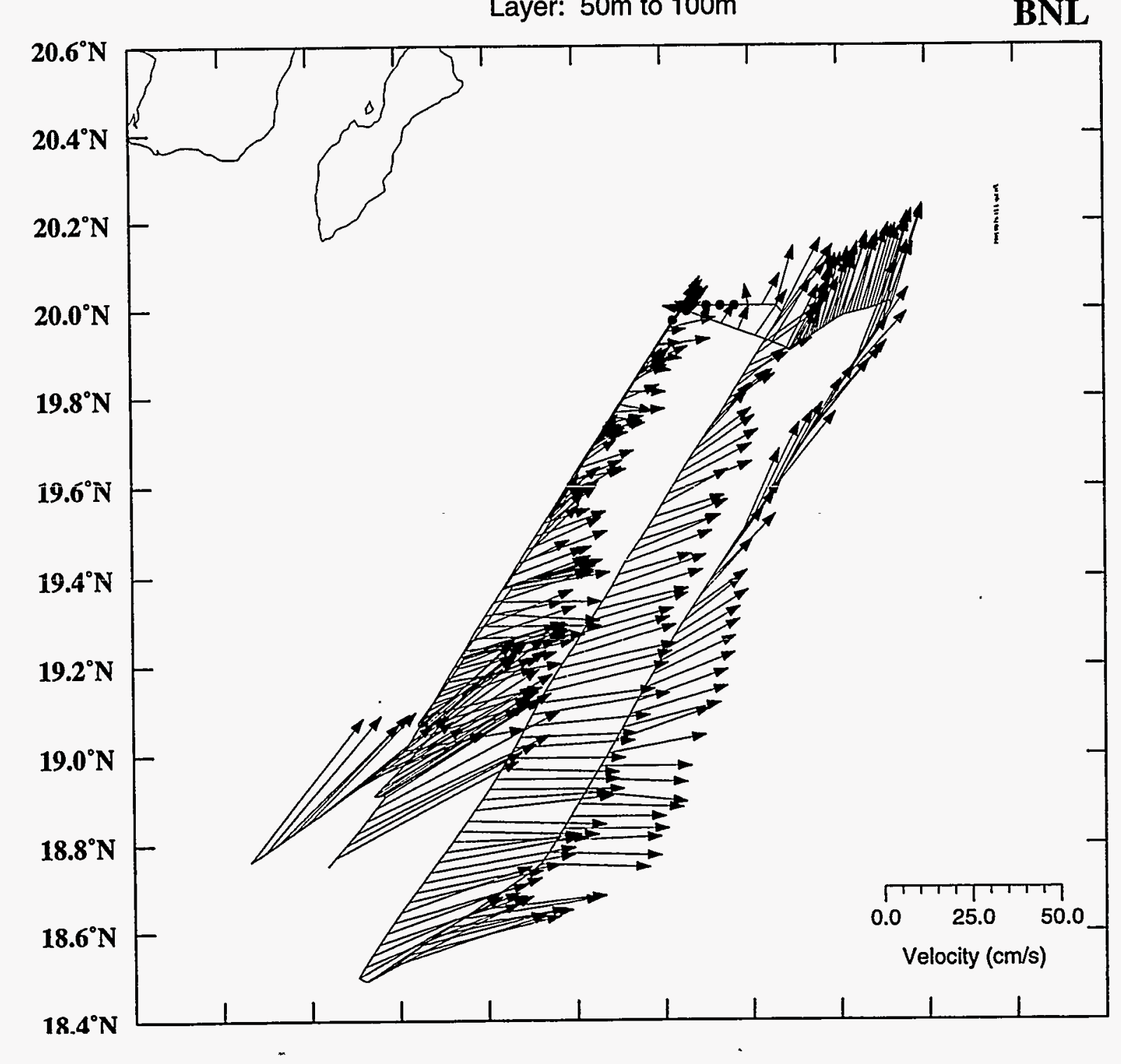




\section{JGOFS Arabian Sea}

TN048 Section 3 (06/23/95 to 06/26/95) Layer: $100 \mathrm{~m}$ to $200 \mathrm{~m}$

BNL

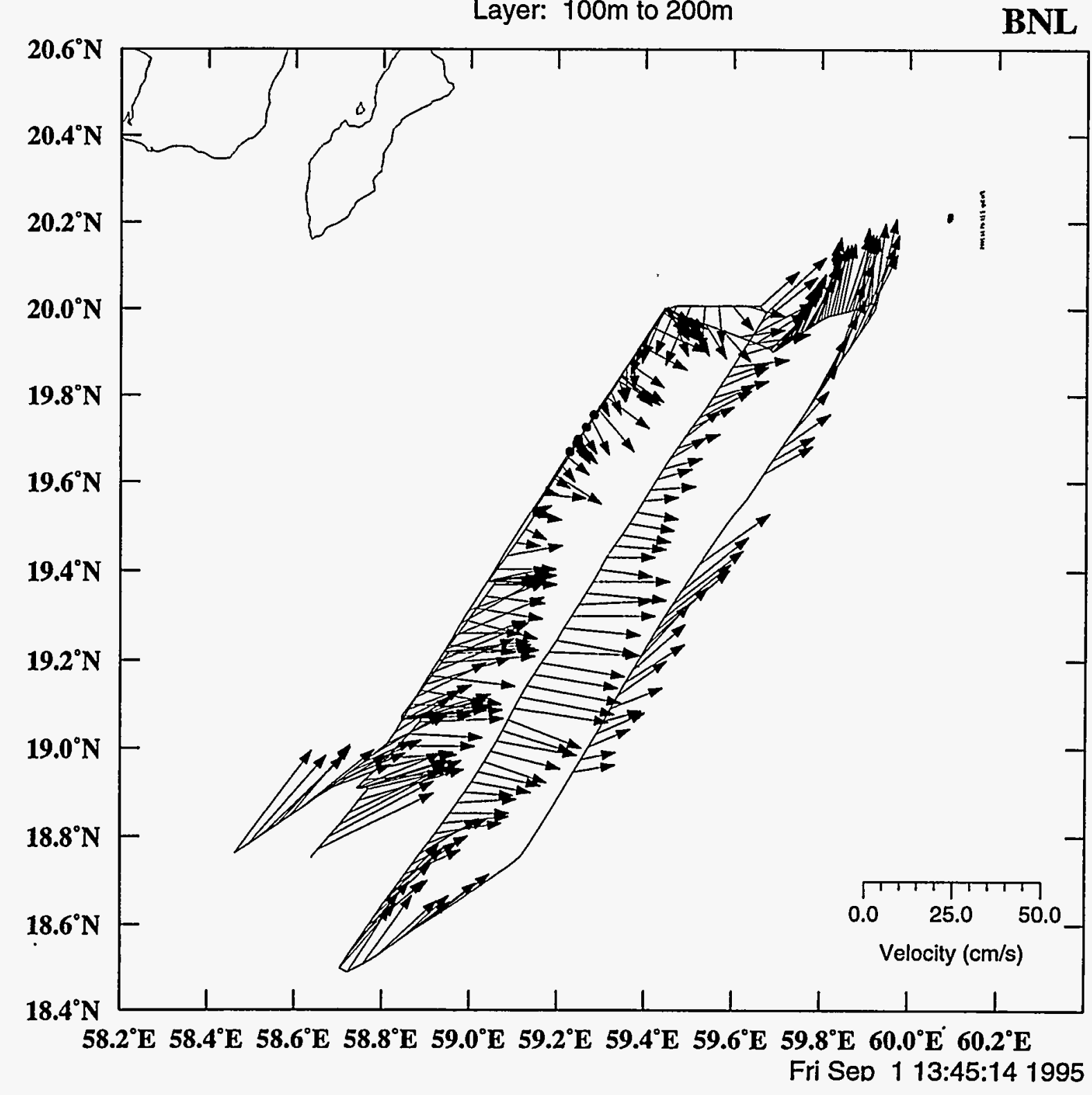




\section{JGOFS Arabian Sea}

TN048 Section 3 (06/23/95 to 06/26/95)

Layer: $200 \mathrm{~m}$ to $300 \mathrm{~m}$

BNL

$\mathscr{8}$

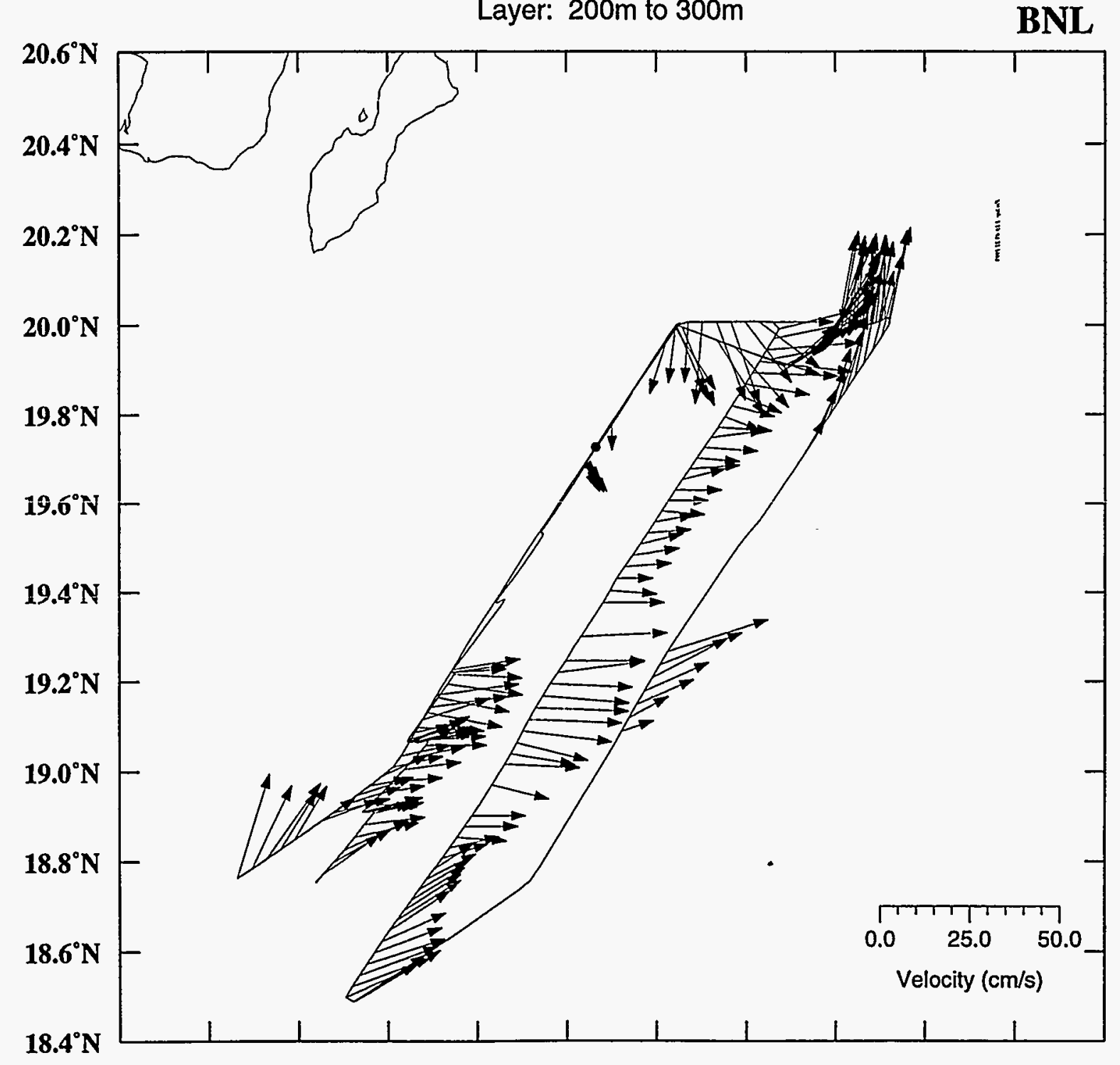




\section{JGOFS Arabian Sea}

TN048 Section 5 (06/27/95 to 06/29/95) Current Velocity $20 \mathrm{~m}$ to $50 \mathrm{~m}$

\section{BNL}

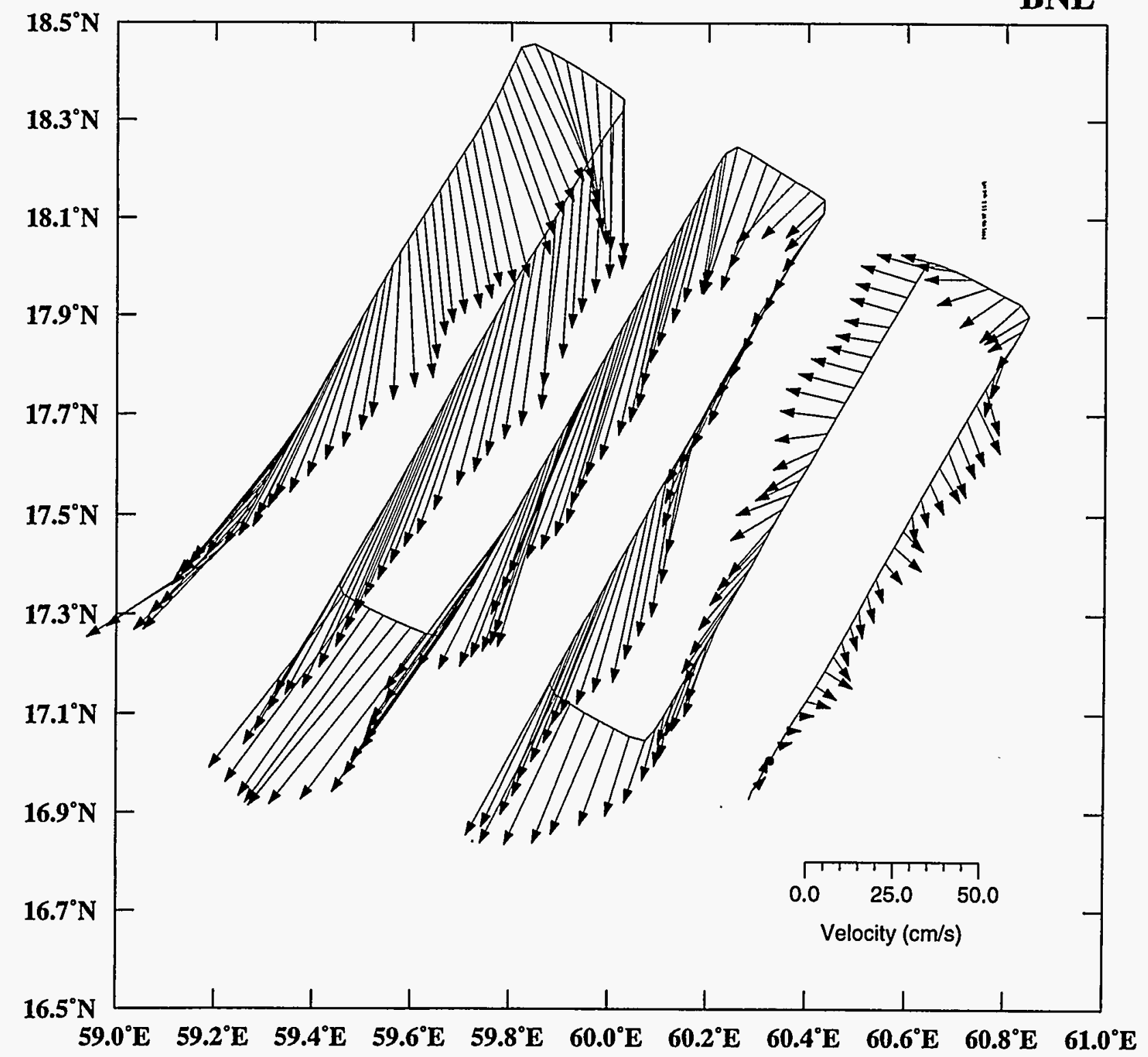




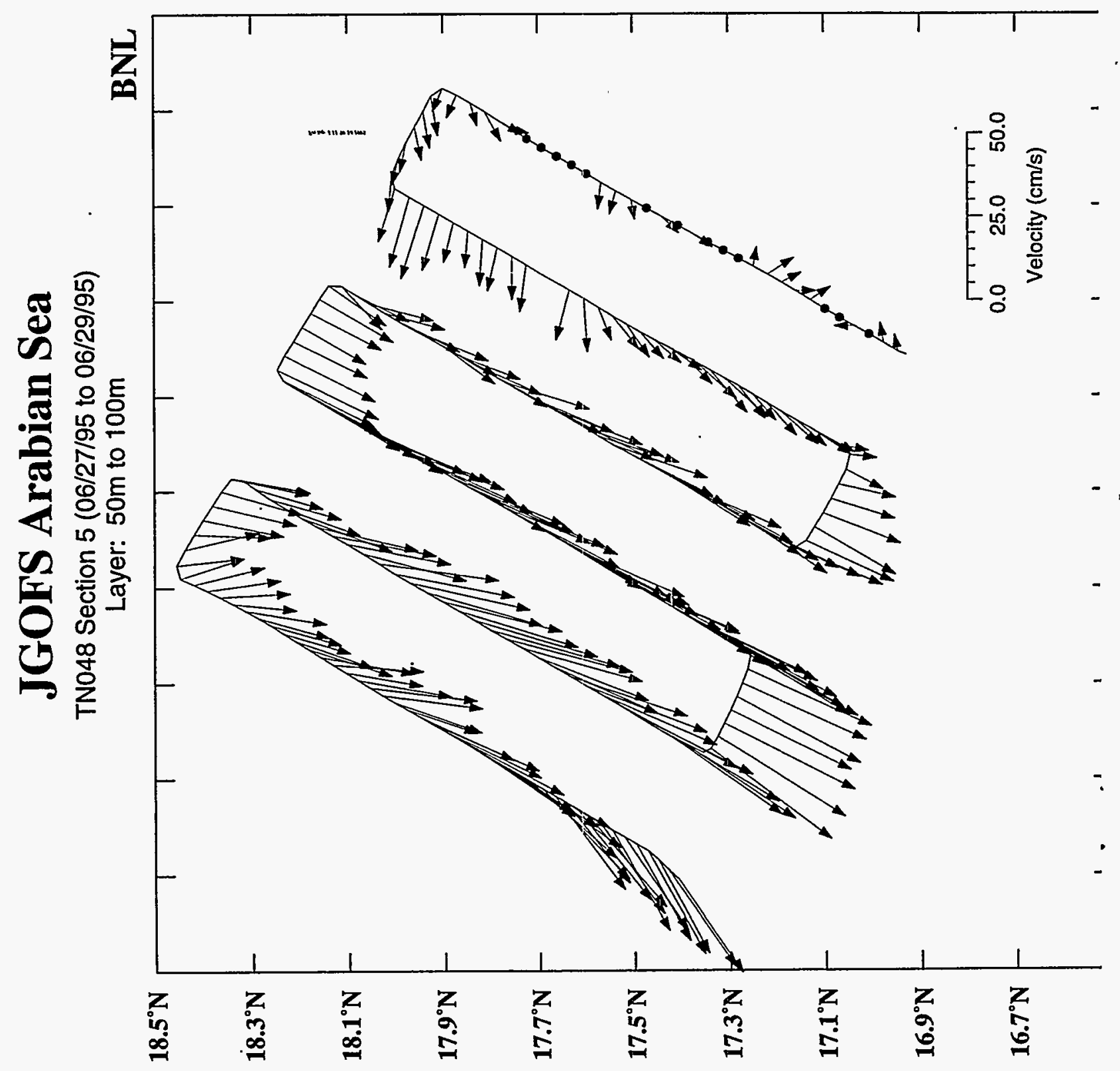




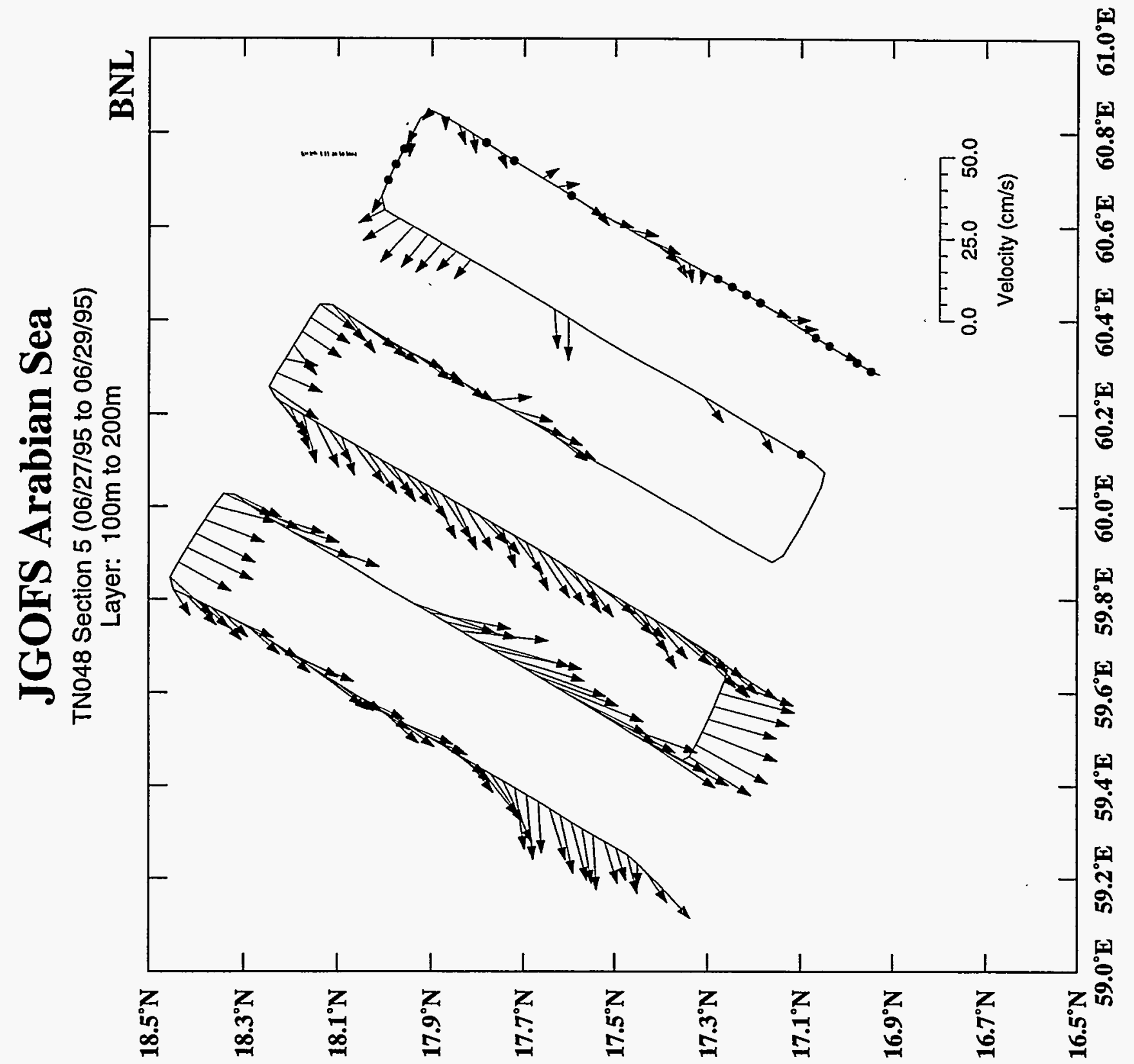




\section{JGOFS Arabian Sea}

TN048 Section 5 (06/27/95 to 06/29/95)

Layer: $200 \mathrm{~m}$ to $300 \mathrm{~m}$

BNL

홍

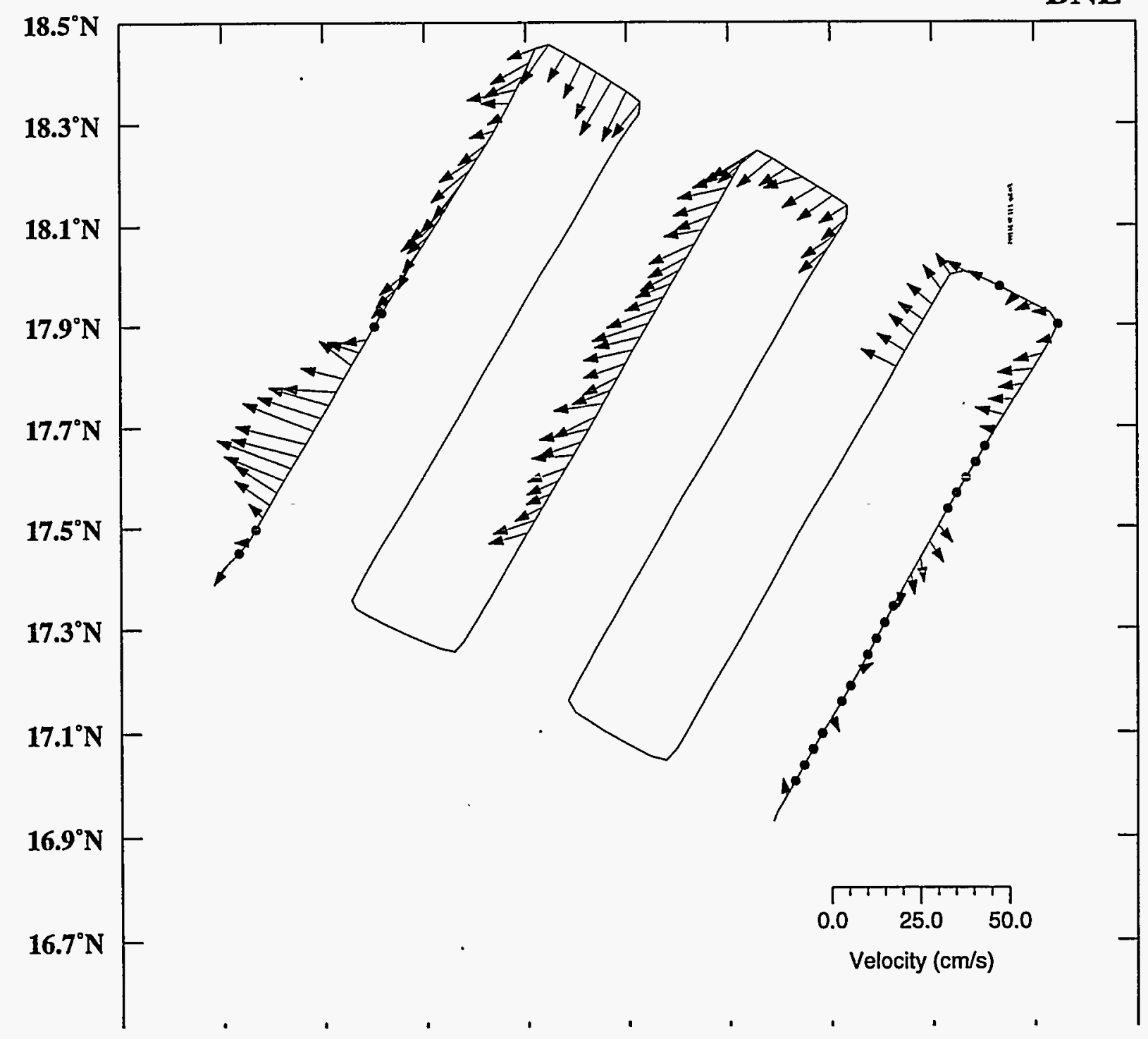




\section{JGOFS Arabian Sea}

TN048 Section 7 (06/30/95 to 07/01/95)

Current Velocity $20 \mathrm{~m}$ to $50 \mathrm{~m}$

BNL

宫

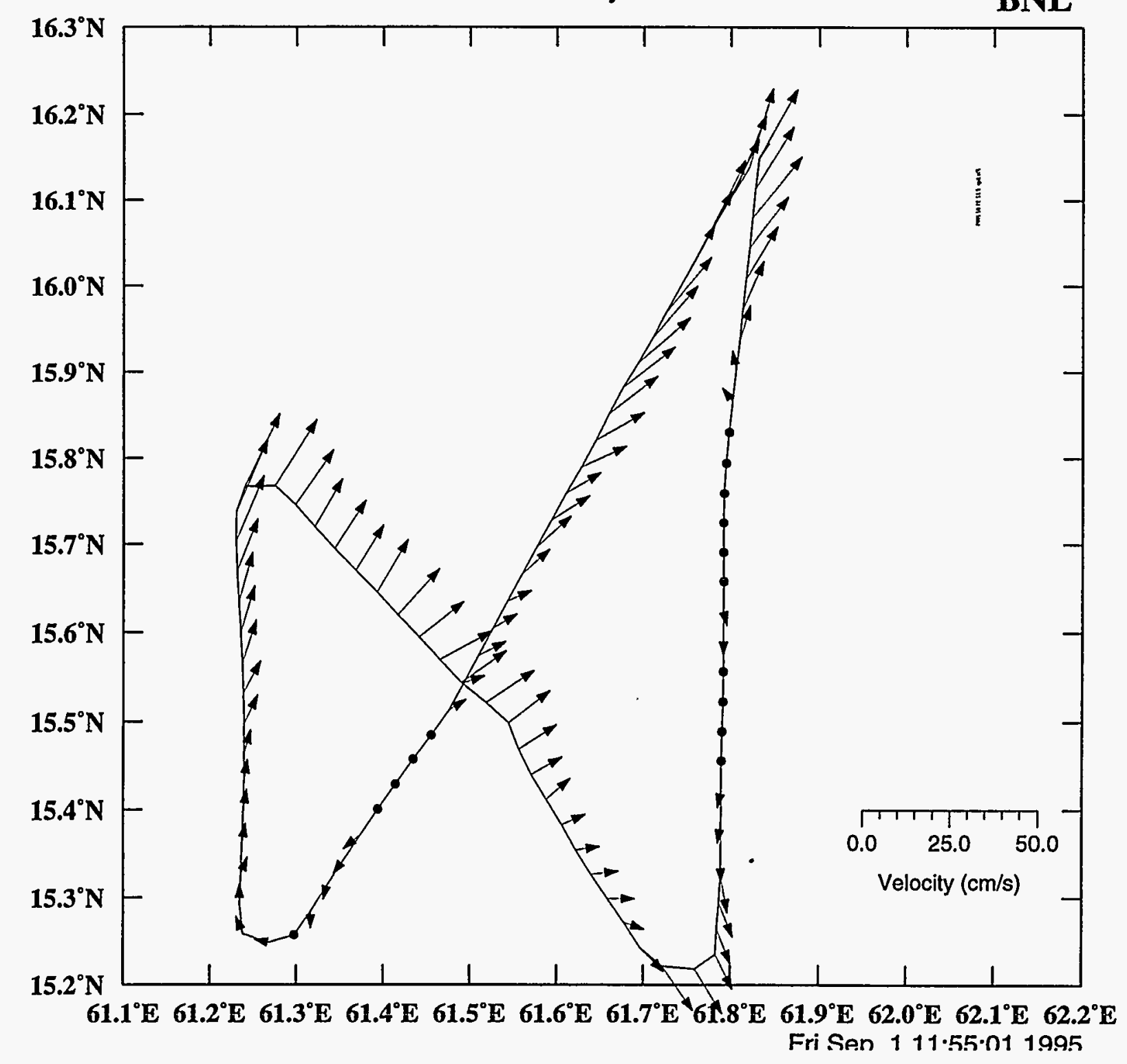




\section{JGOFS Arabian Sea}

TN048 Section 7 (06/30/95 to 07/01/95) Layer: $50 \mathrm{~m}$ to $100 \mathrm{~m}$

\section{BNL}

范

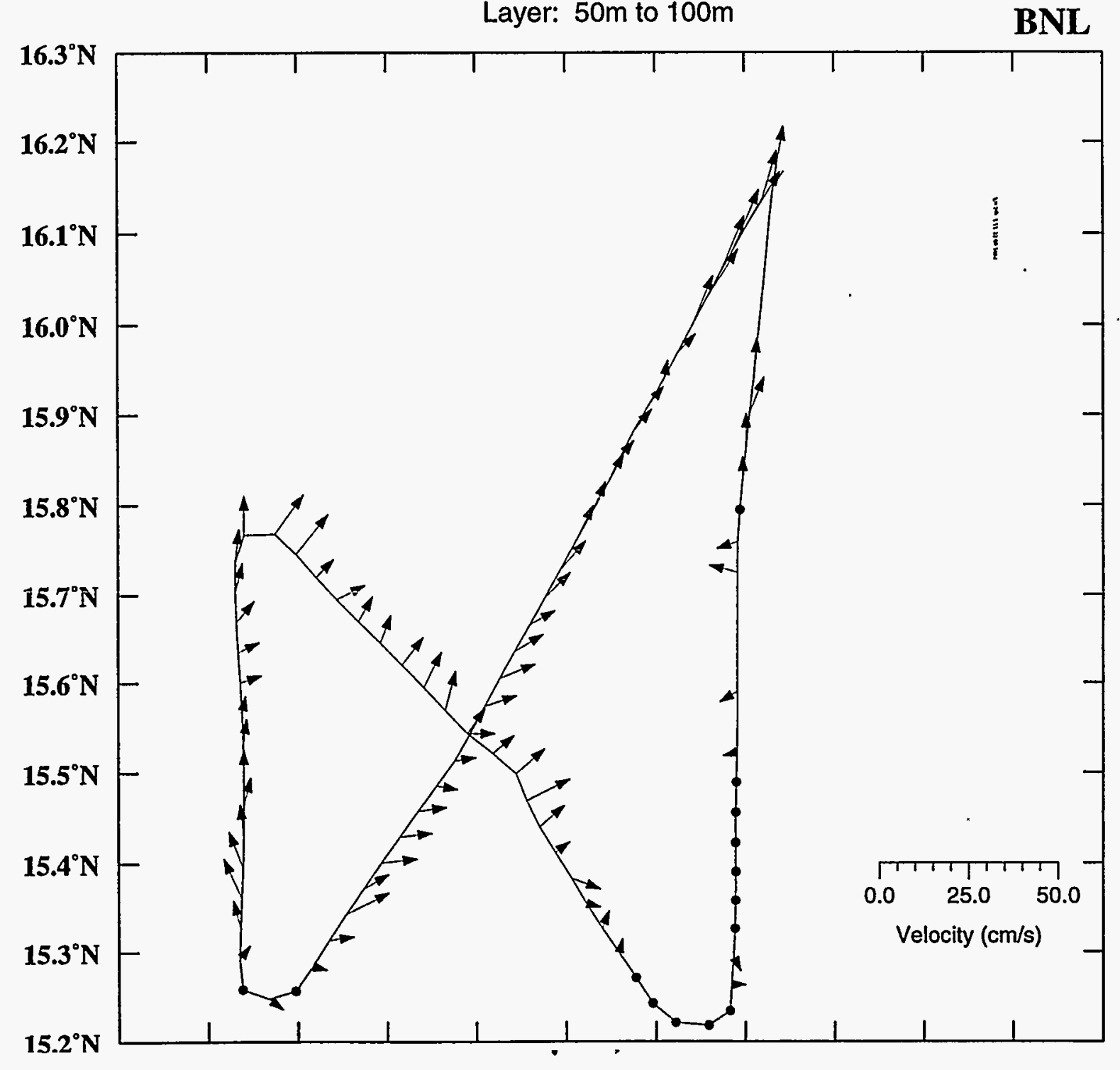




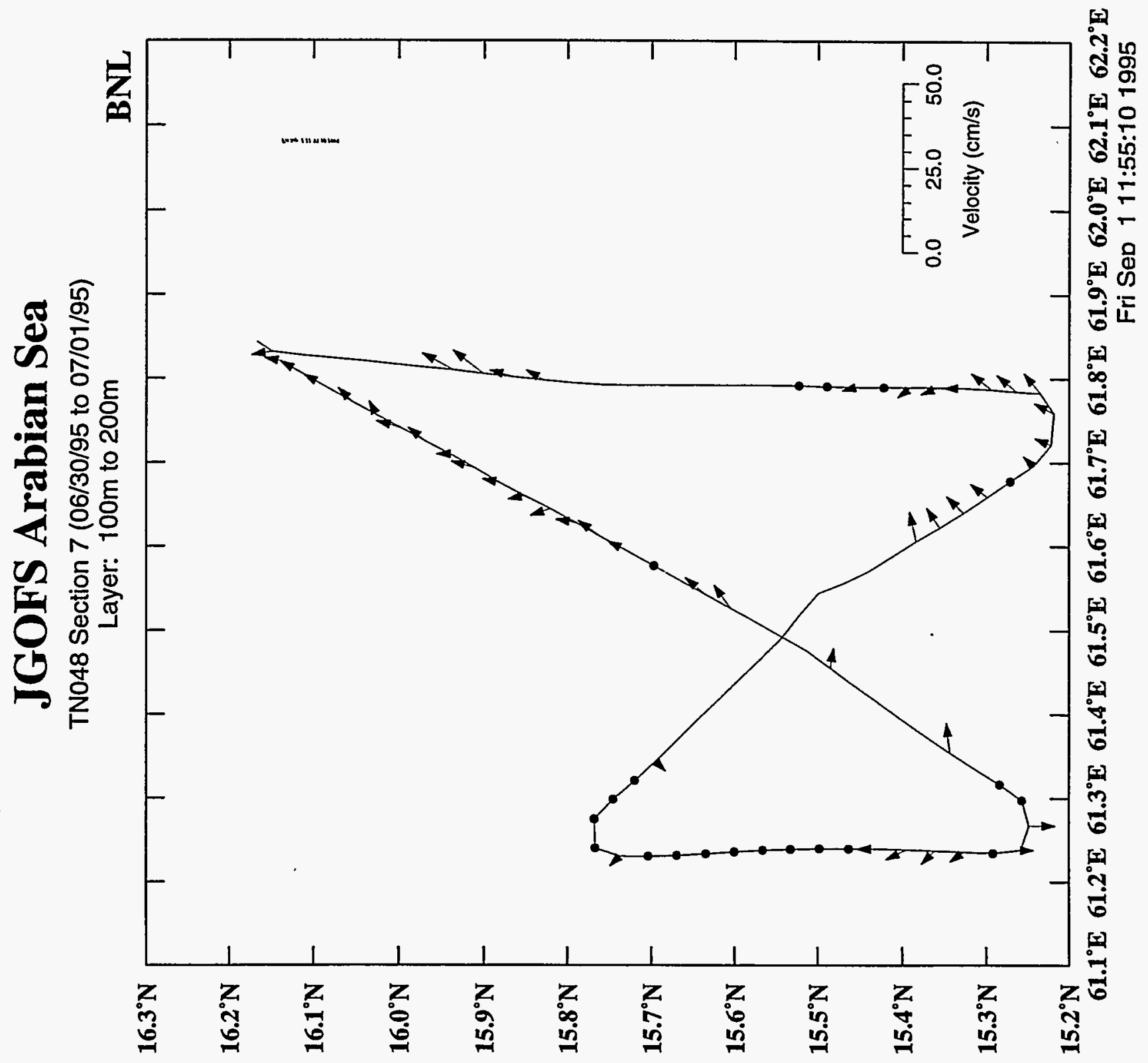




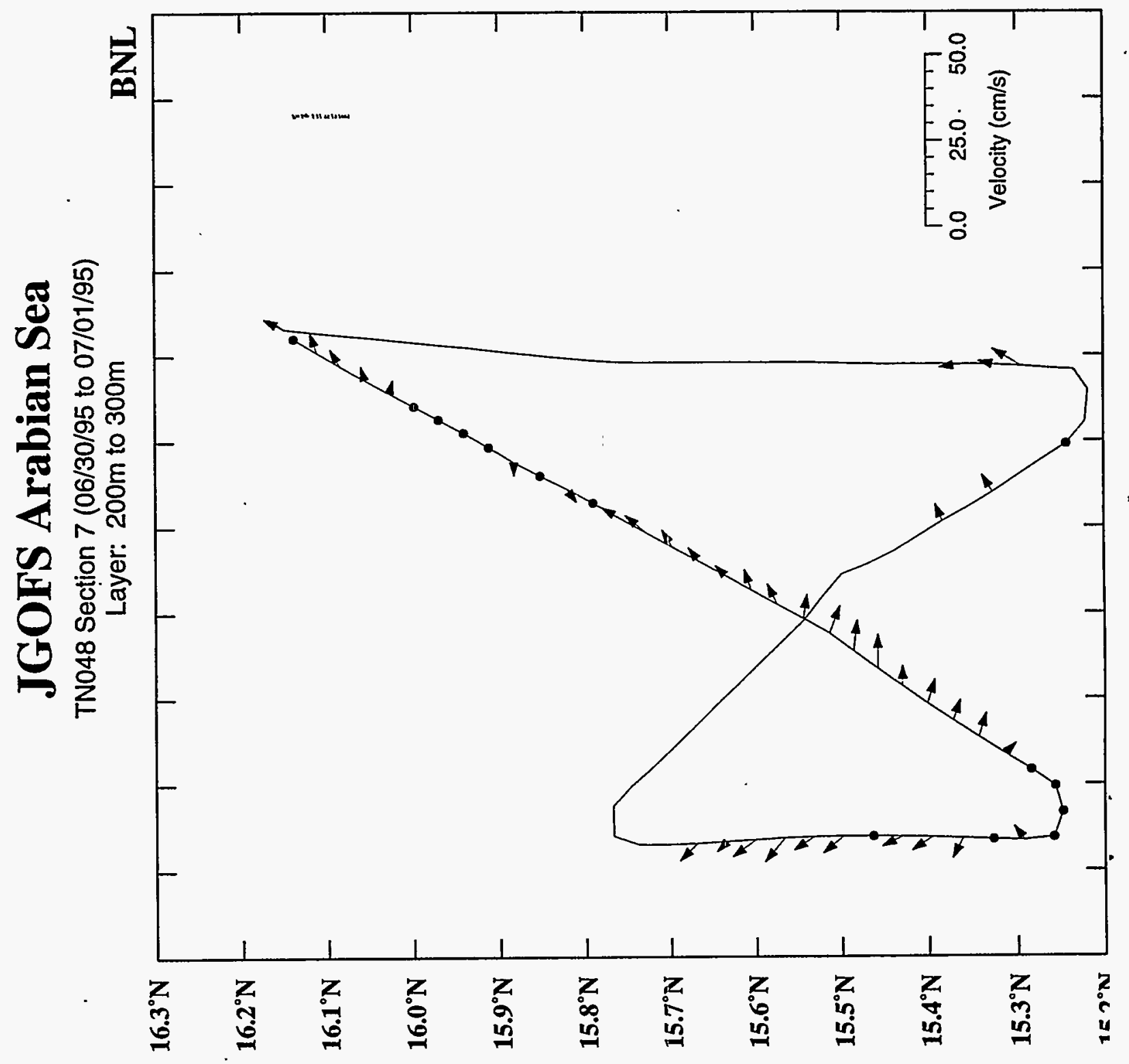




\section{JGOFS Arabian Sea}

TN048 Section 9 (07/01/95 to 07/03/95)

Current Velocity $20 \mathrm{~m}$ to $50 \mathrm{~m}$

BNL

完

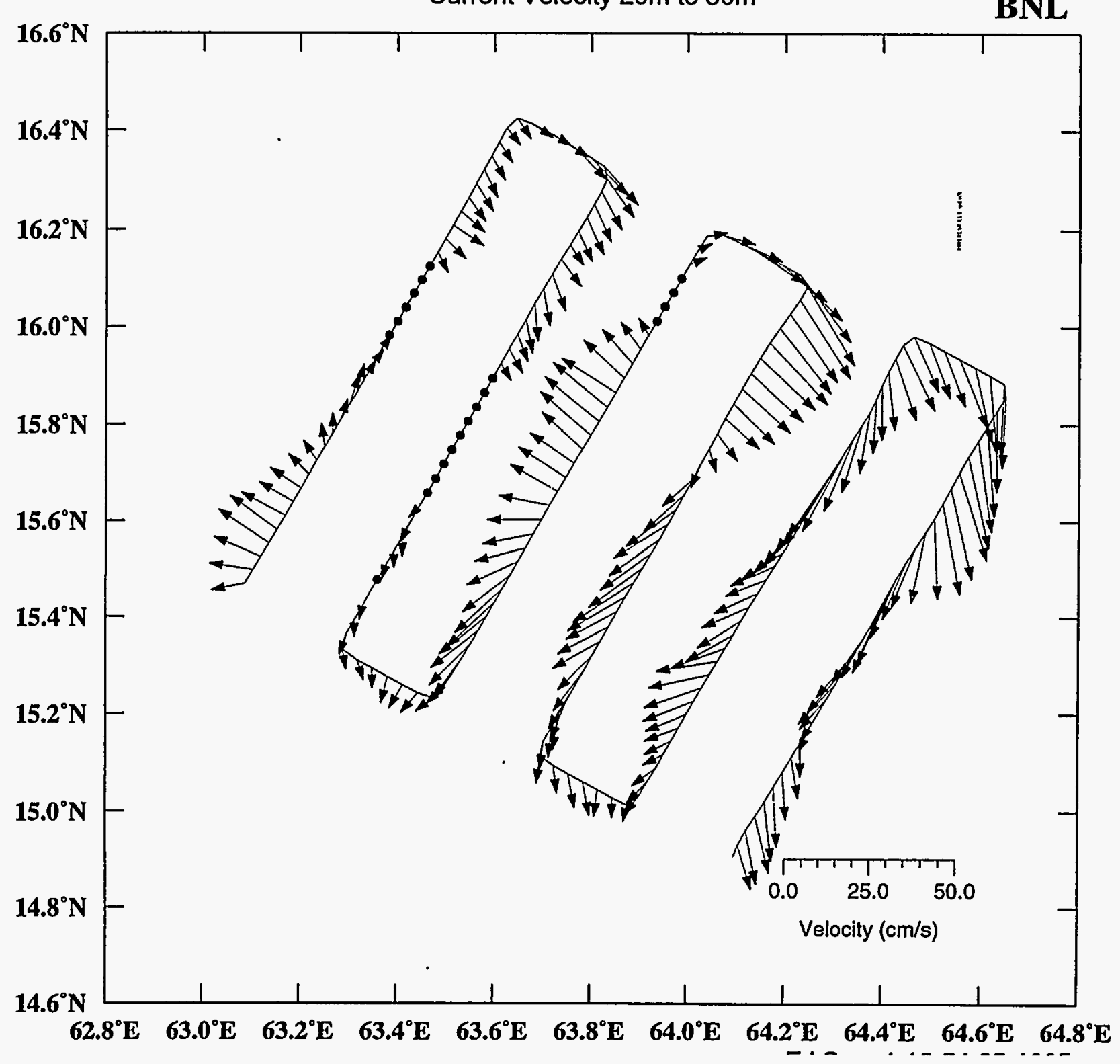




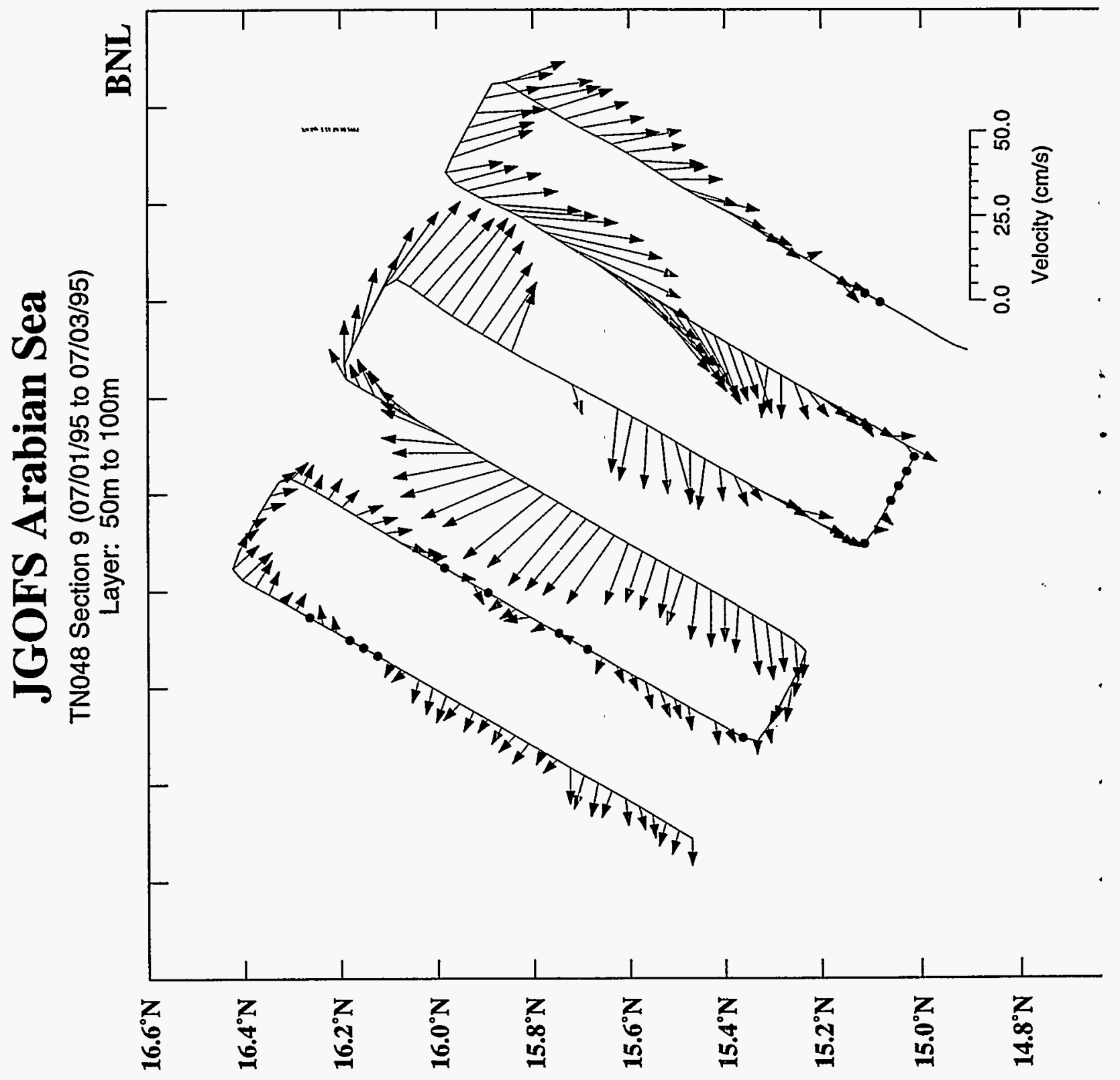




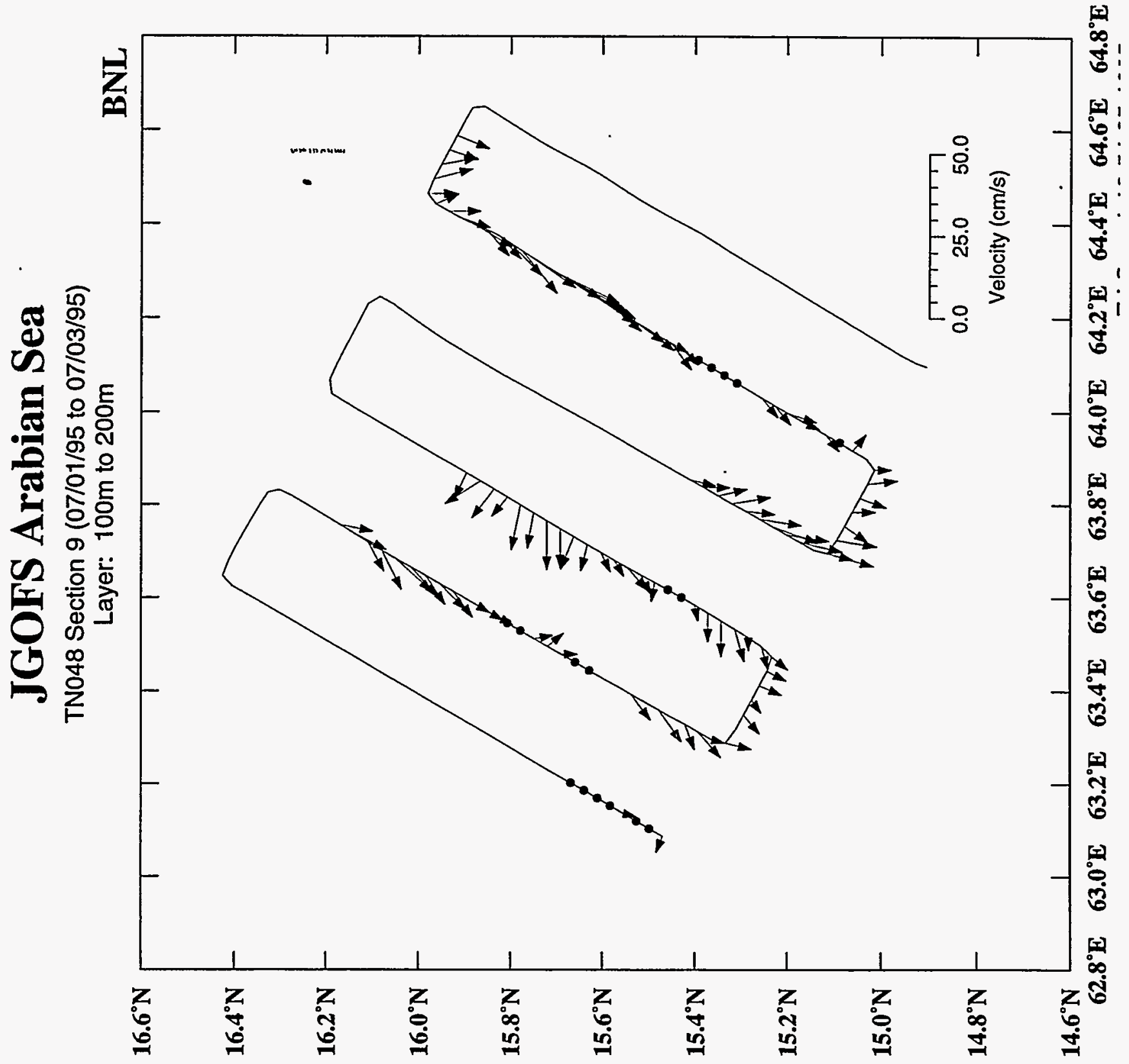




\section{JGOFS Arabian Sea}

TN048 Section 9 (07/01/95 to 07/03/95)

Layer: $200 \mathrm{~m}$ to $300 \mathrm{~m}$

BNL

实

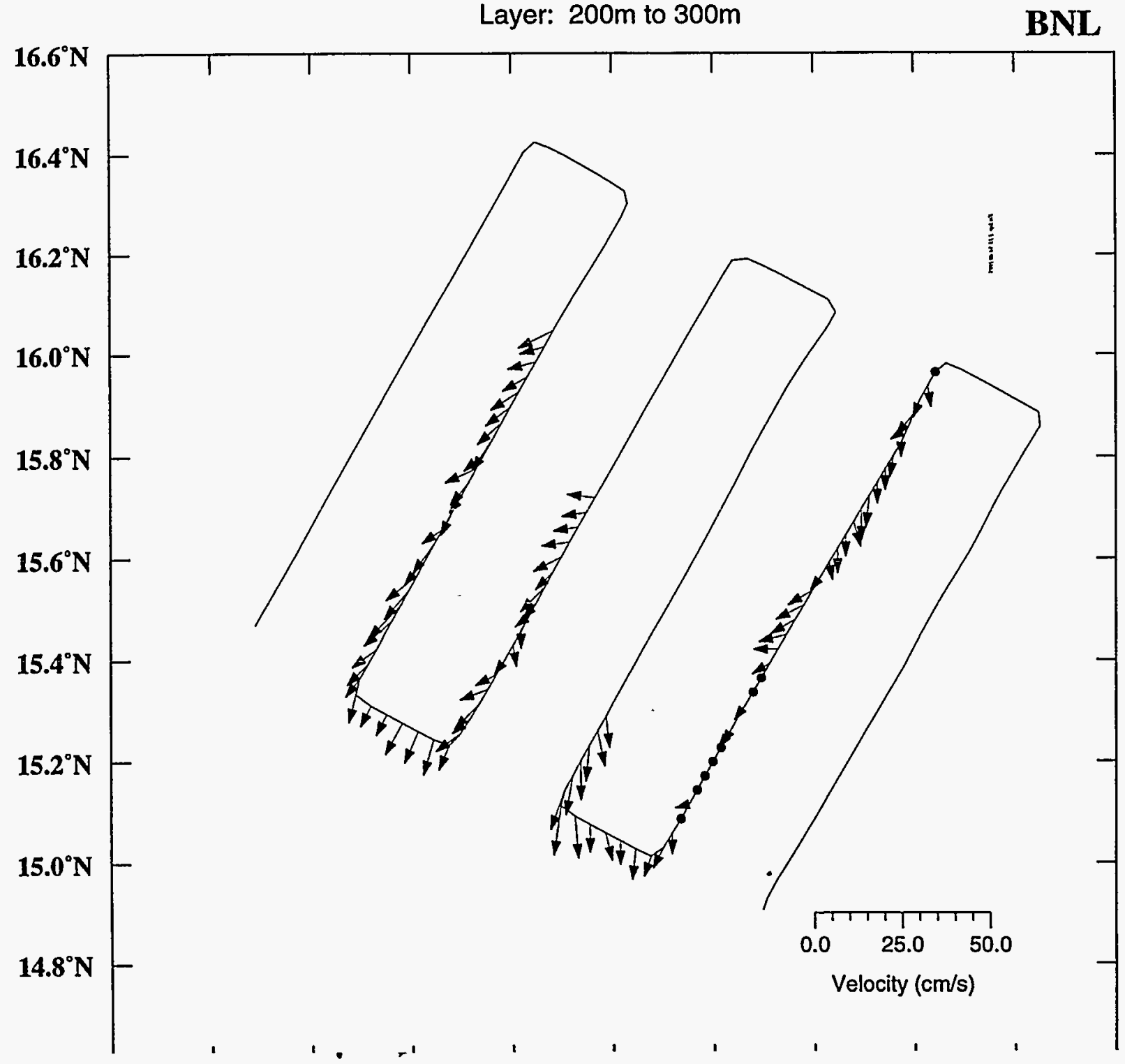




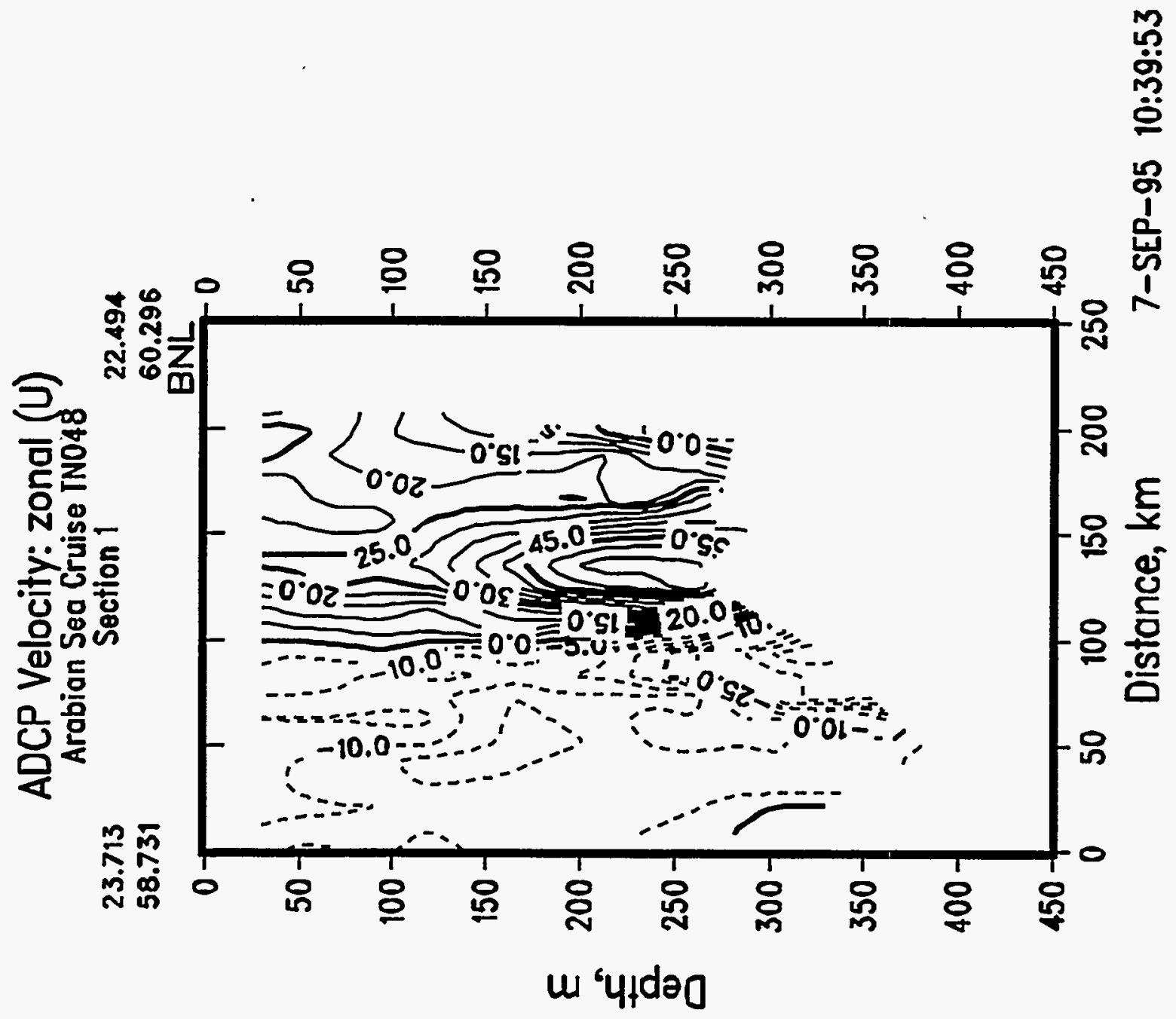




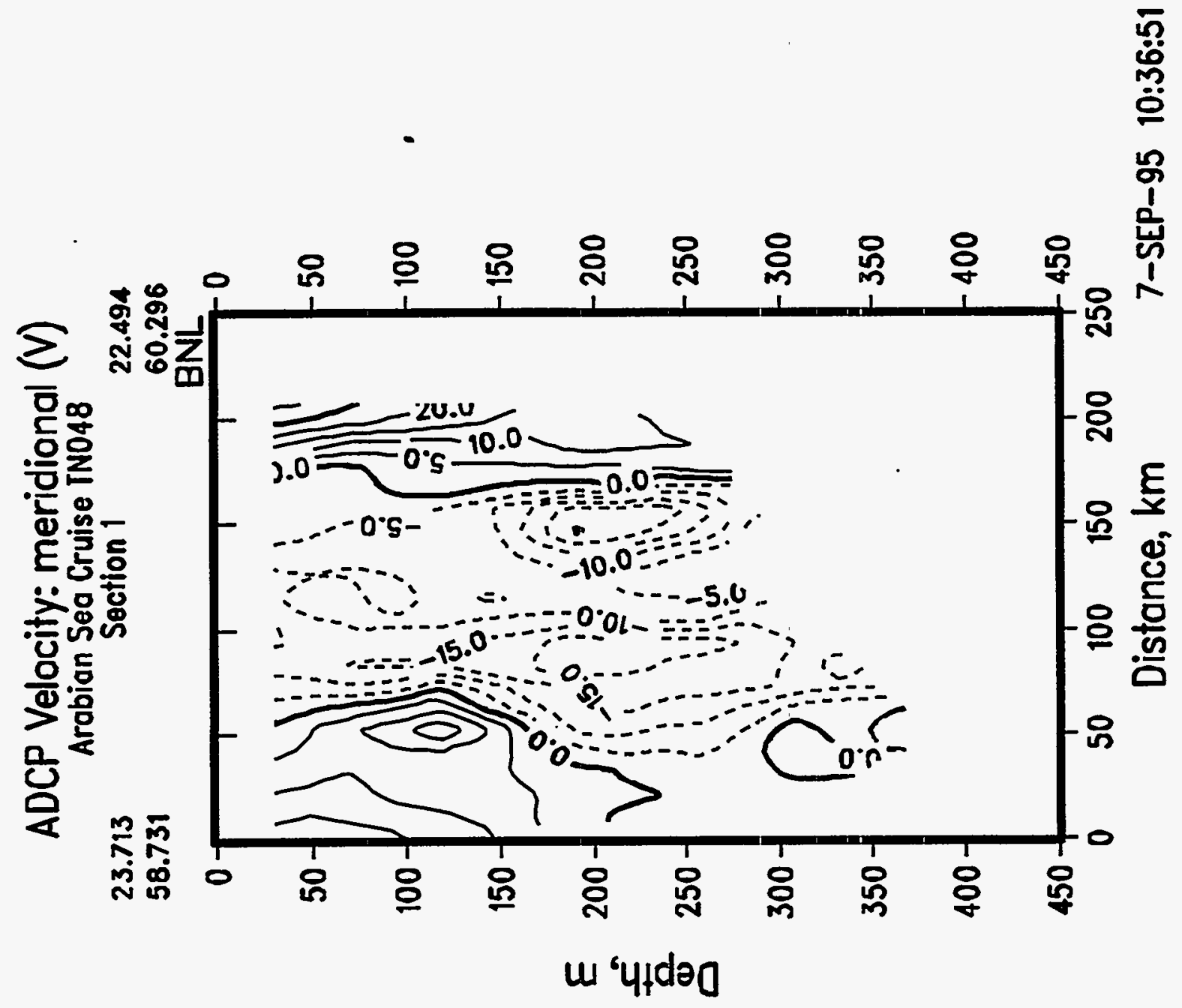




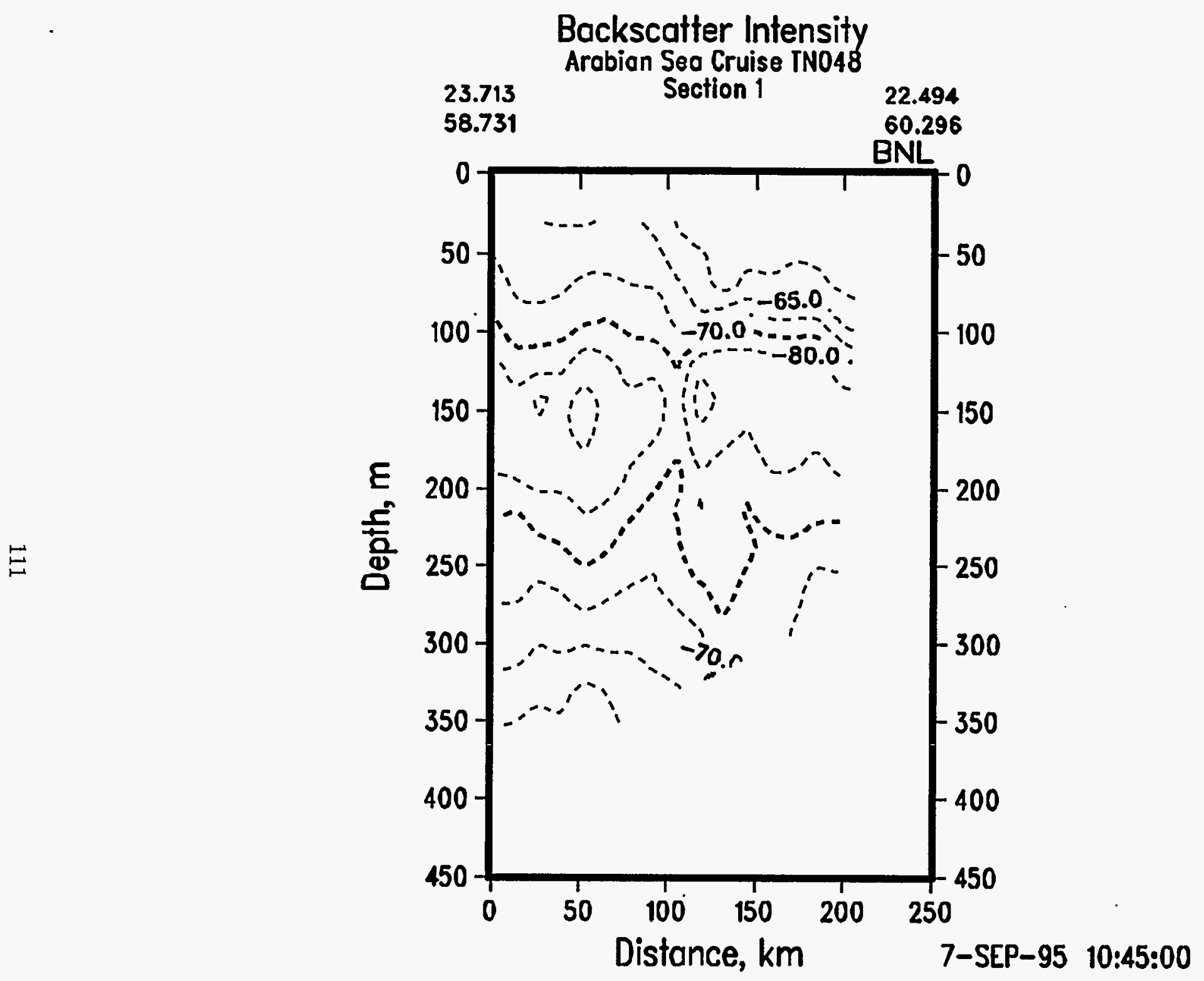




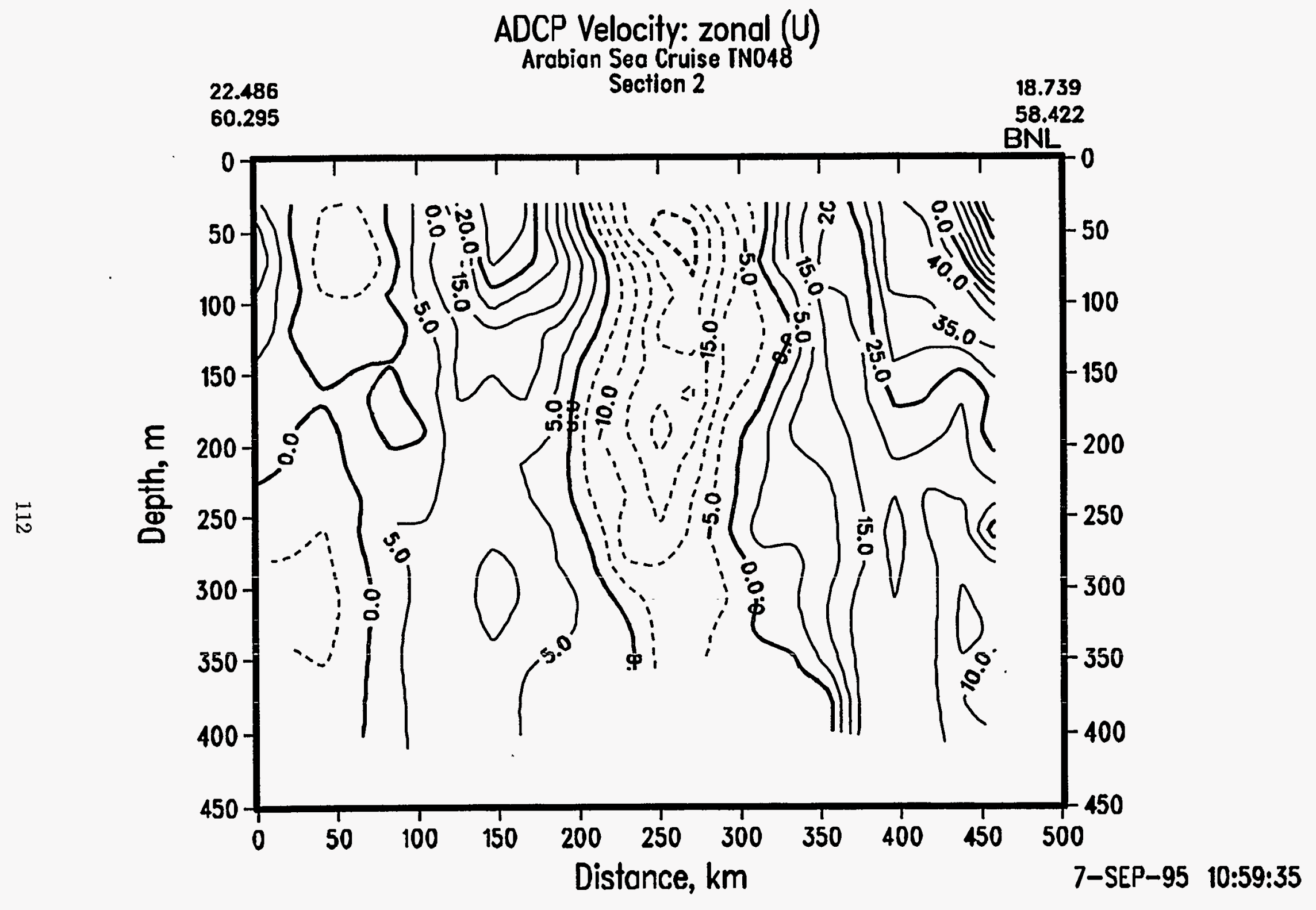




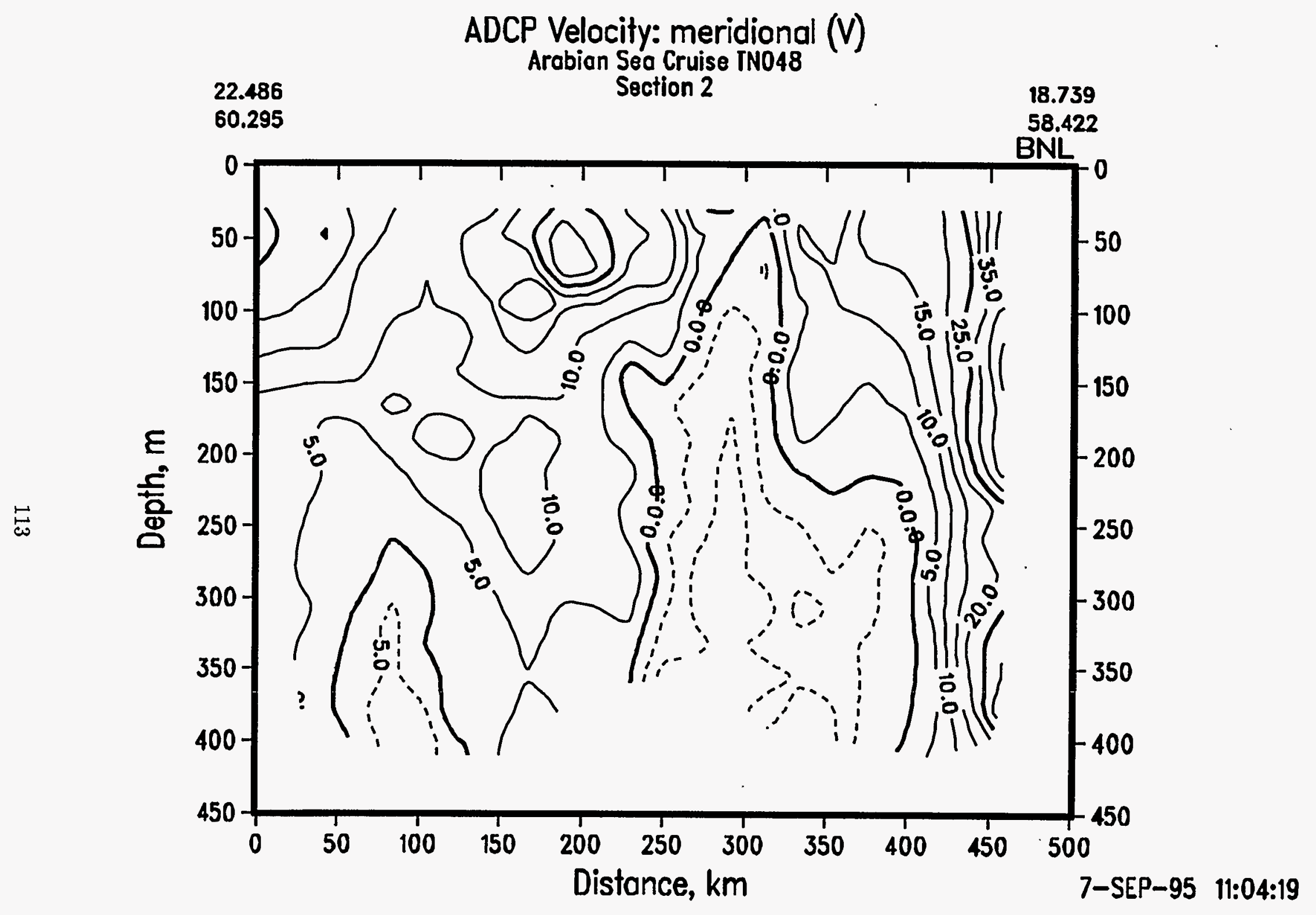




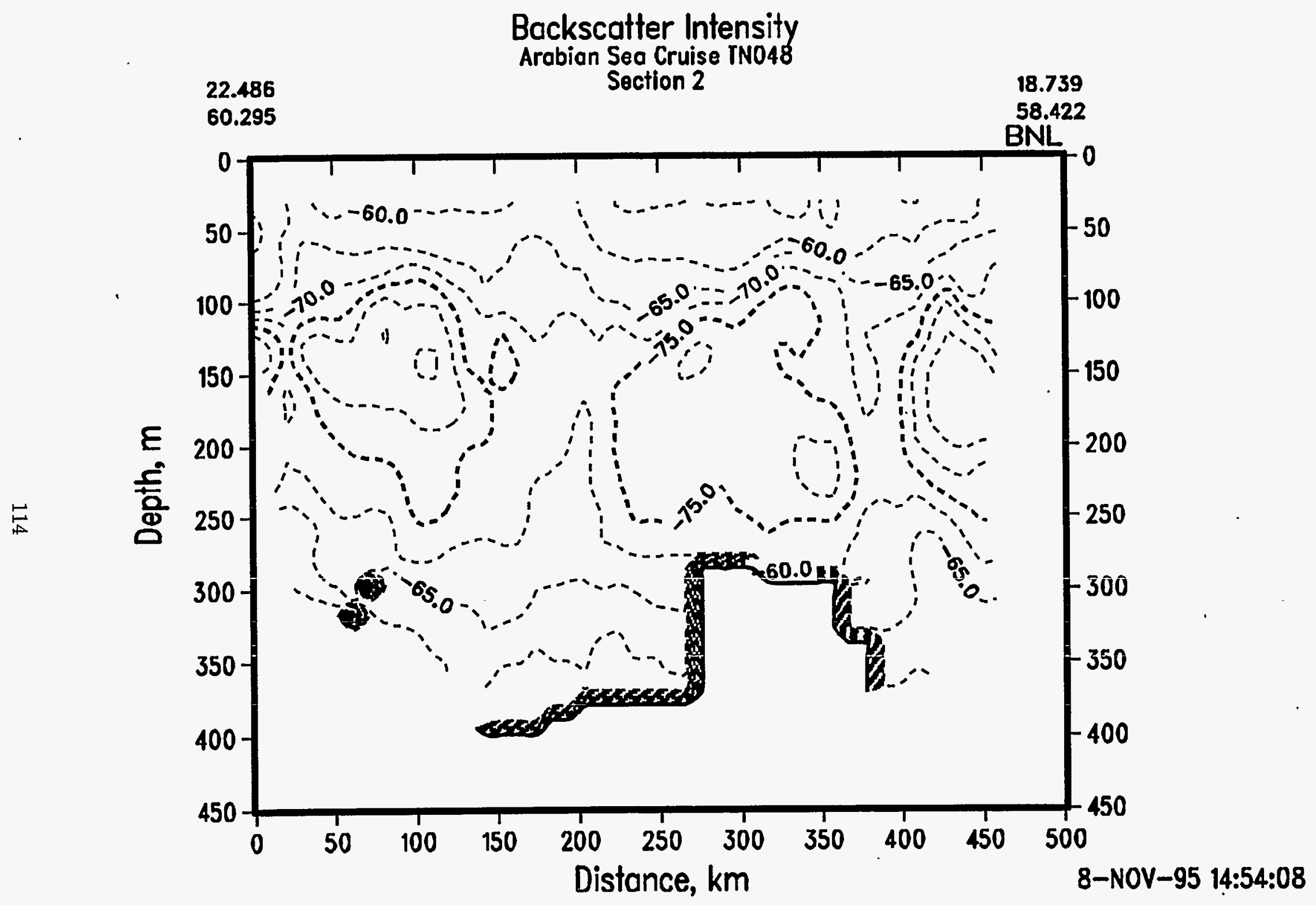




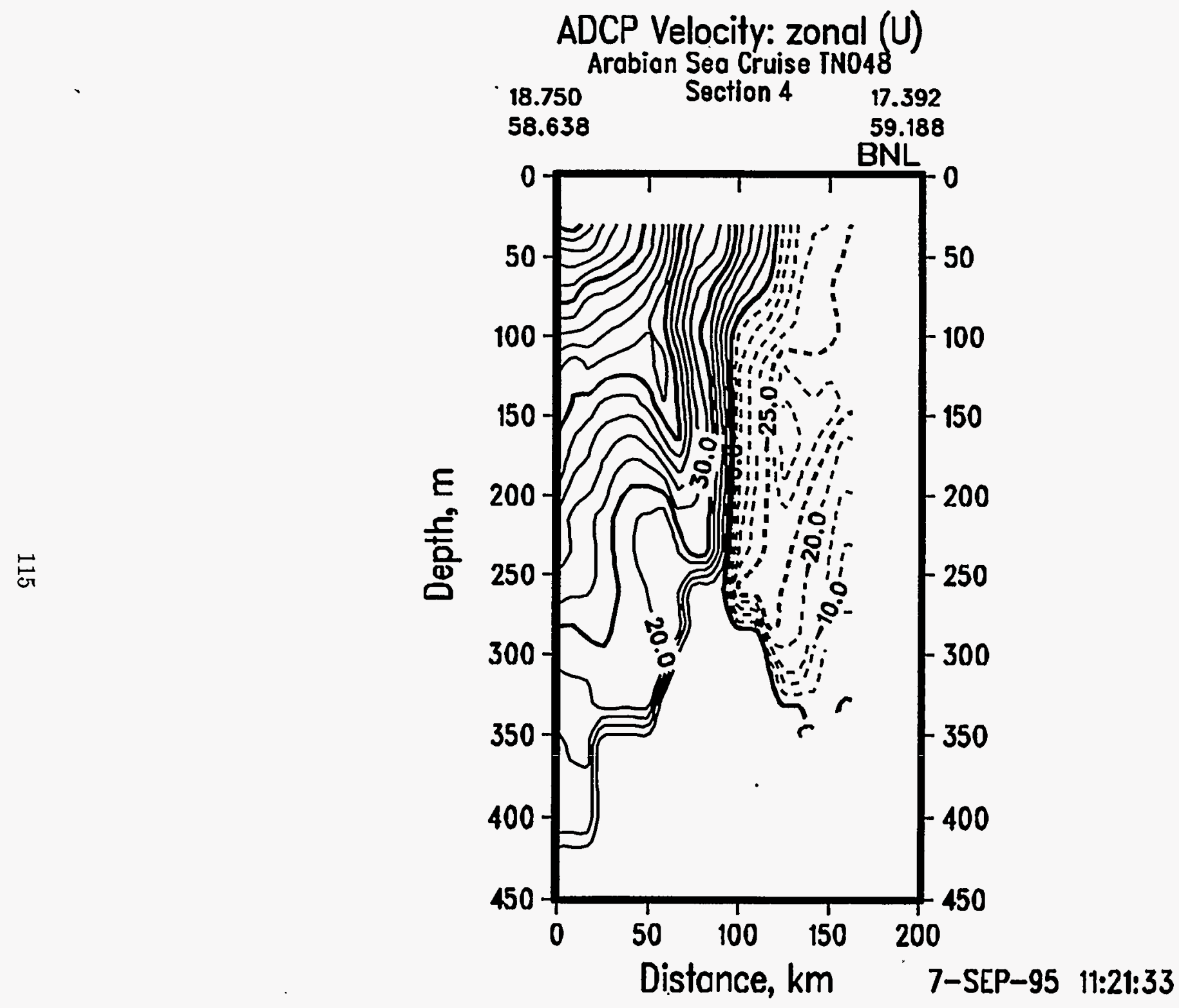




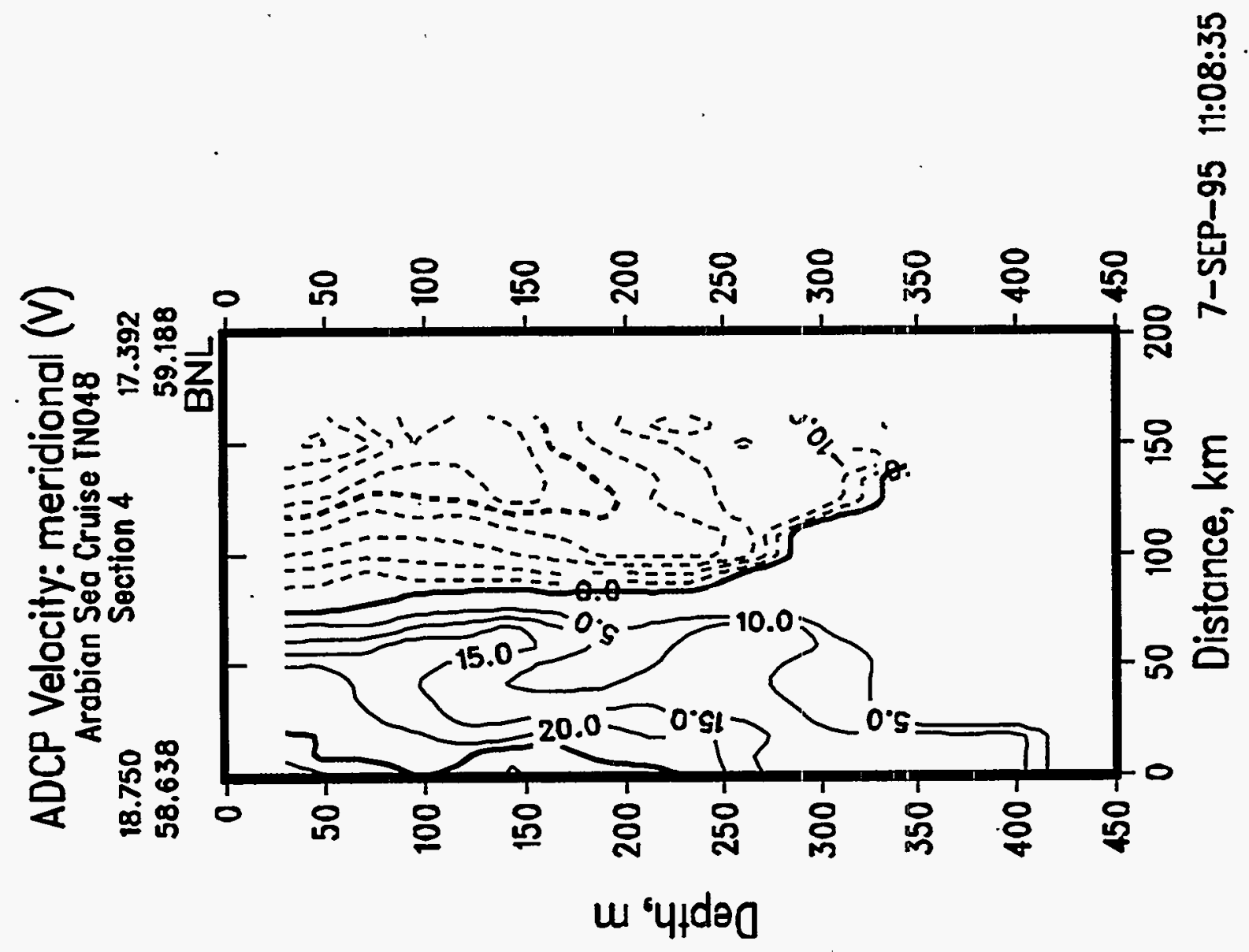




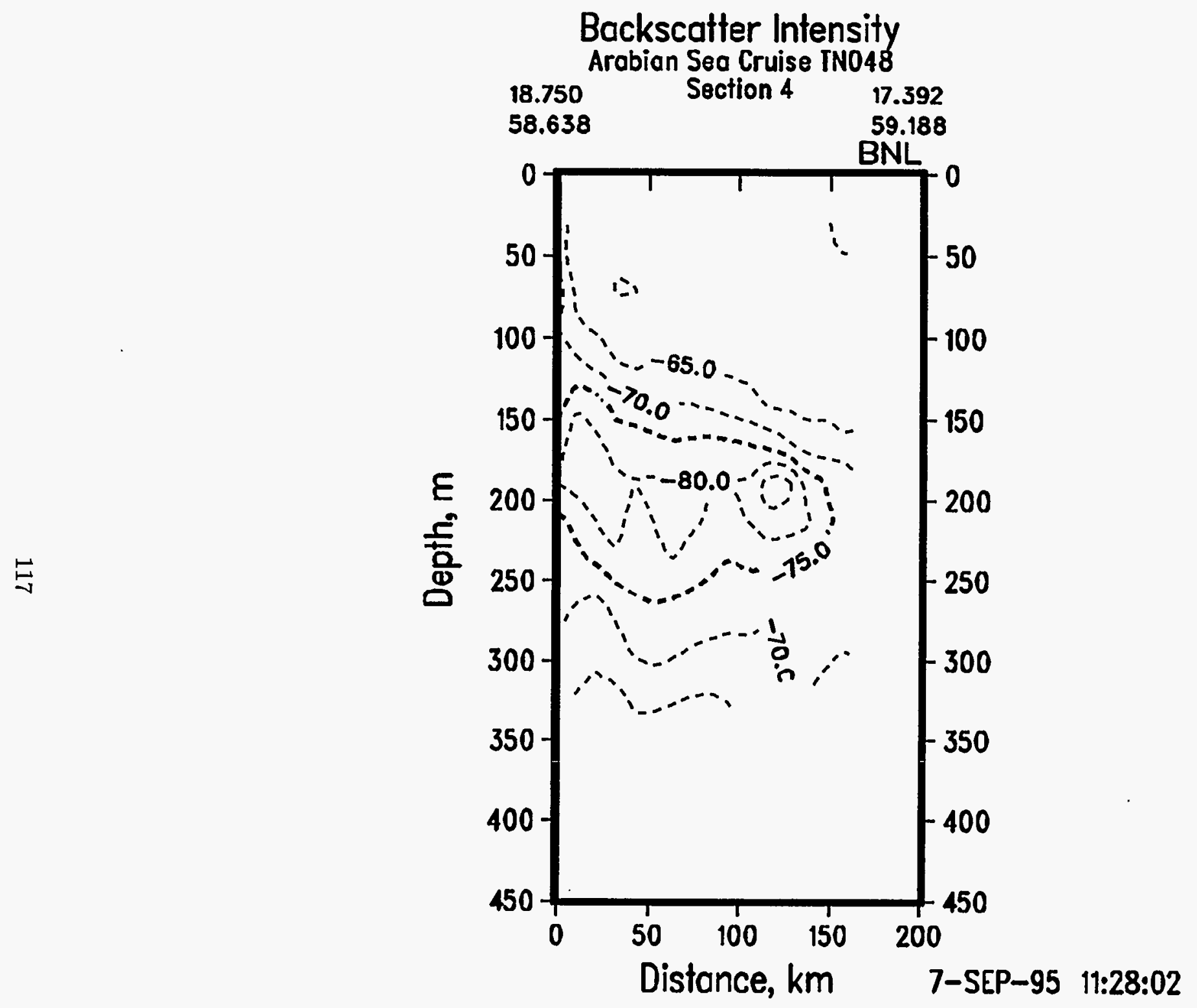




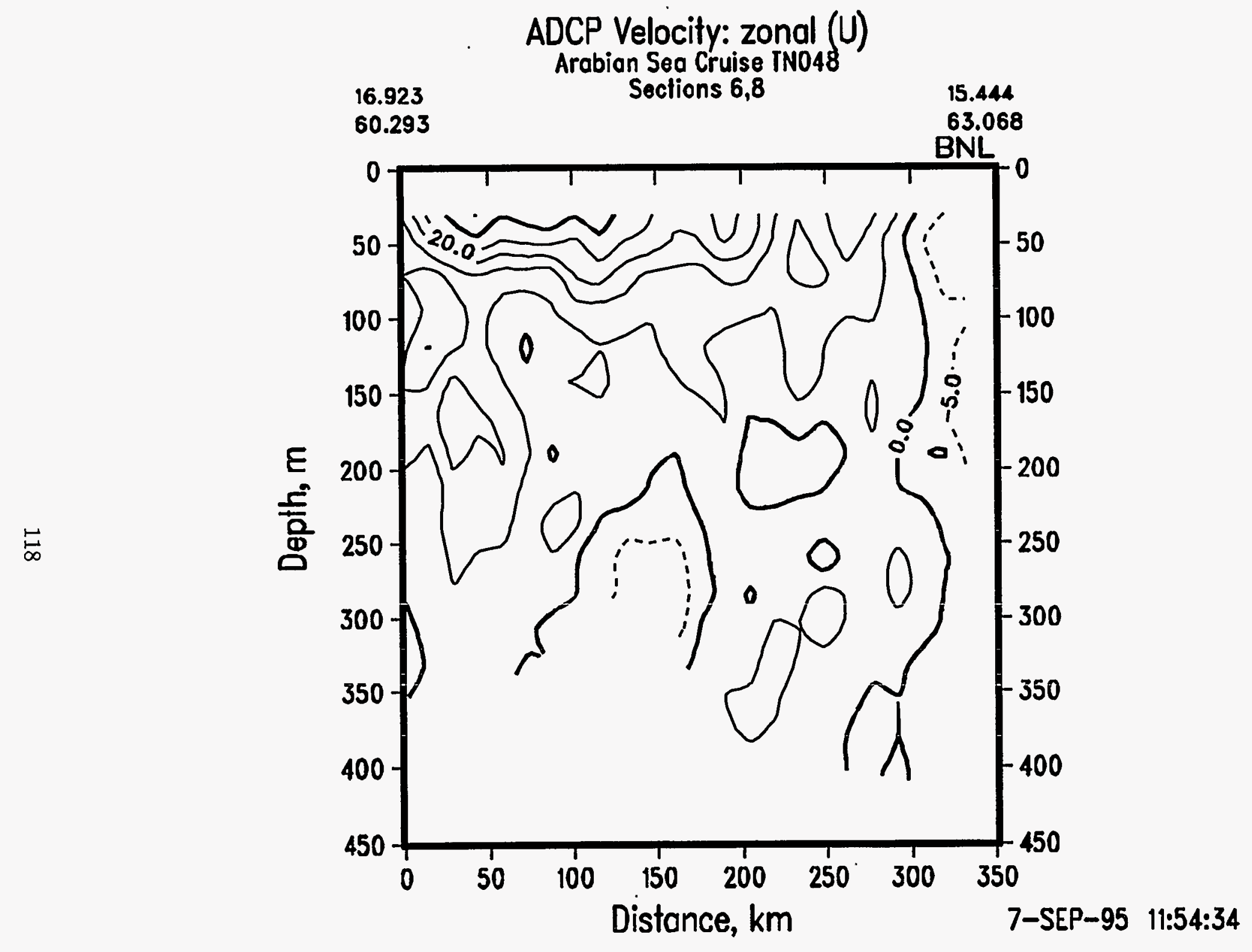




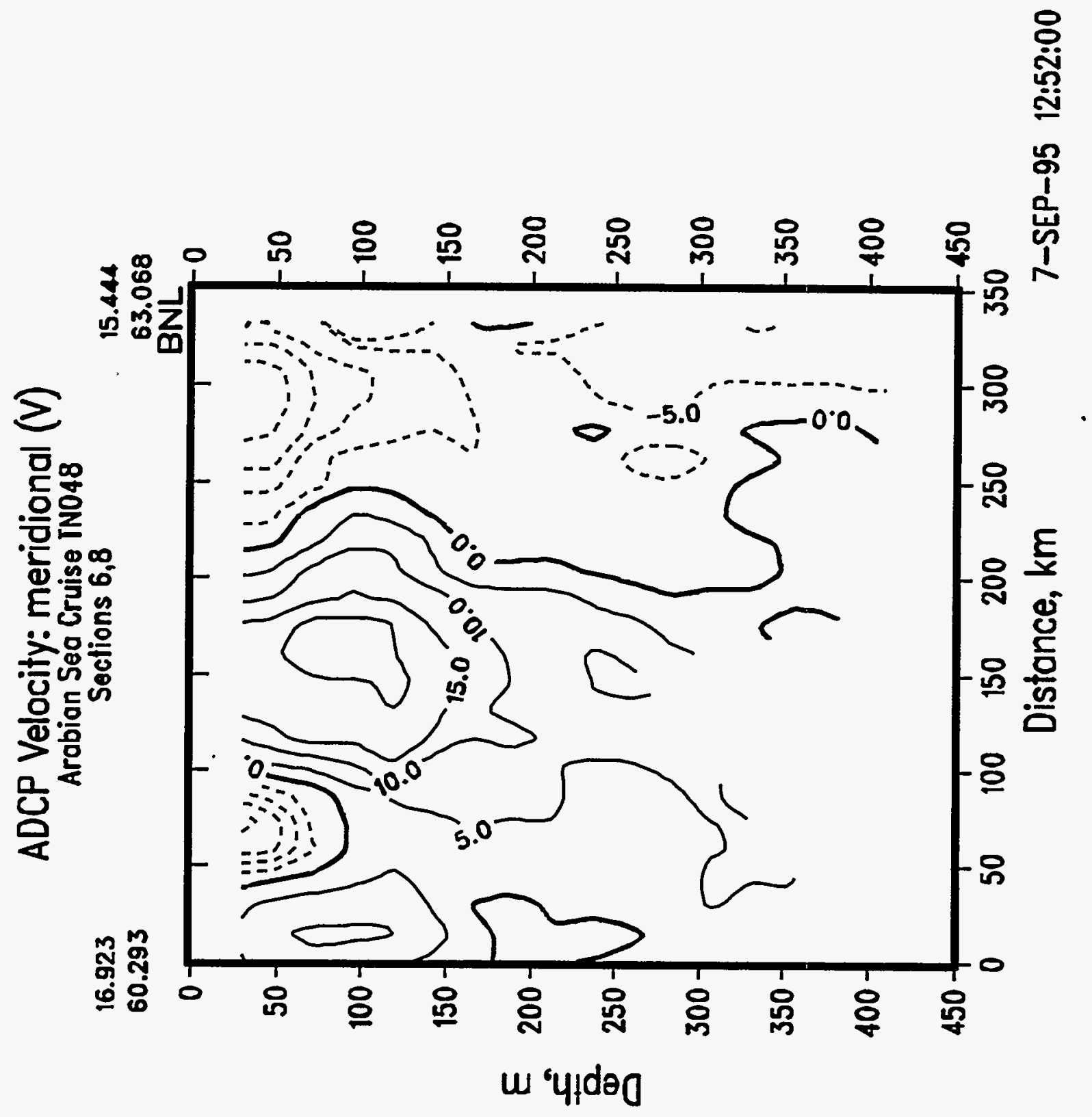




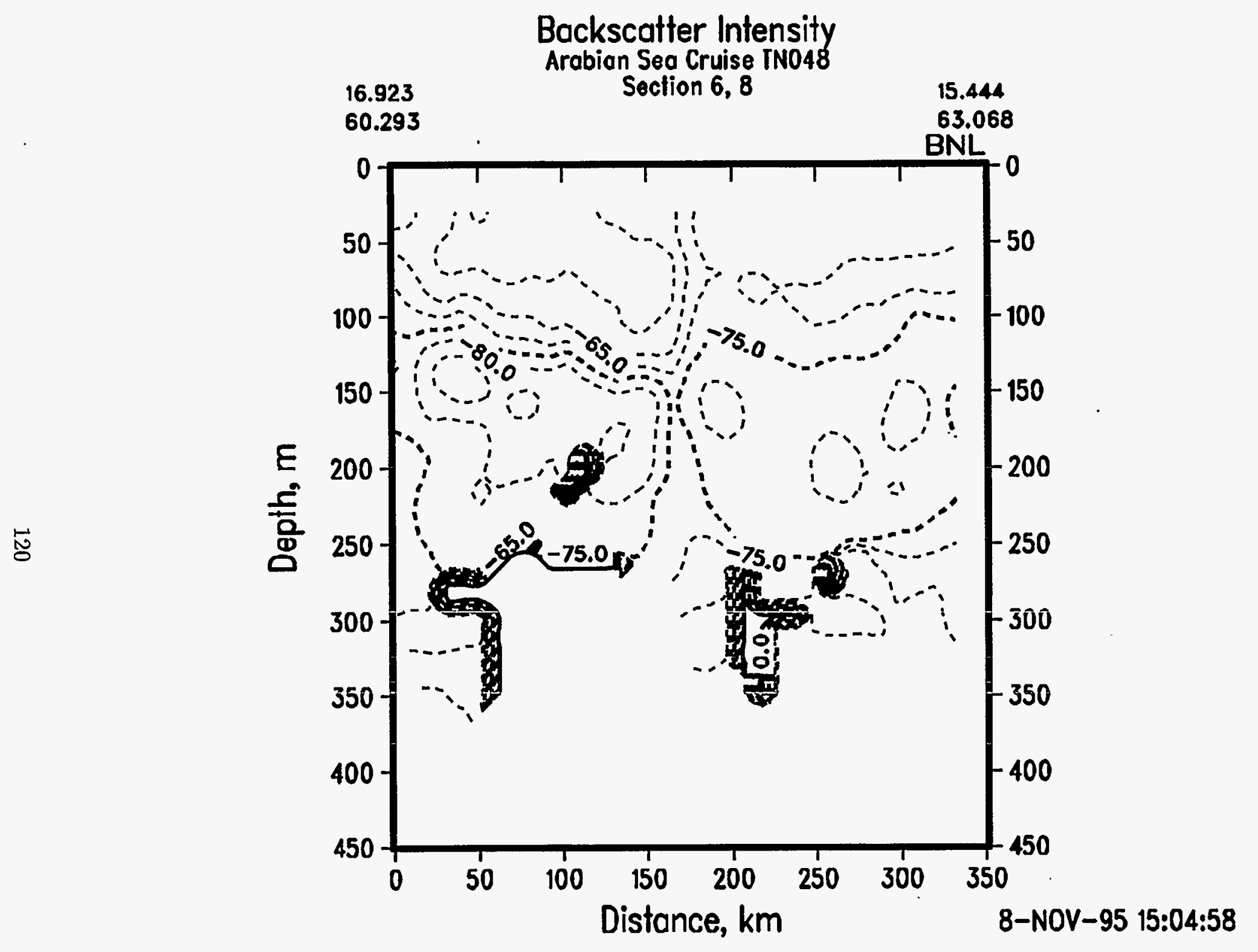




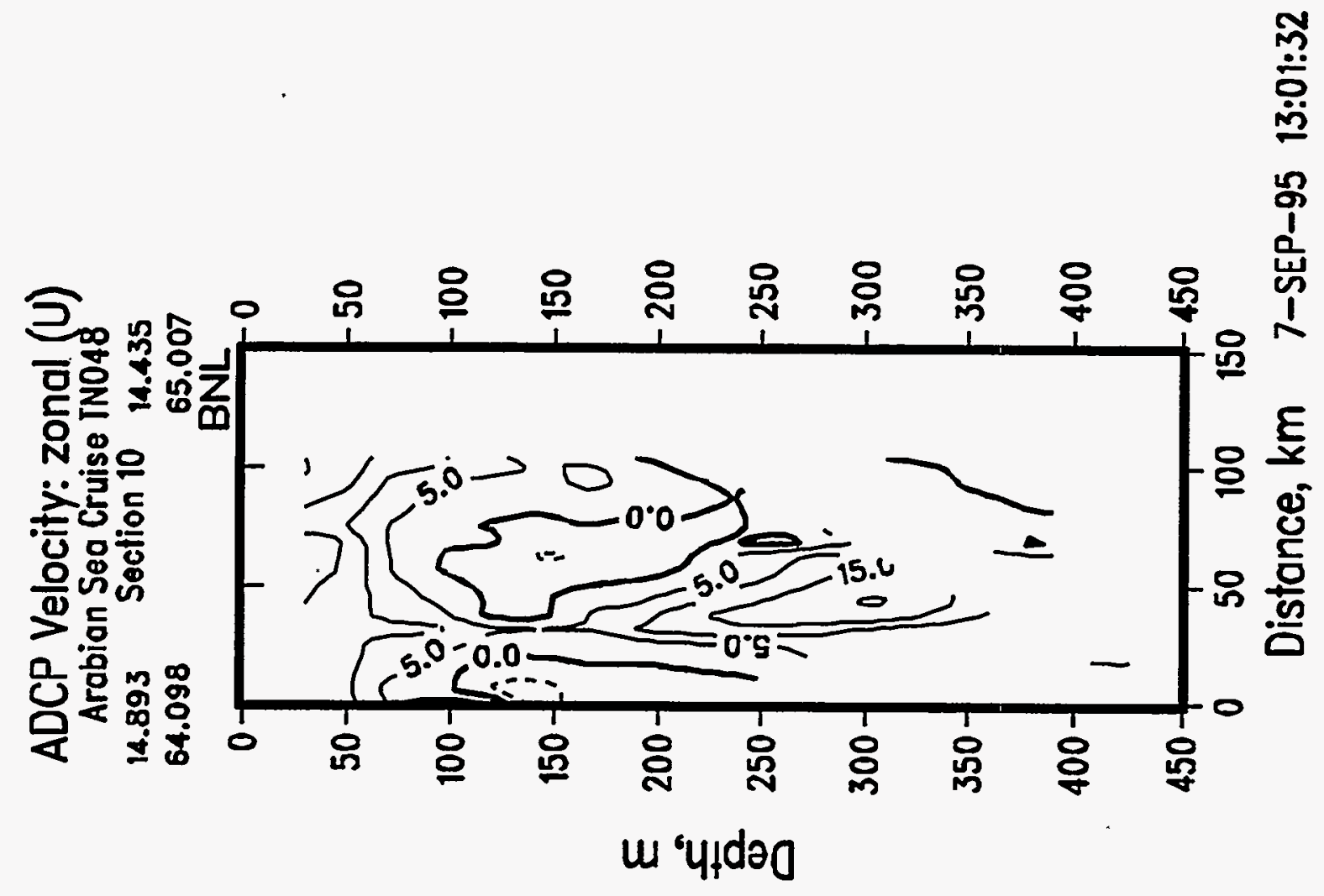




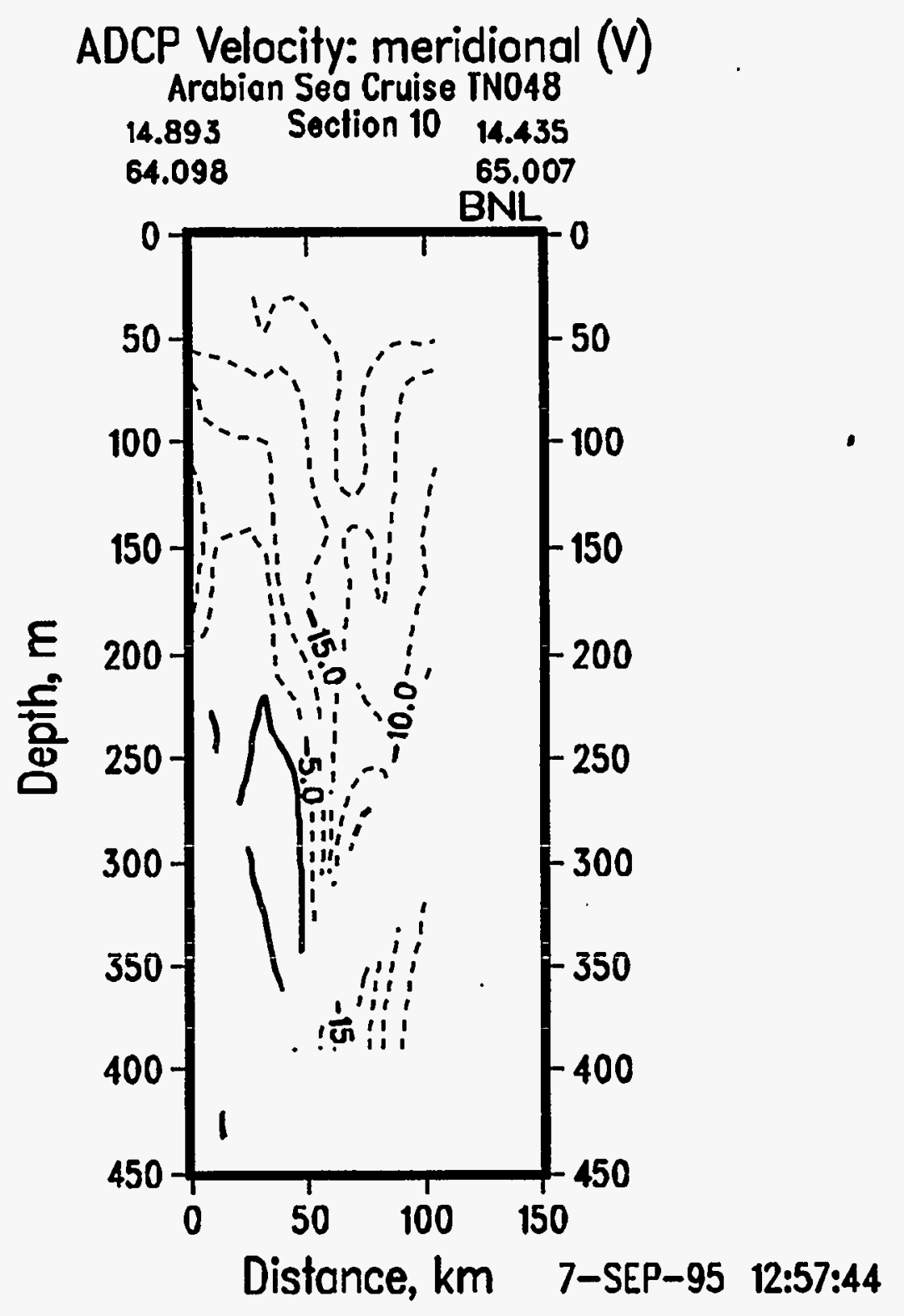




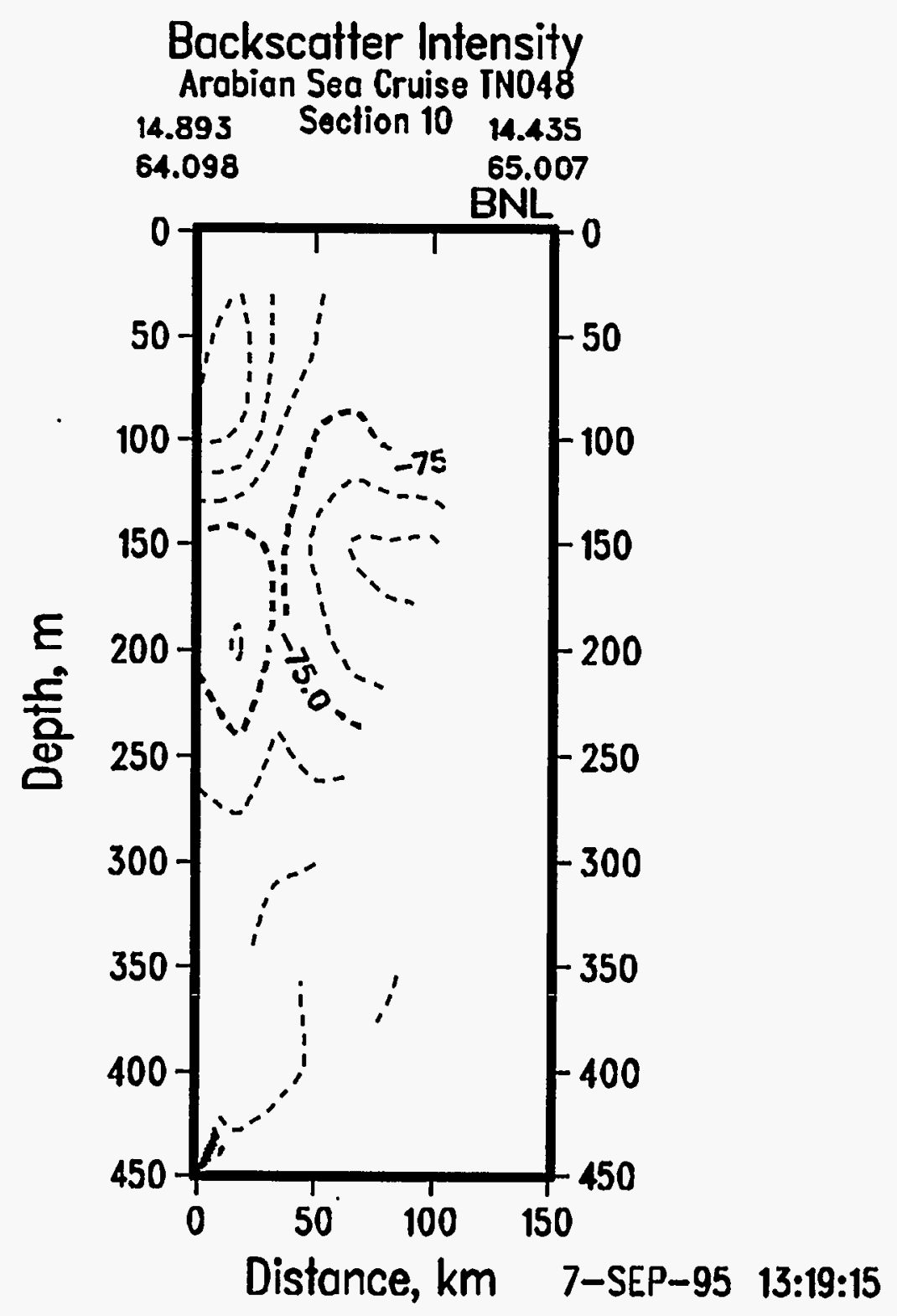




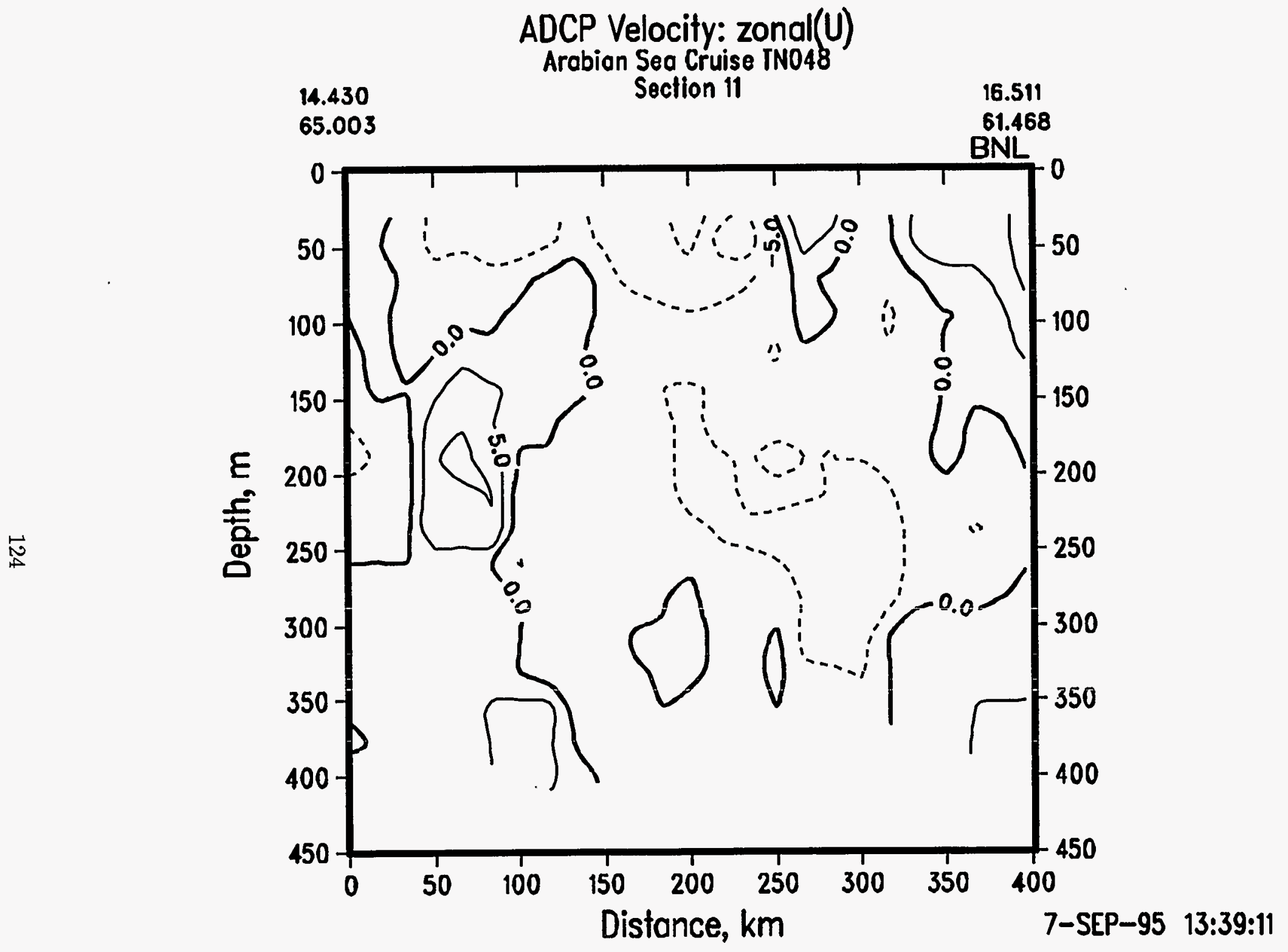




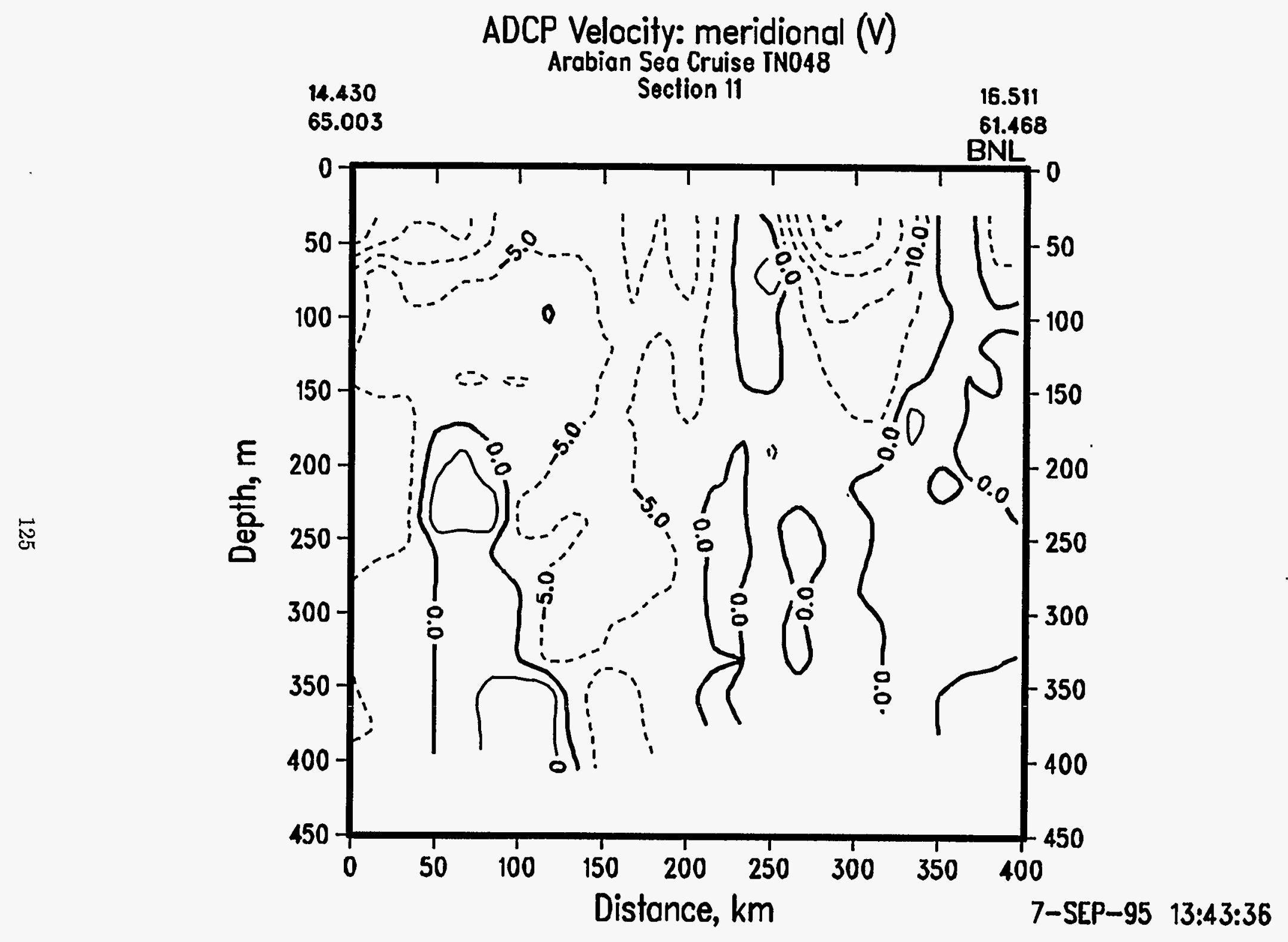




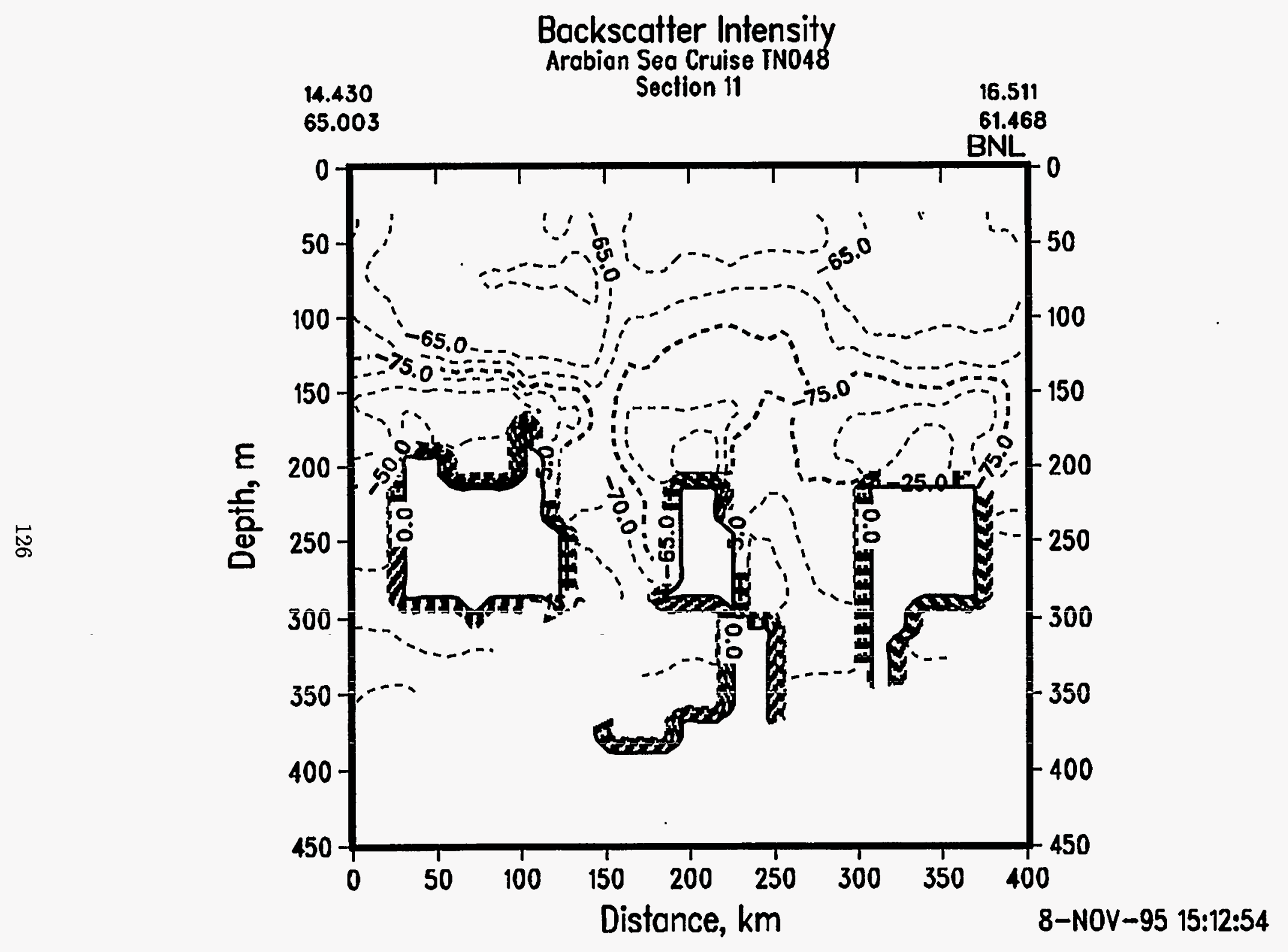




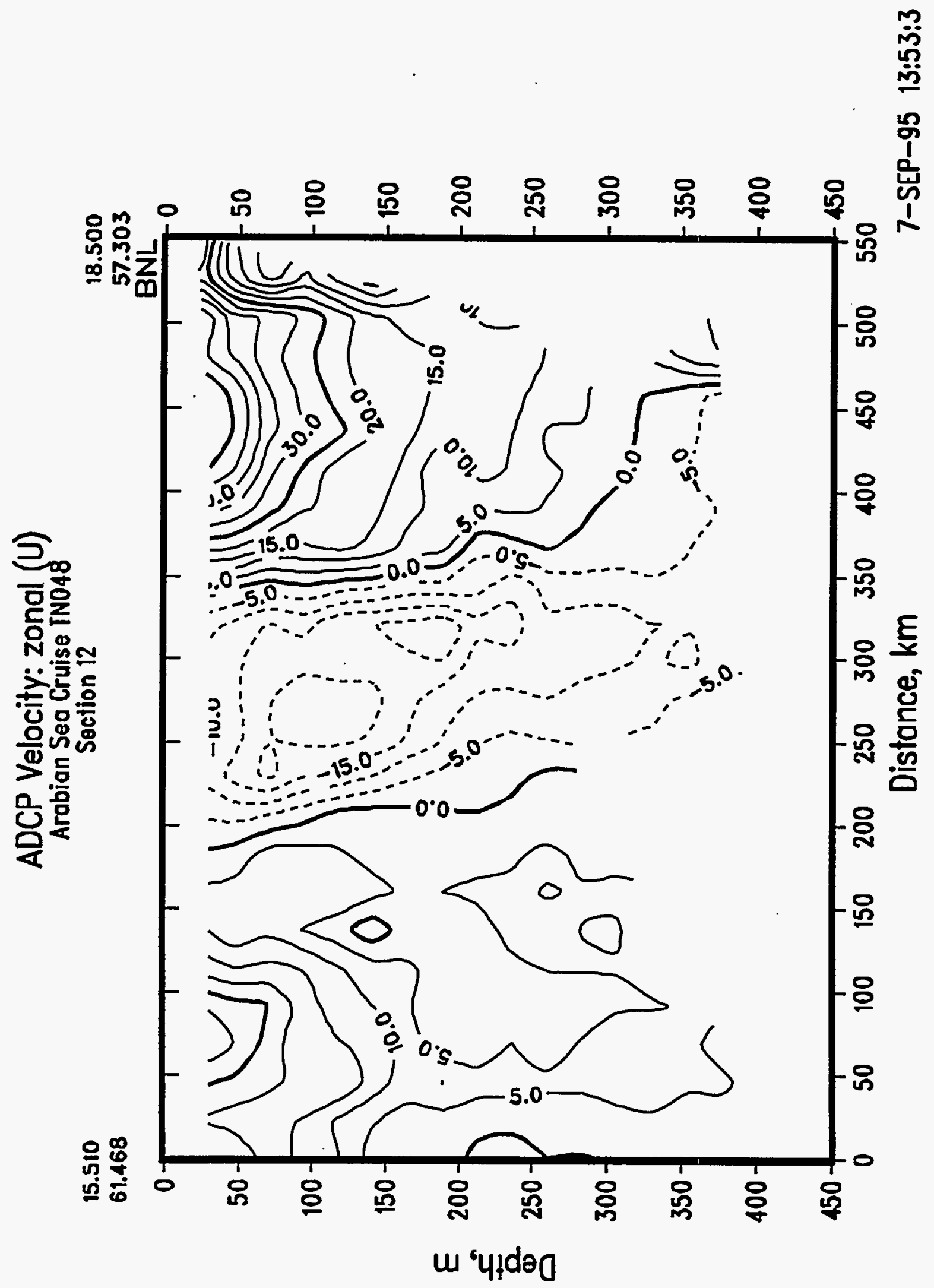




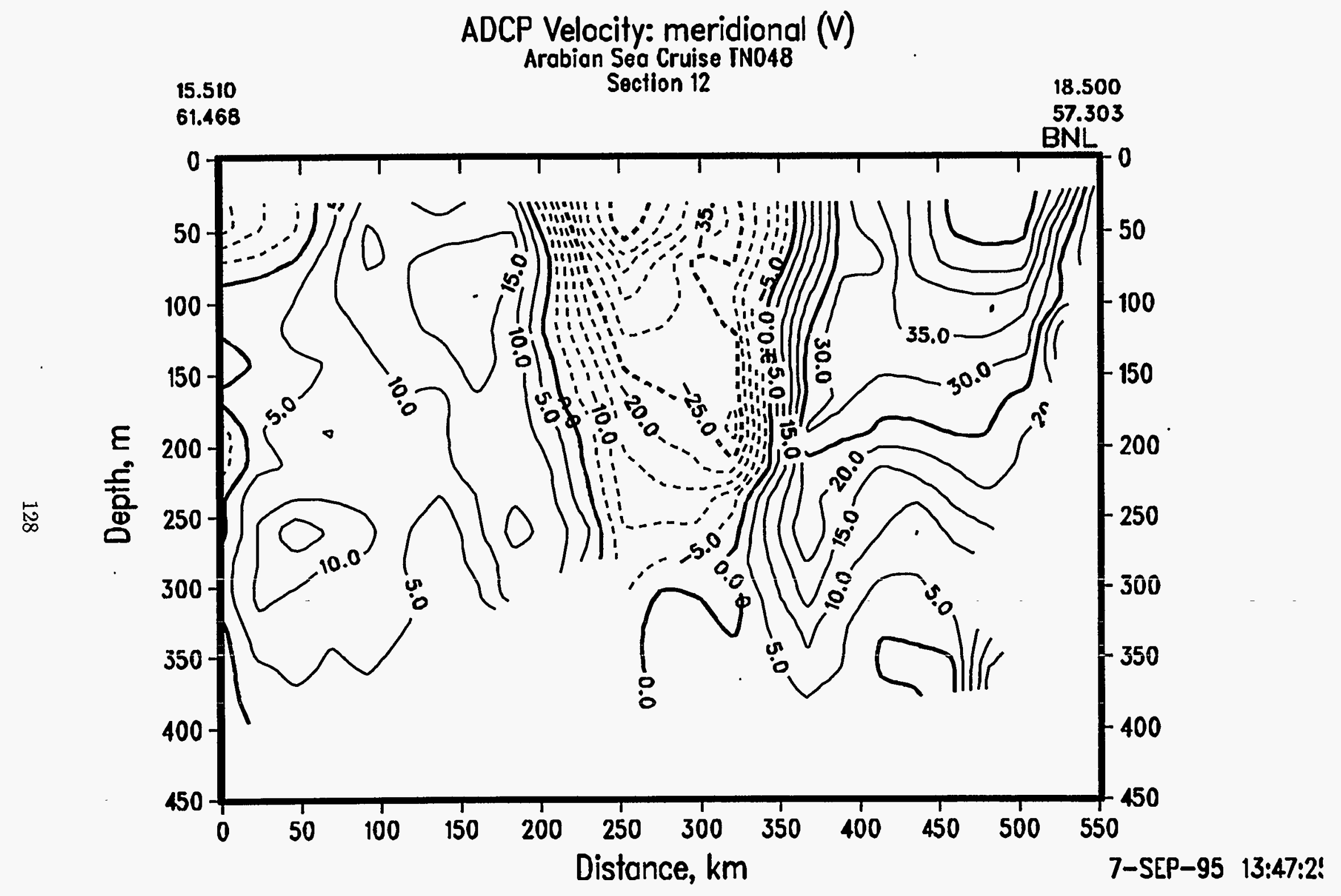




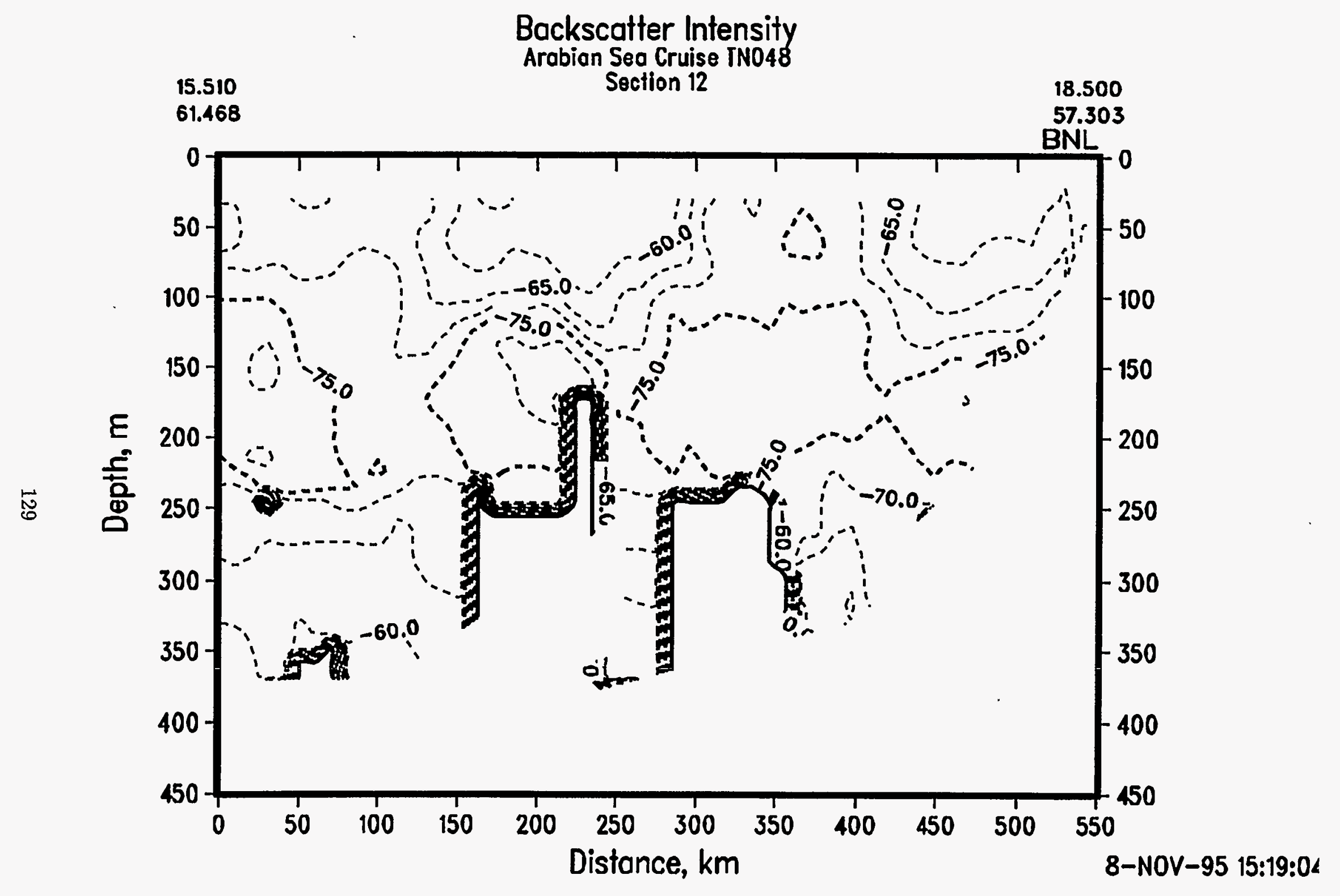




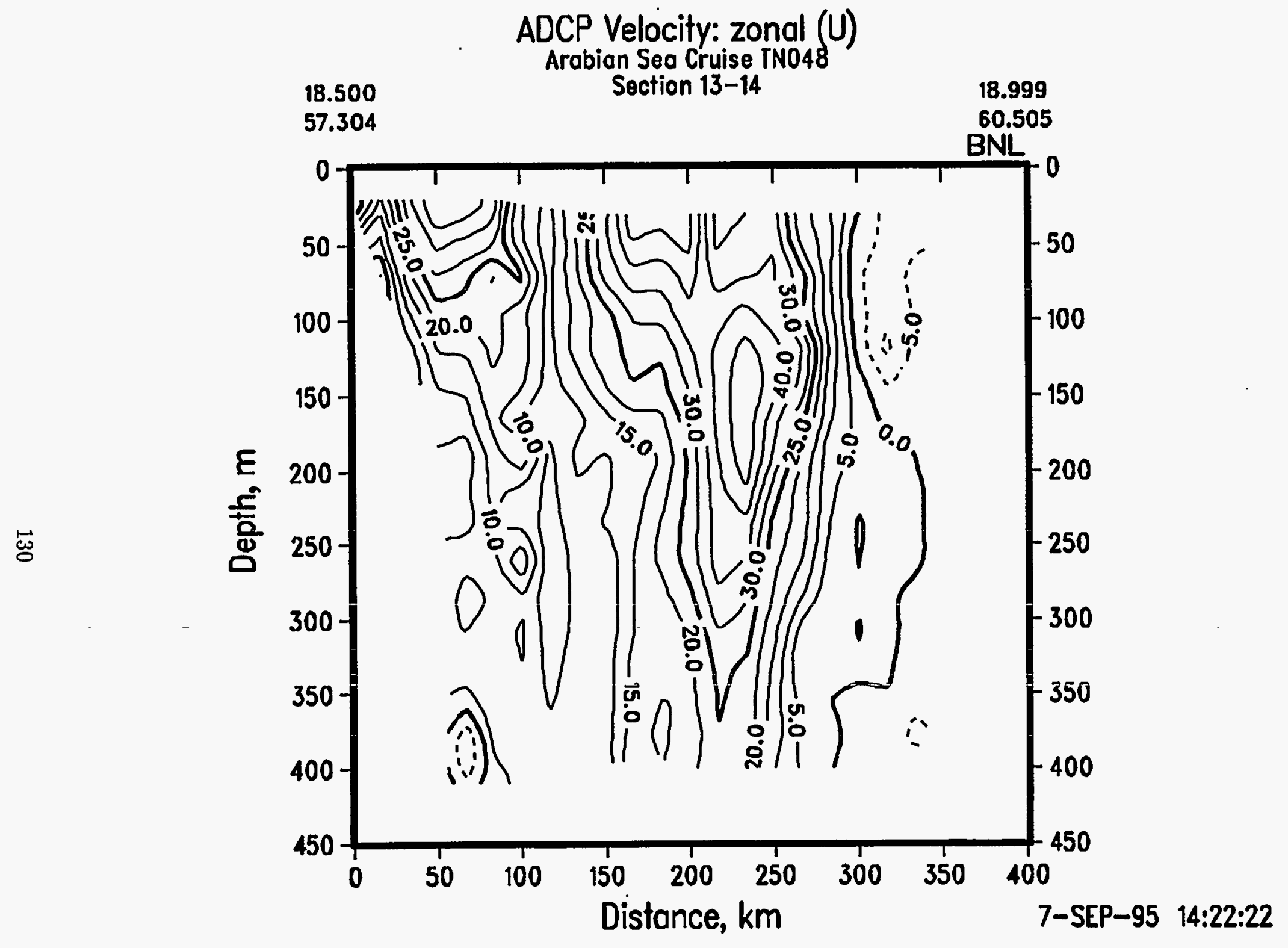




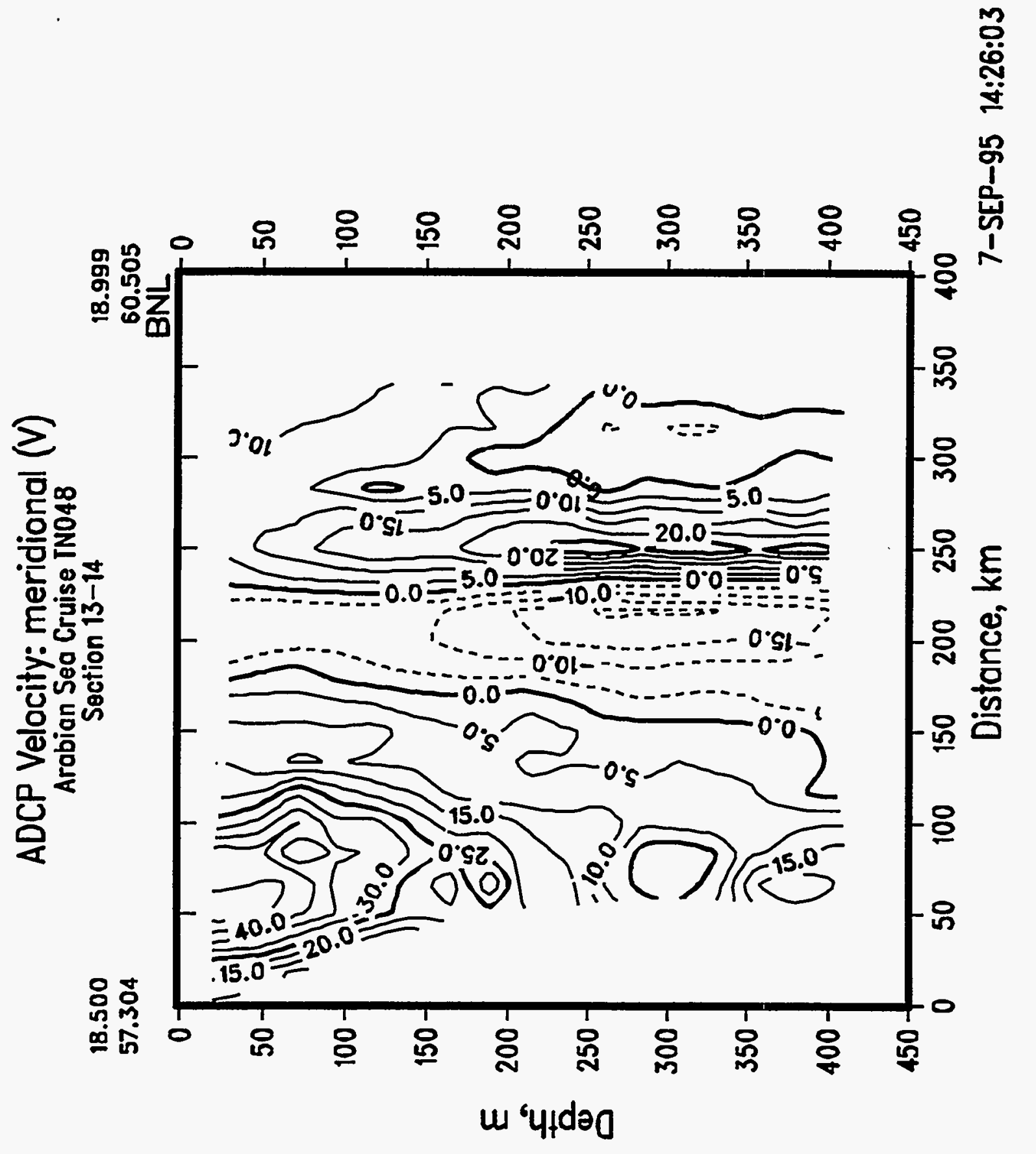




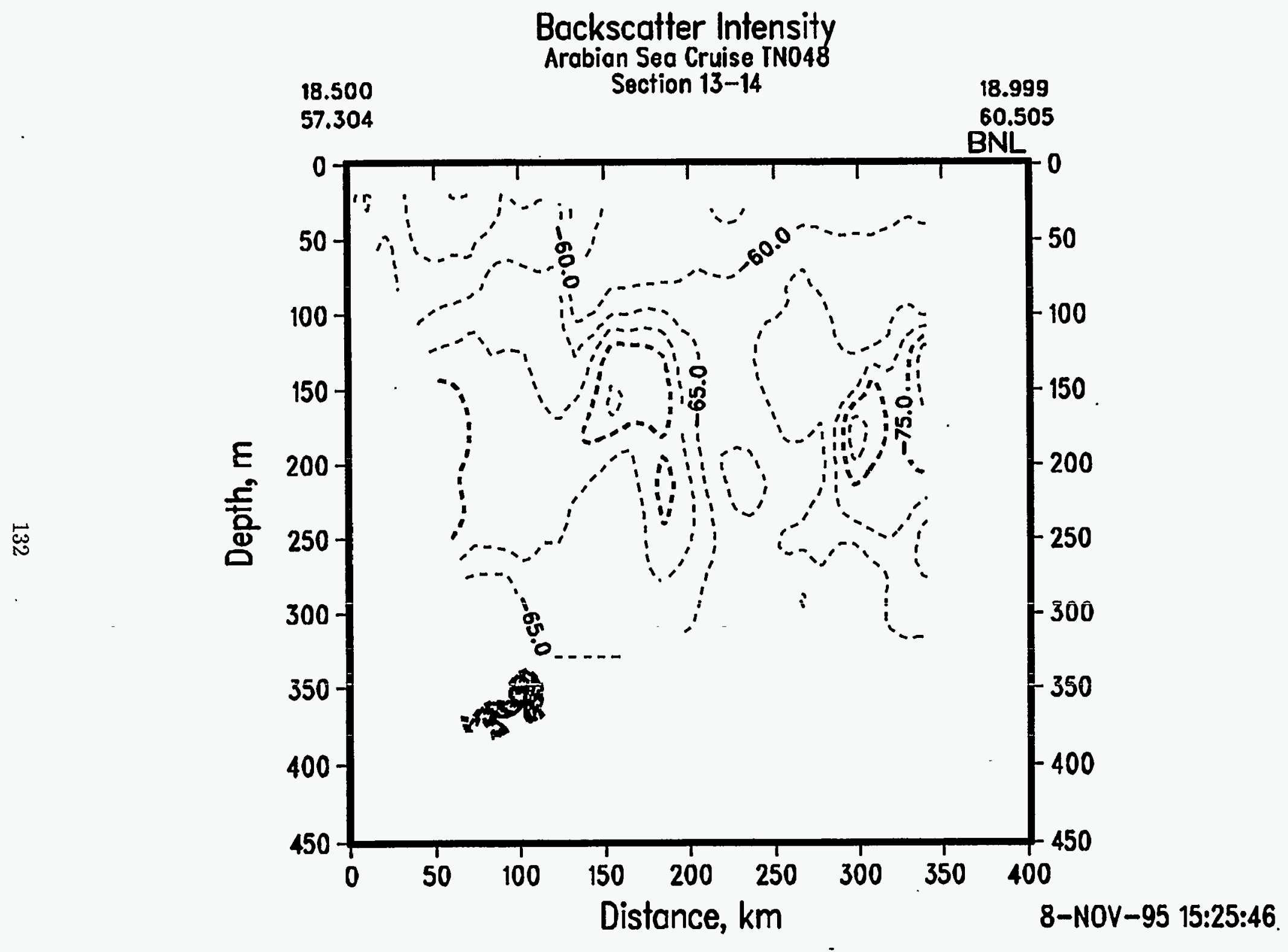




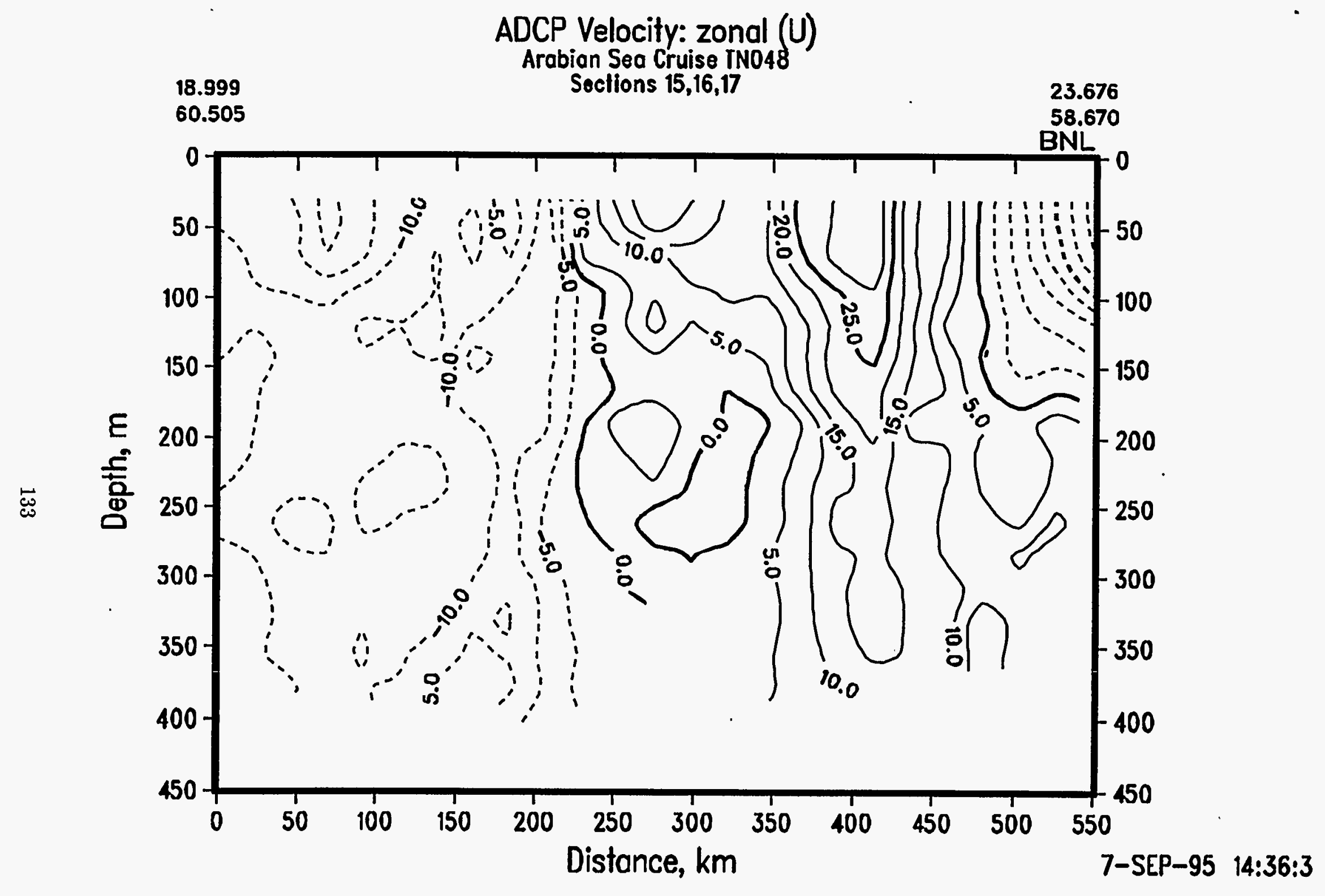




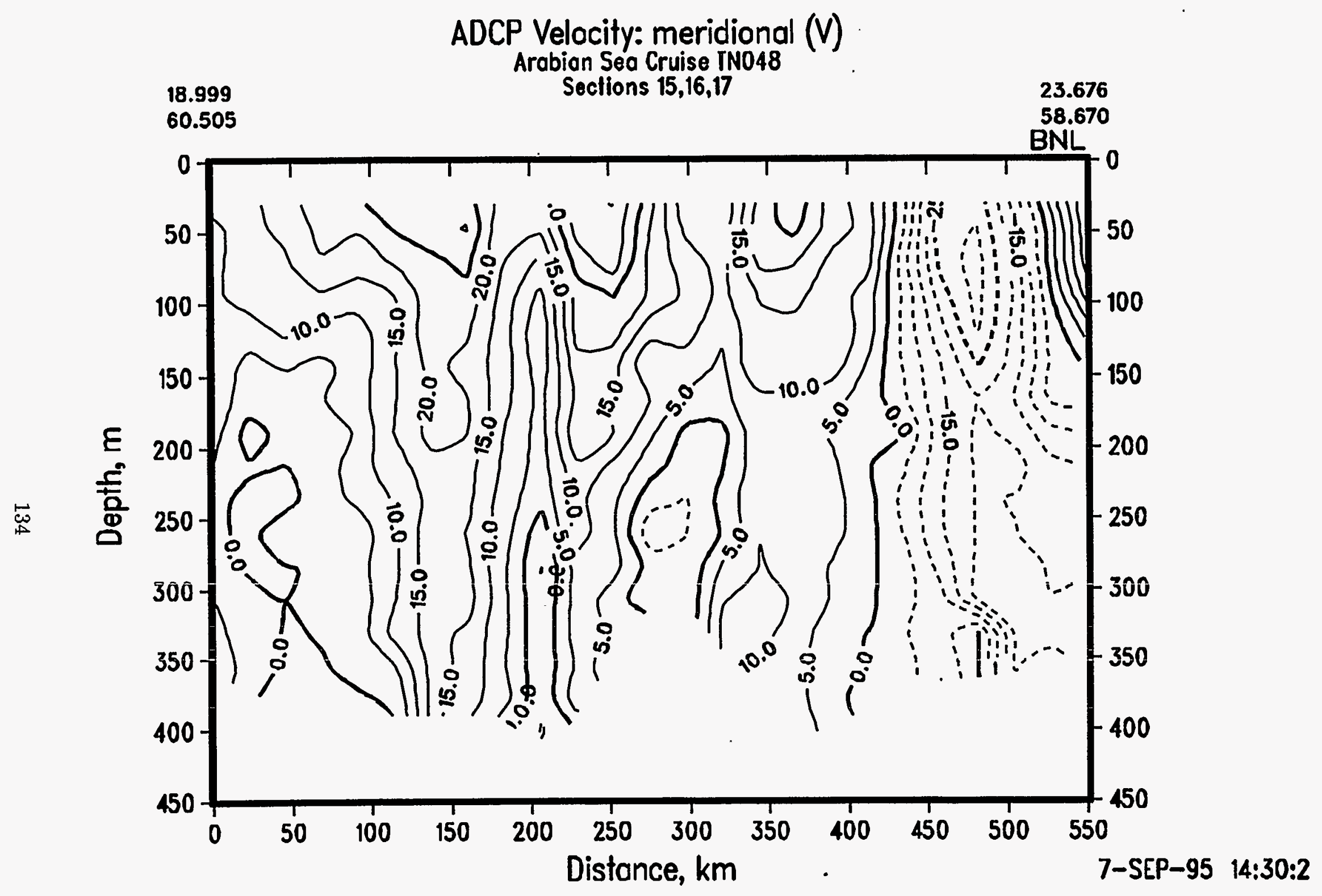




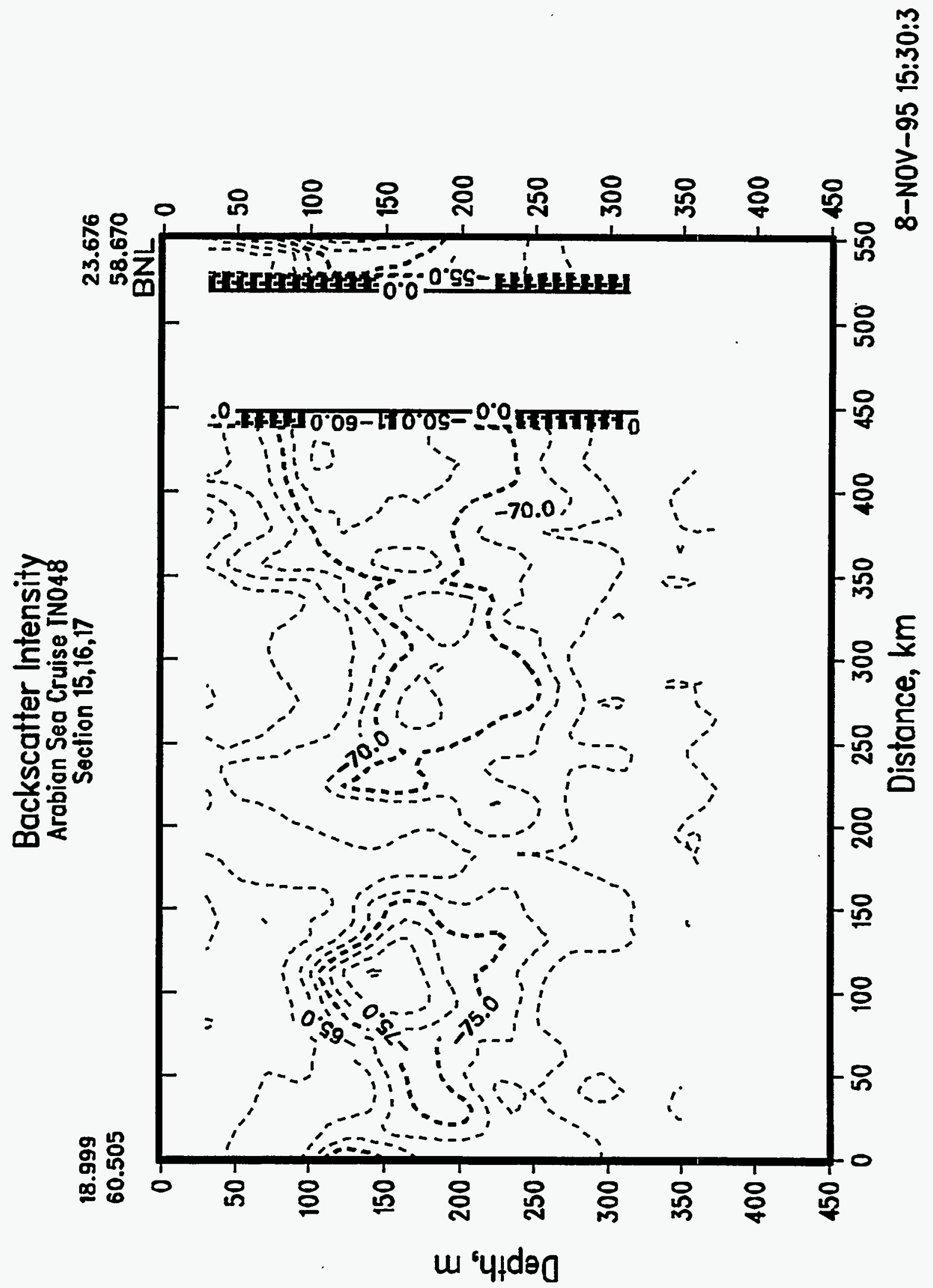


TN049 


\section{JGOFS Arabian Sea}

TN049 Whole Cruise (07/17/95 to 08/15/95) Current Velocity $20 \mathrm{~m}$ to $50 \mathrm{~m}$

BNL

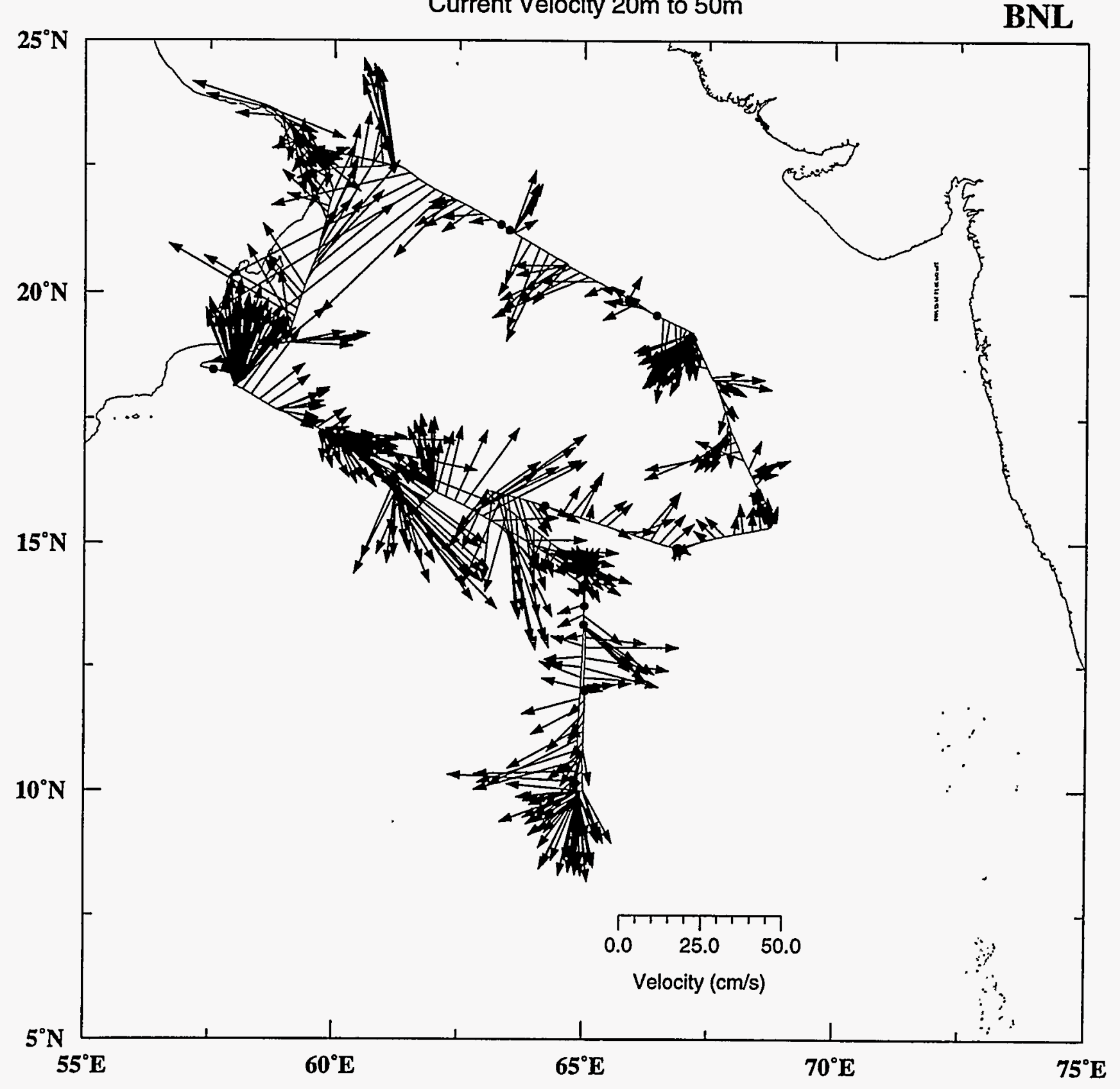




\section{JGOFS Arabian Sea}

TN049 Whole Cruise (07/17/95 to 08/15/95)

Layer: $50 \mathrm{~m}$ to $100 \mathrm{~m}$

BNL

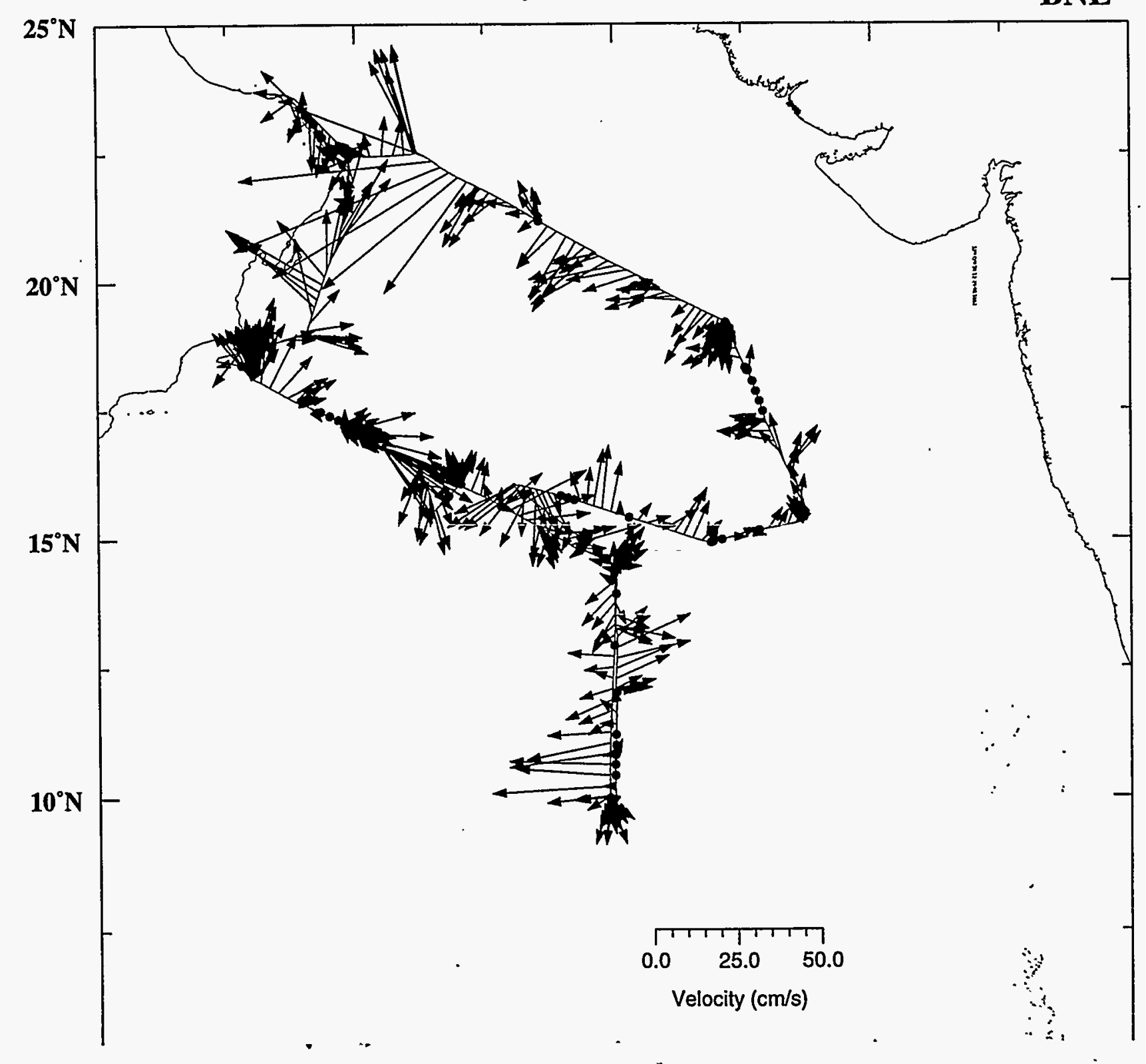




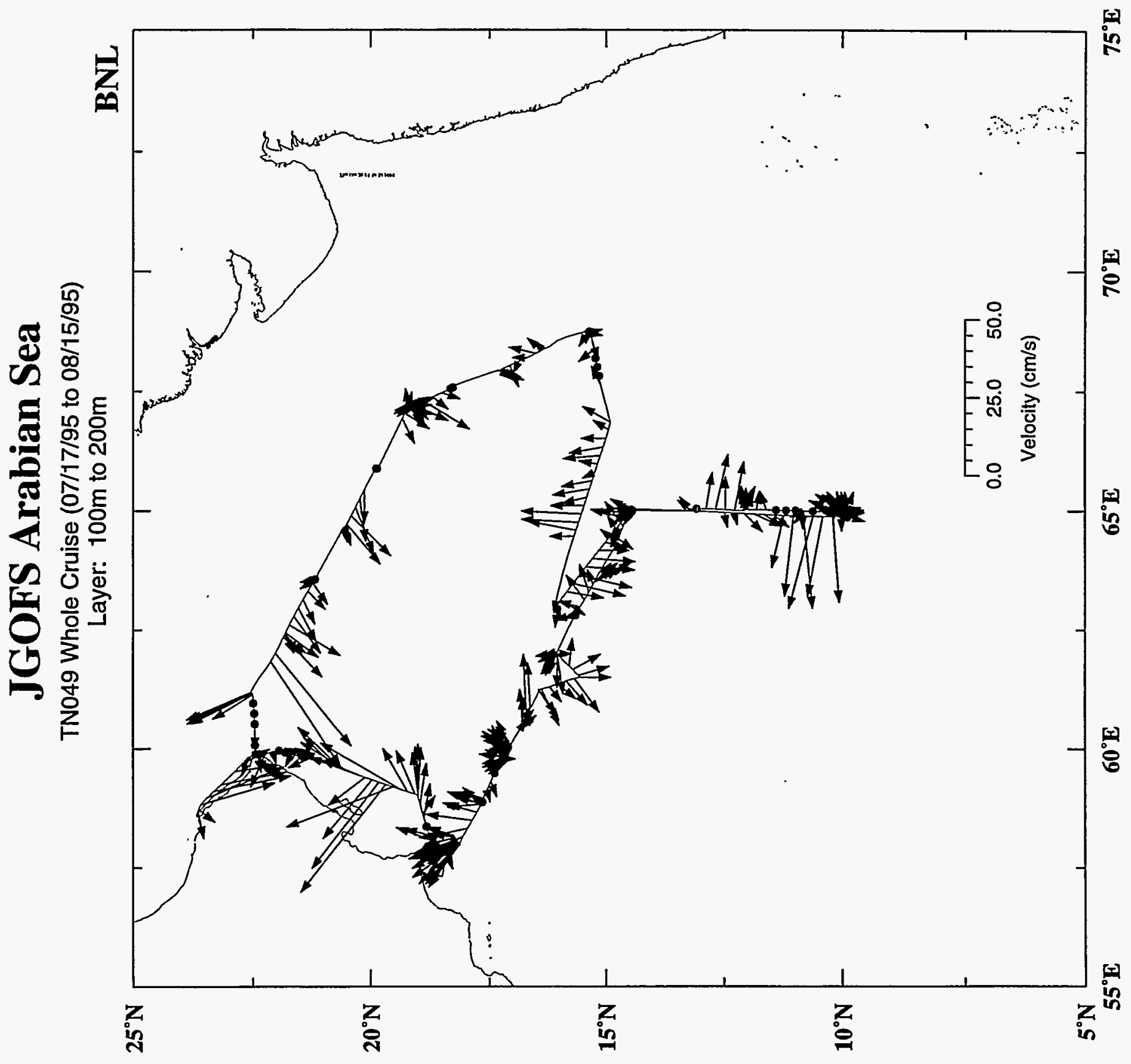




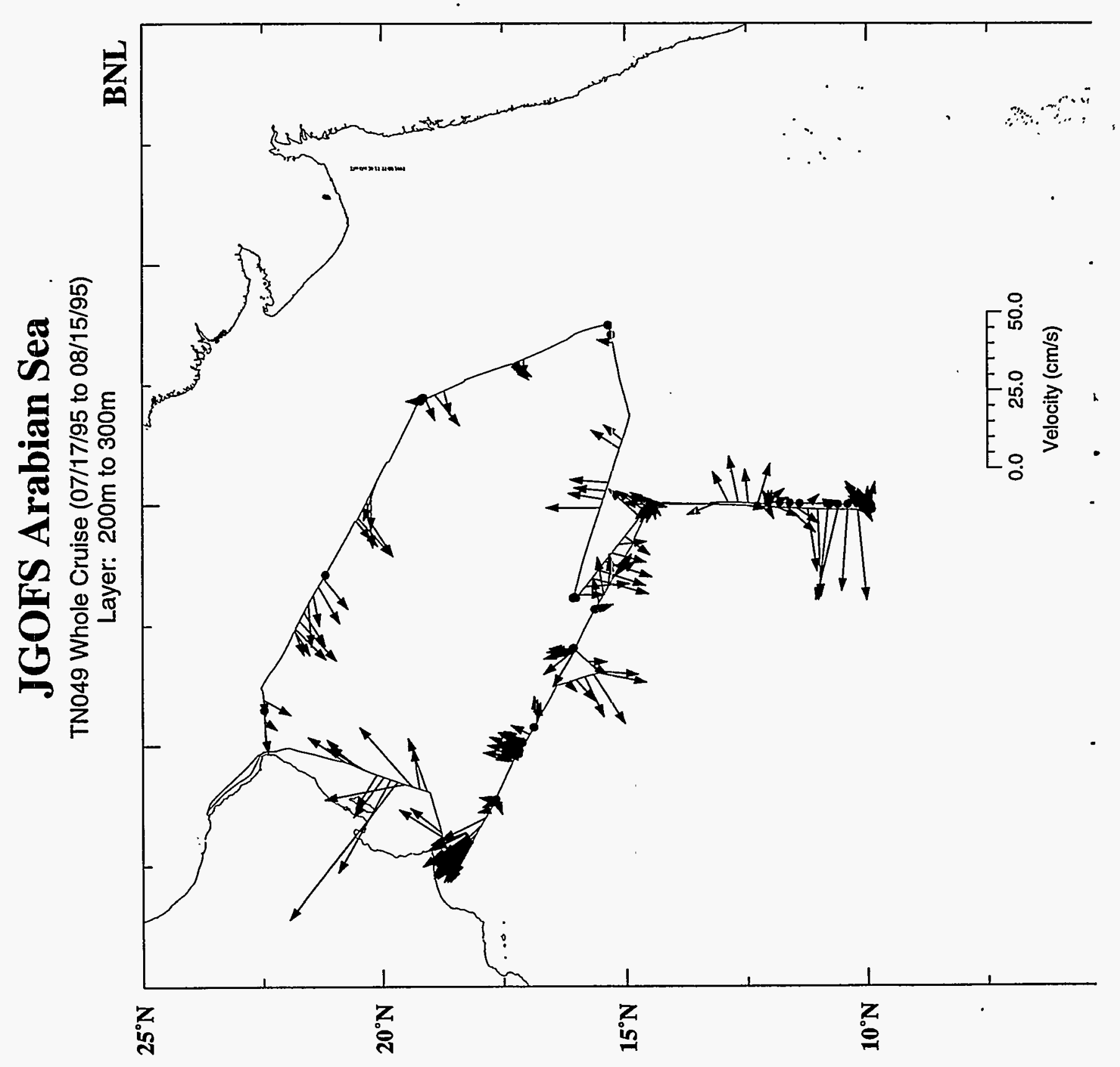




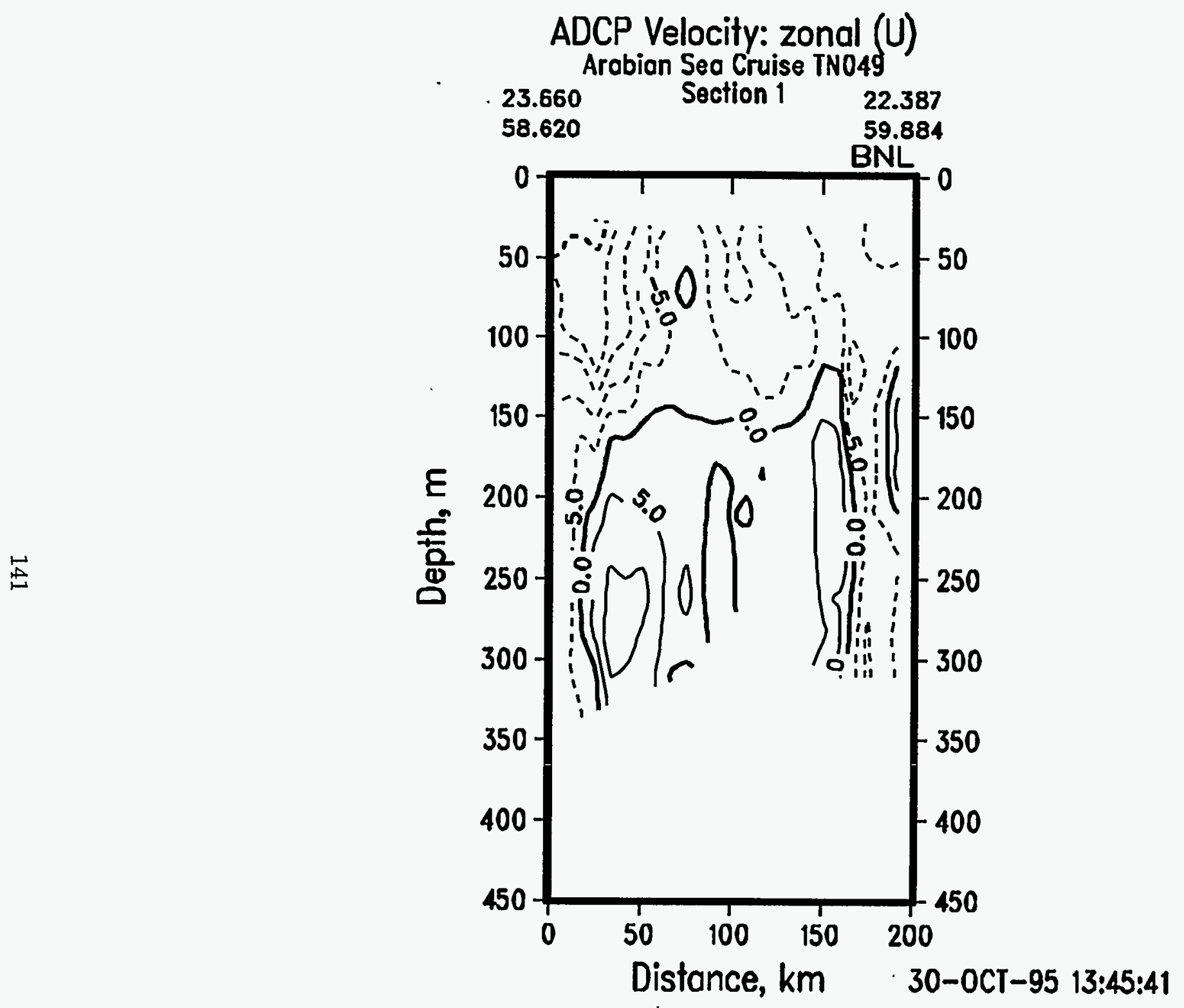




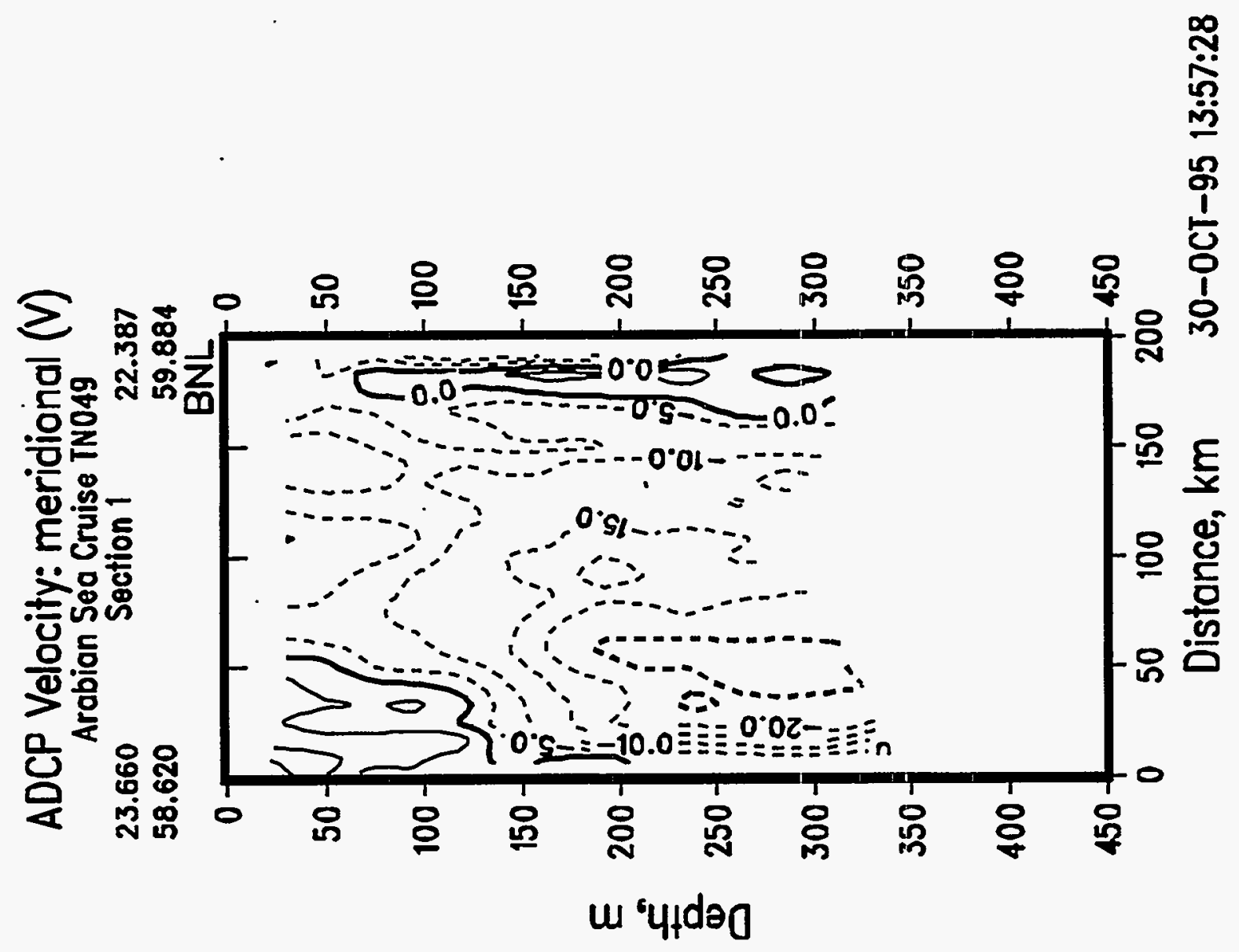




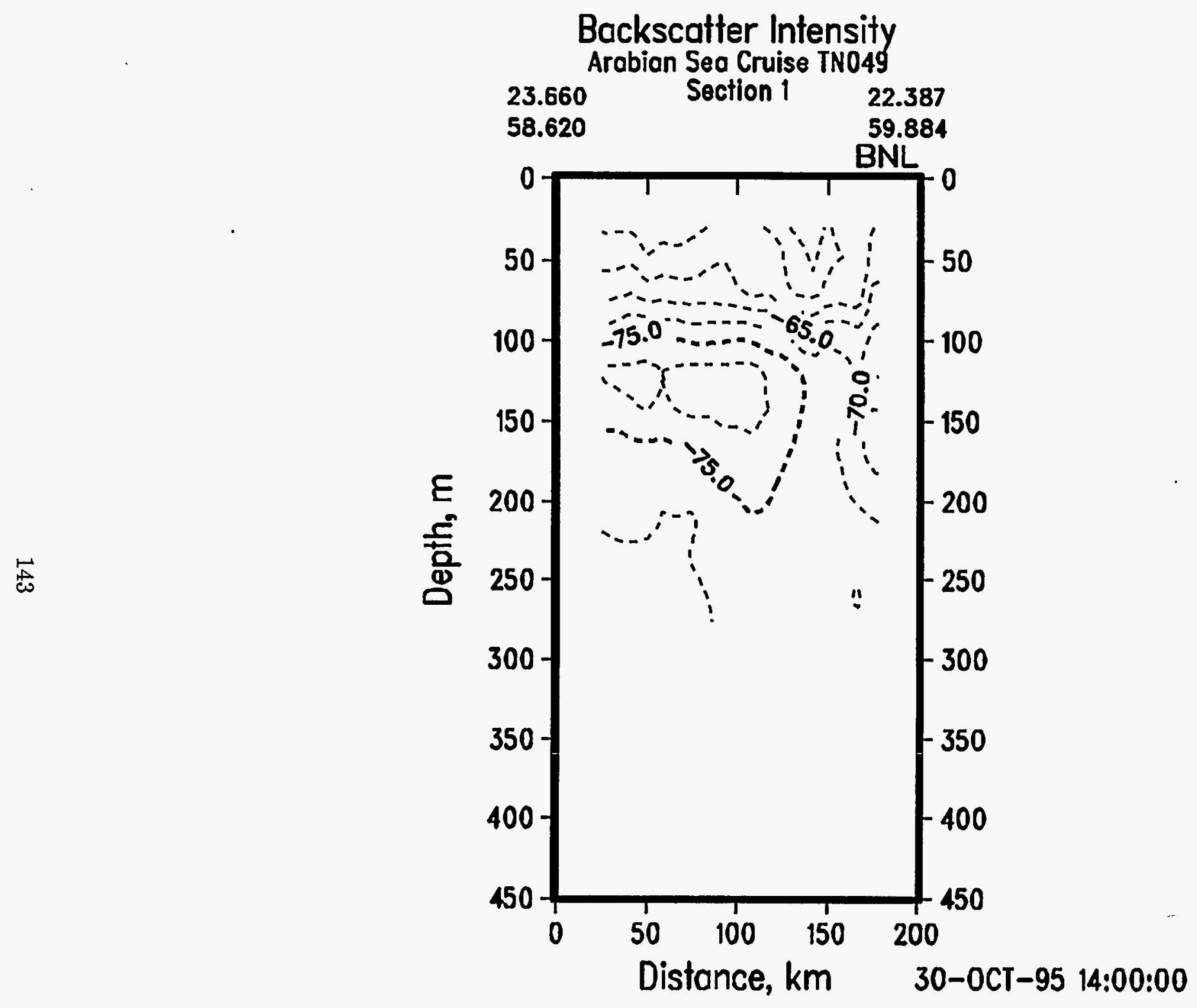




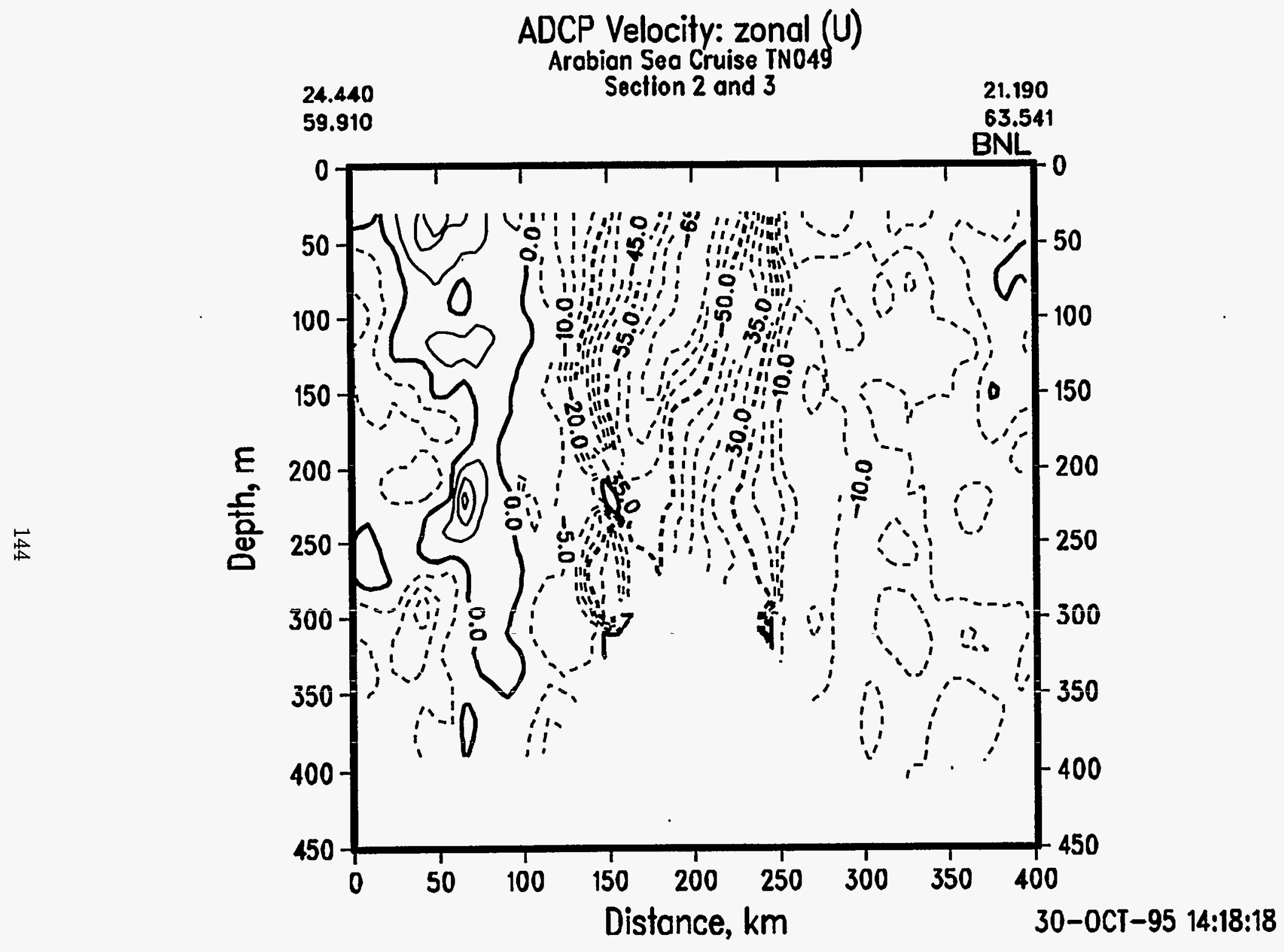




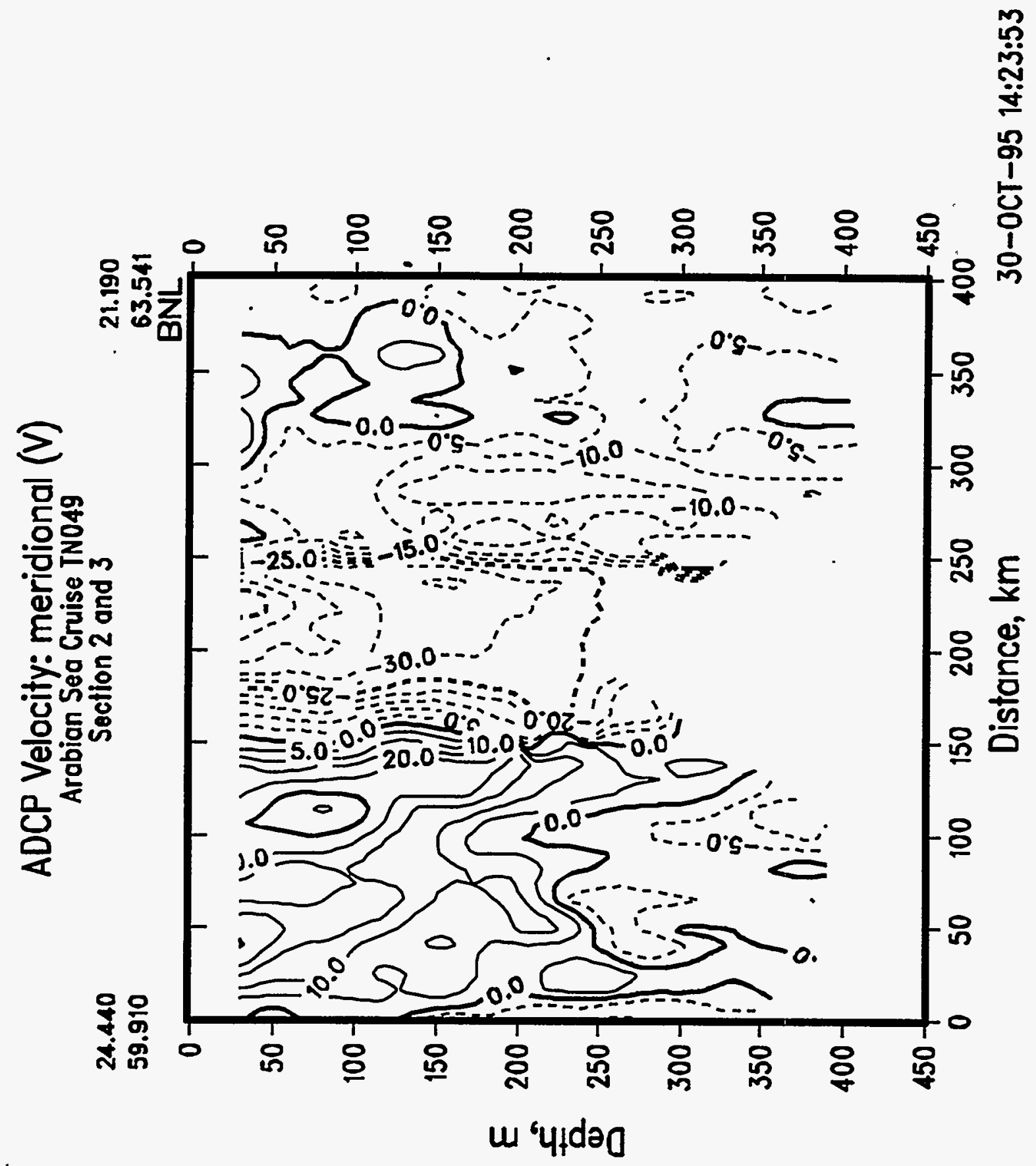




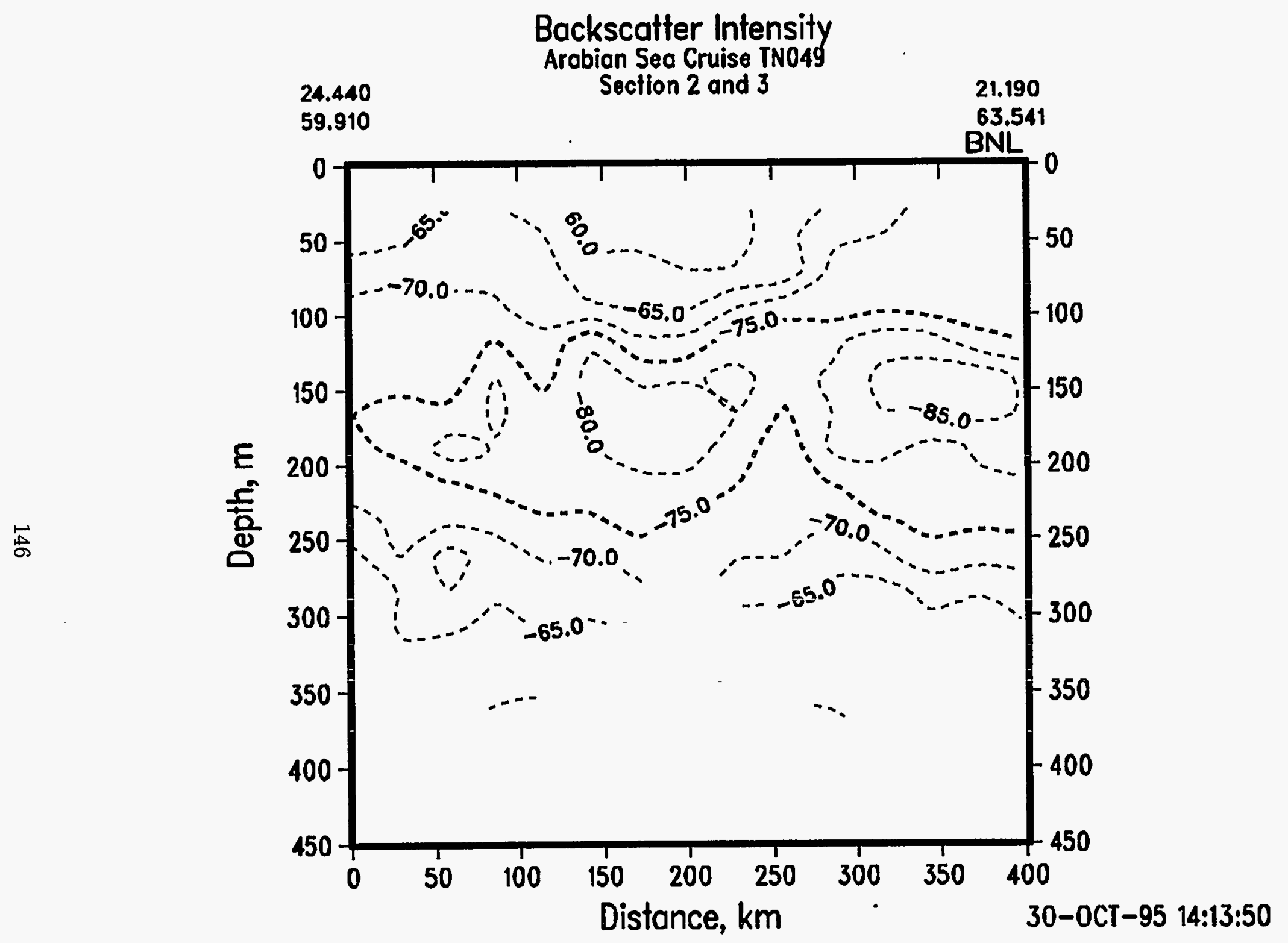




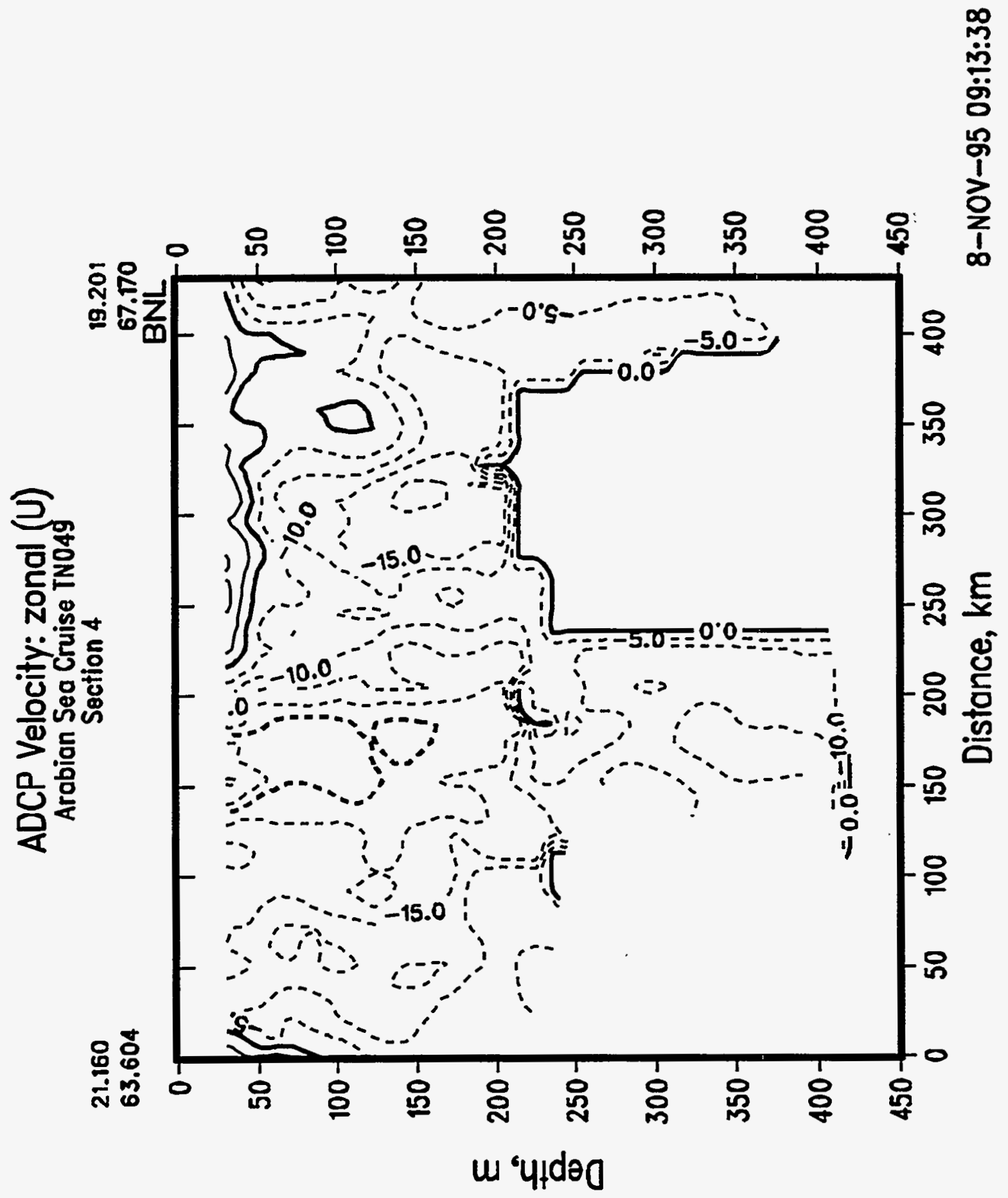




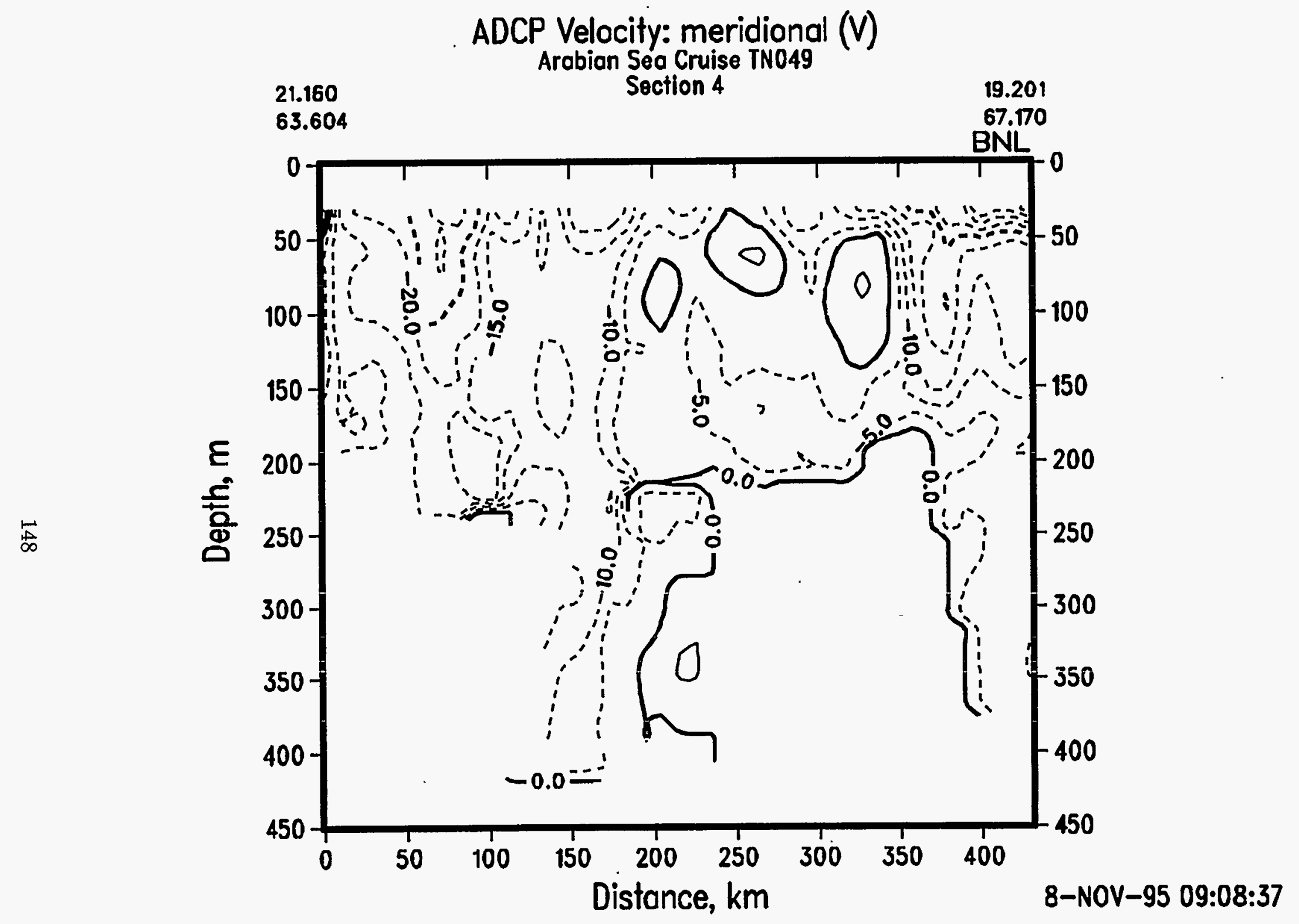




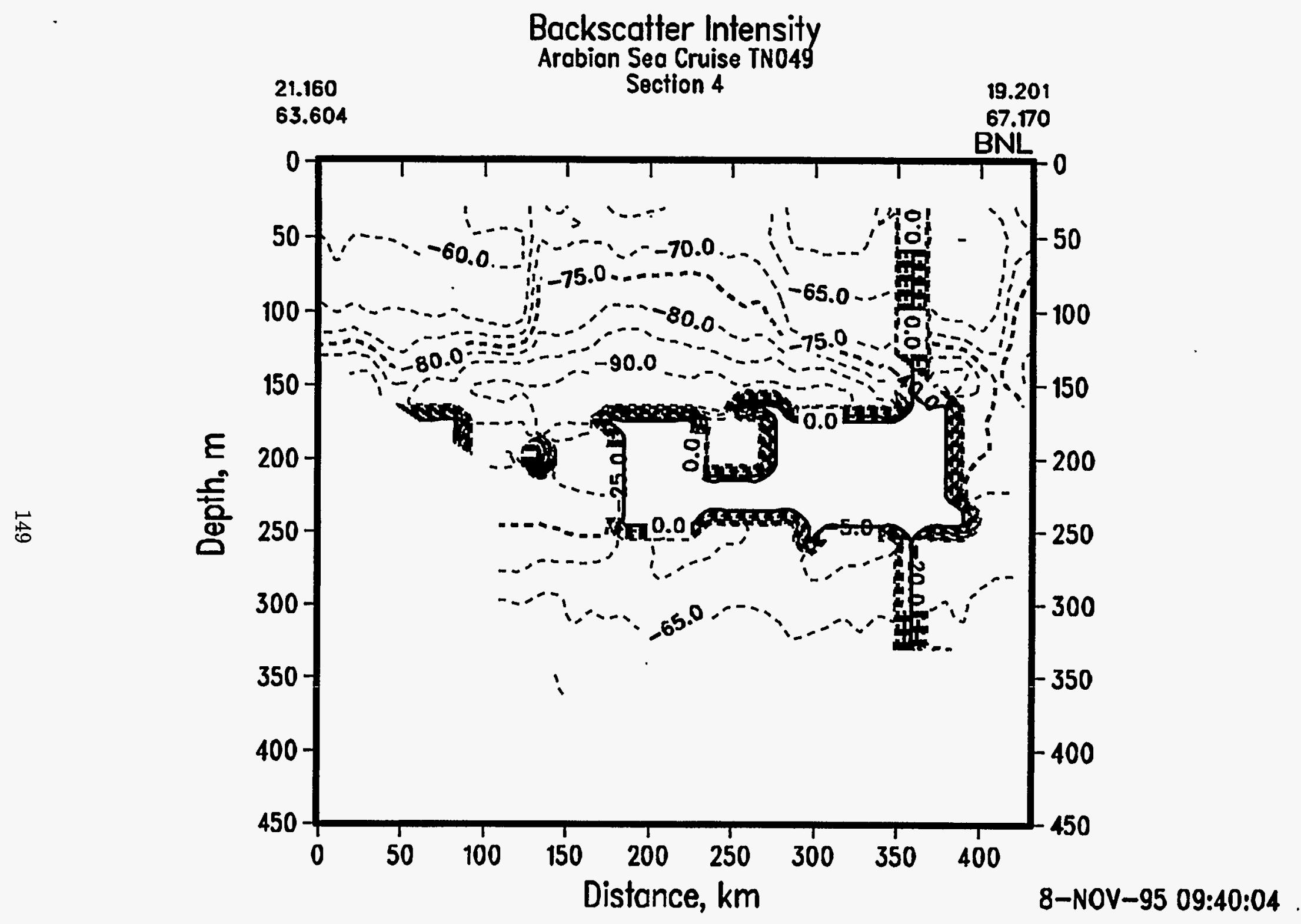




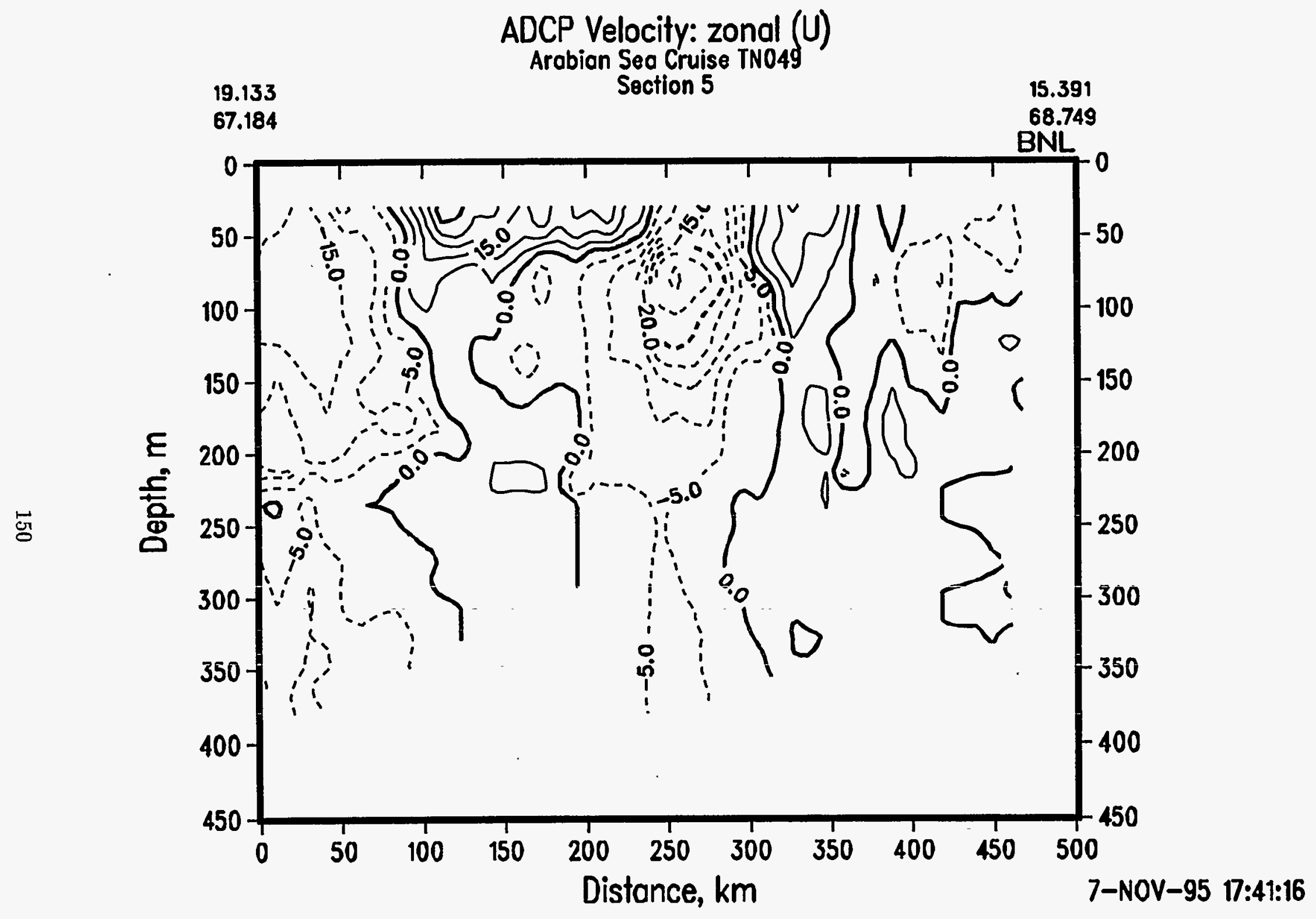




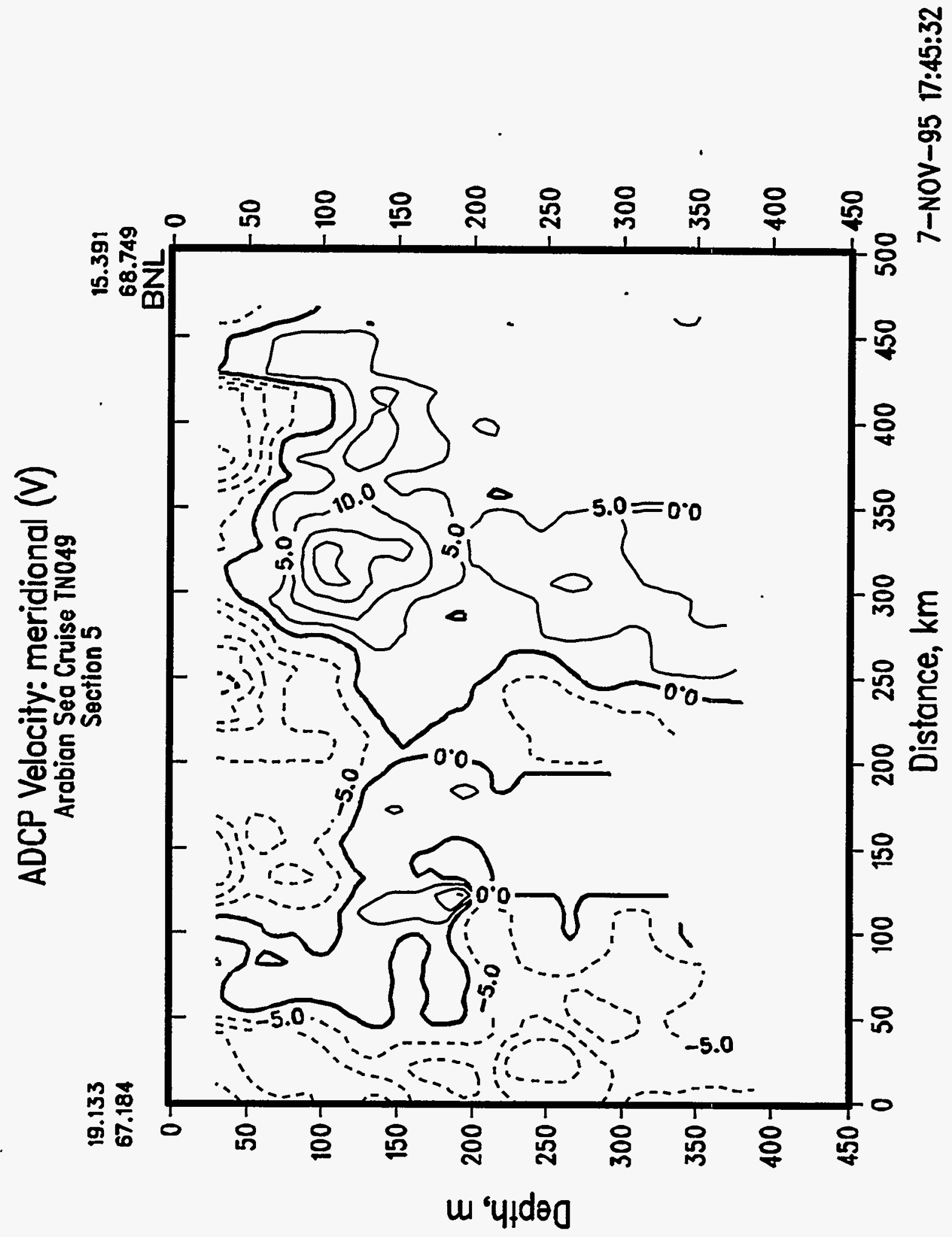




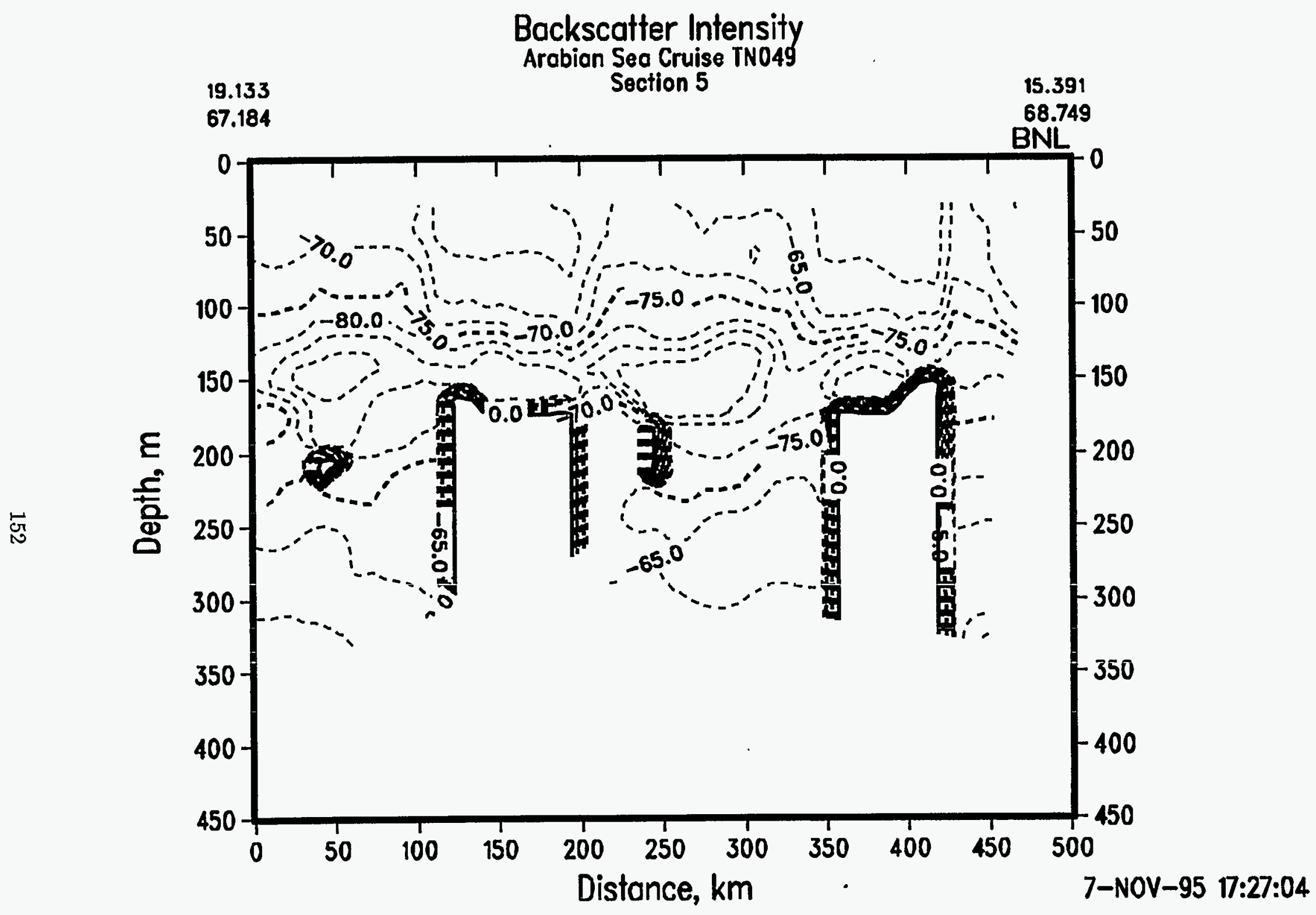




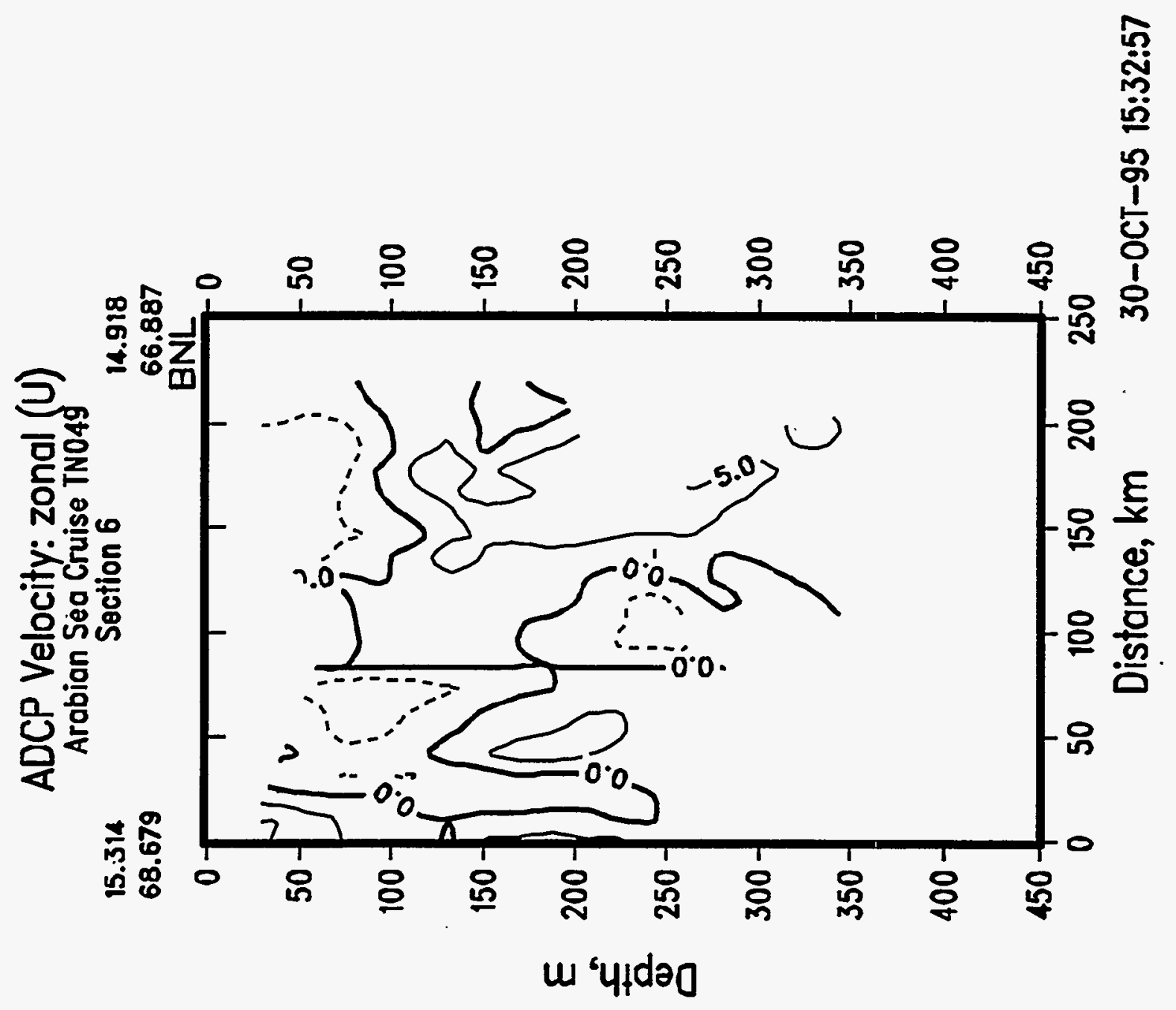




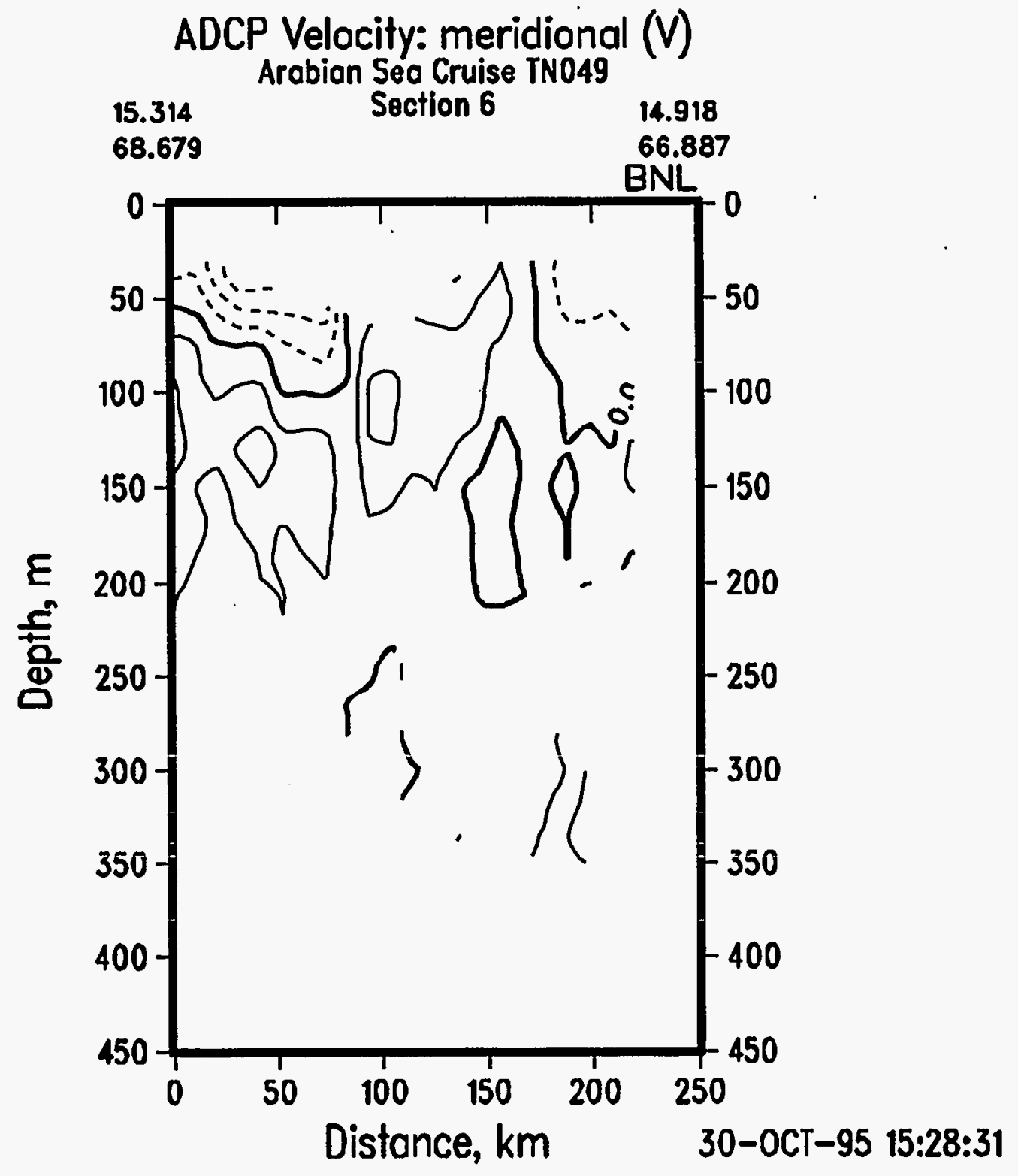




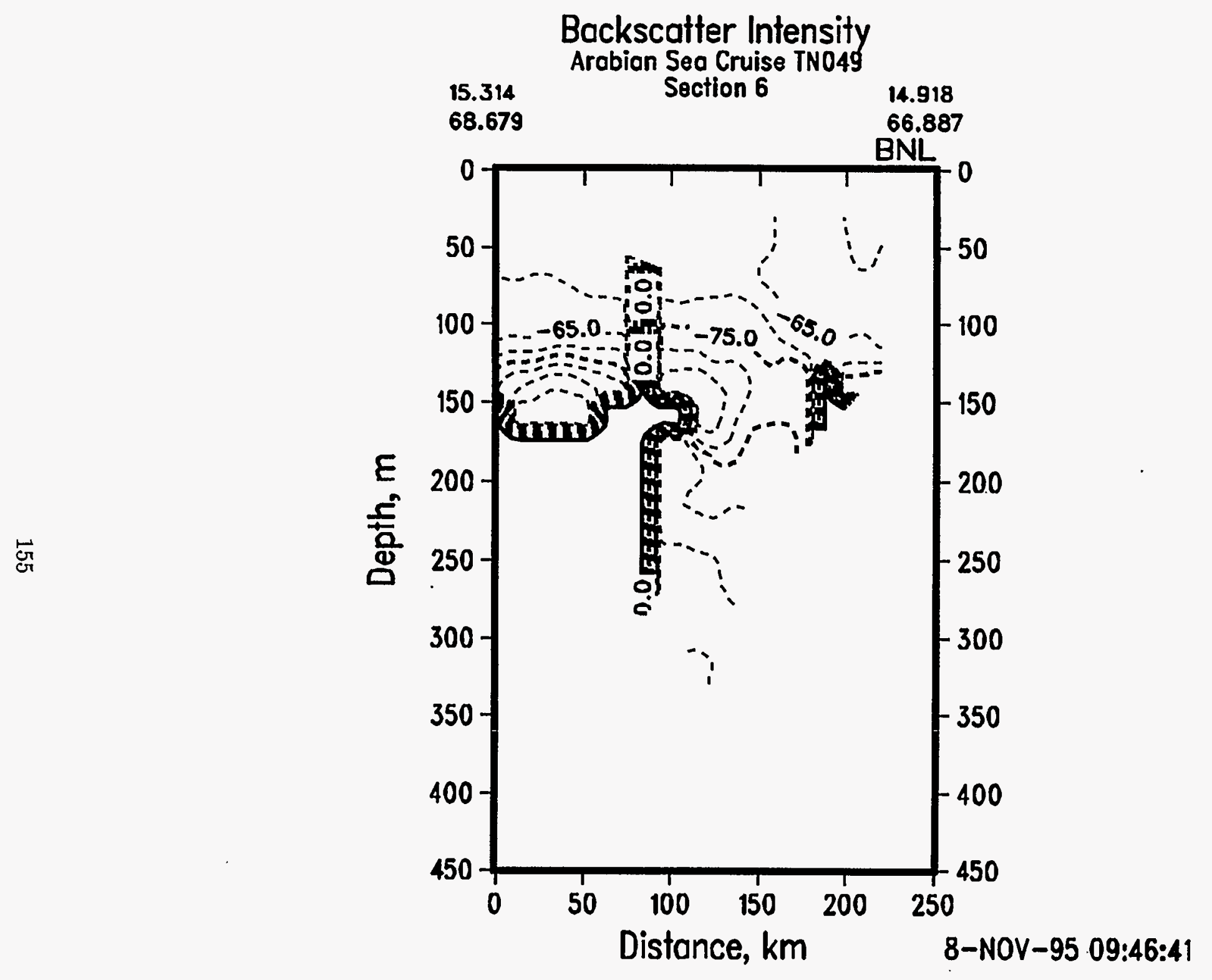




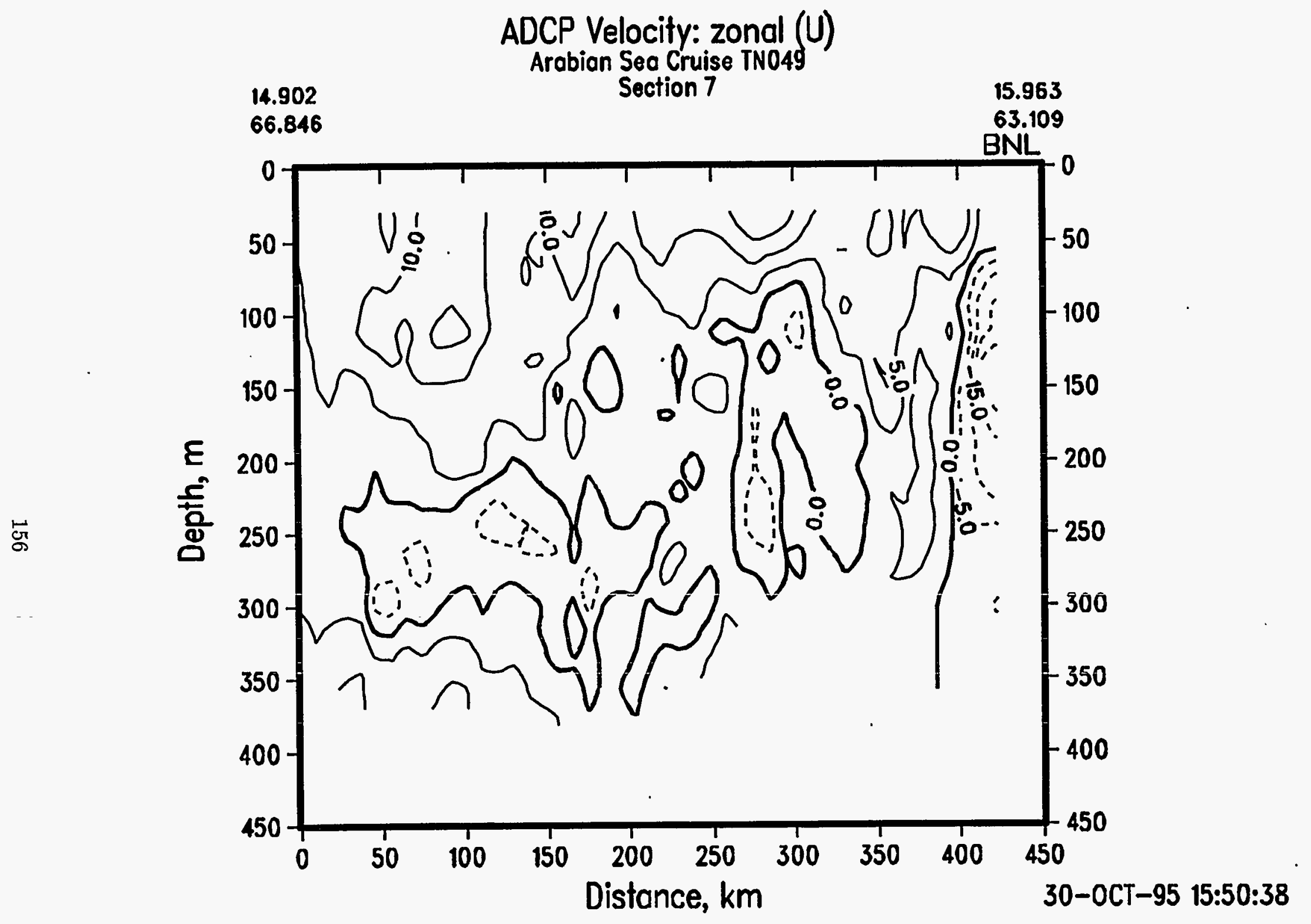




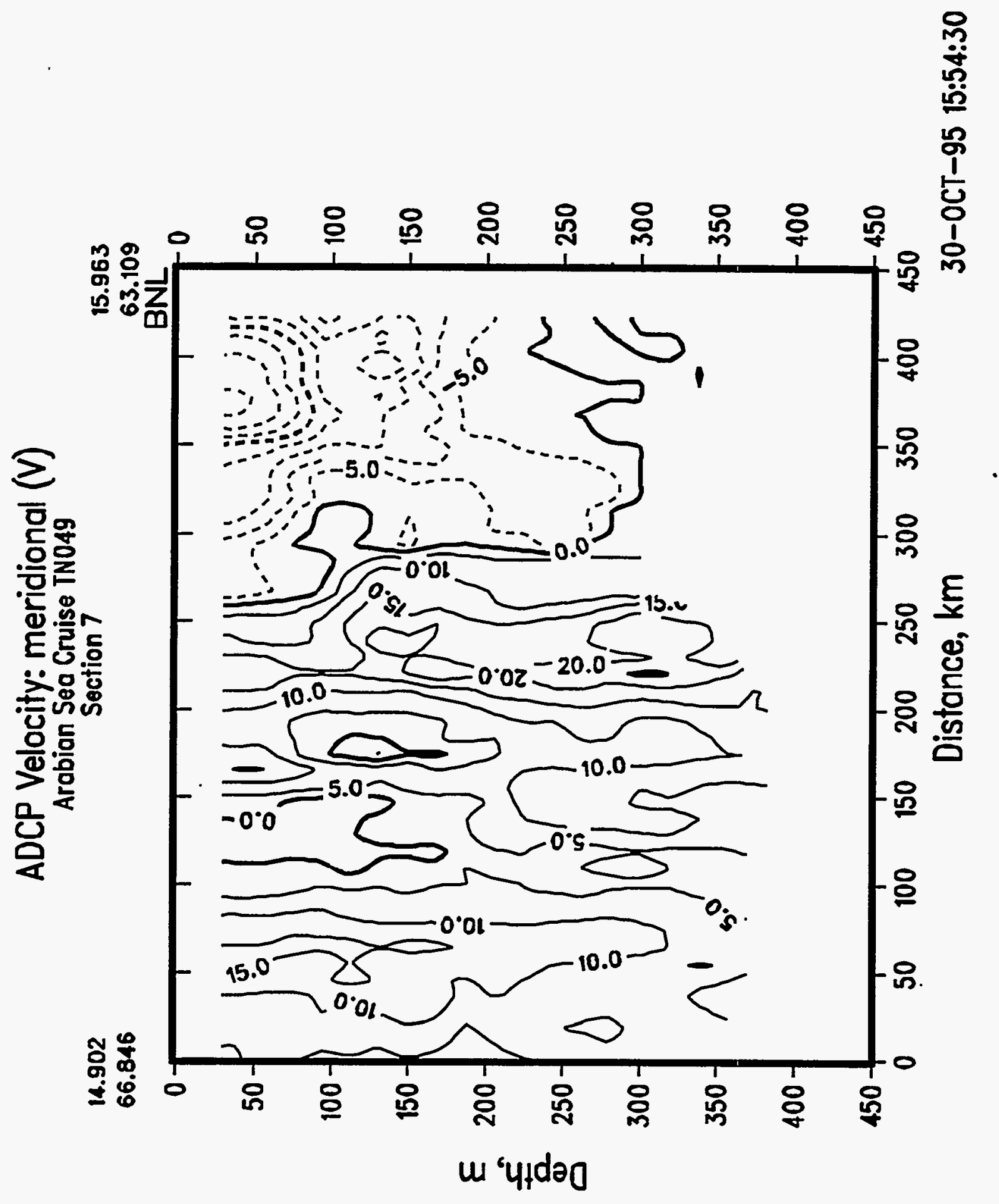




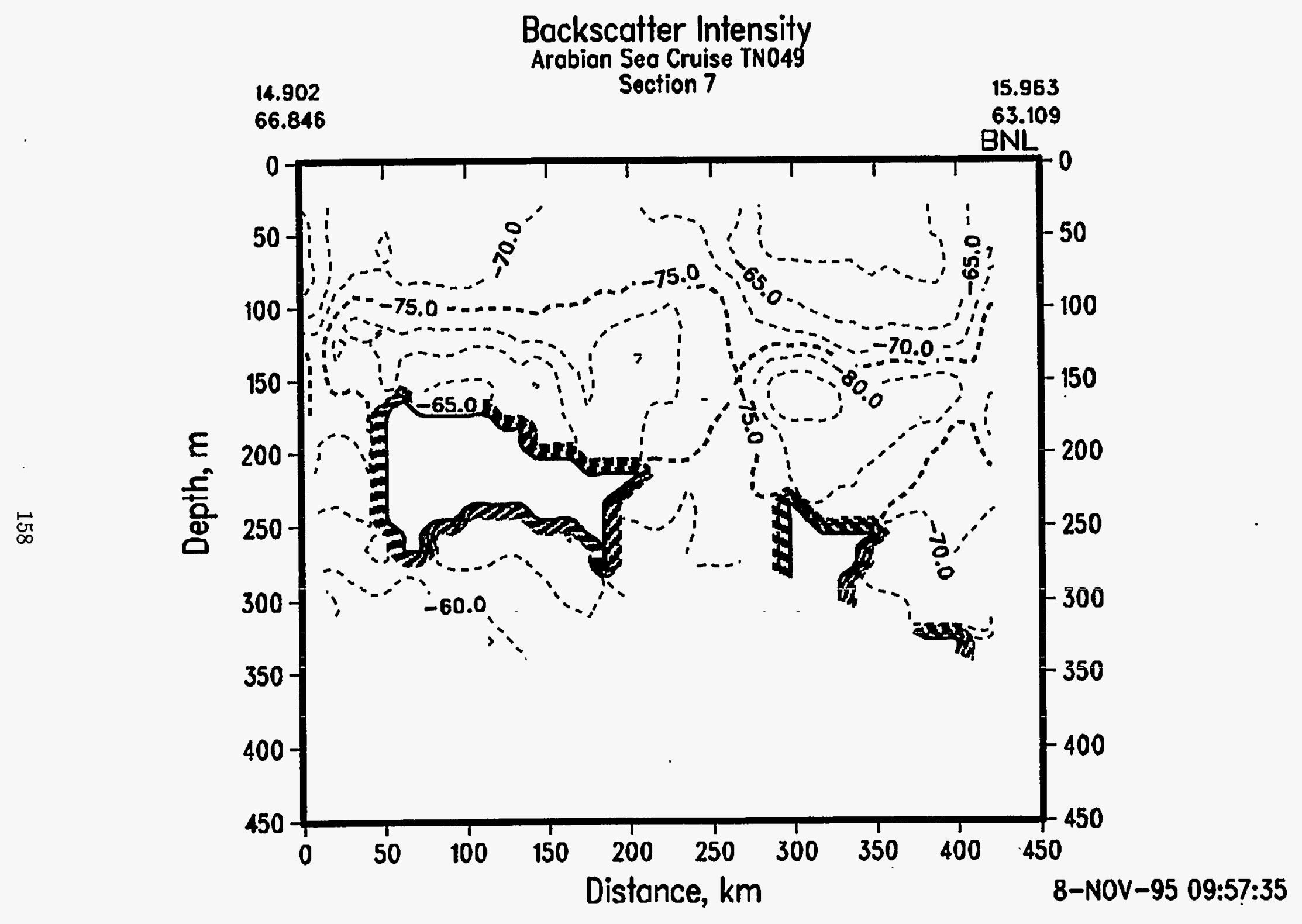




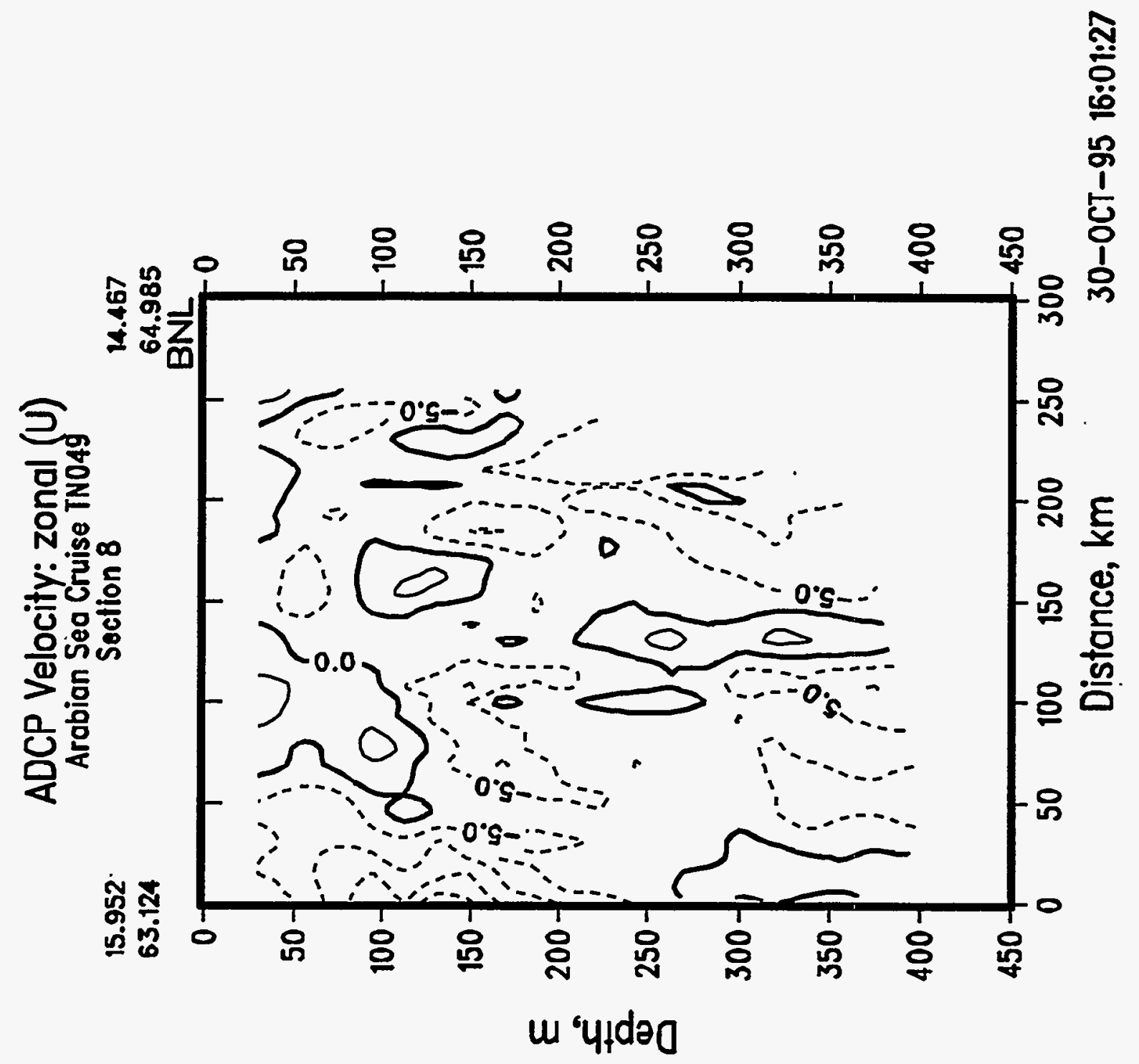




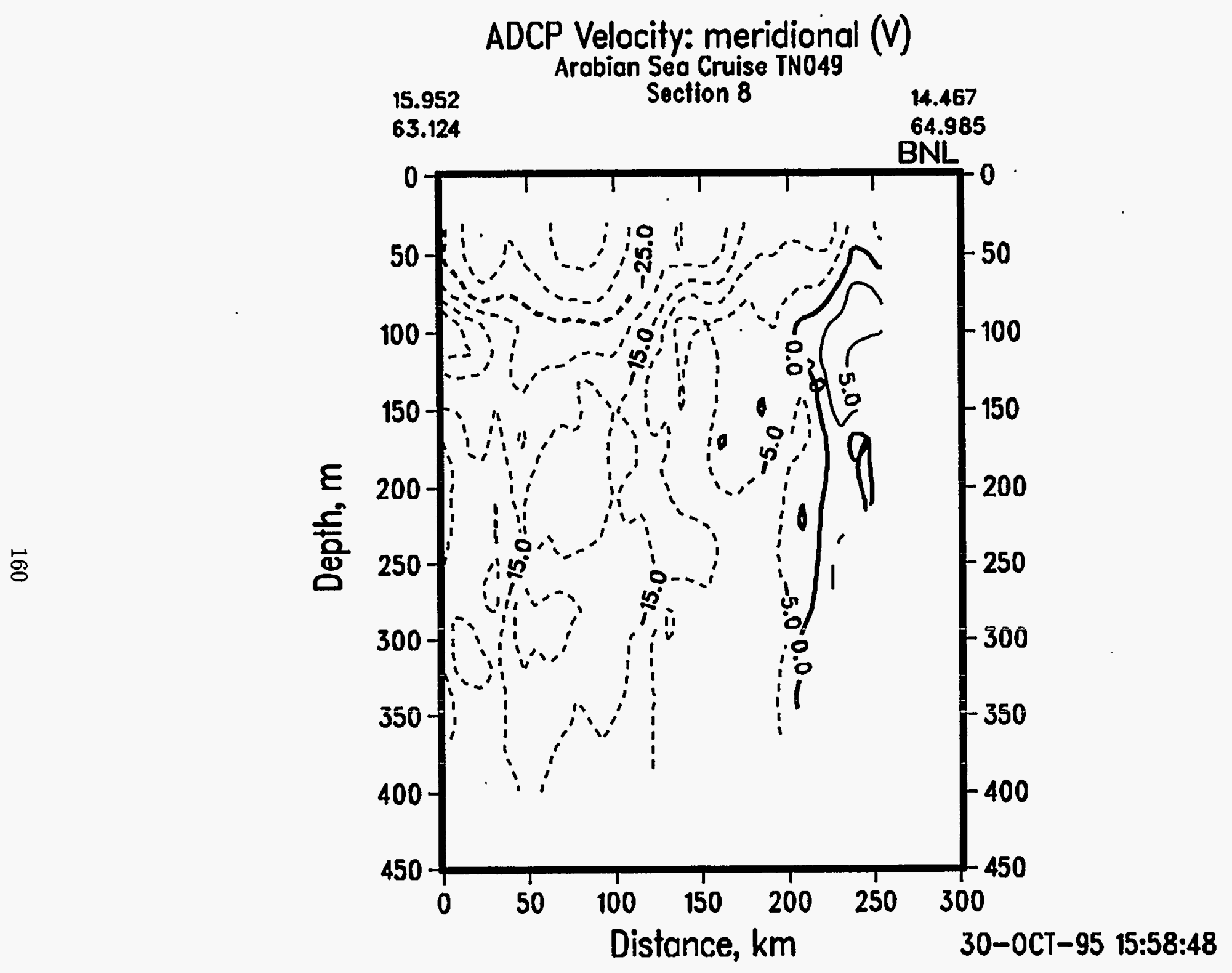




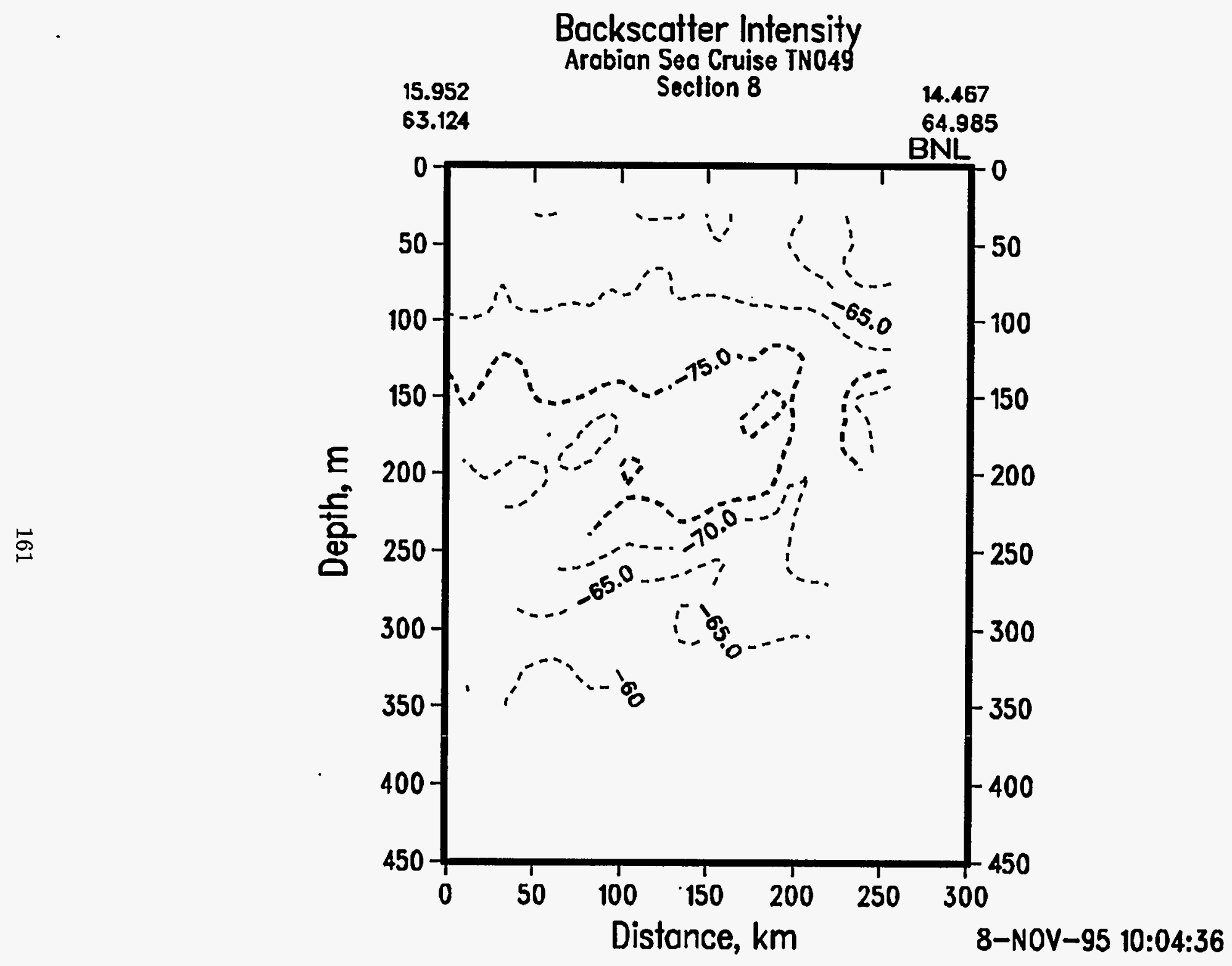




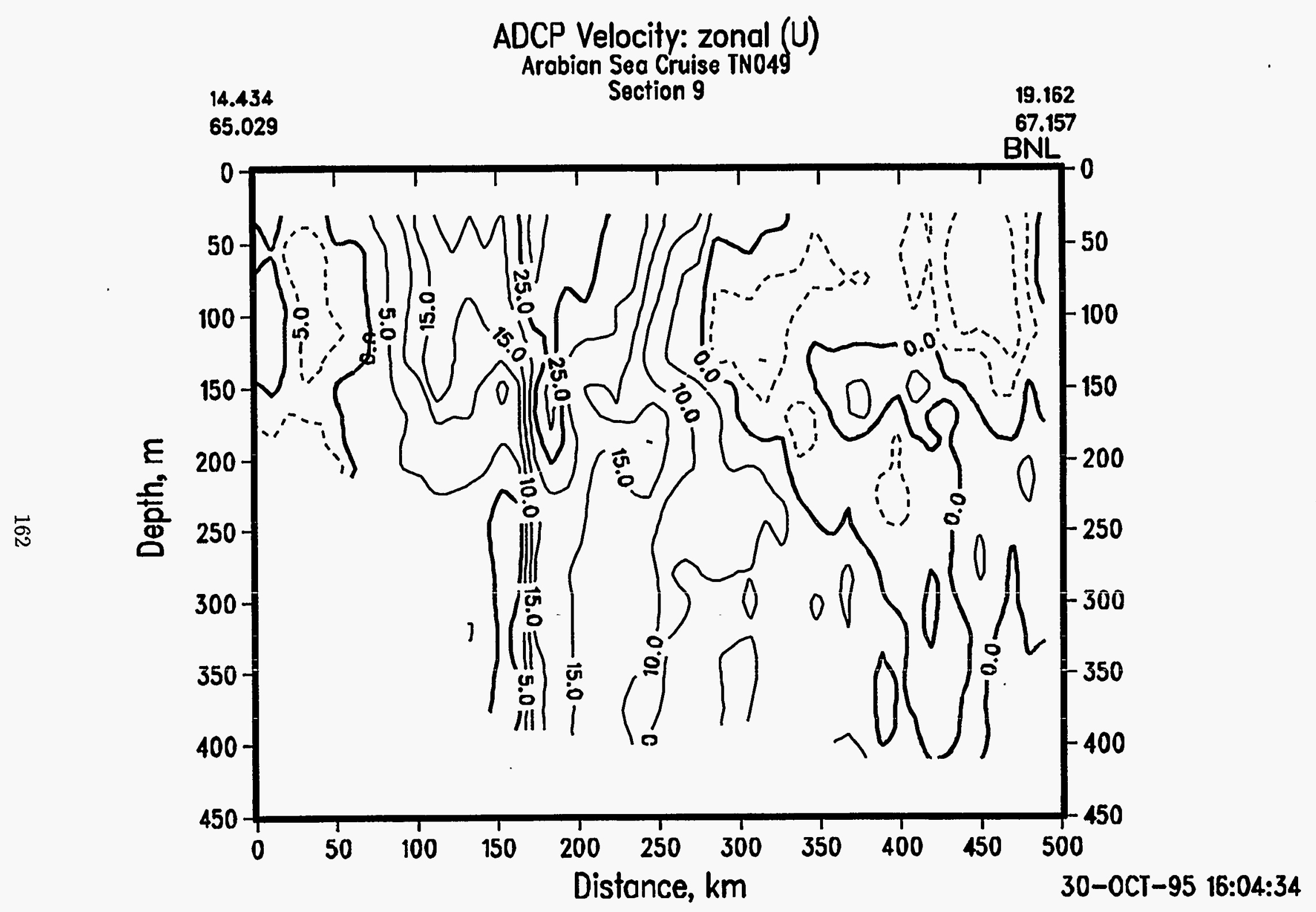




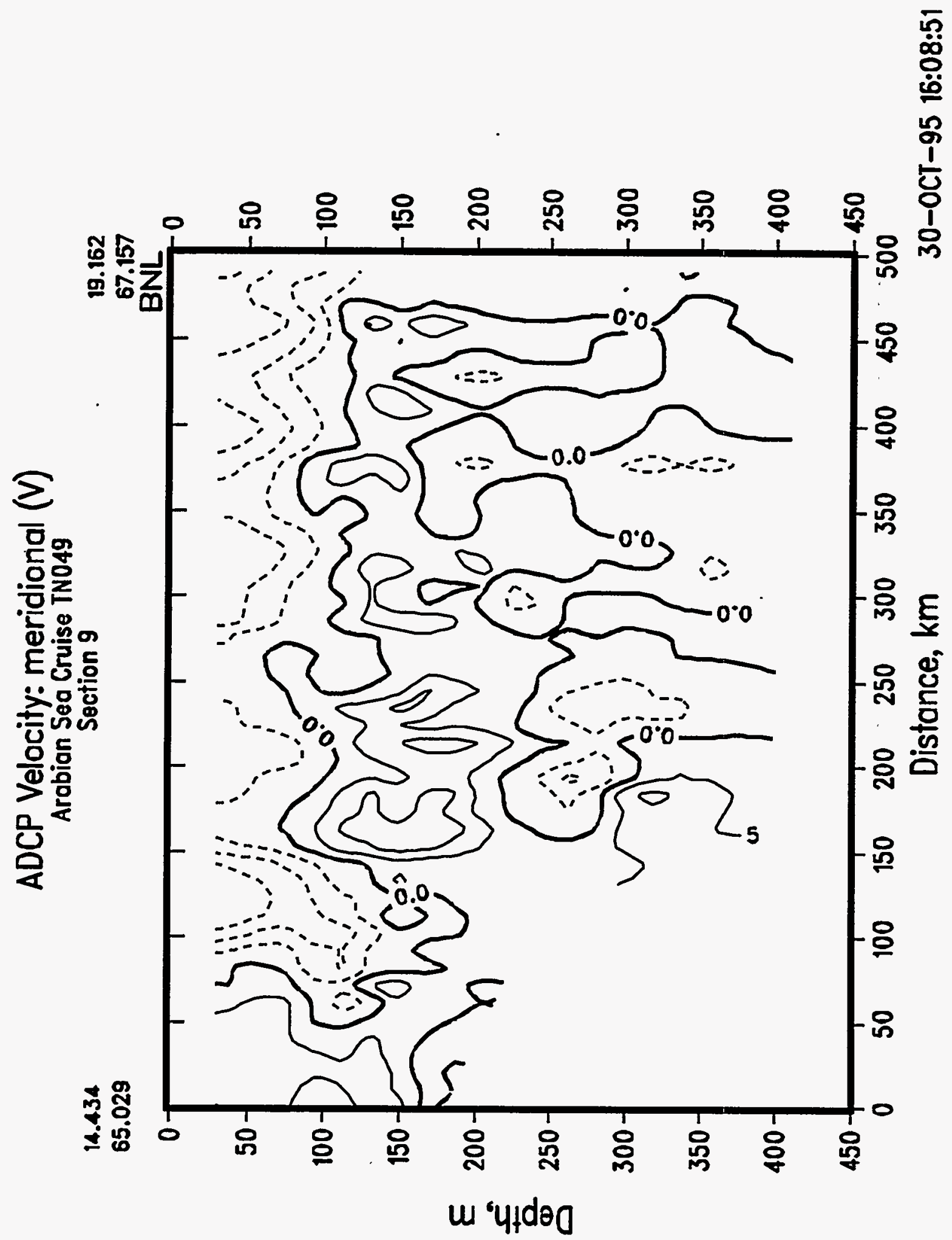




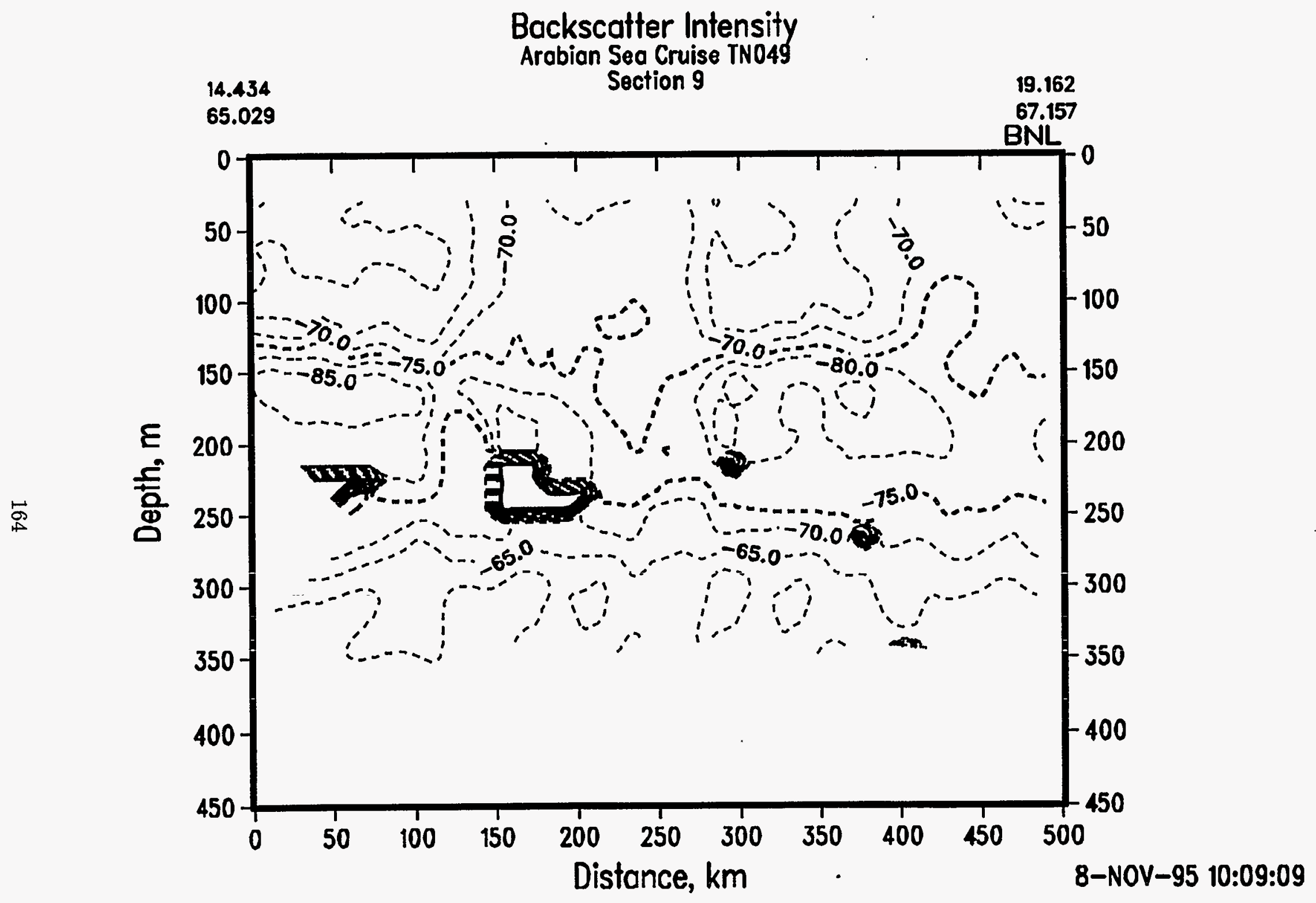




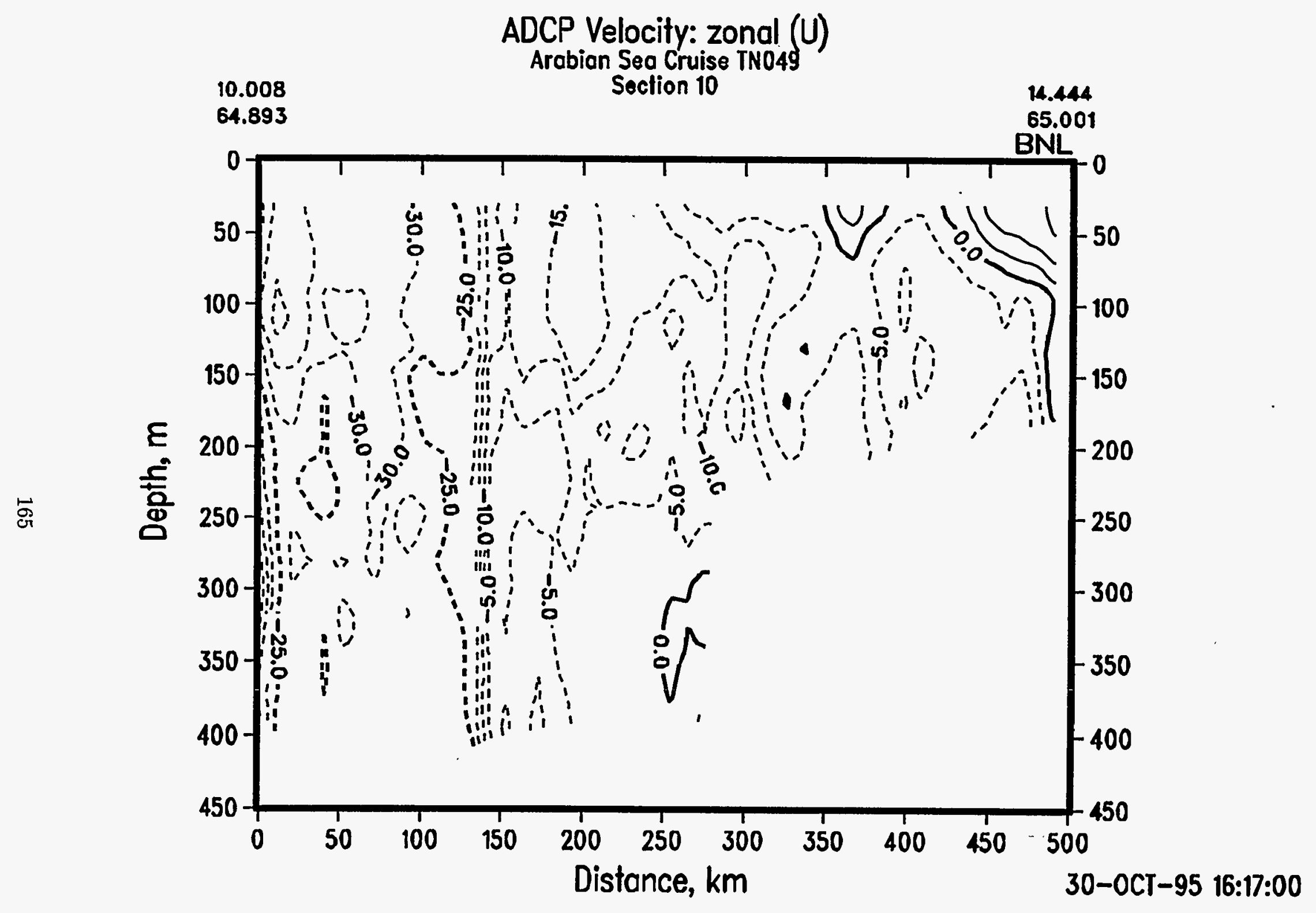




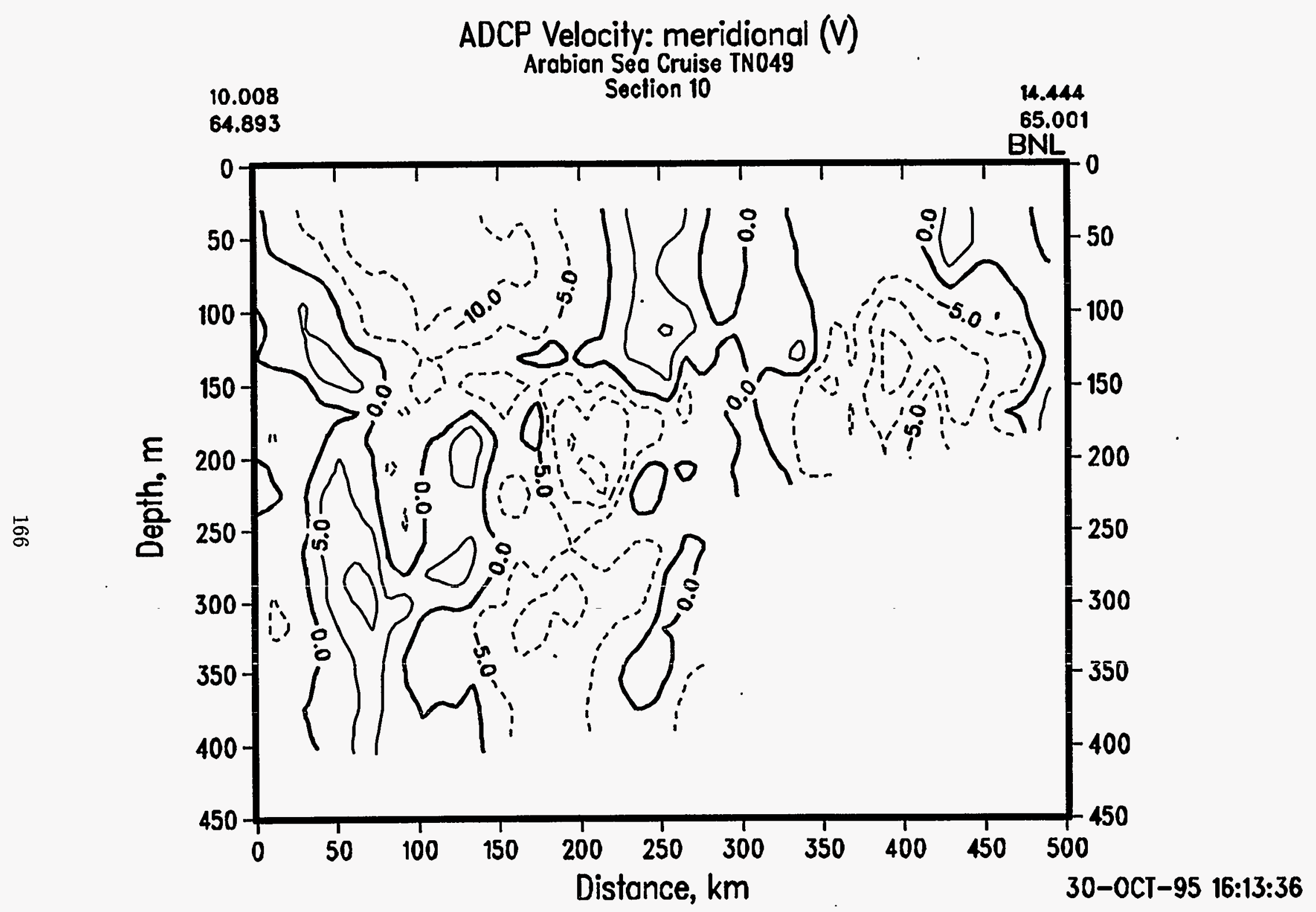




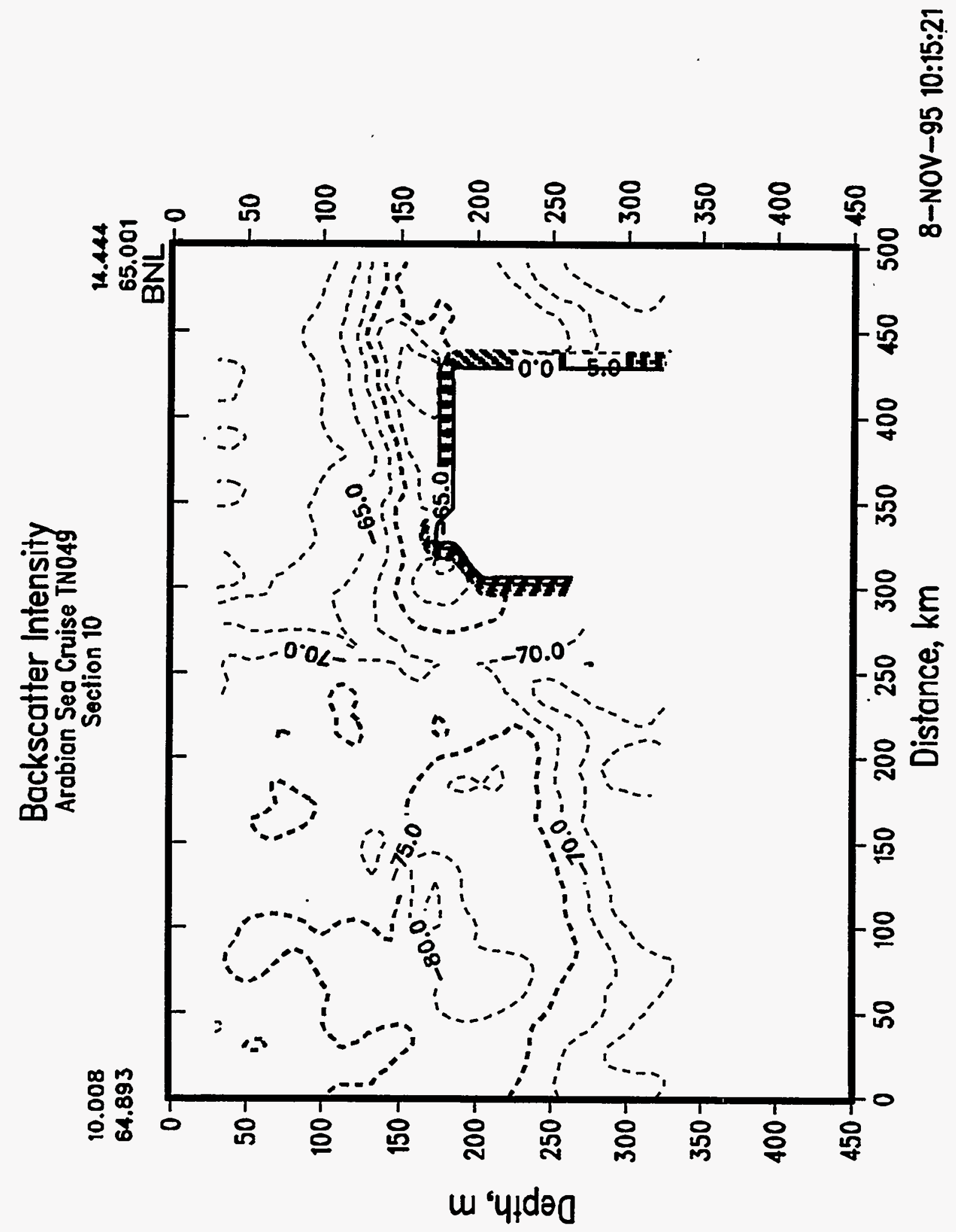




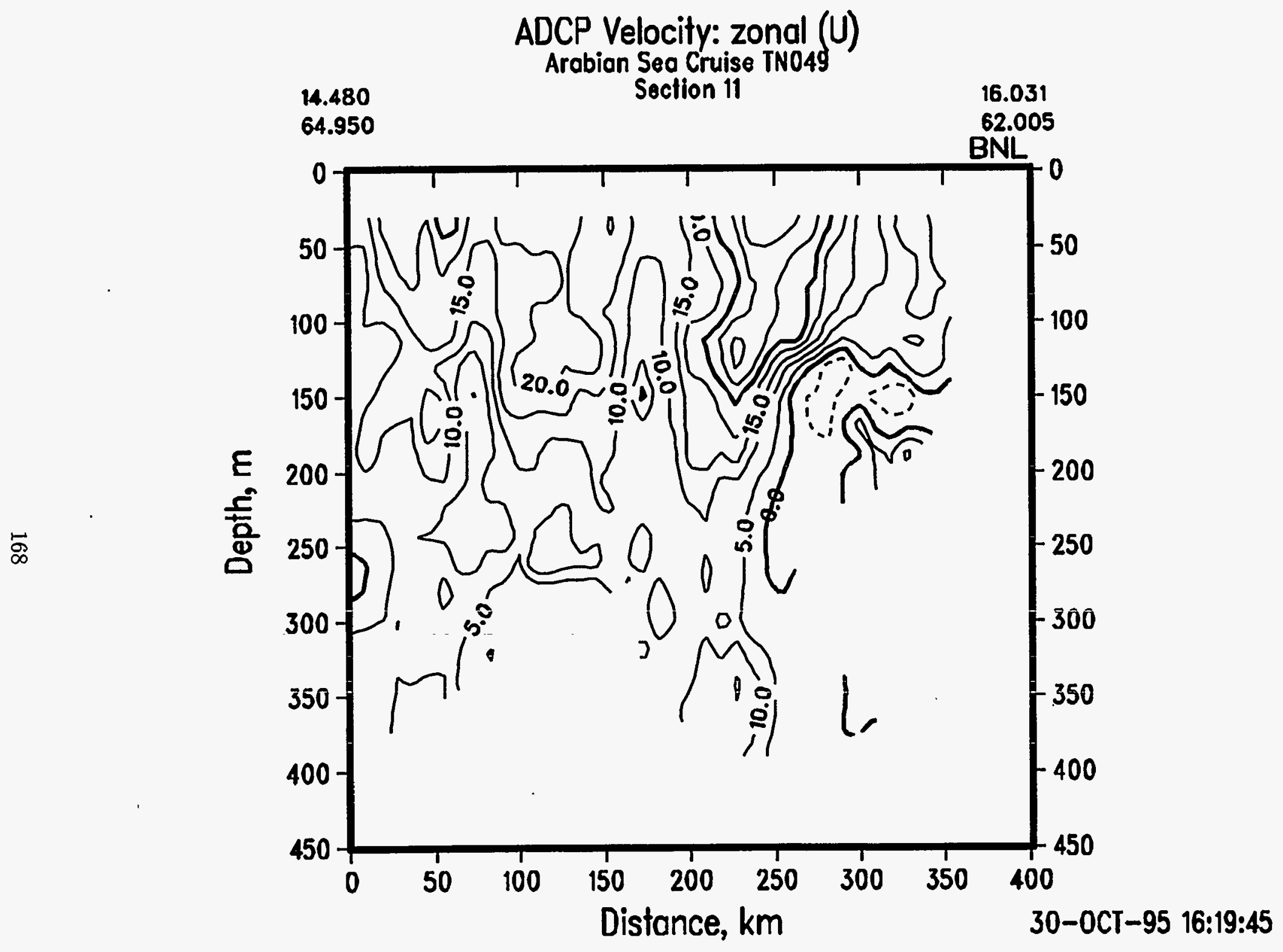




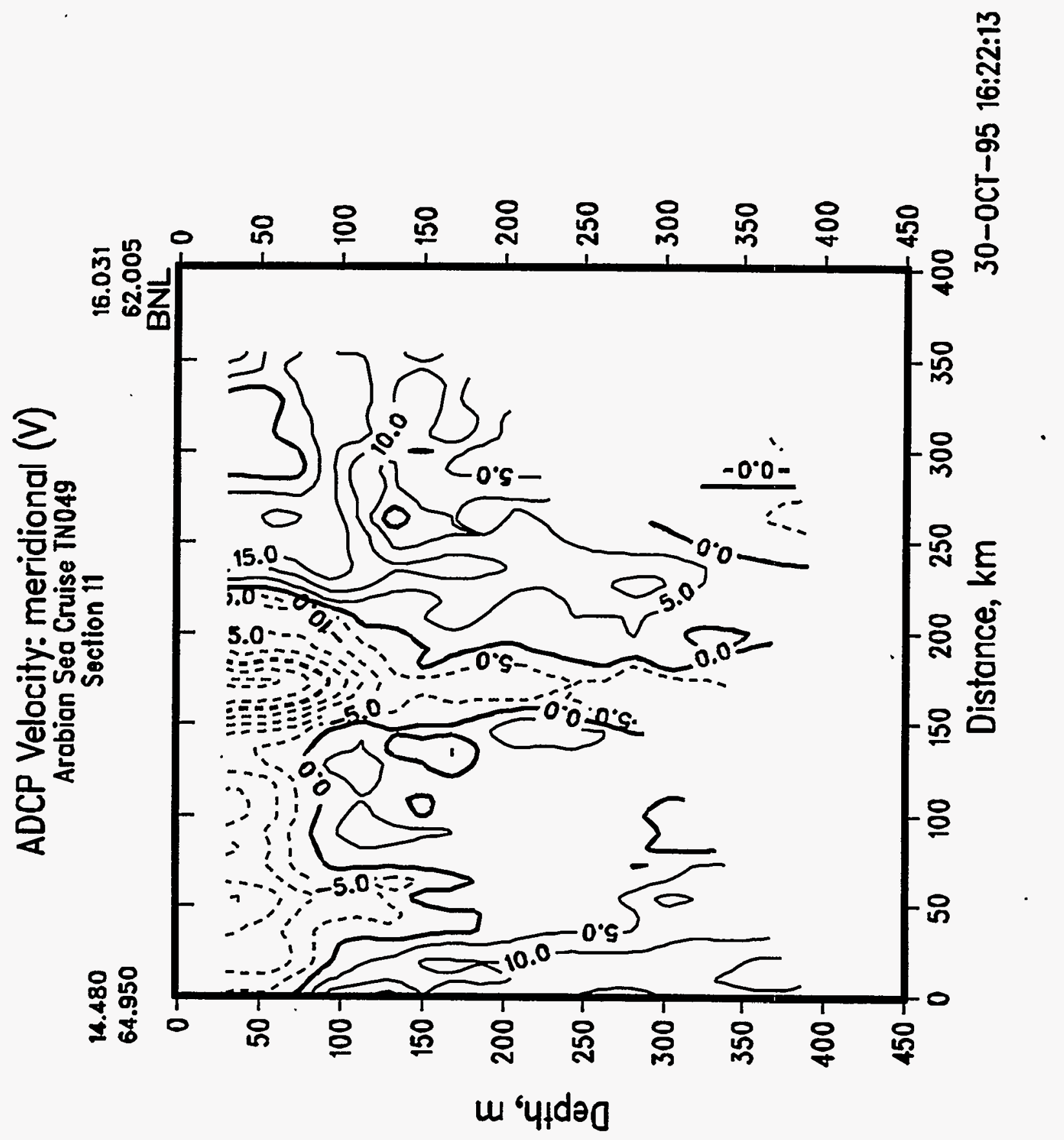




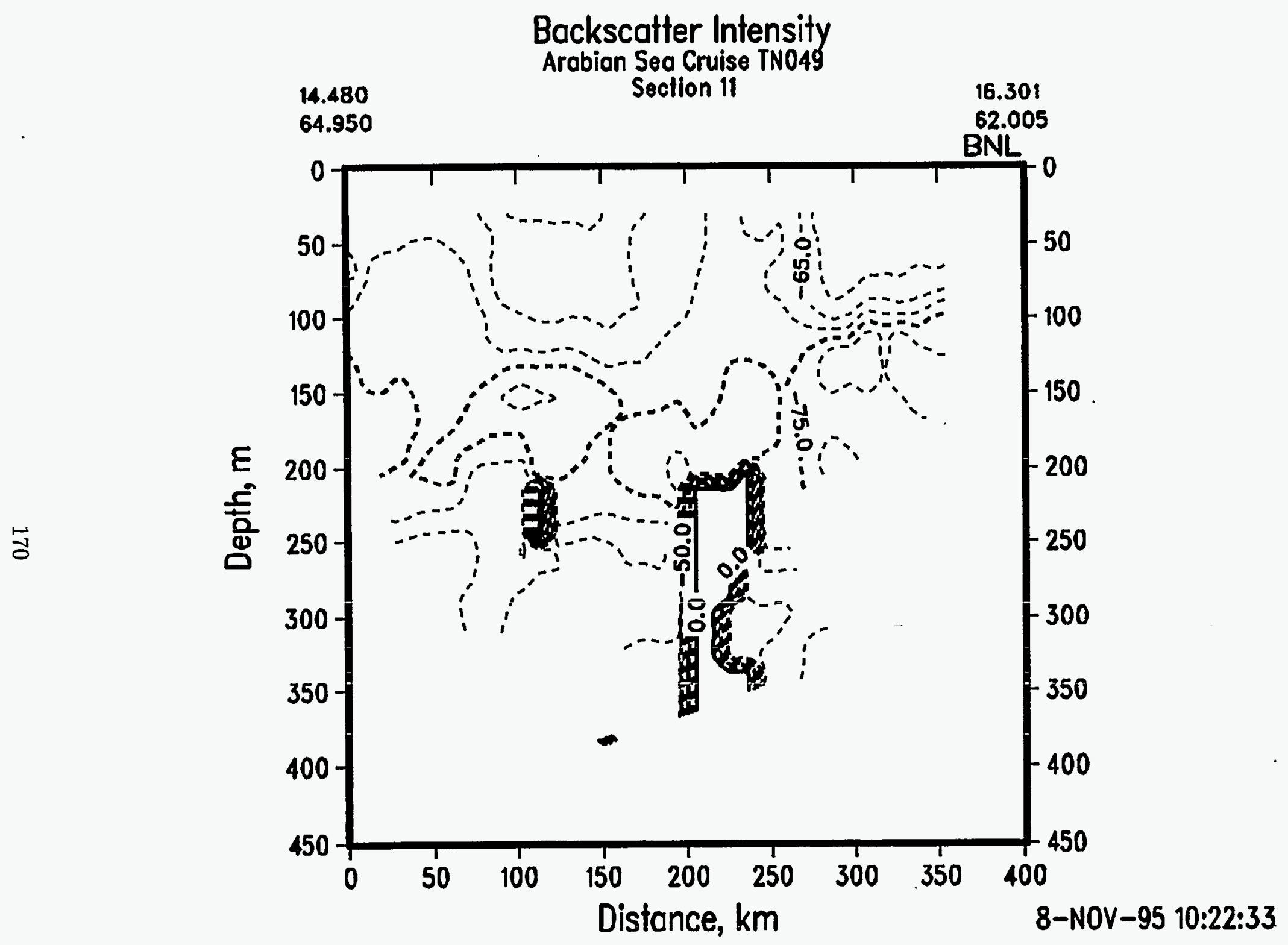




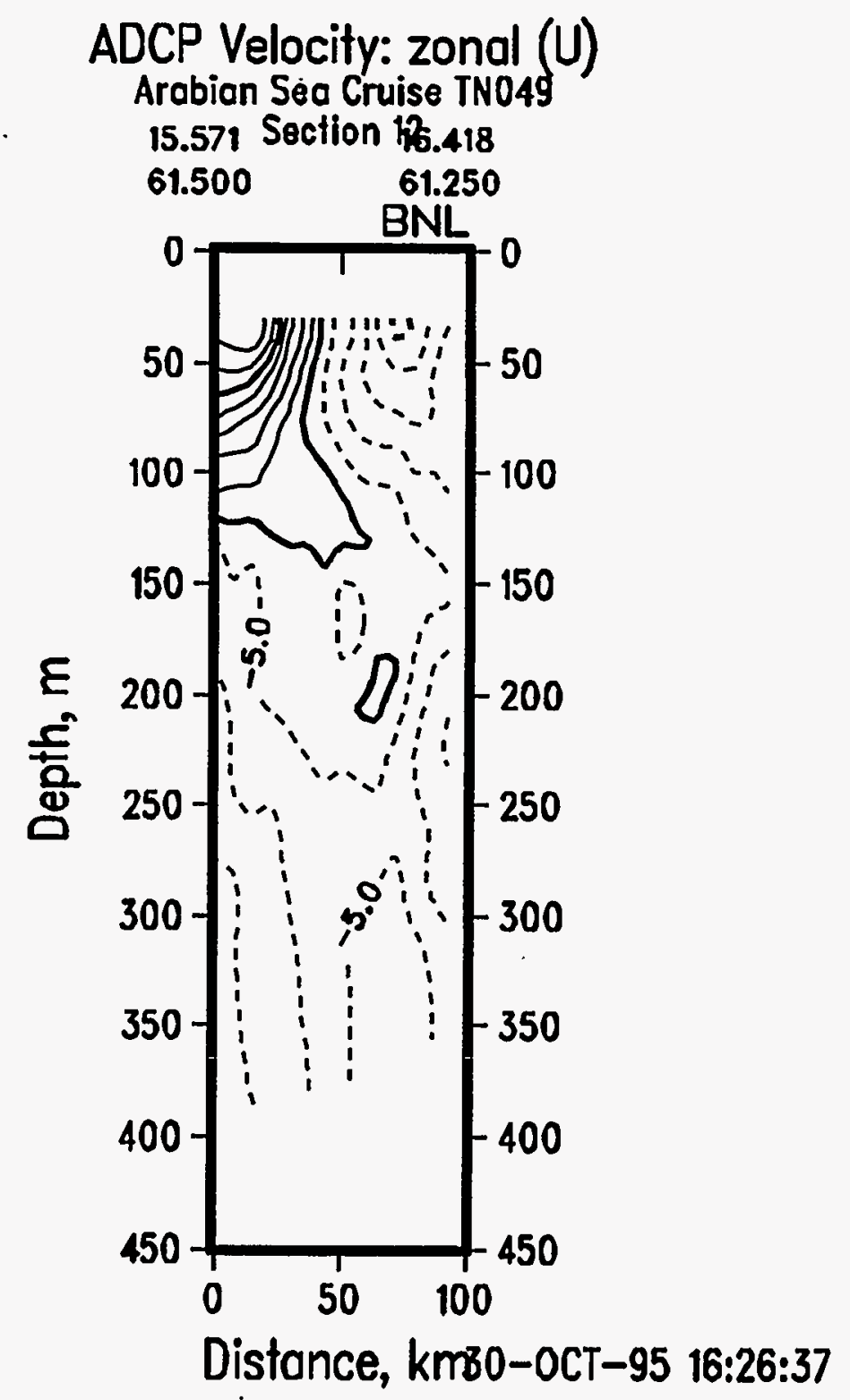




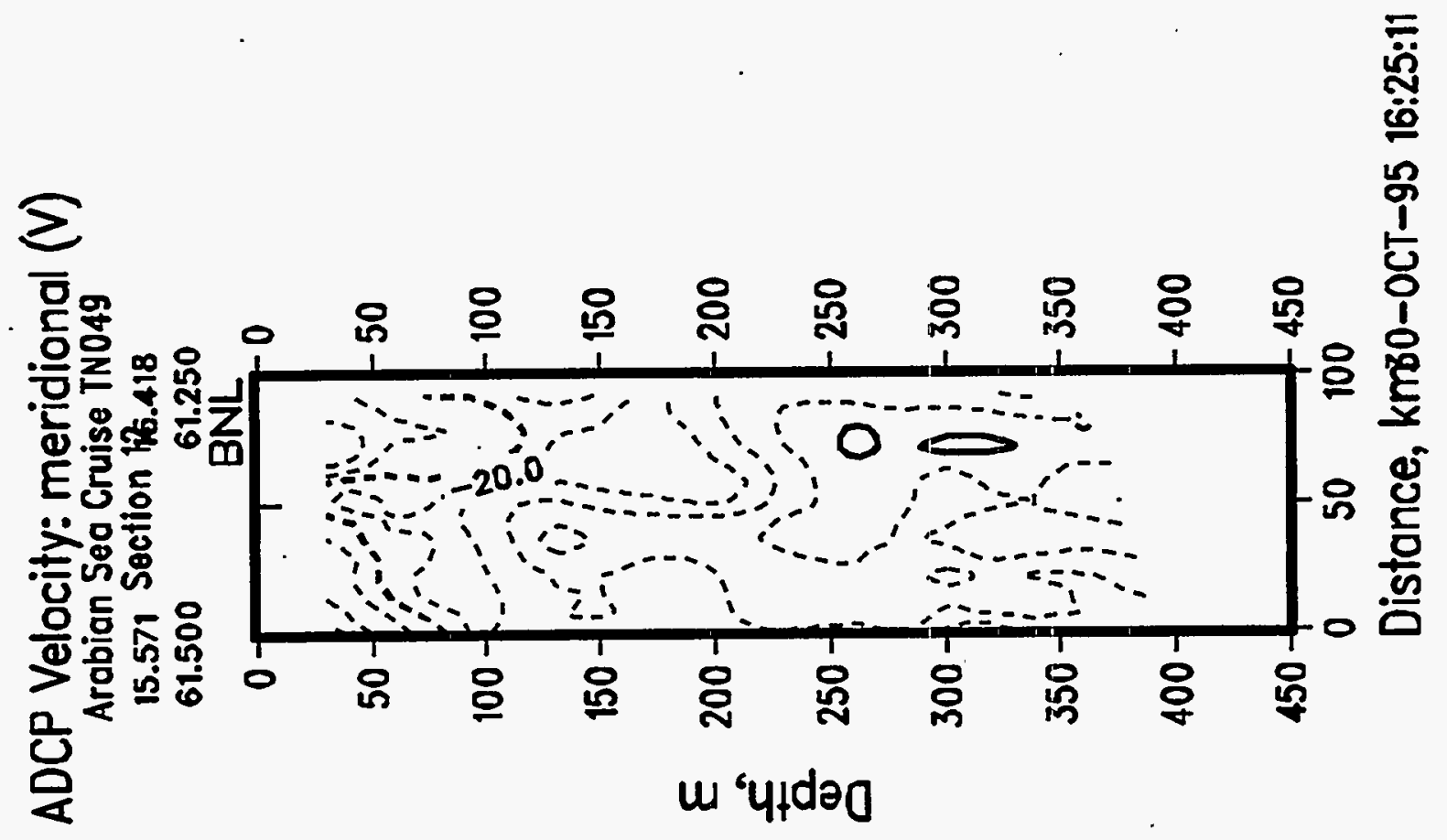




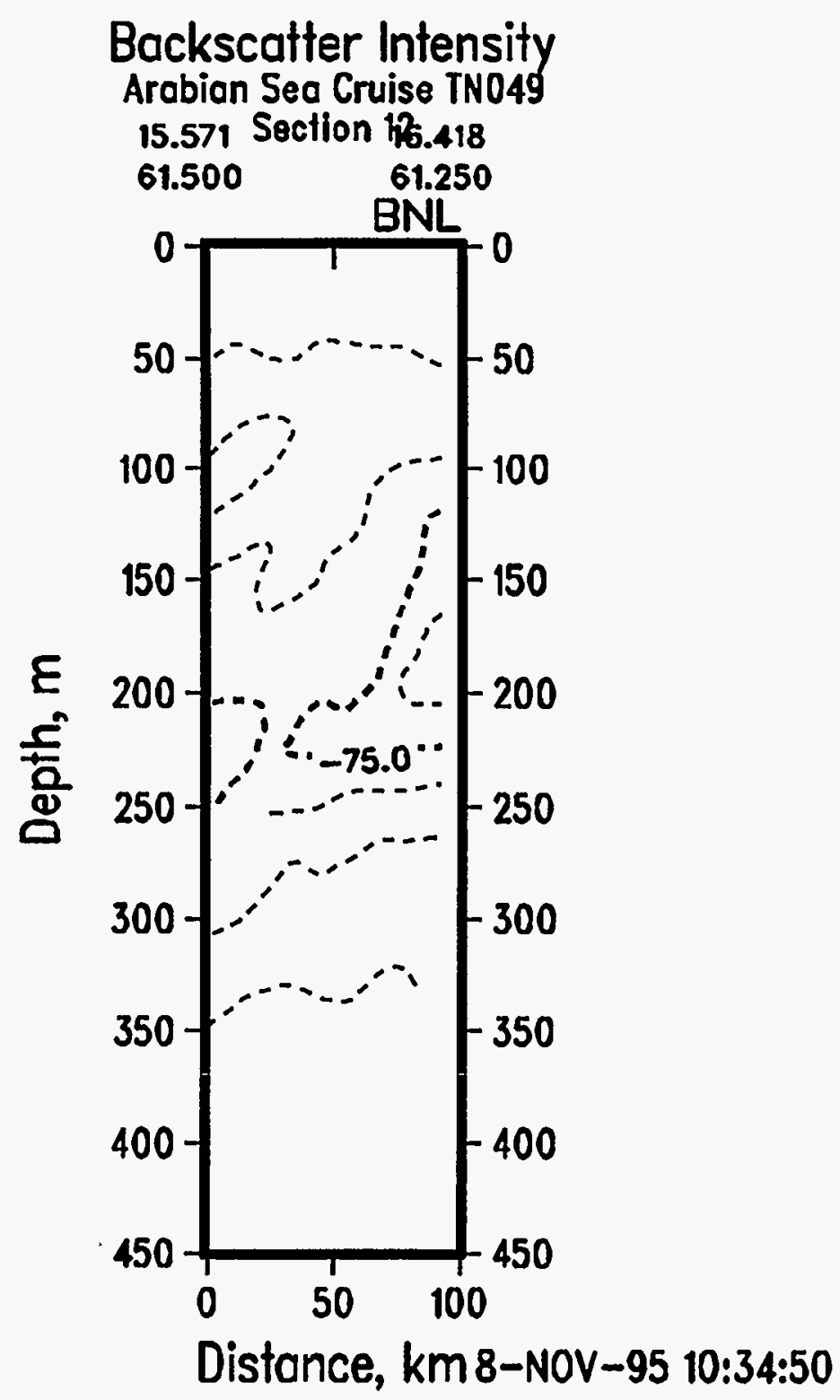




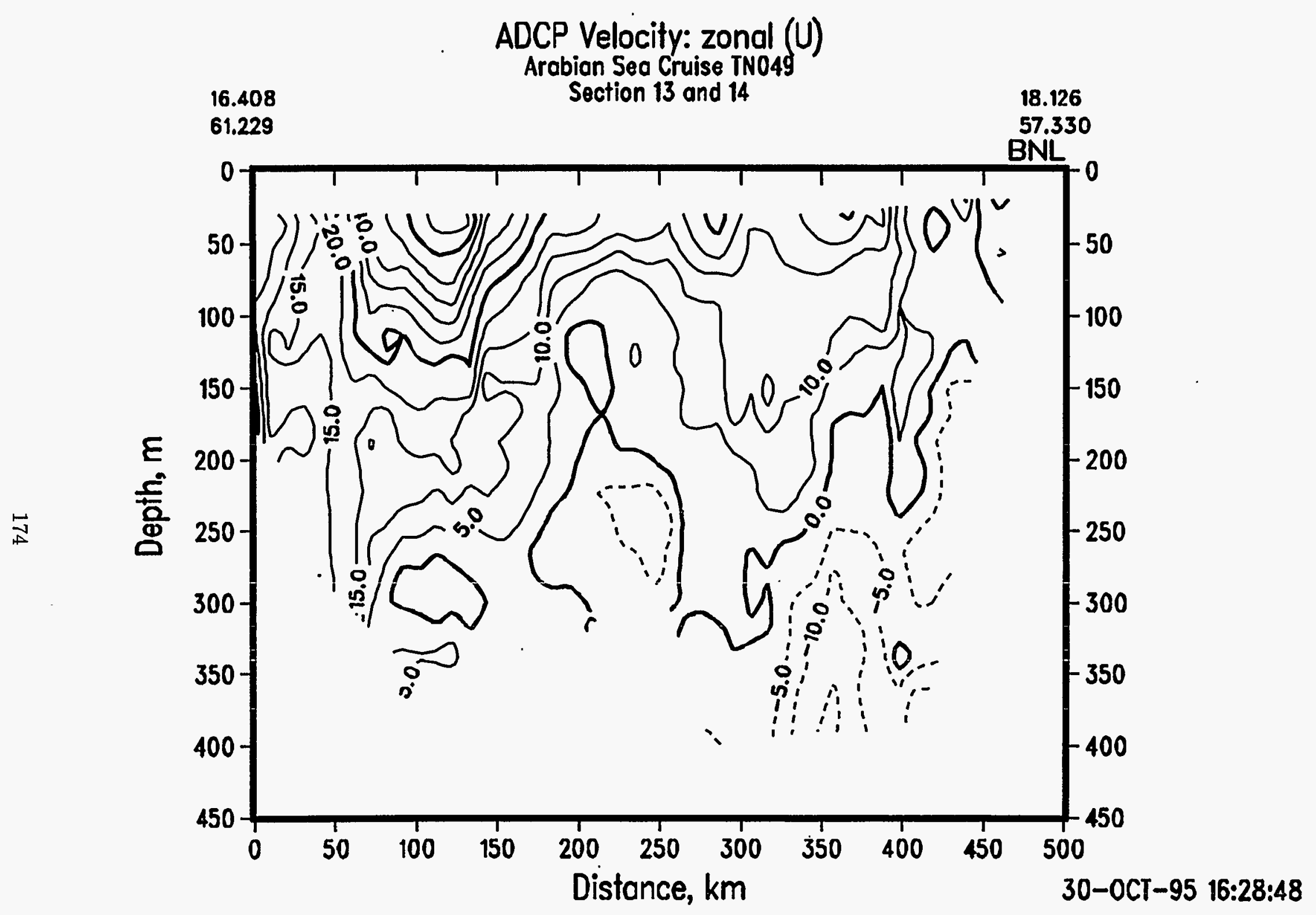




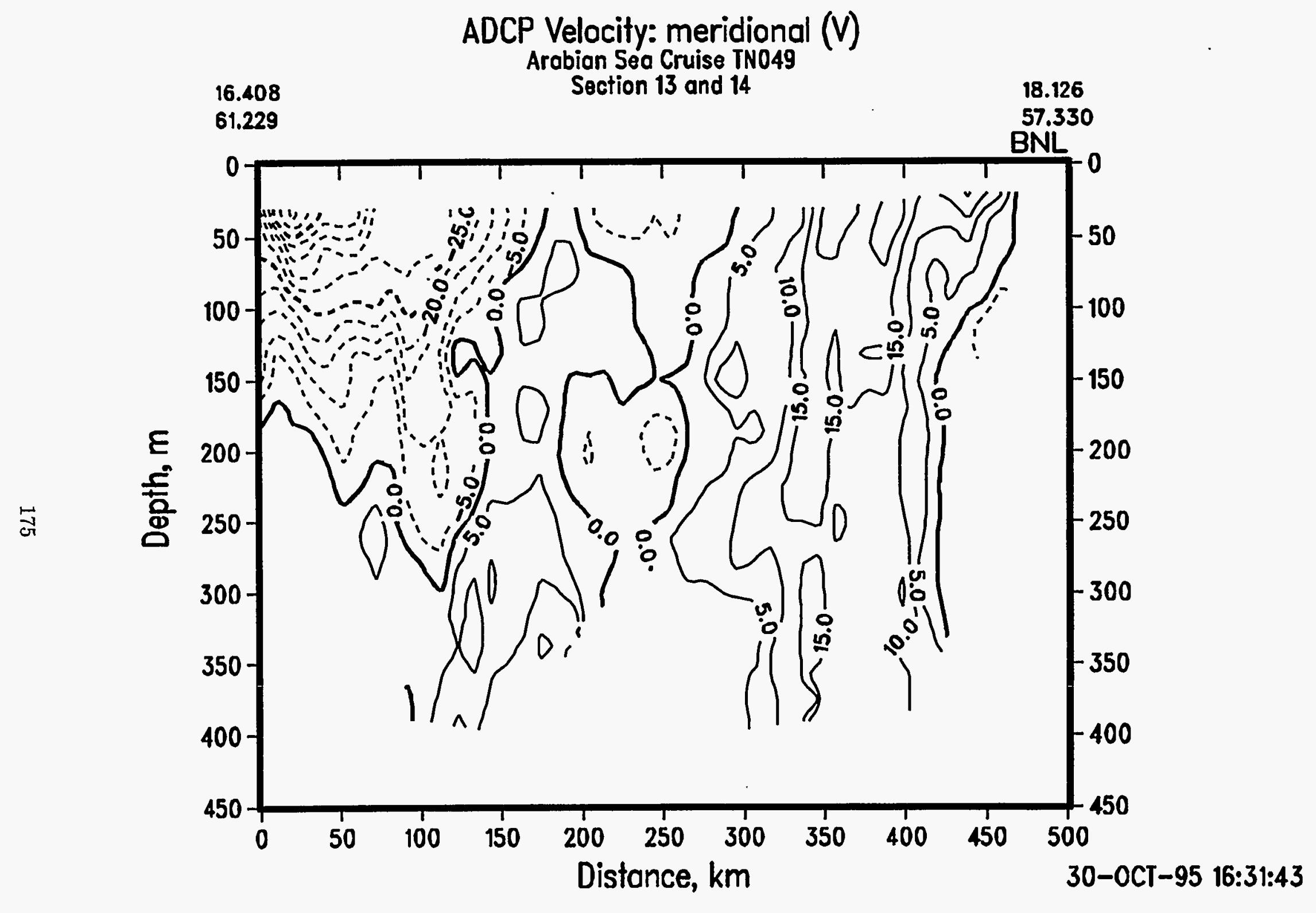




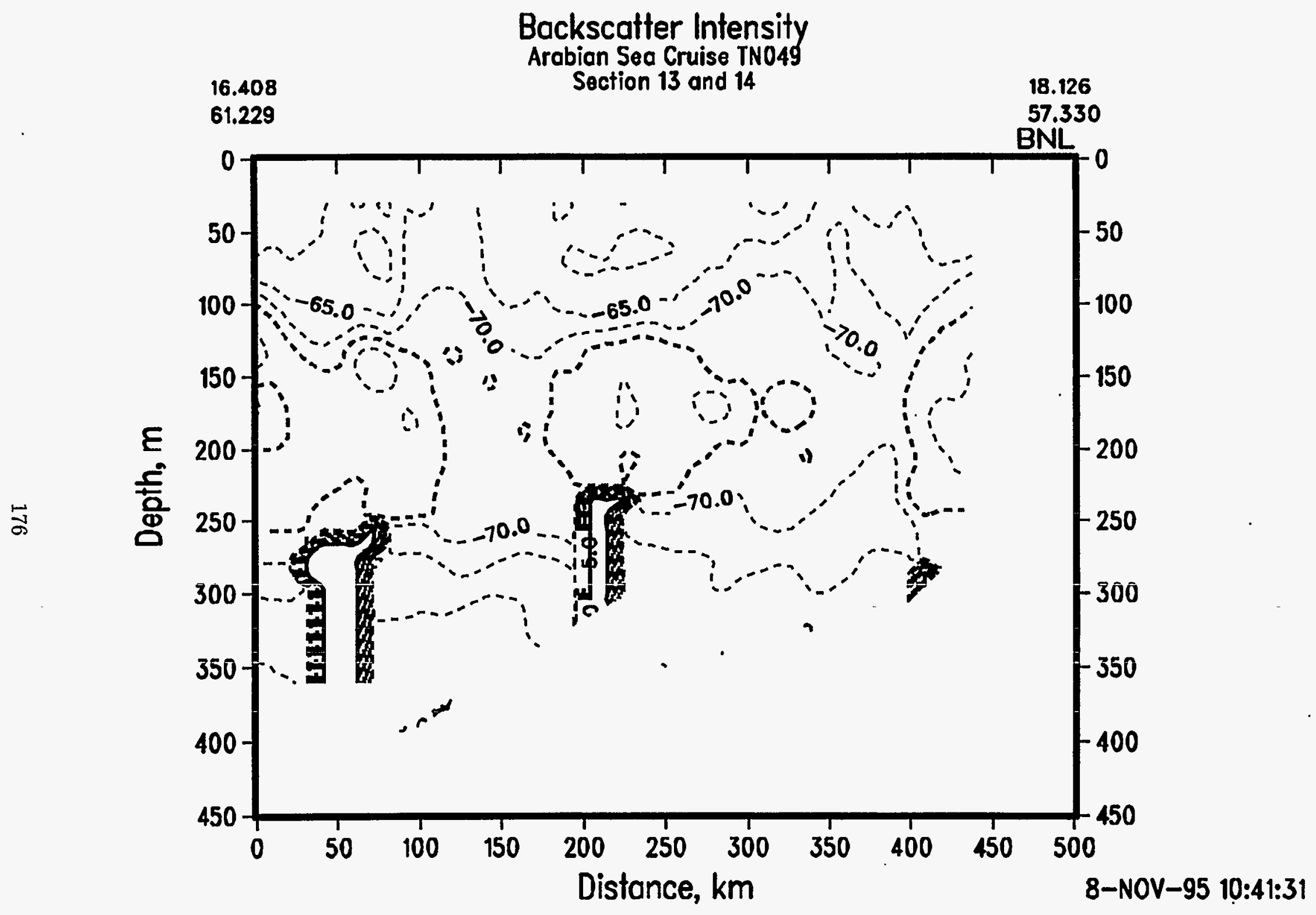




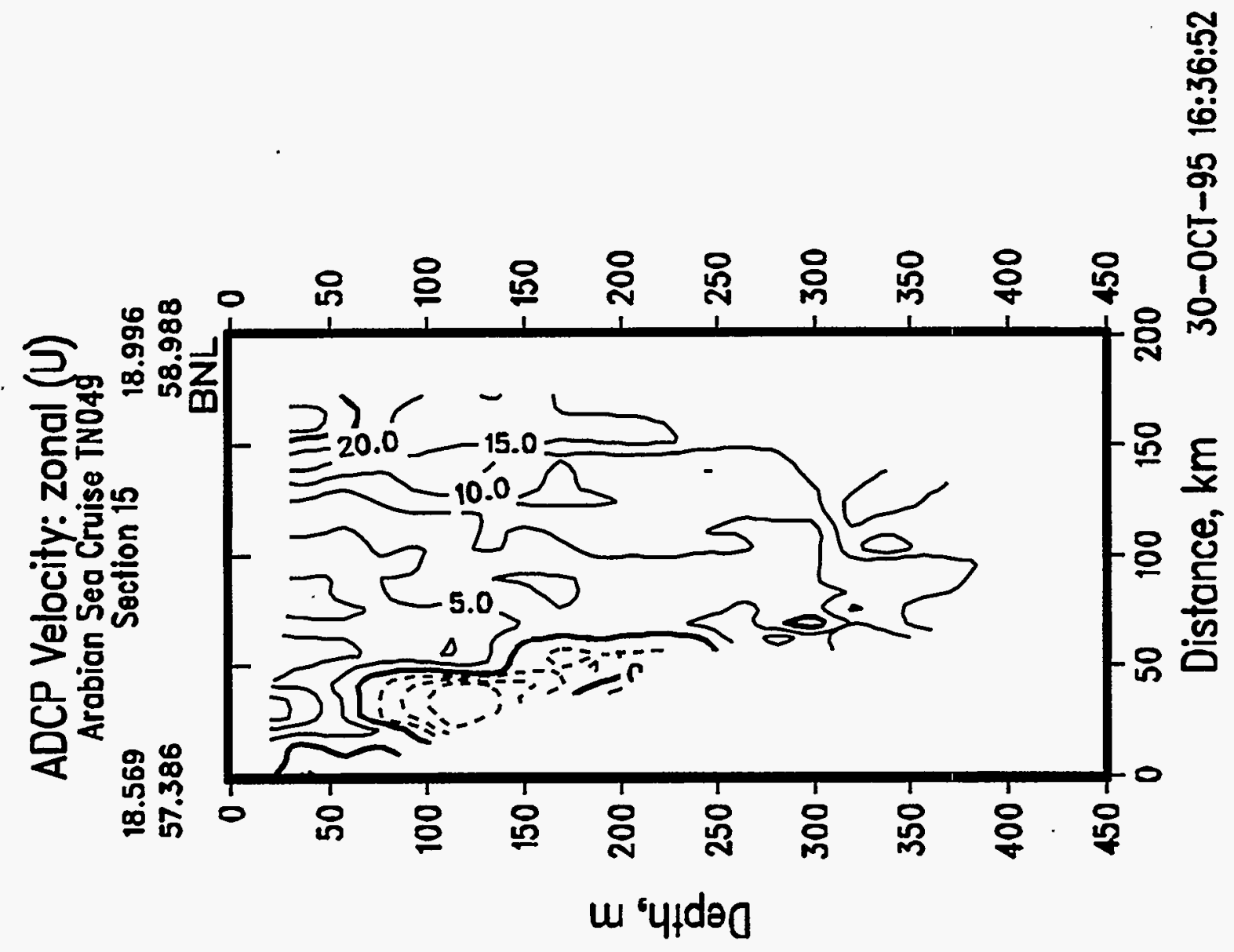




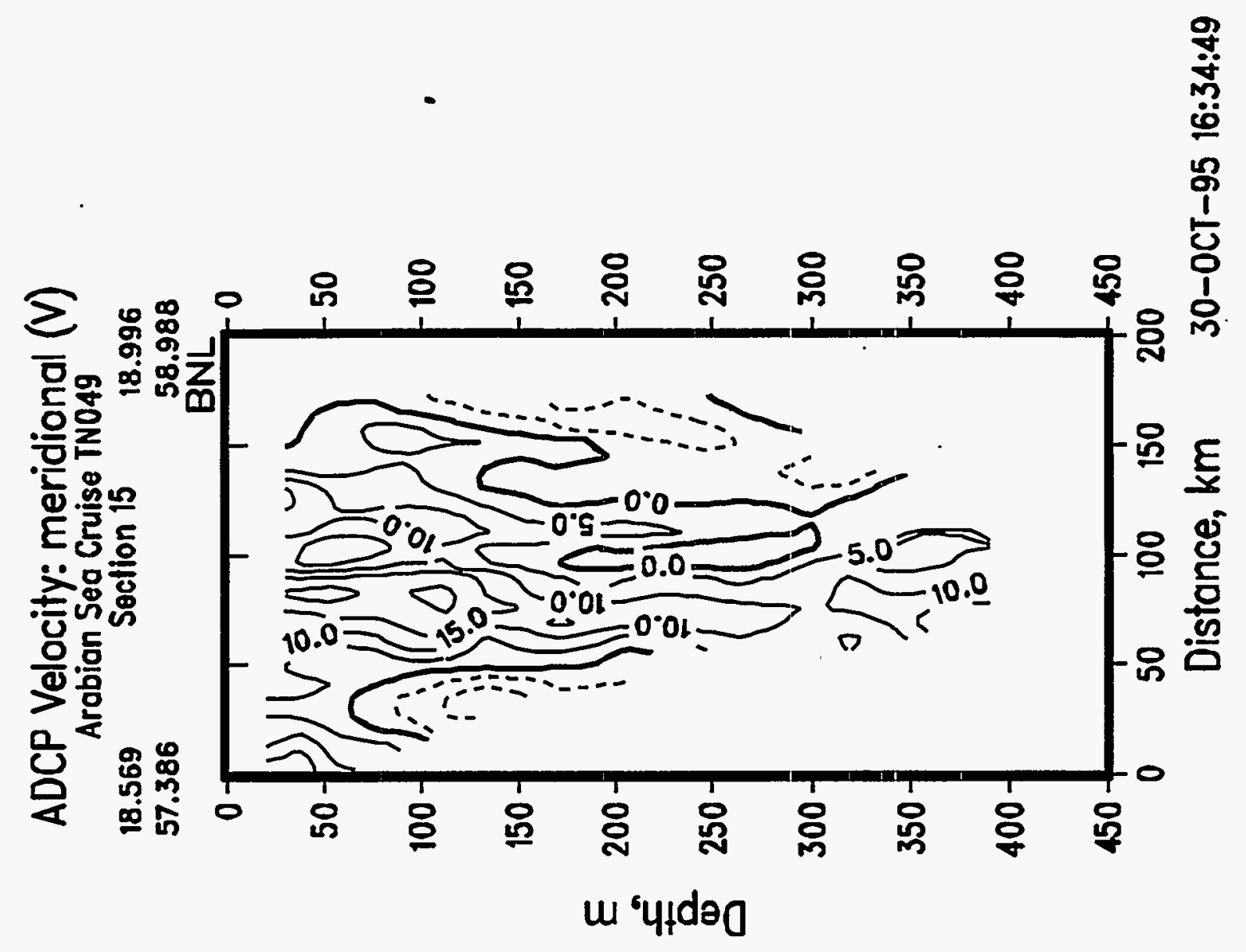




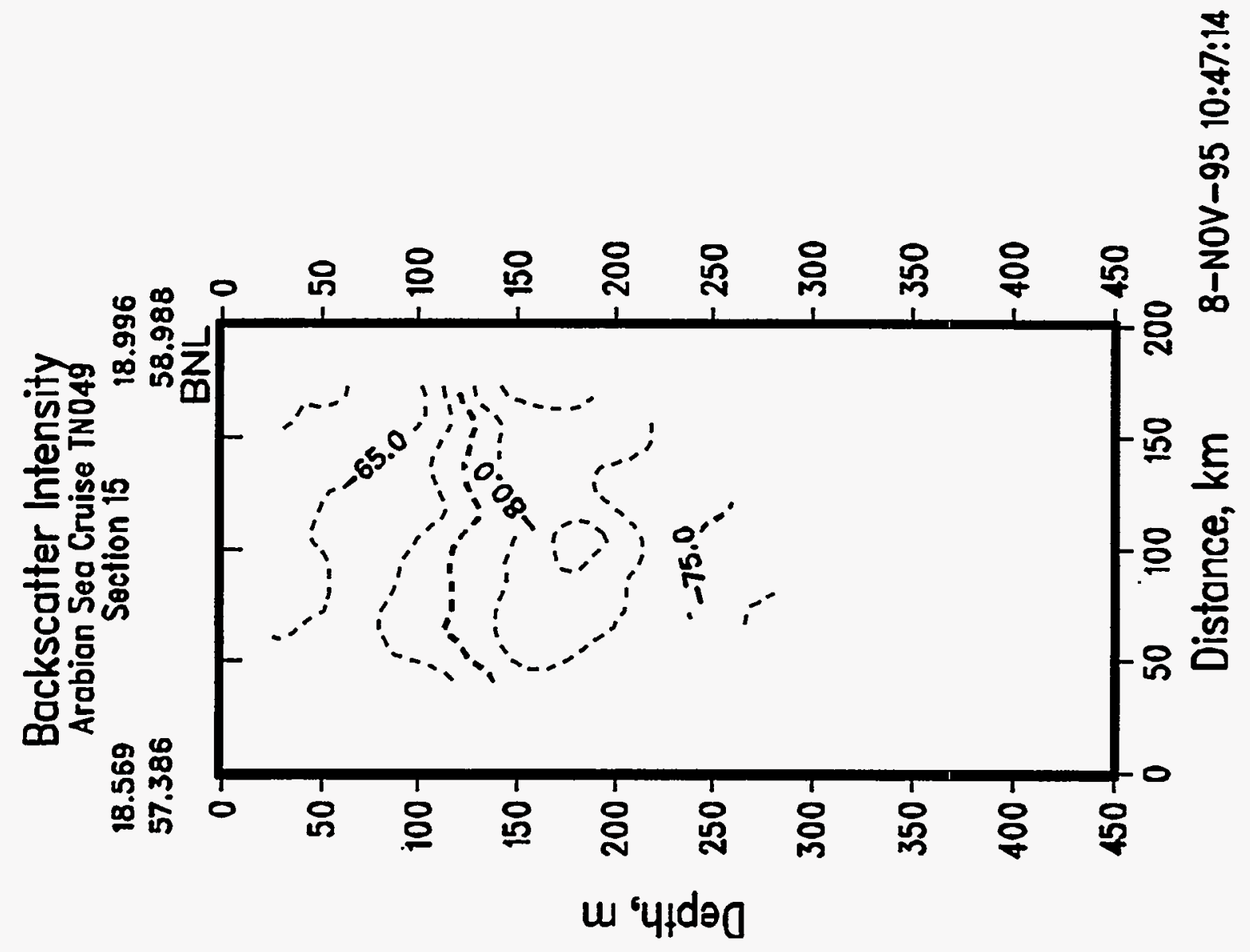




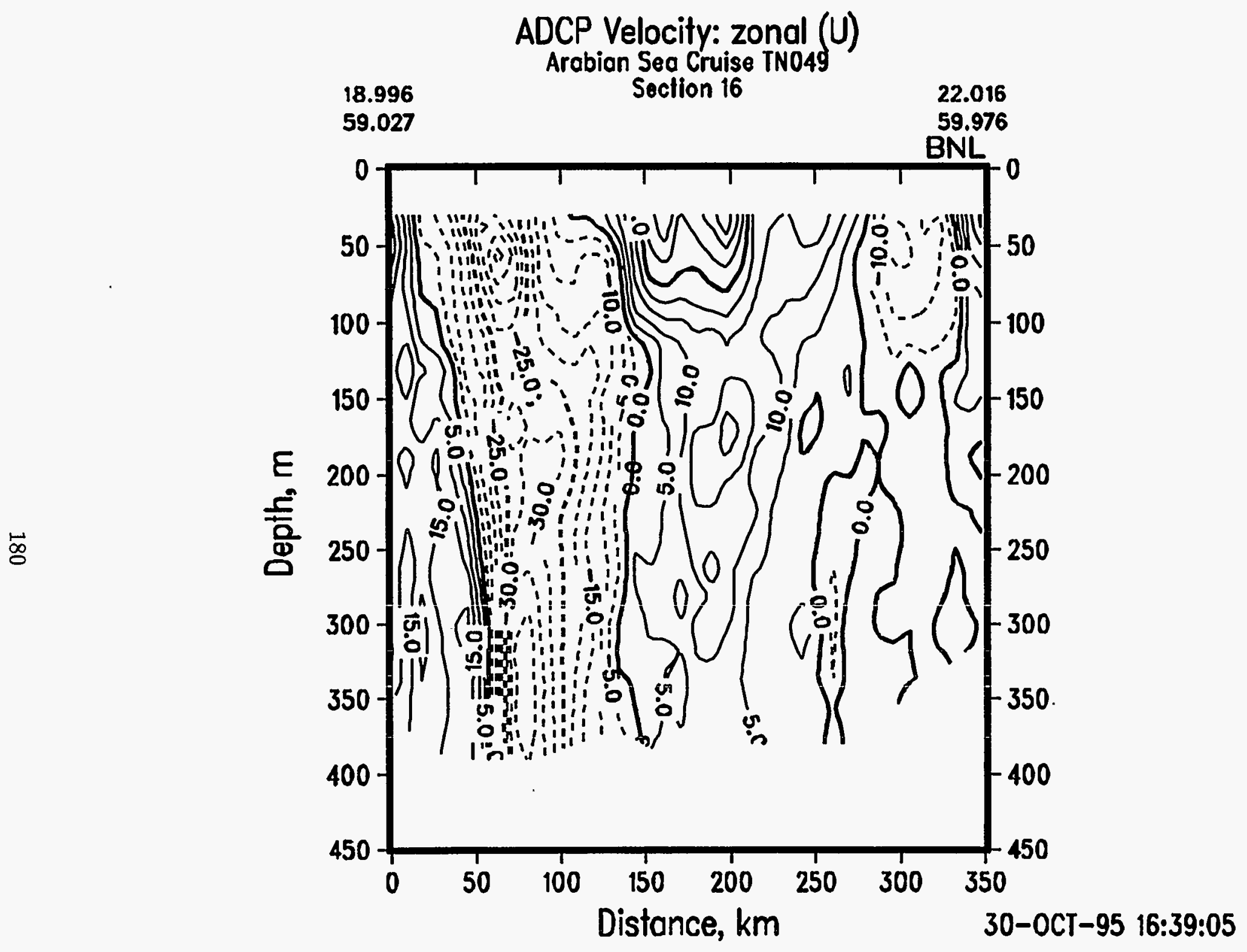




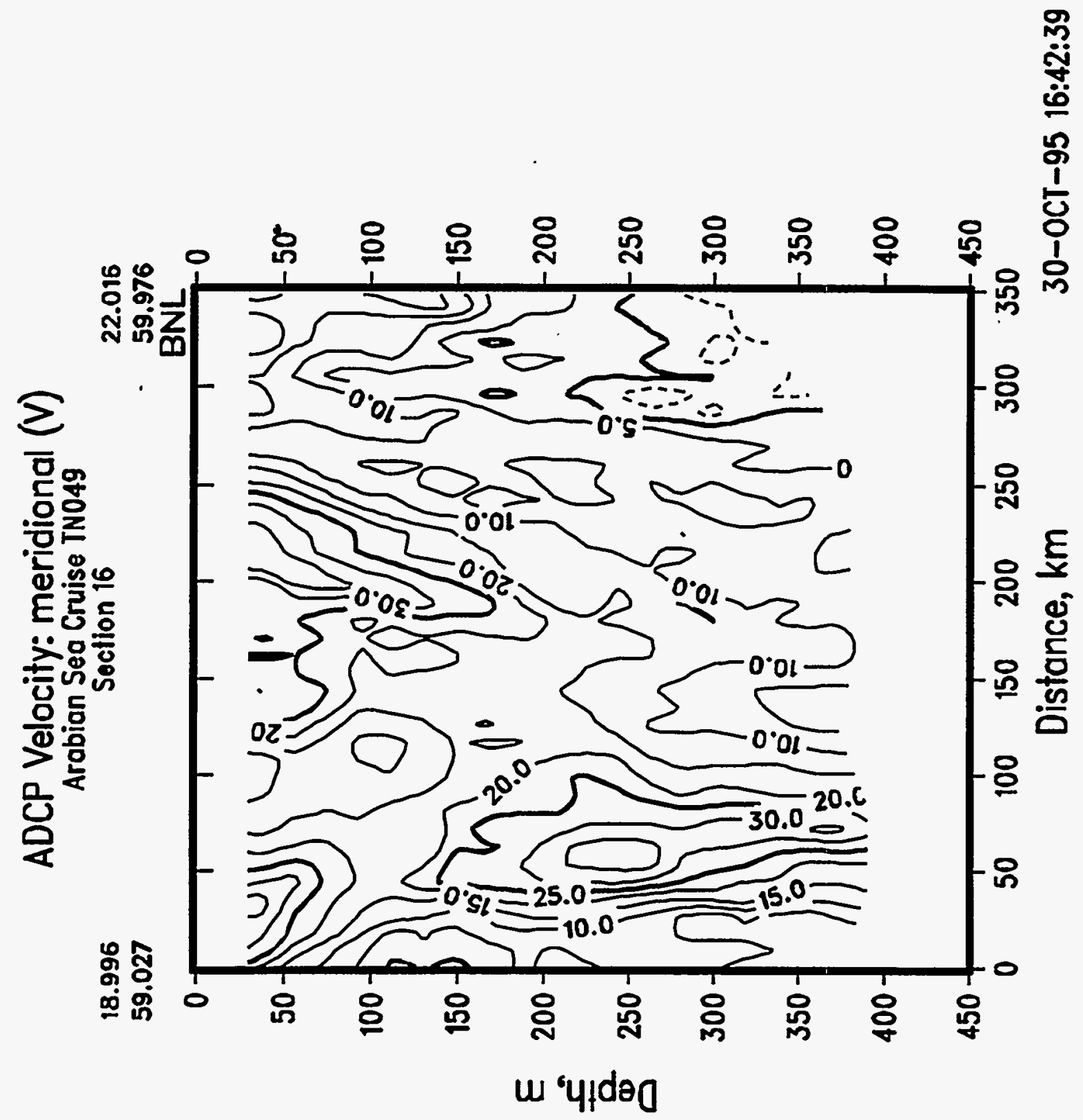




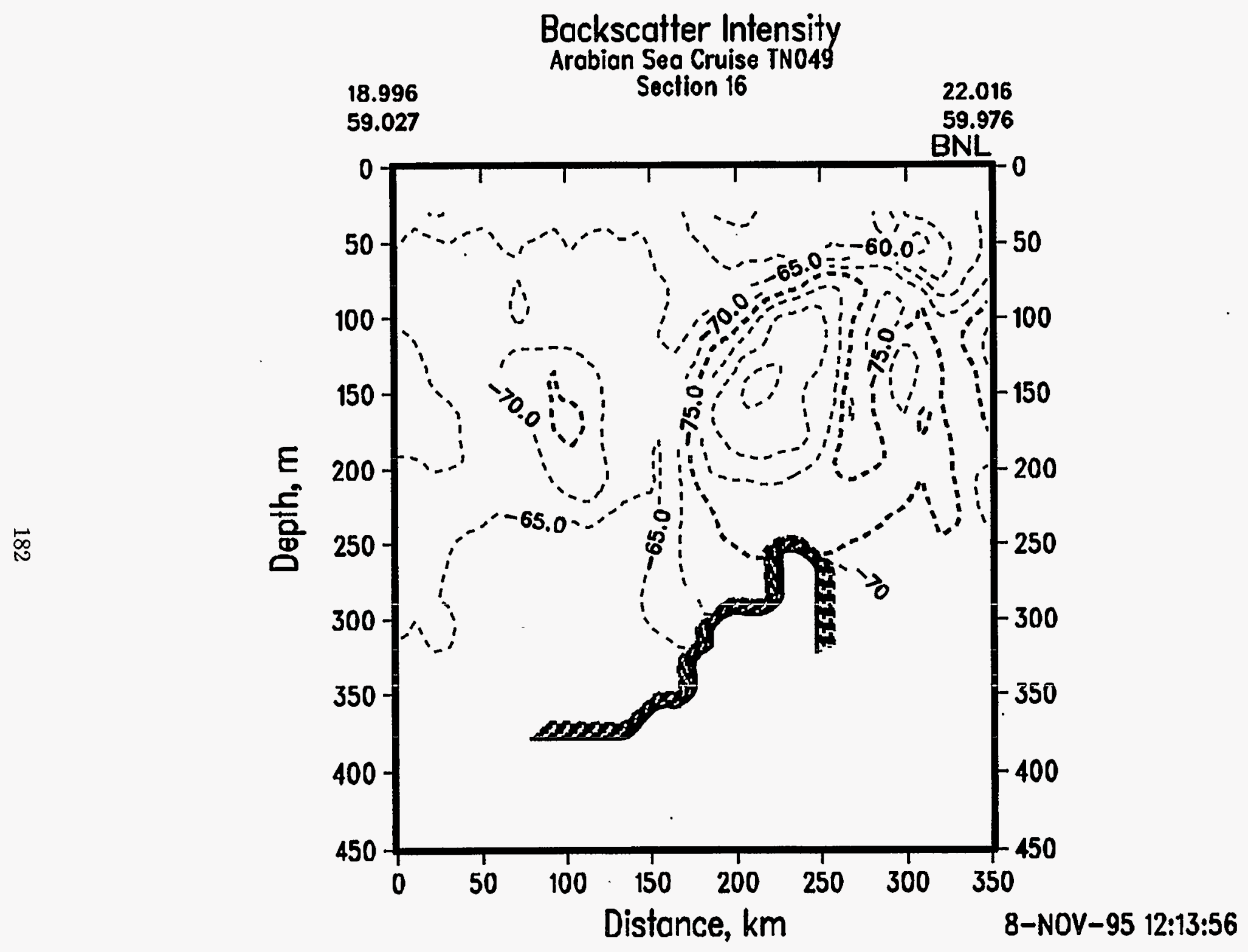




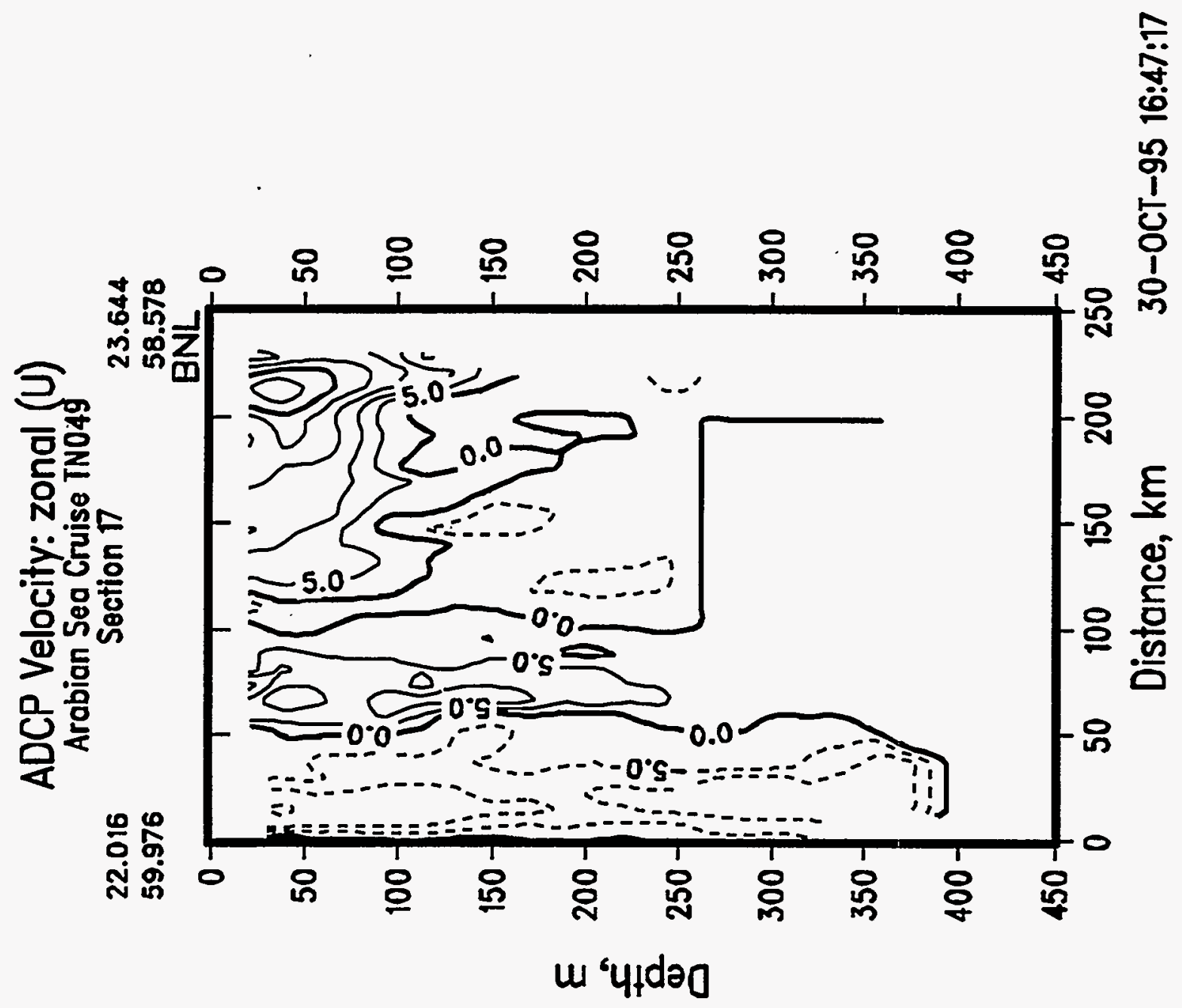




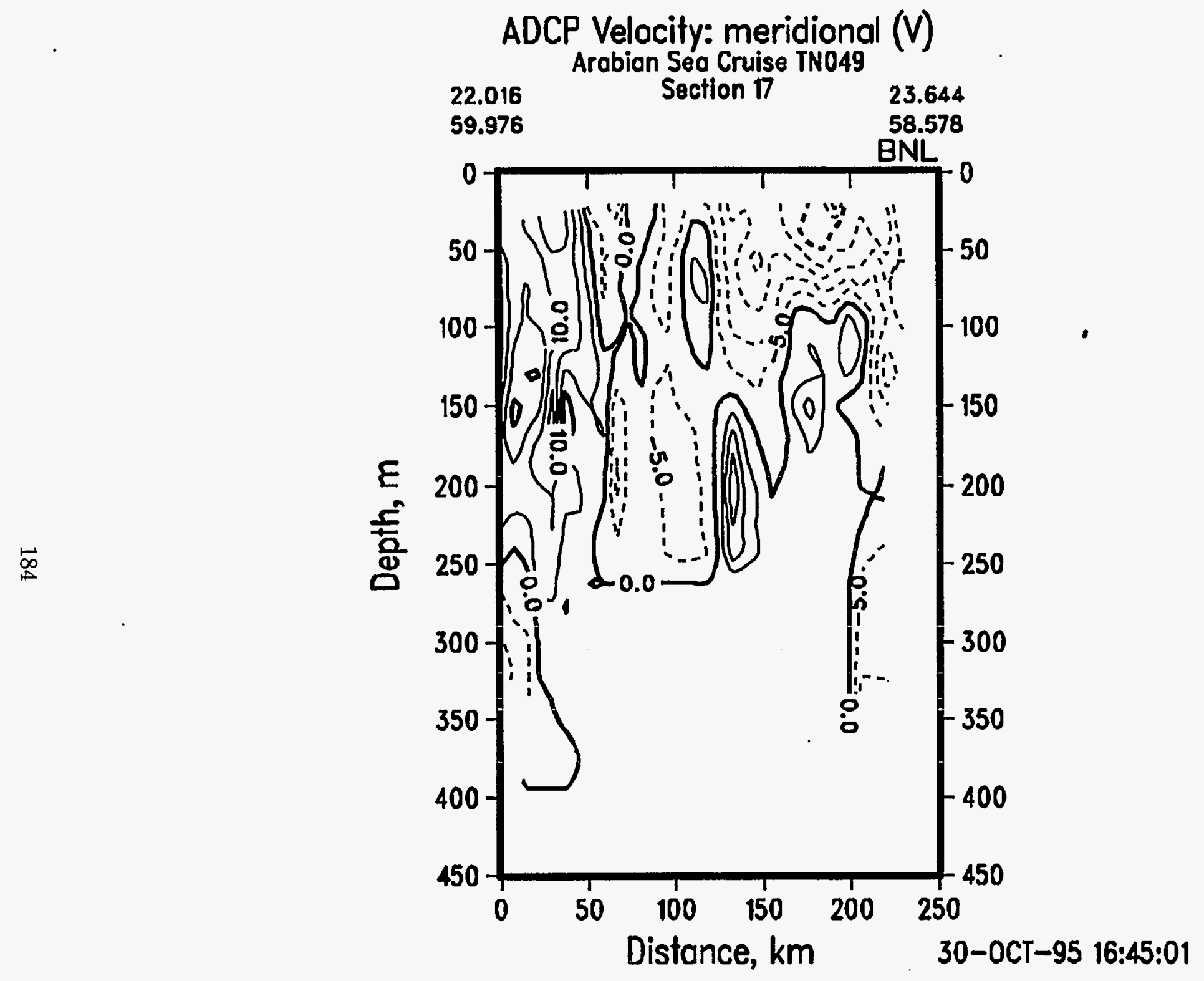




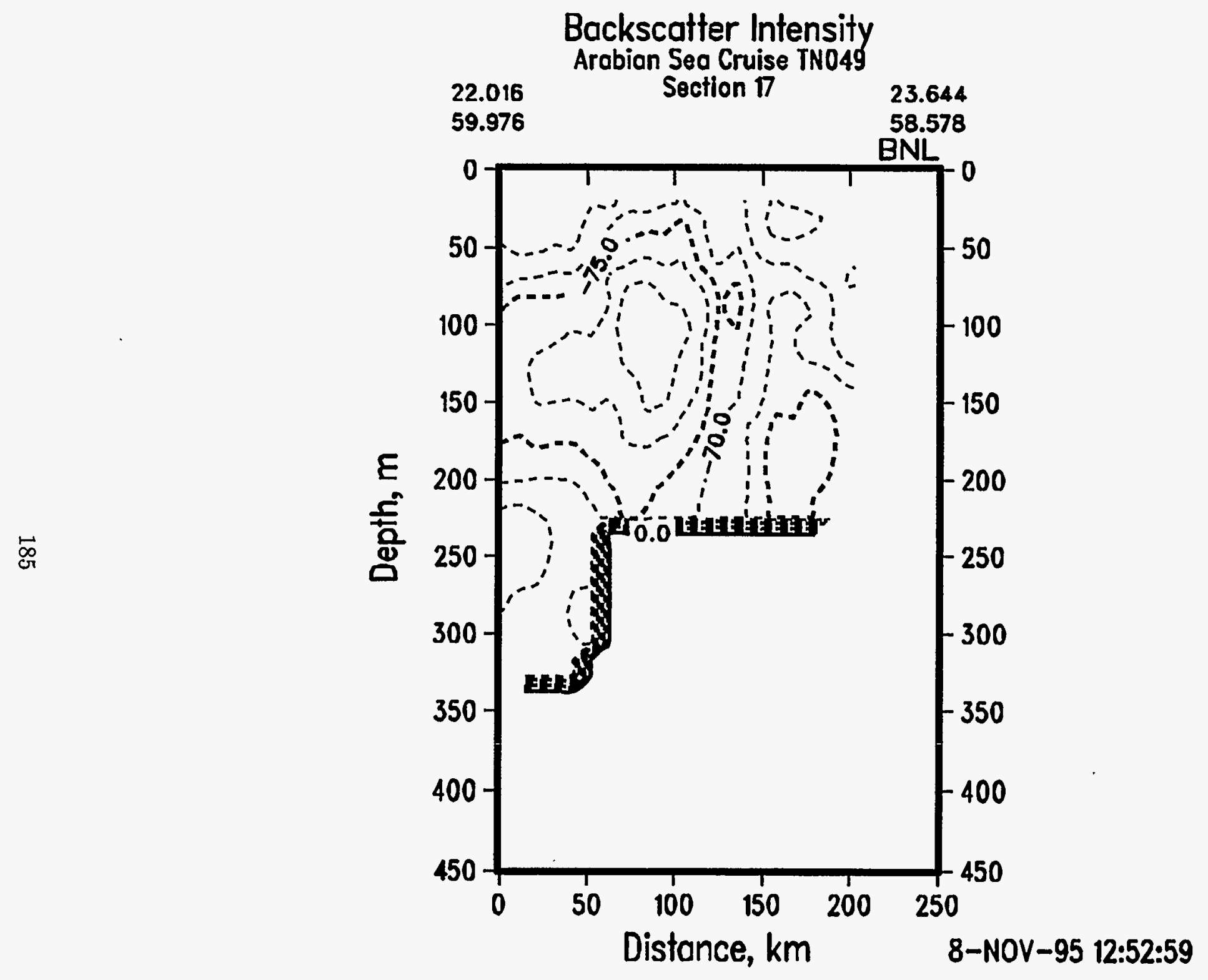




\section{TN050}




\section{JGOFS Arabian Sea}

TN050 Whole Cruise (08/18/95 to 09/15/95)

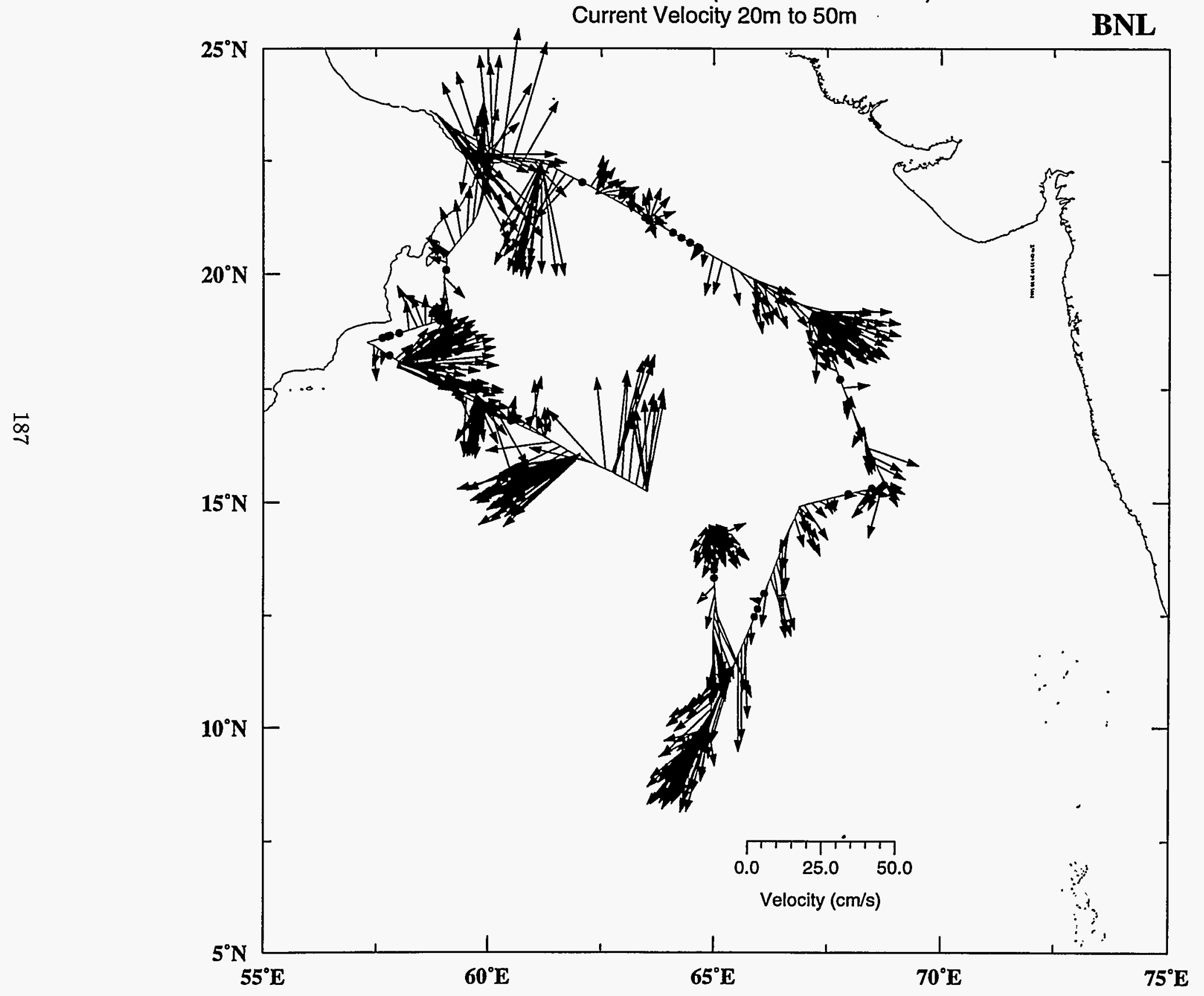




\section{JGOFS Arabian Sea}

TN050 Whole Cruise (08/18/95 to 09/15/95)

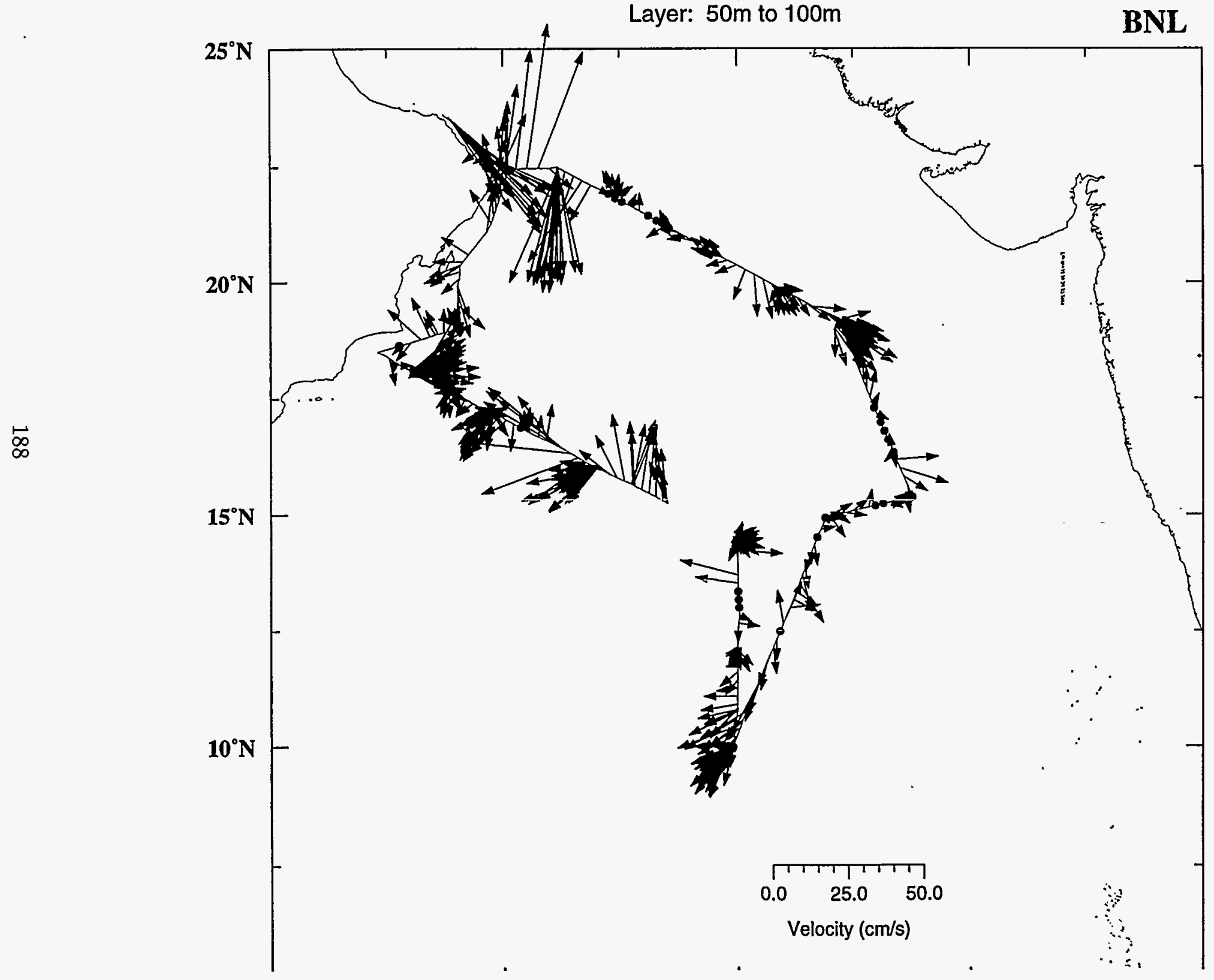




\section{JGOFS Arabian Sea}

TN050 Whole Cruise (08/18/95 to 09/15/95)

Layer: $100 \mathrm{~m}$ to $200 \mathrm{~m}$

\section{BNL}

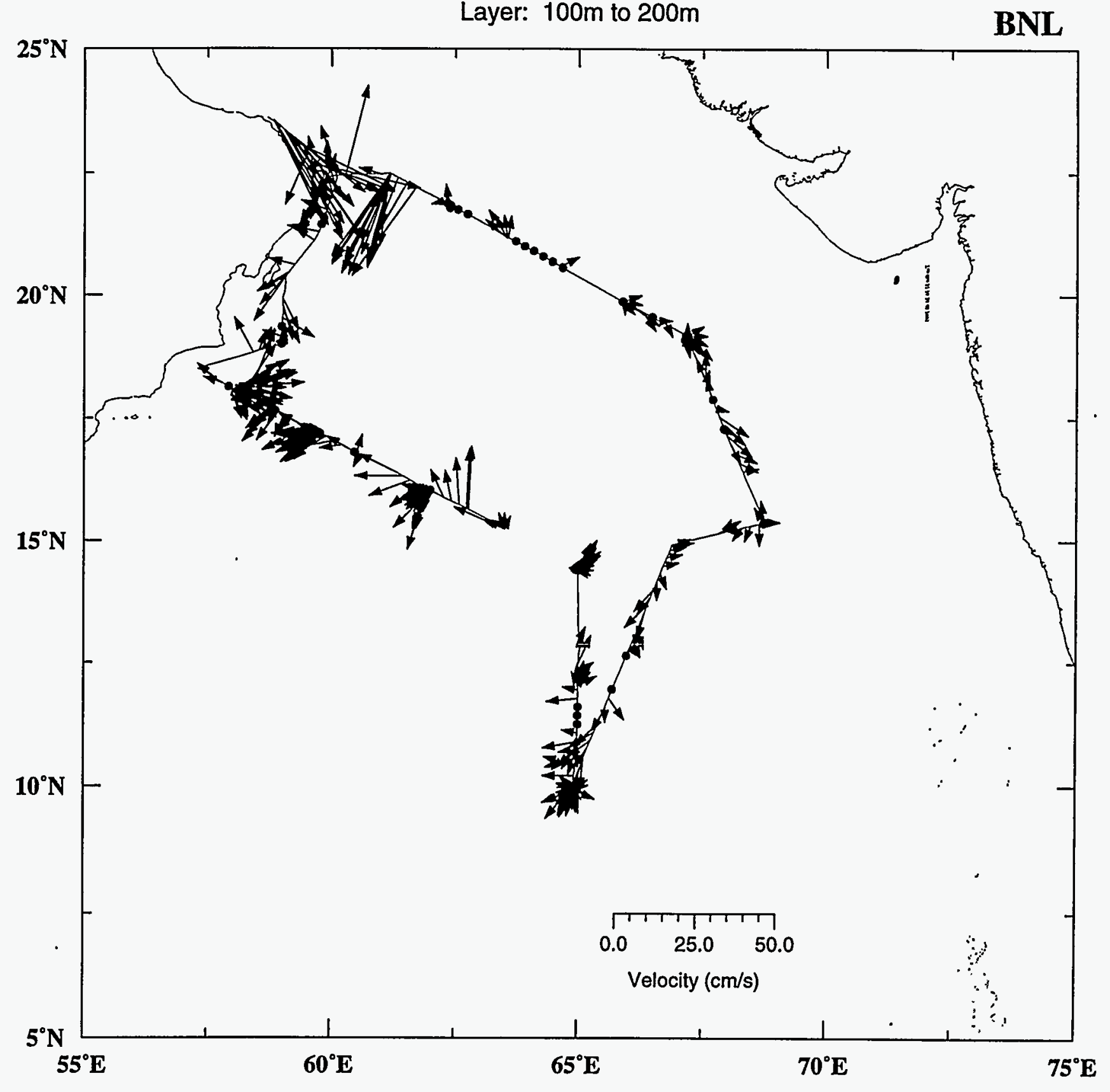




\section{JGOFS Arabian Sea}

TN050 Whole Cruise (08/18/95 to 09/15/95)

Layer: $200 \mathrm{~m}$ to $300 \mathrm{~m}$

BNL

$\stackrel{8}{8}$

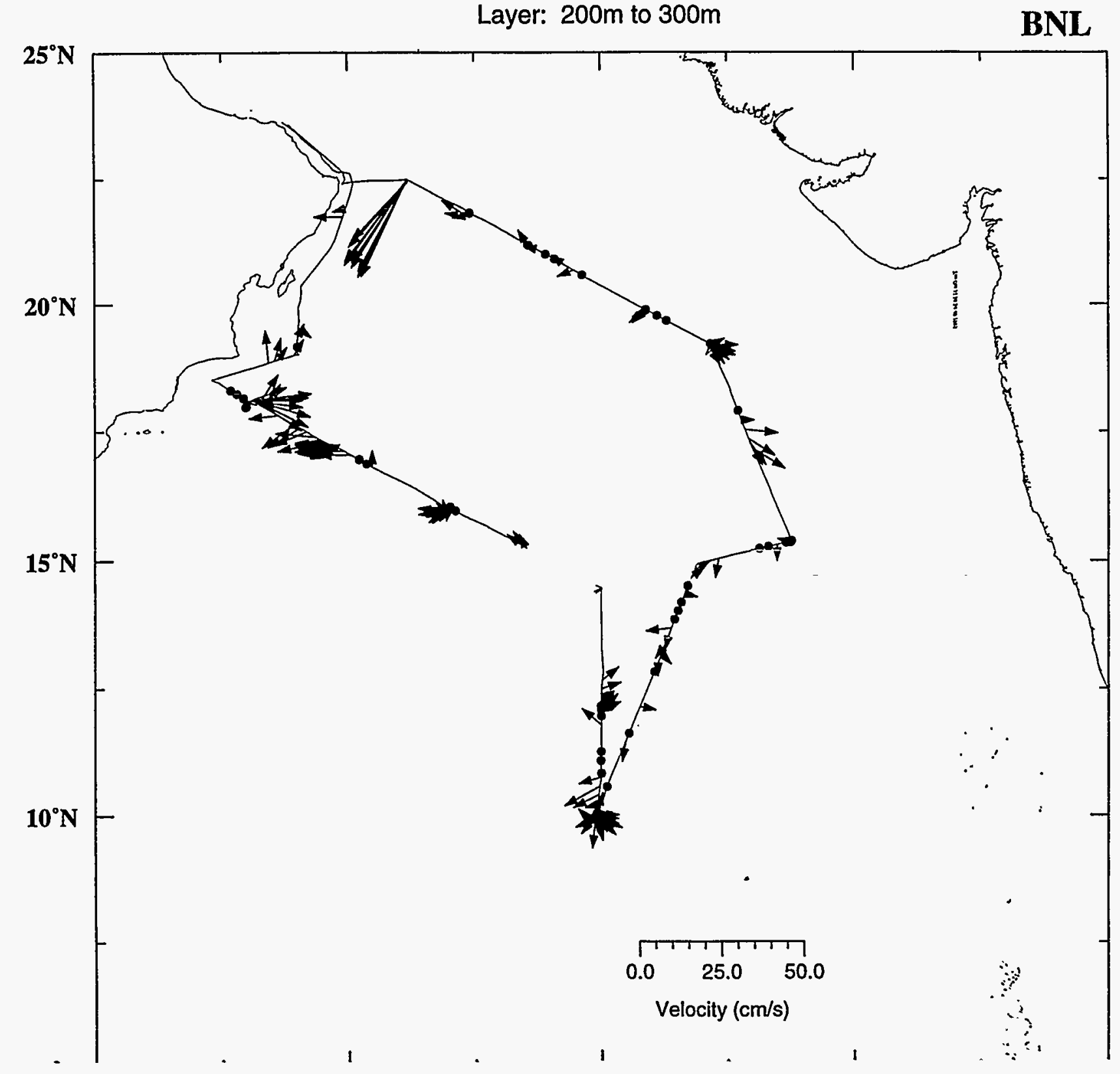




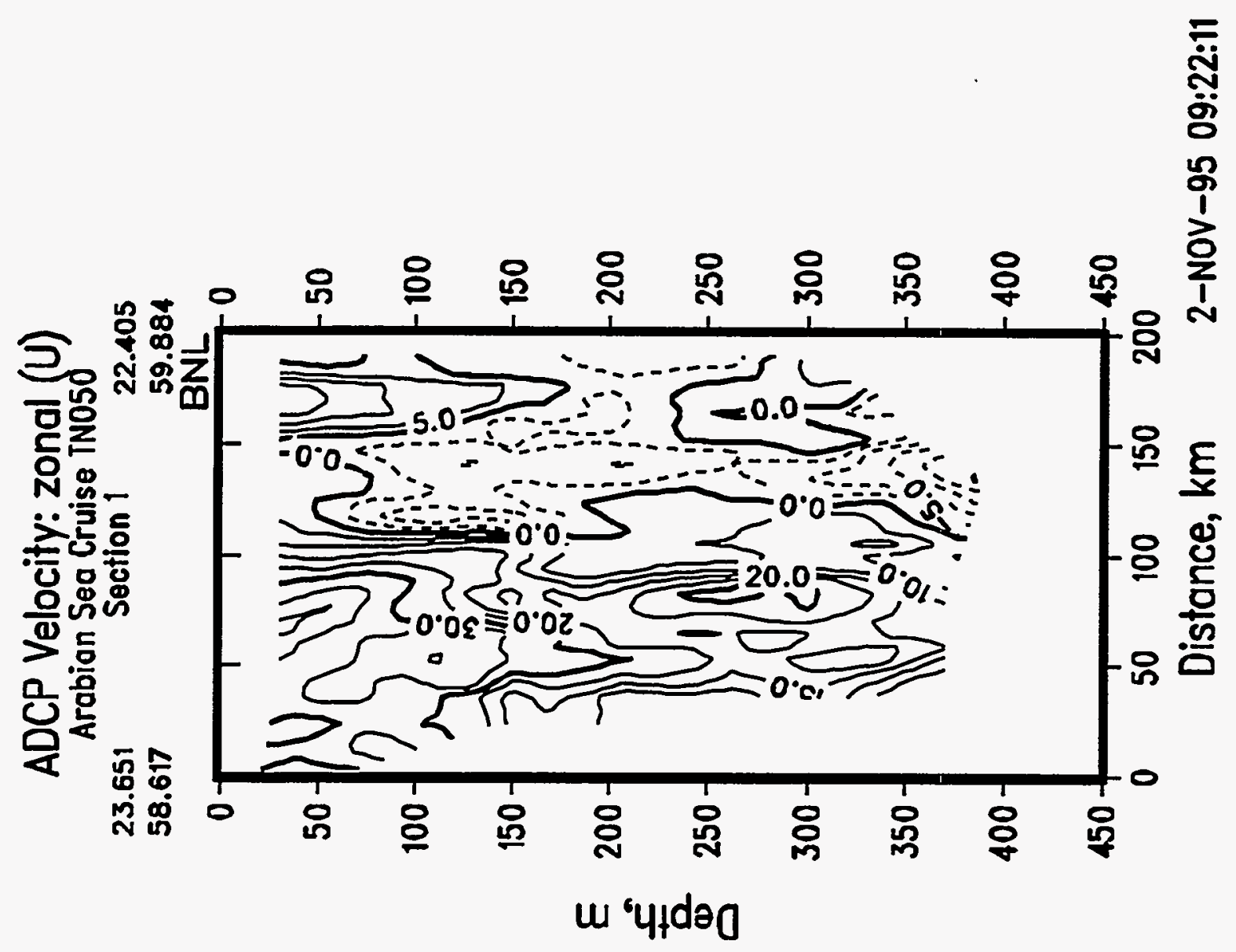




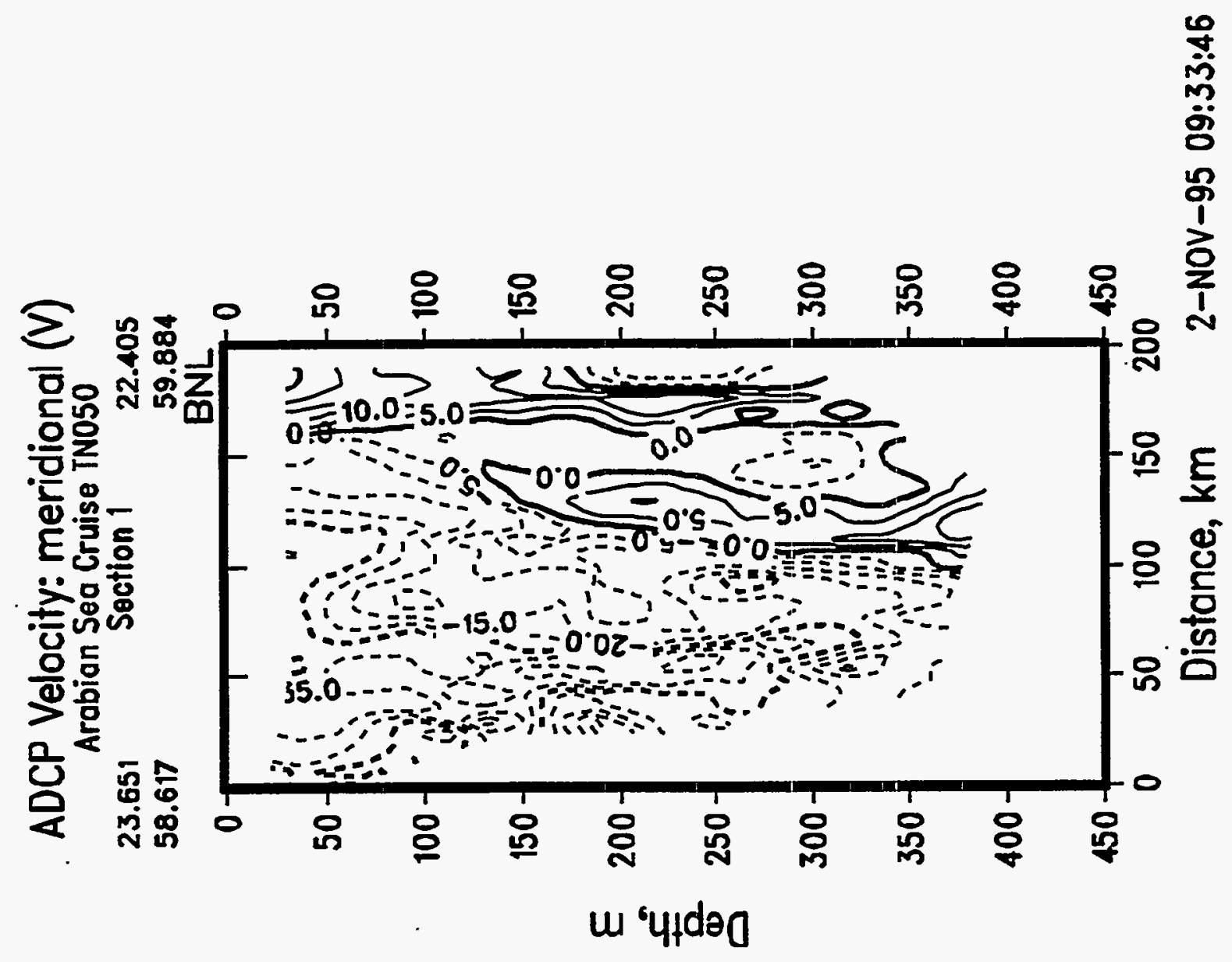




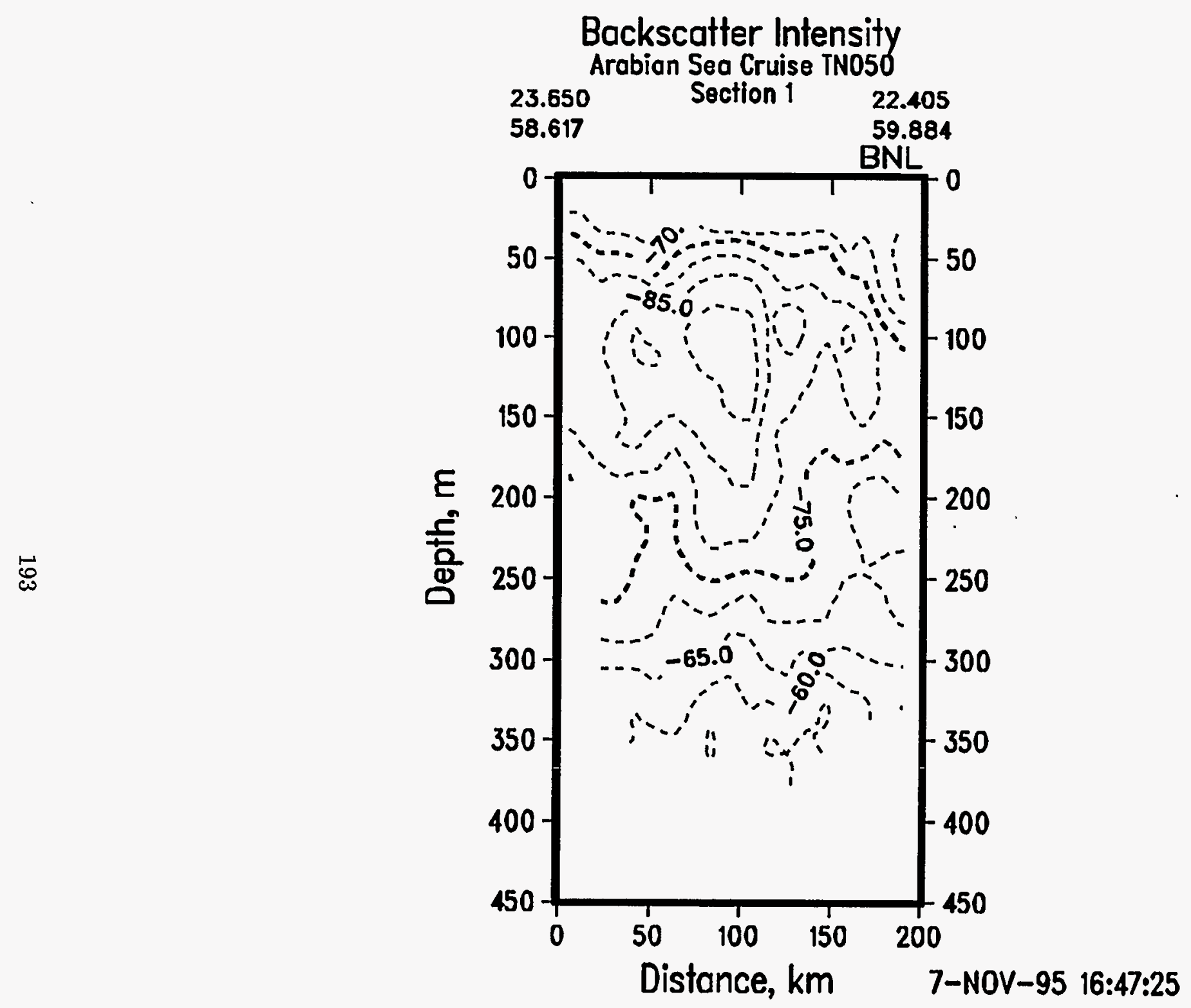




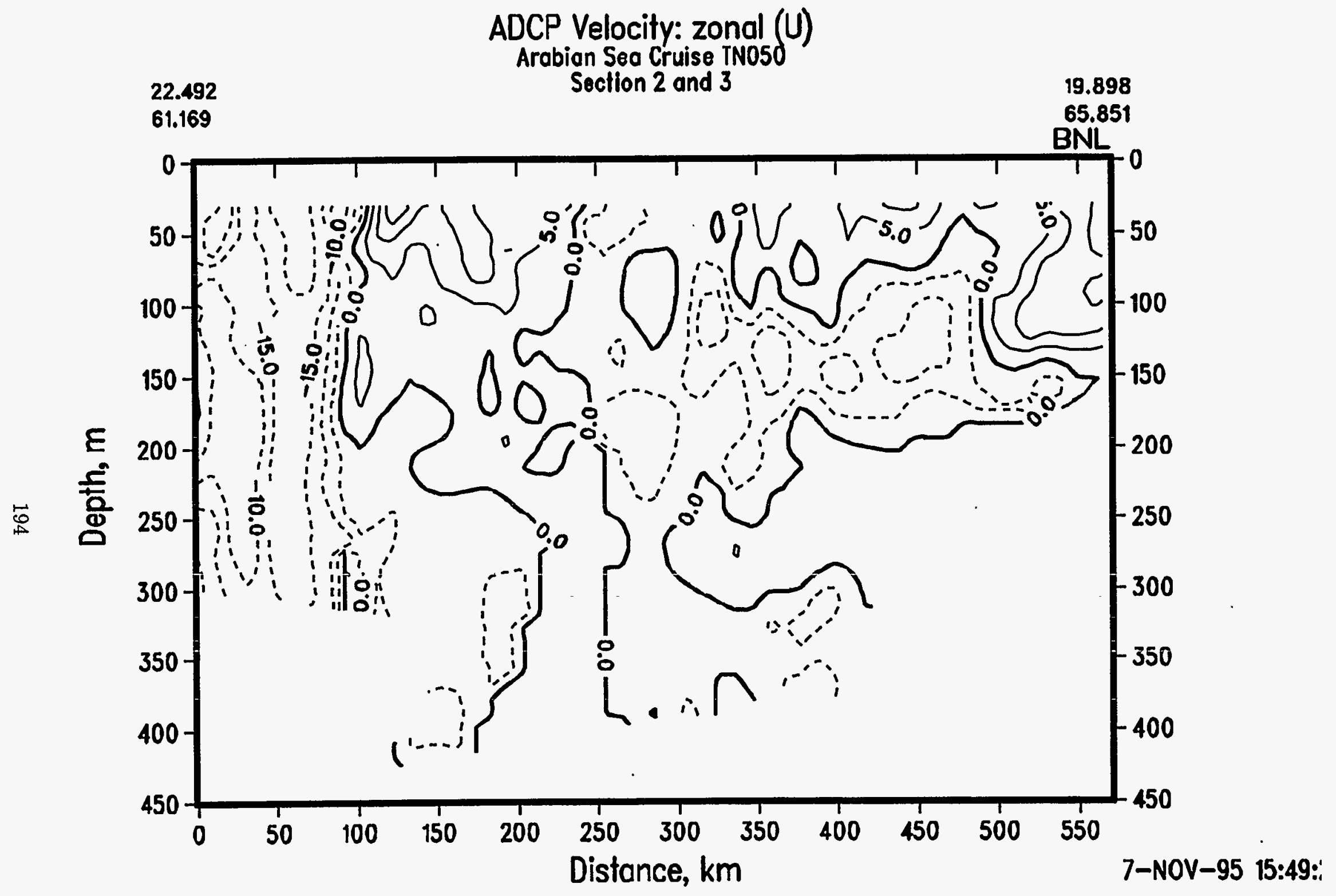




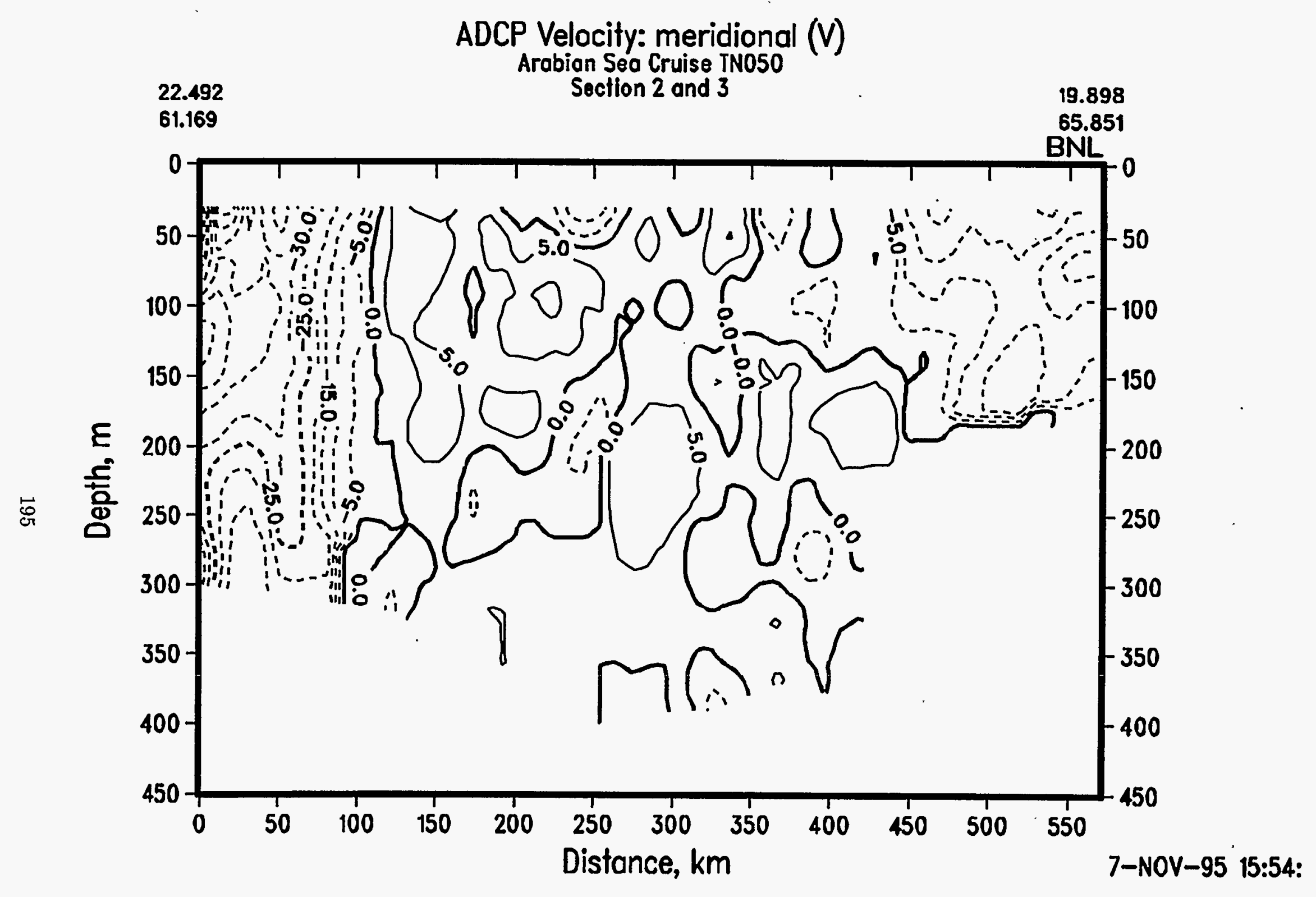




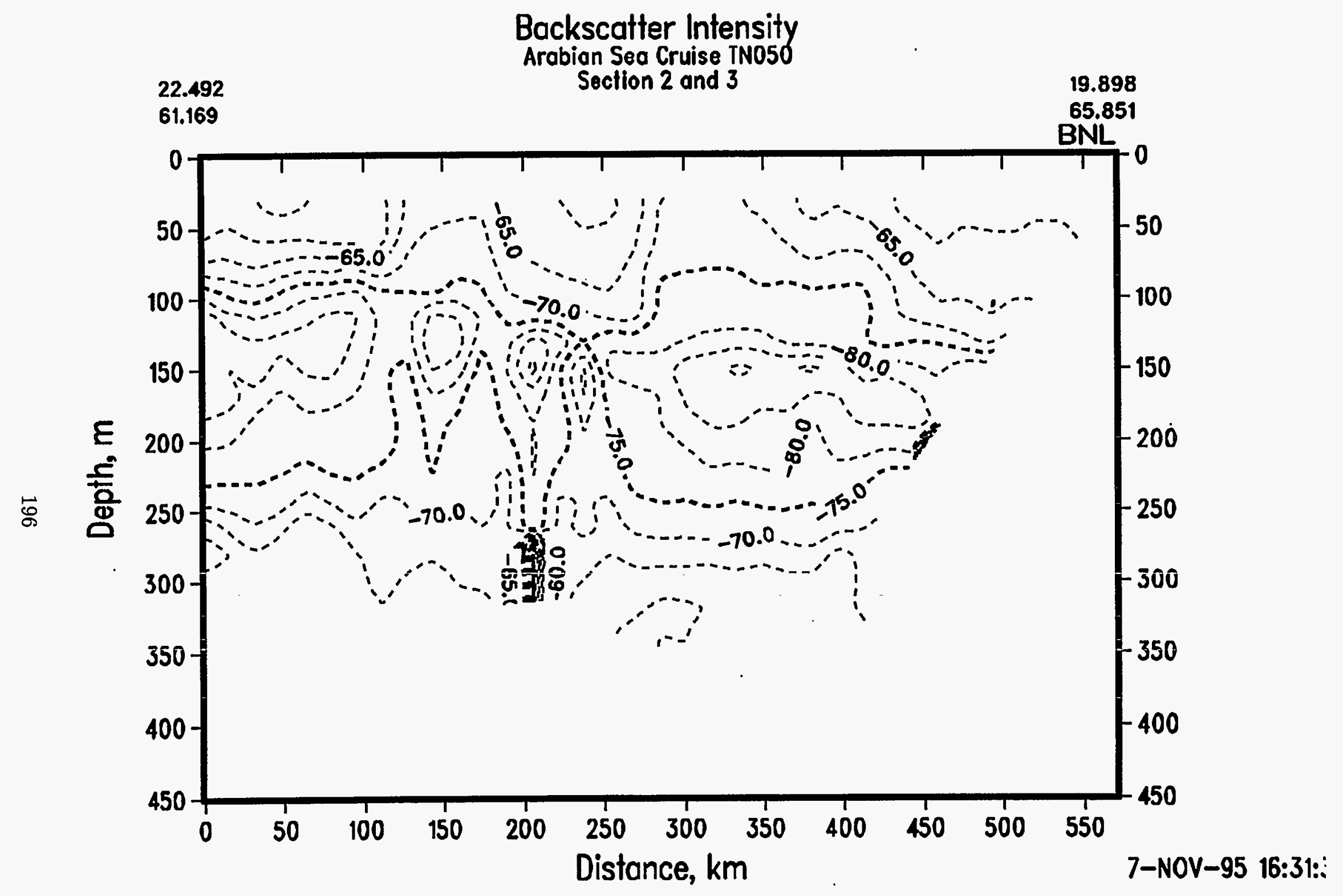




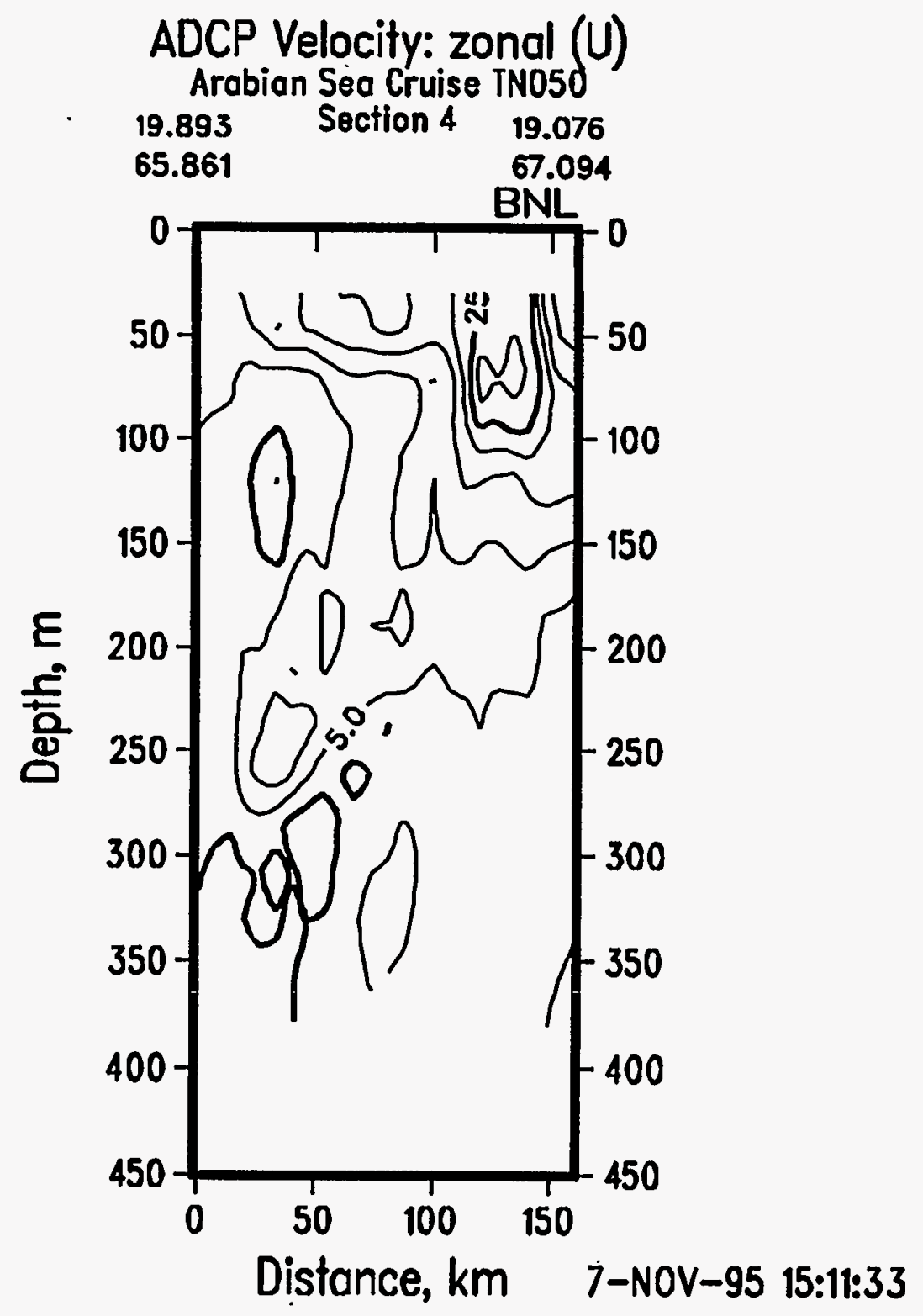




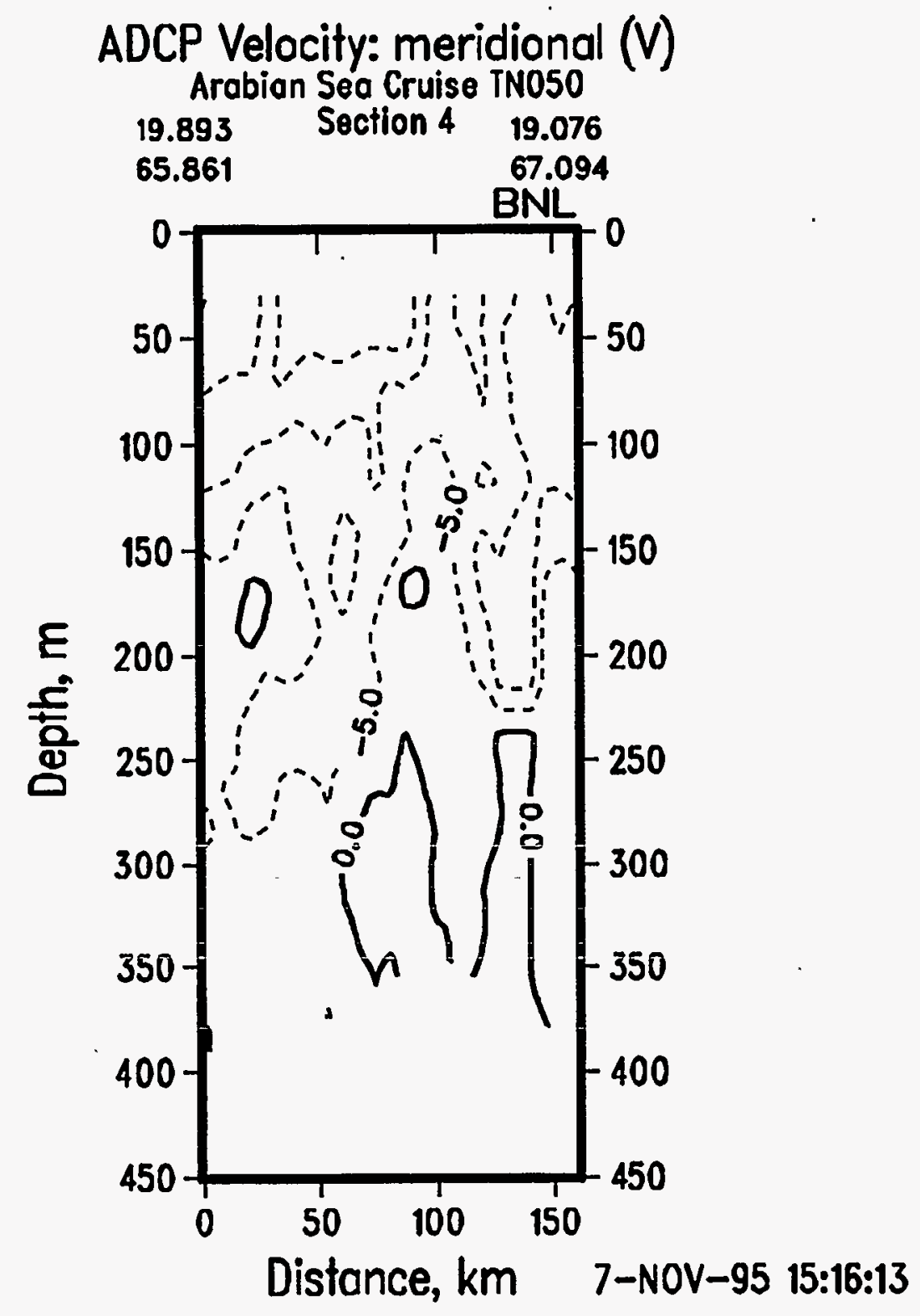




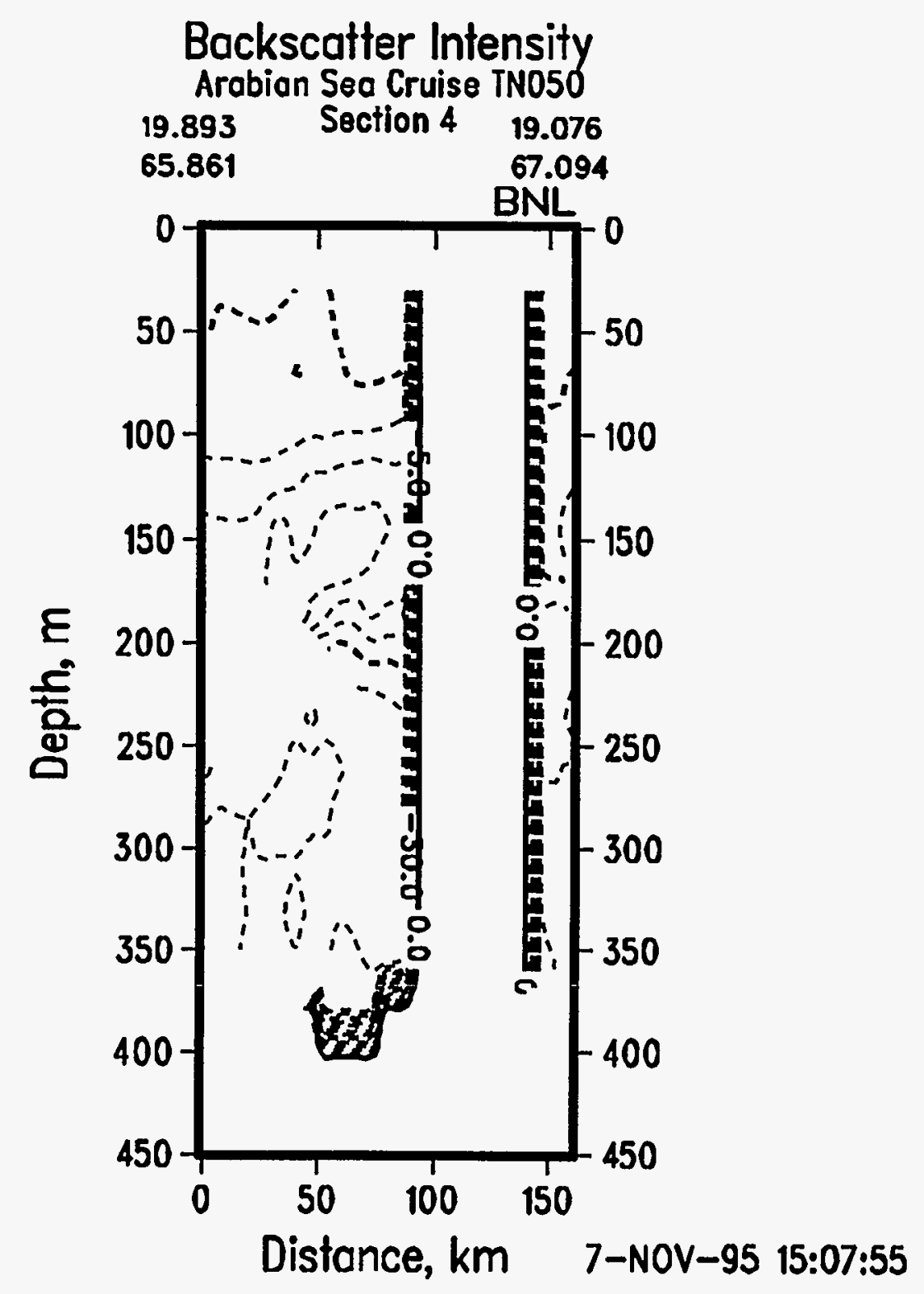




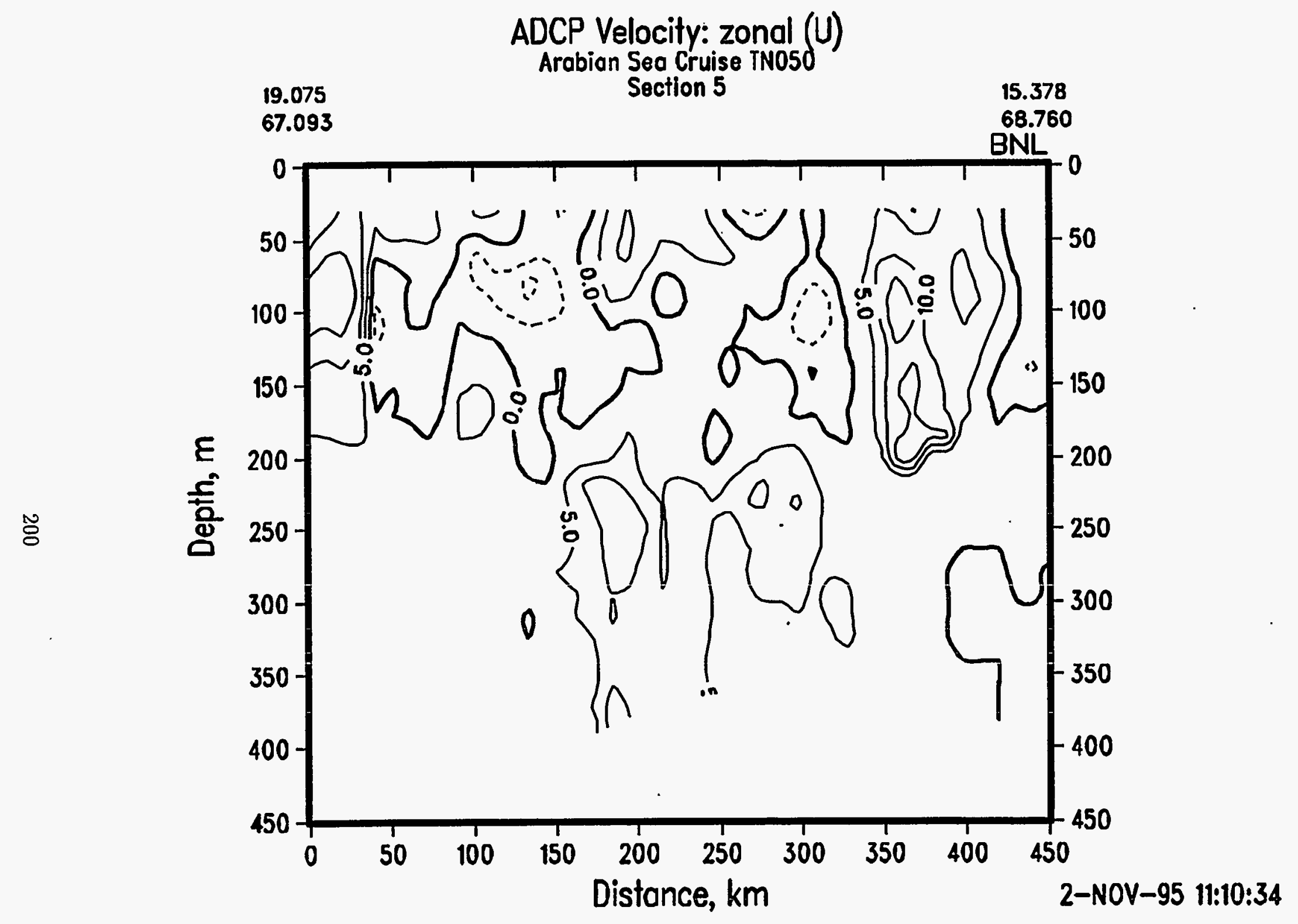




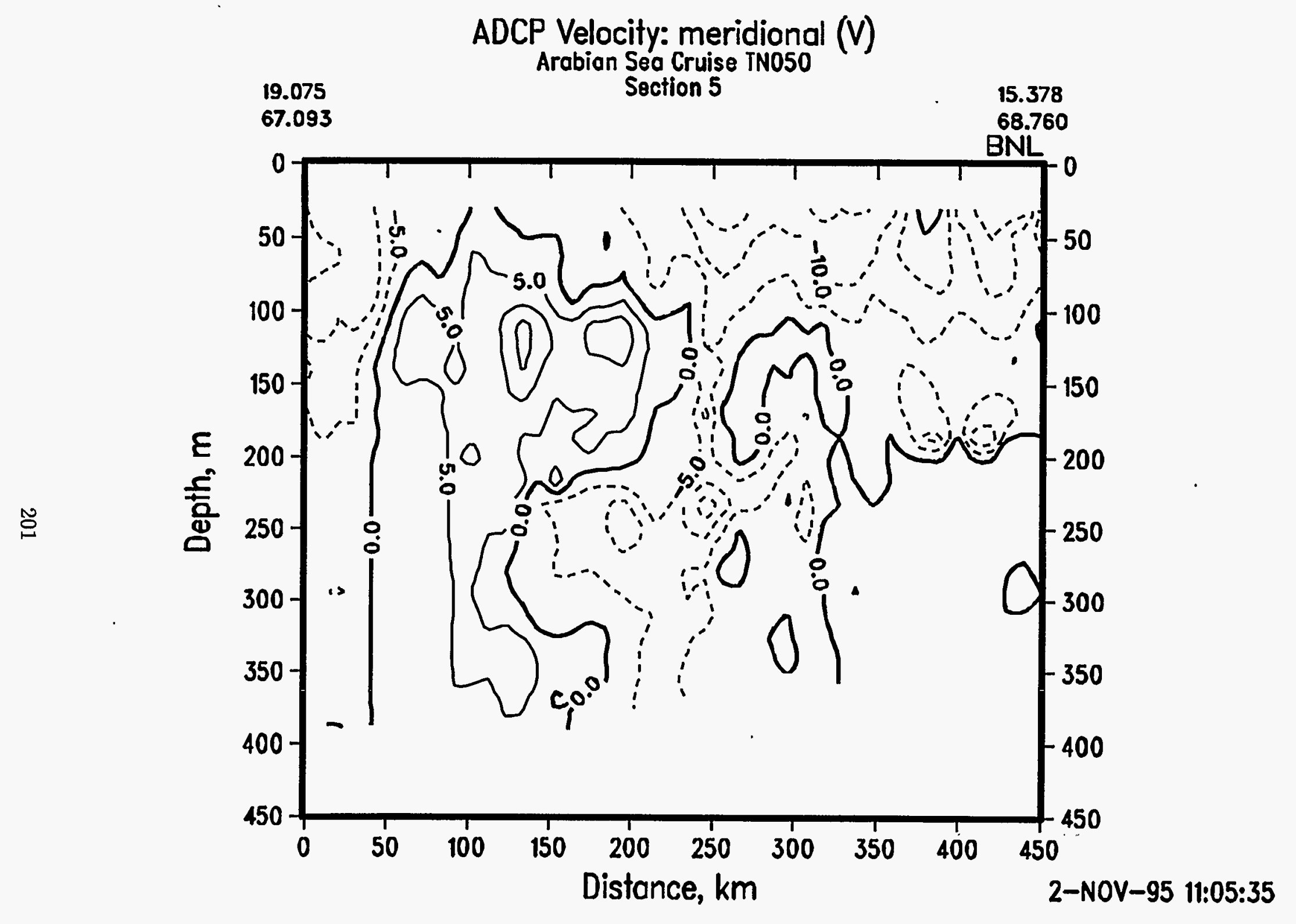




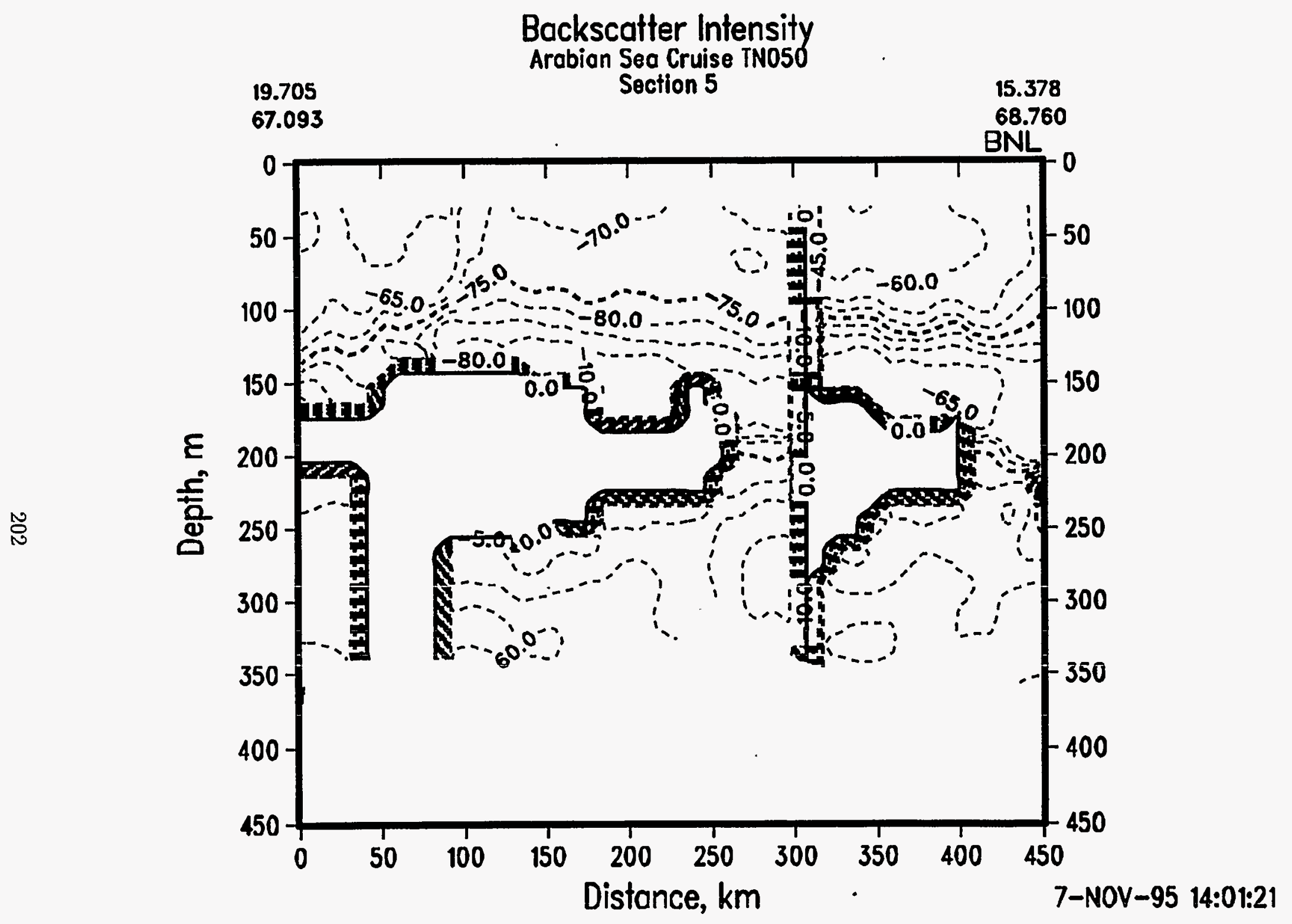




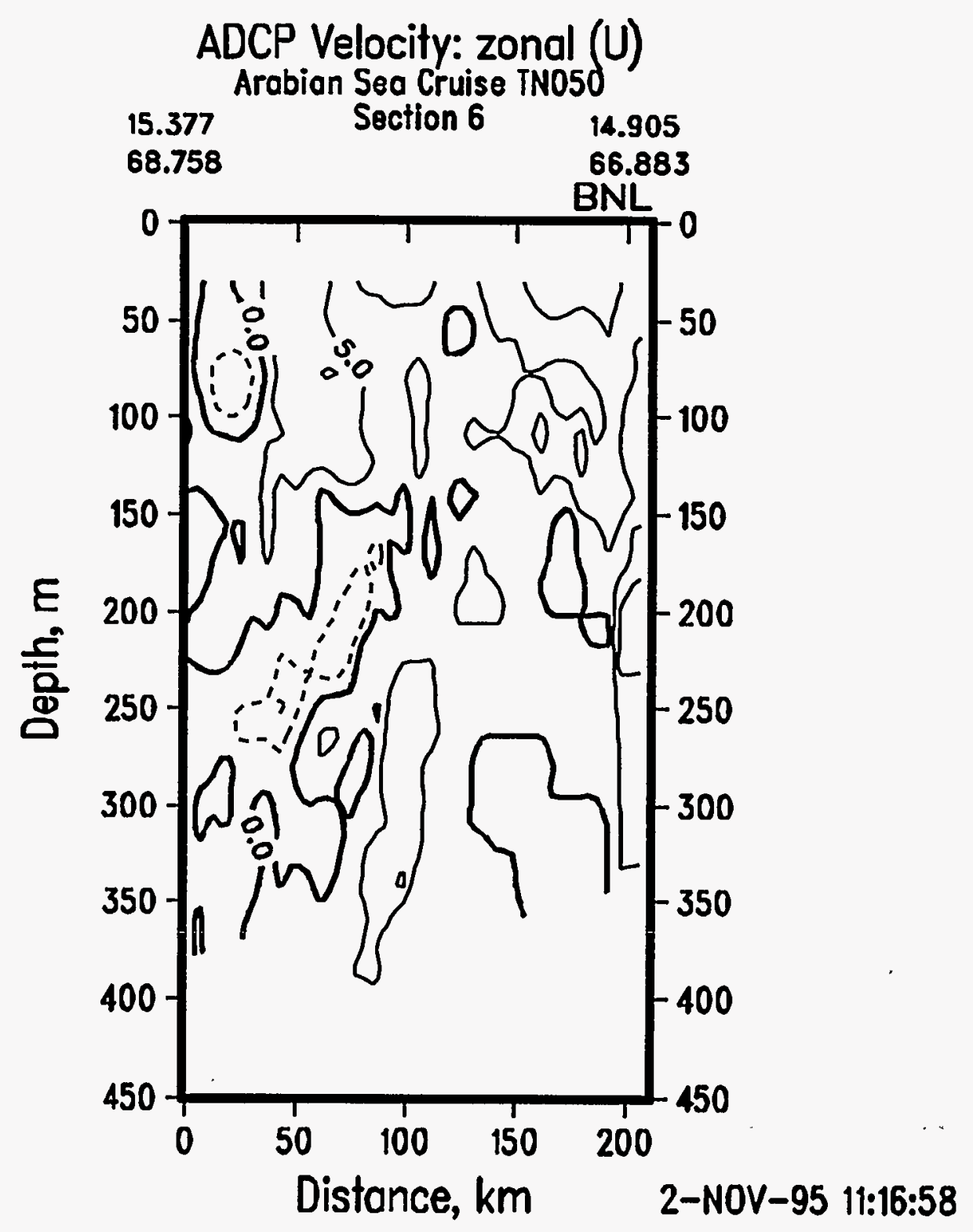




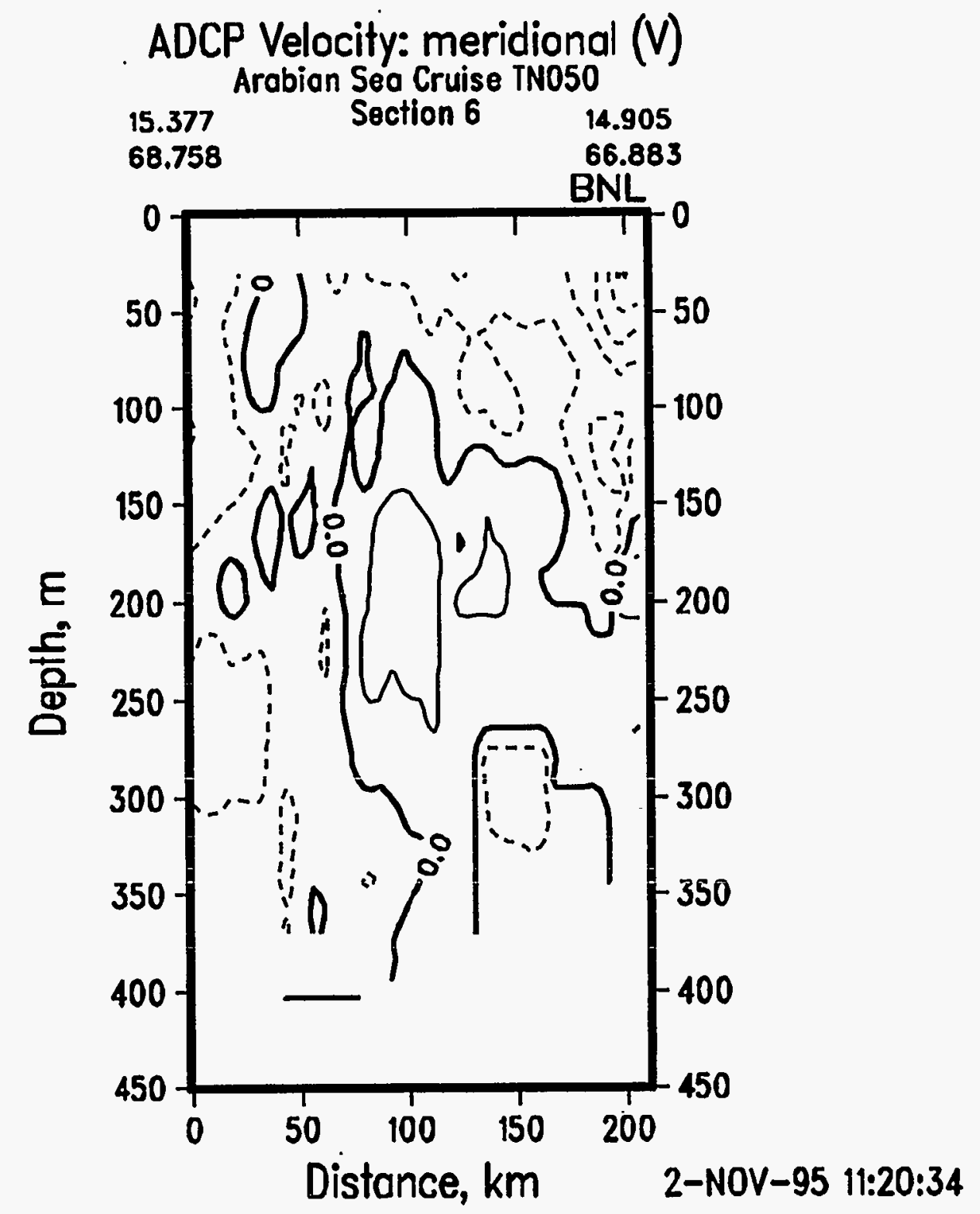




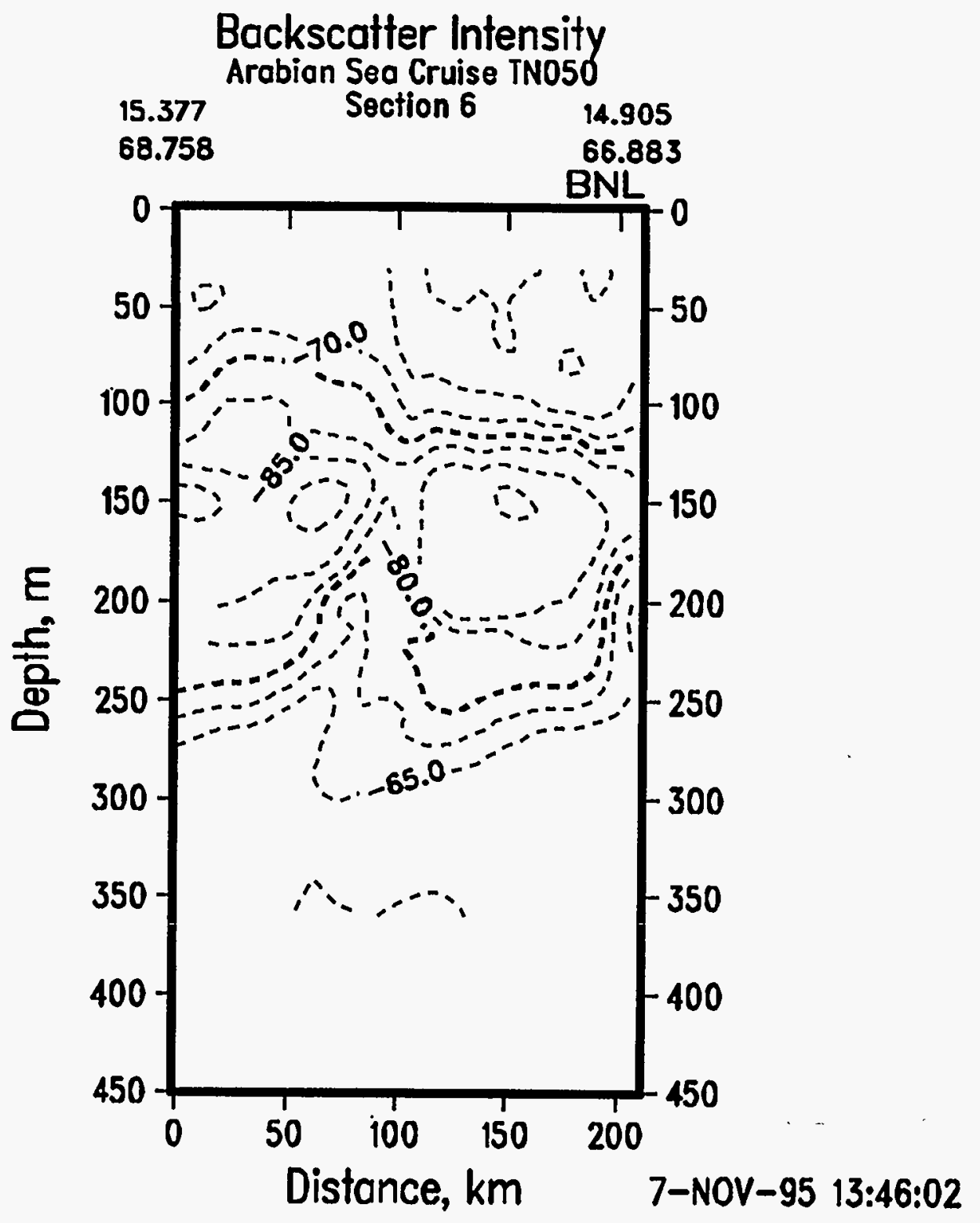




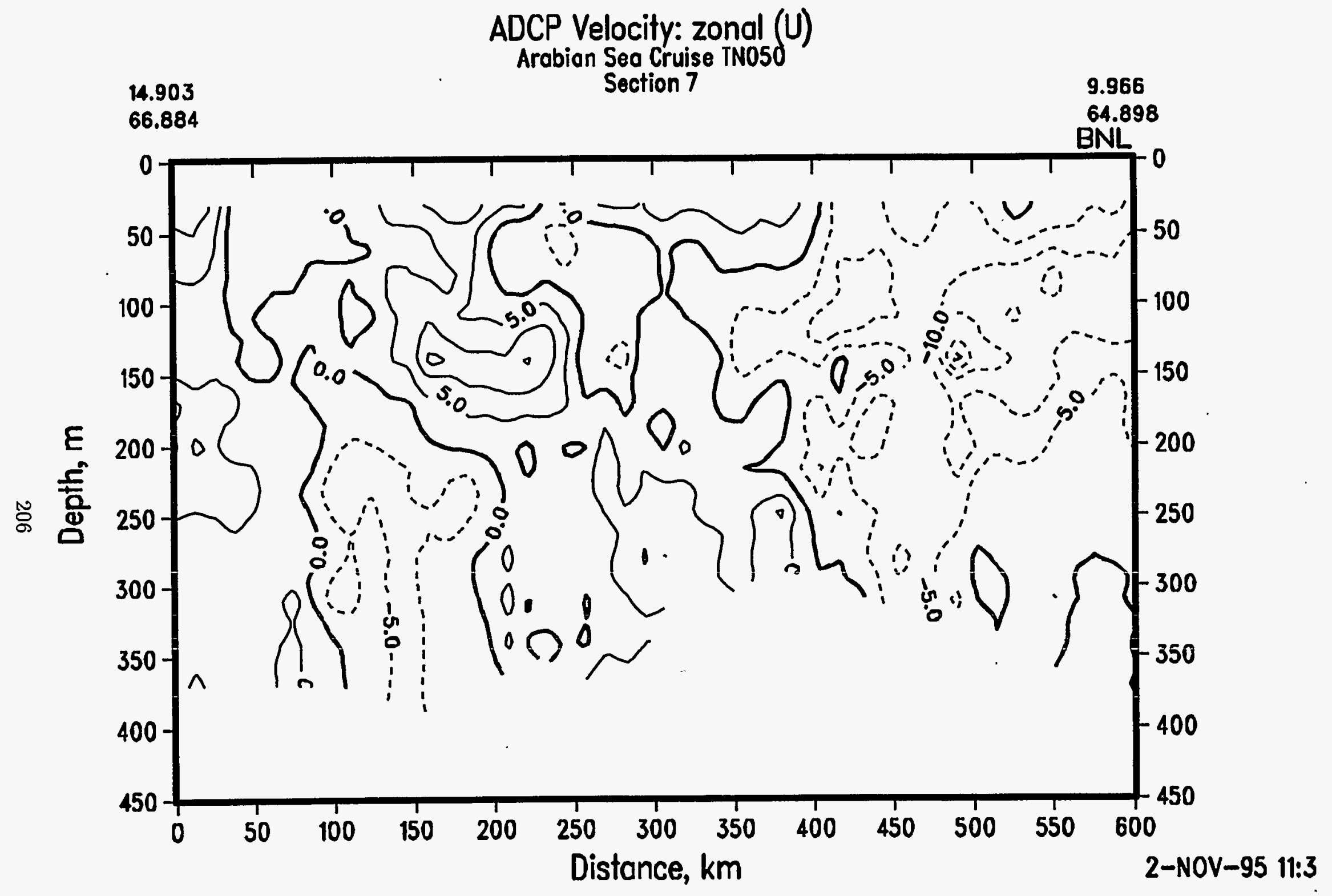




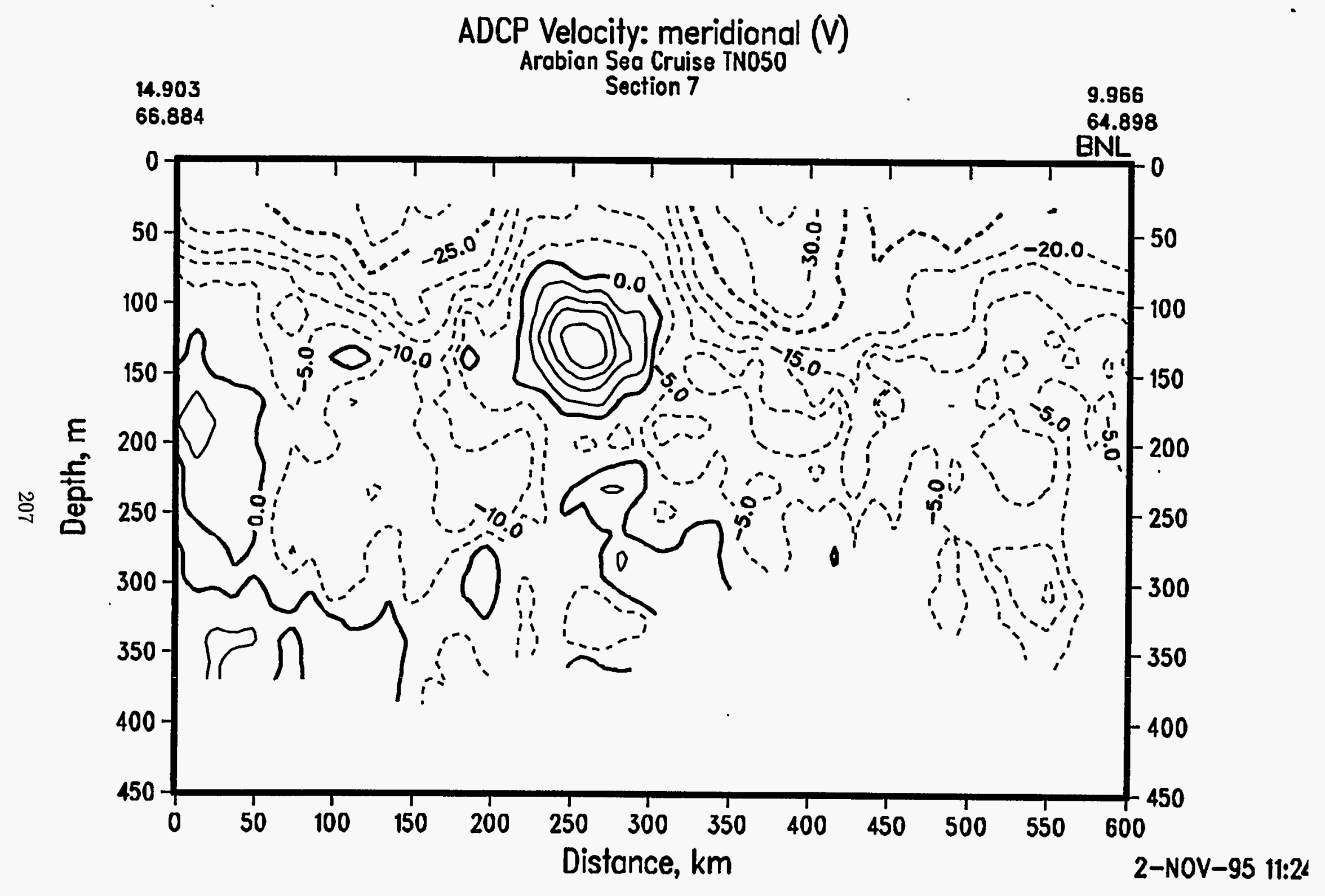




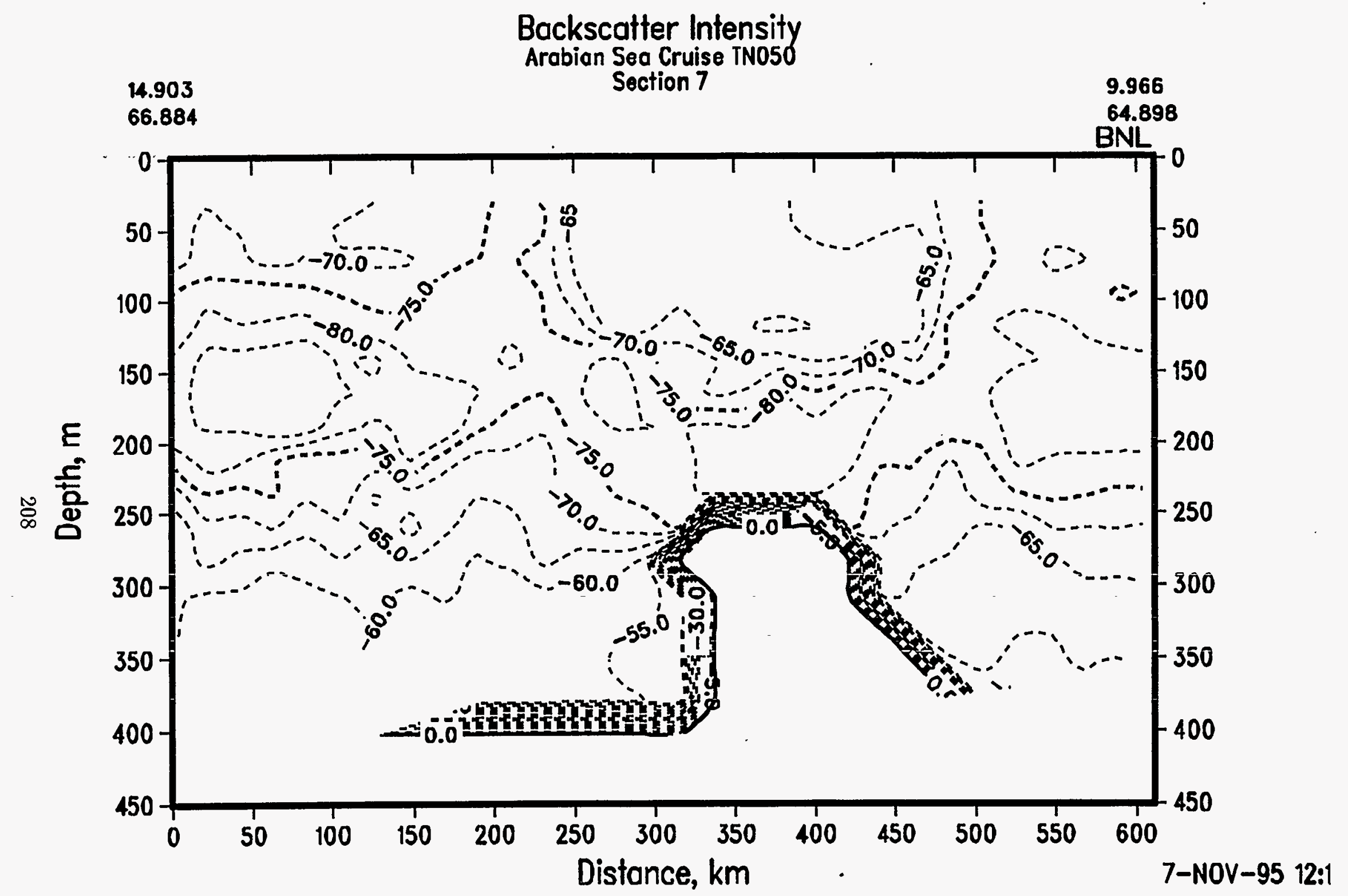




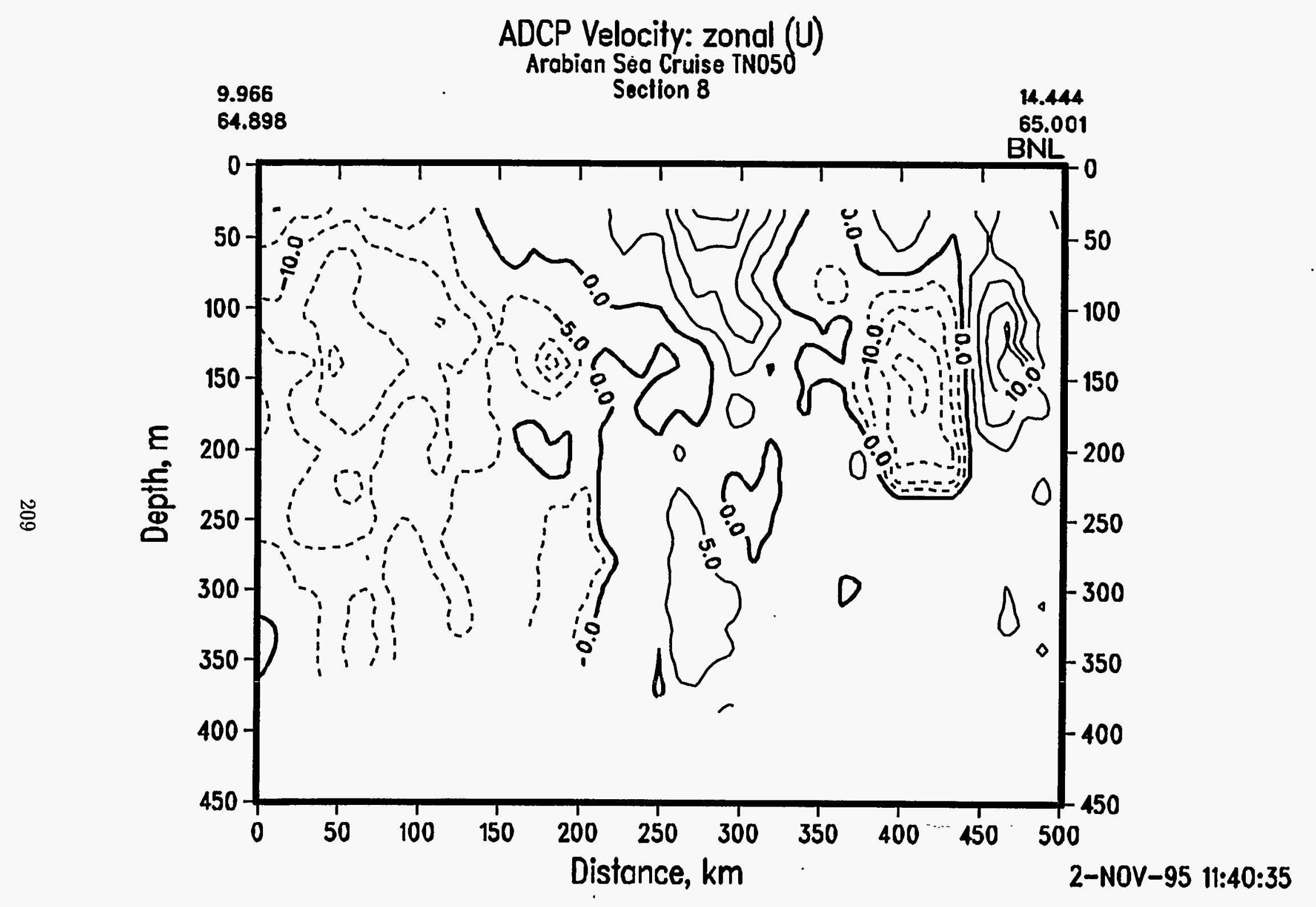




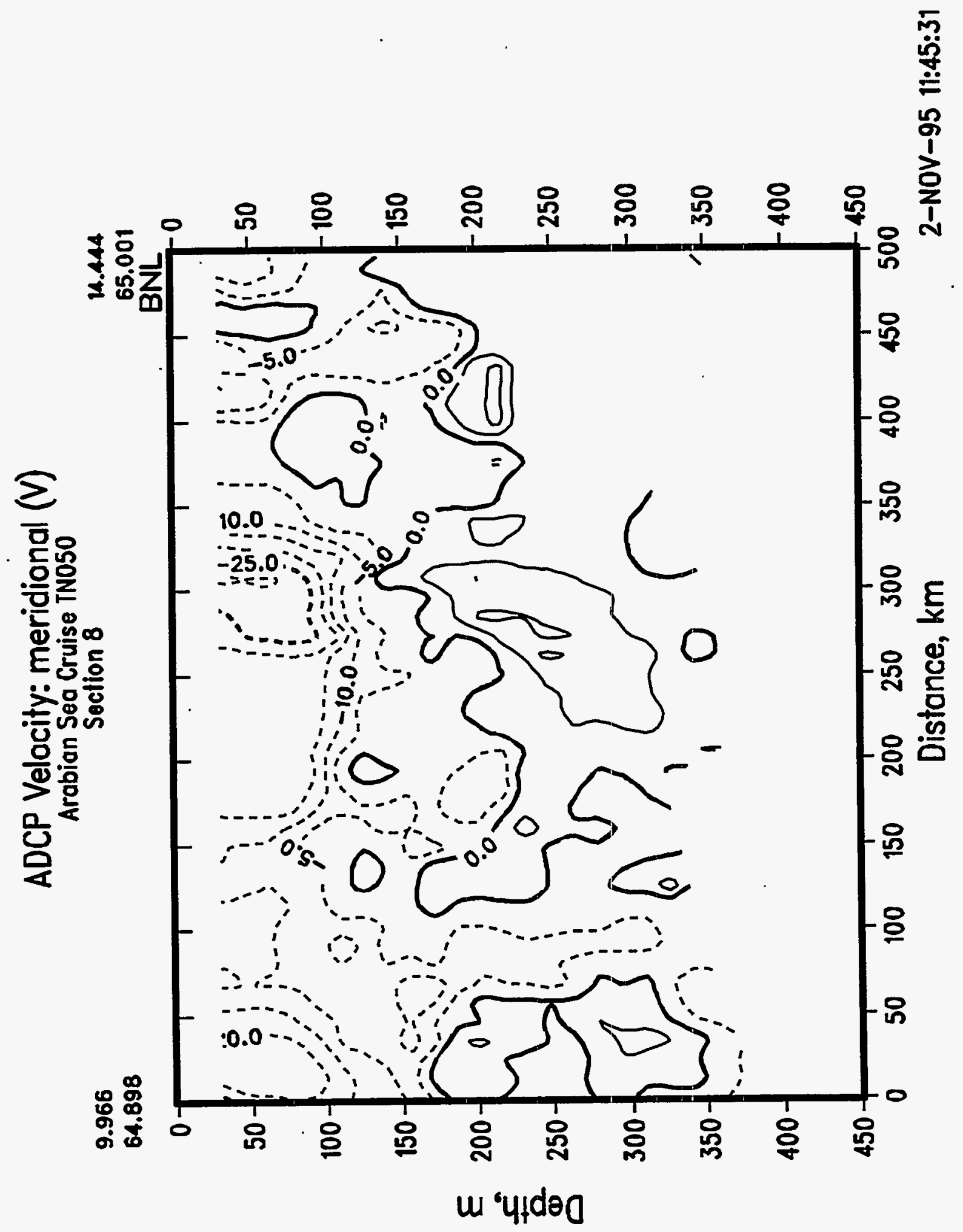




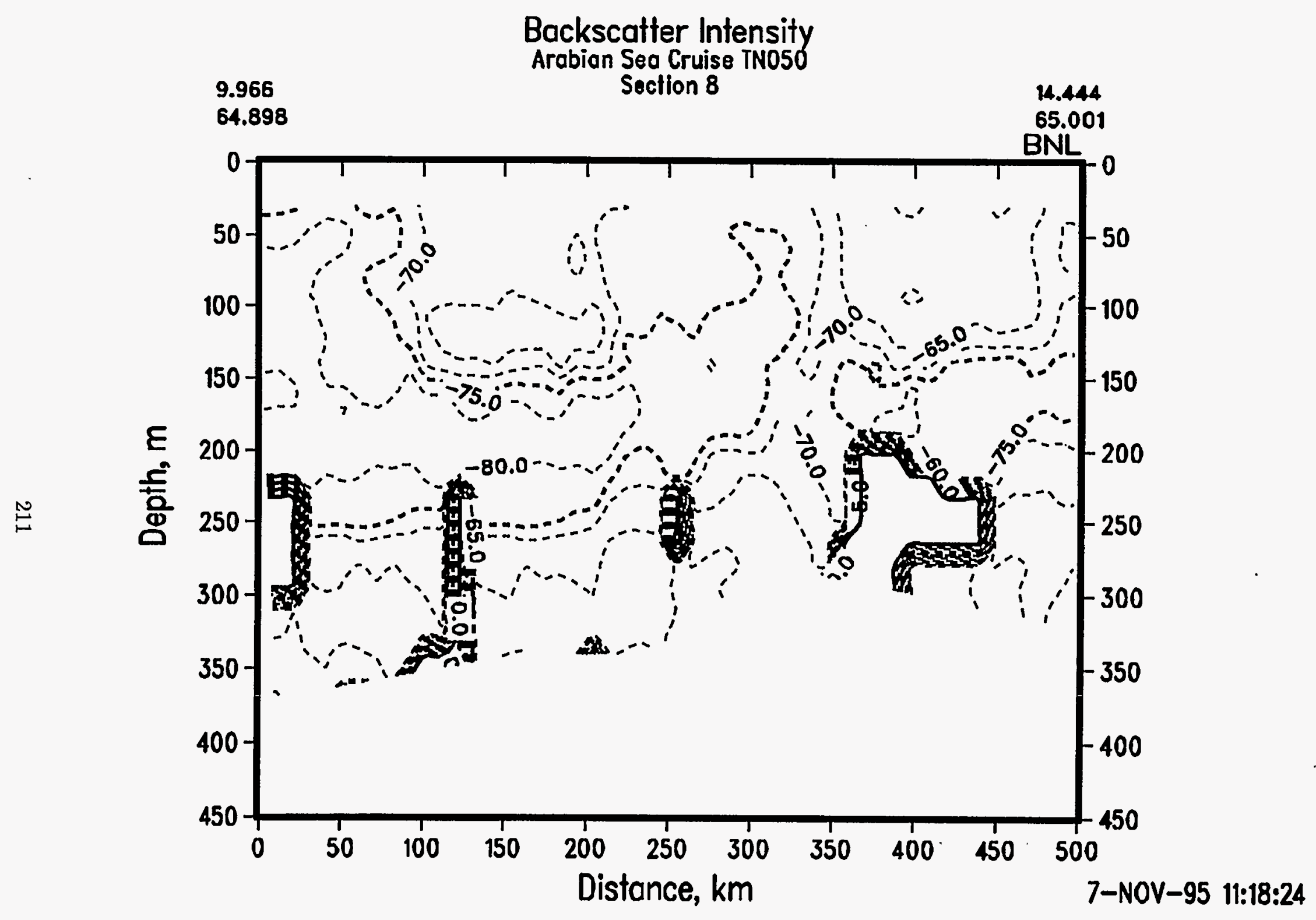




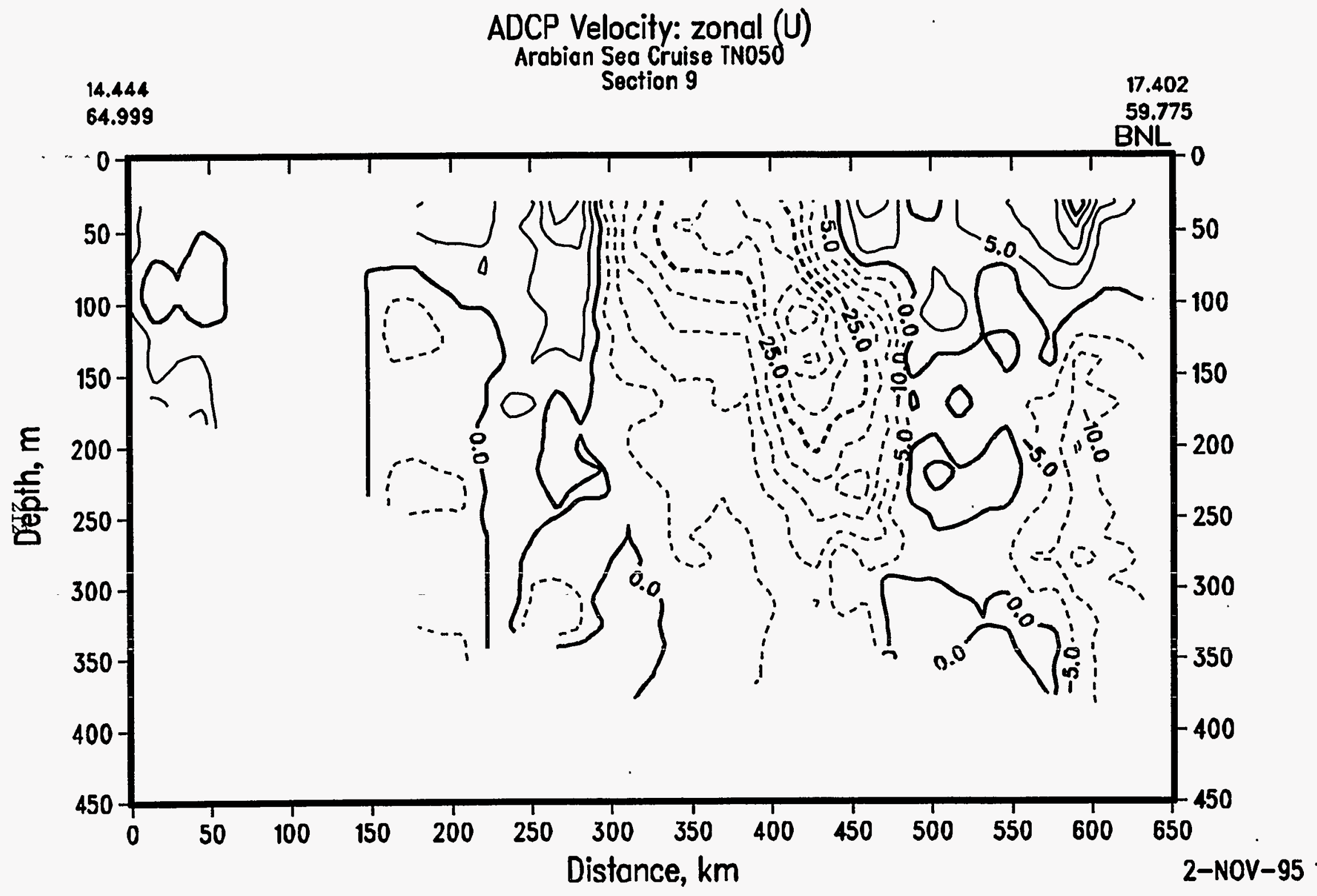




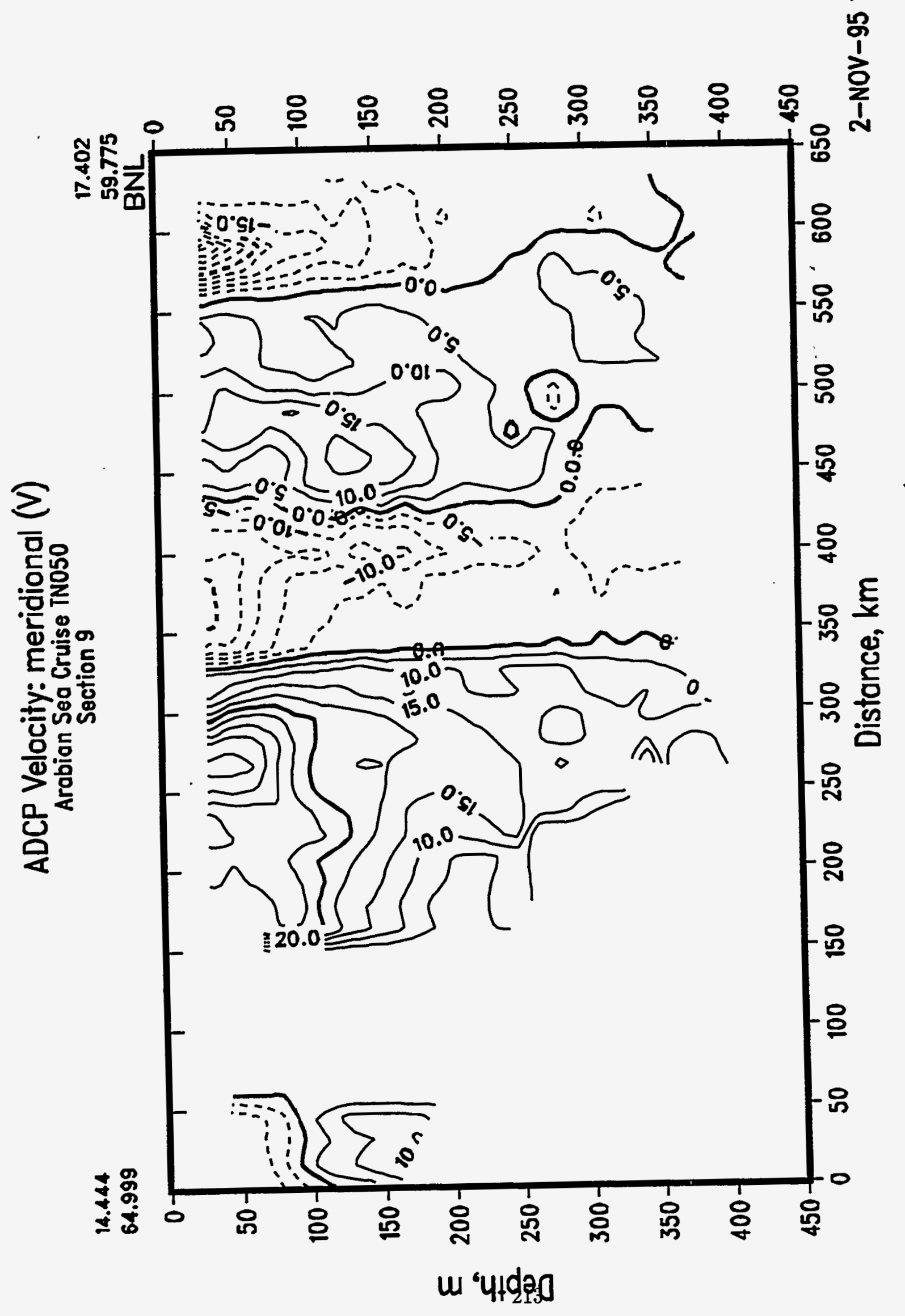




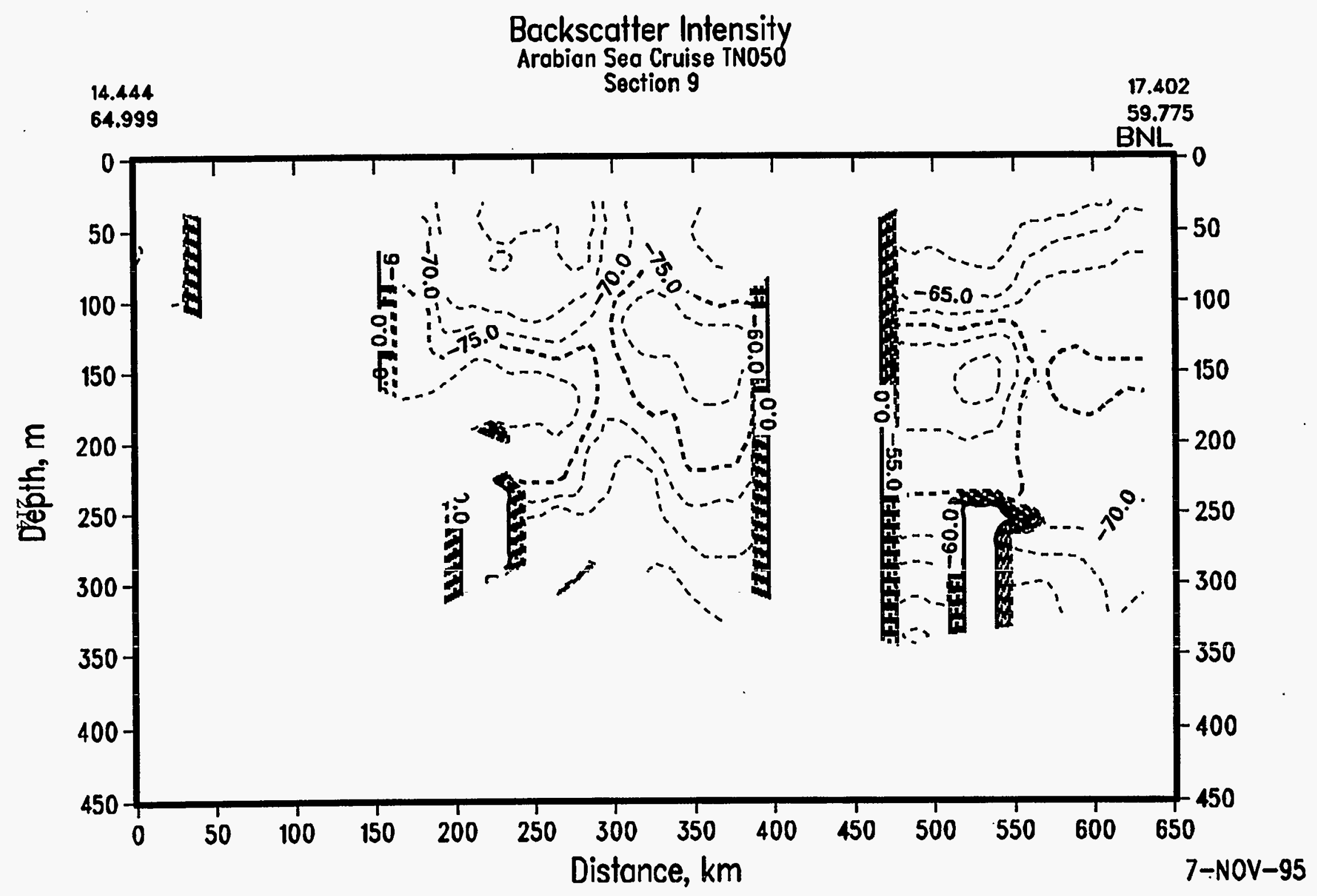




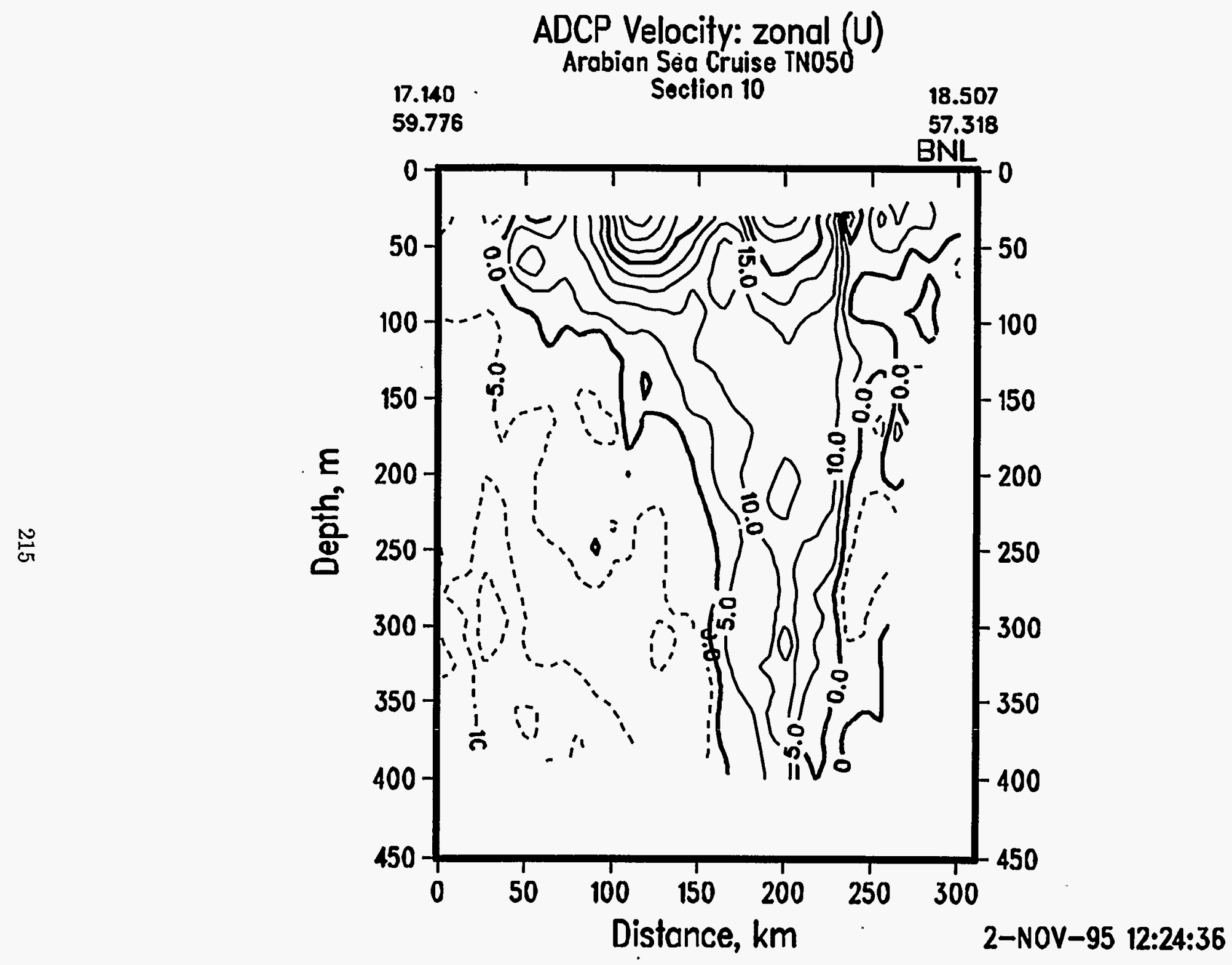




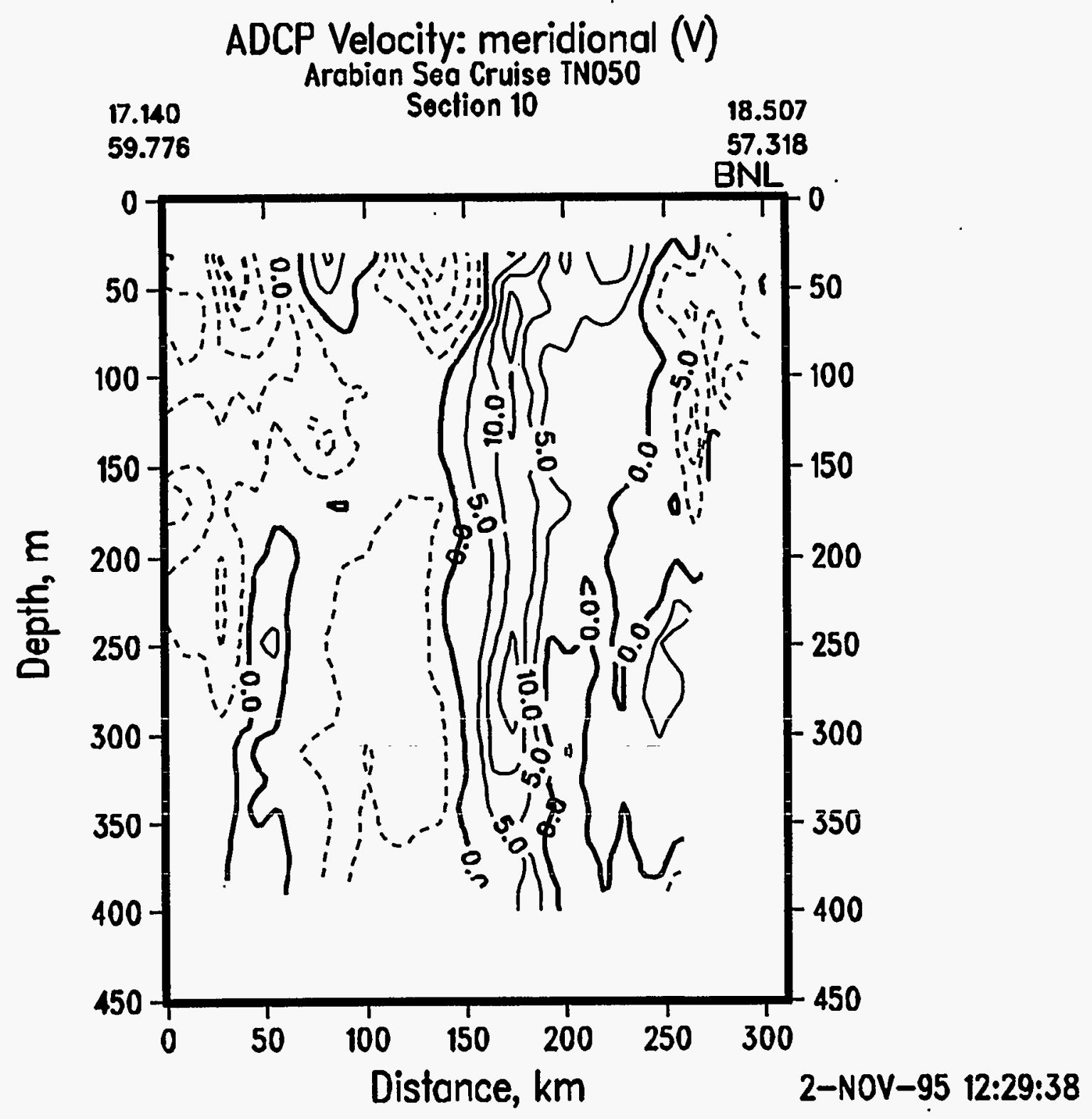




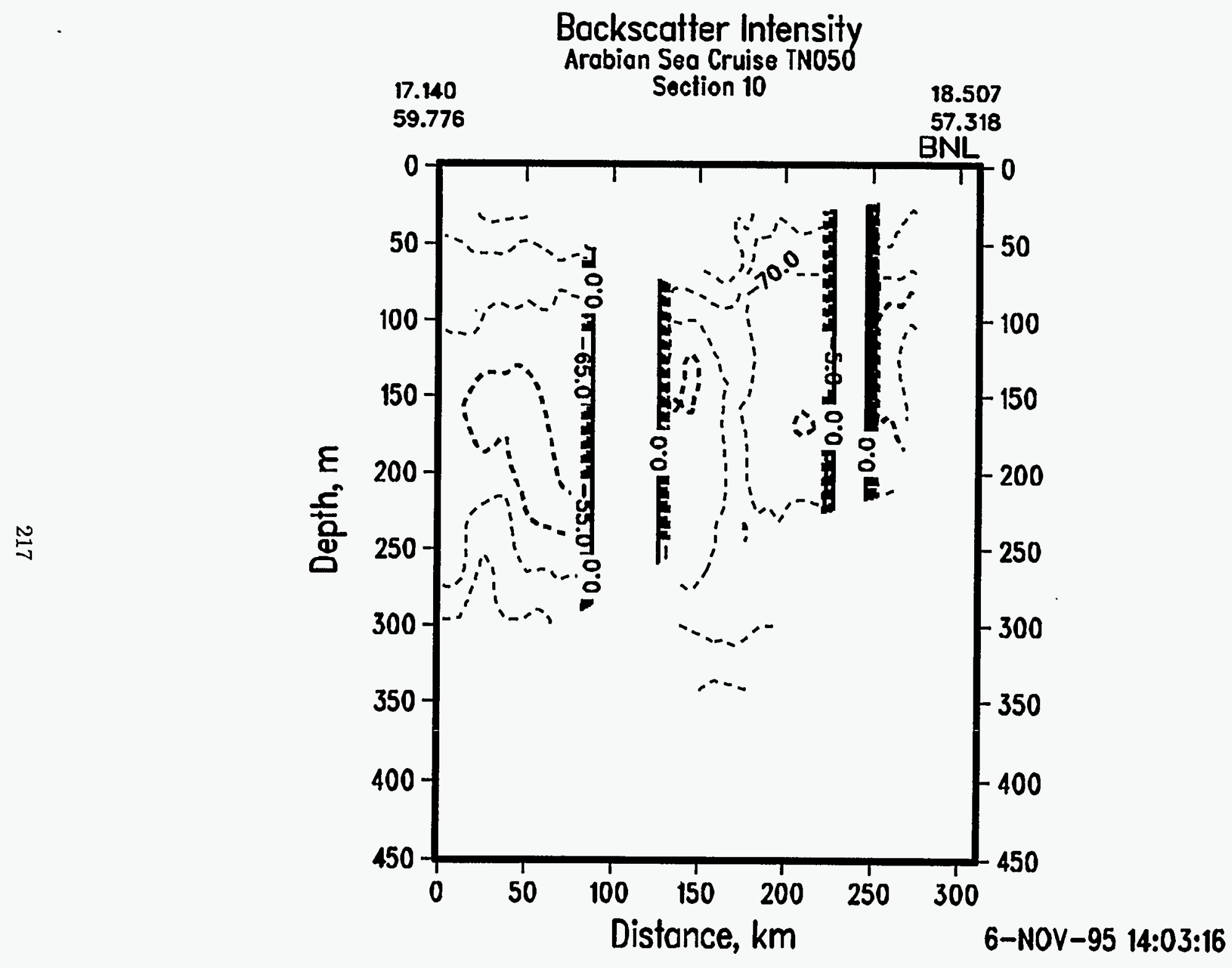




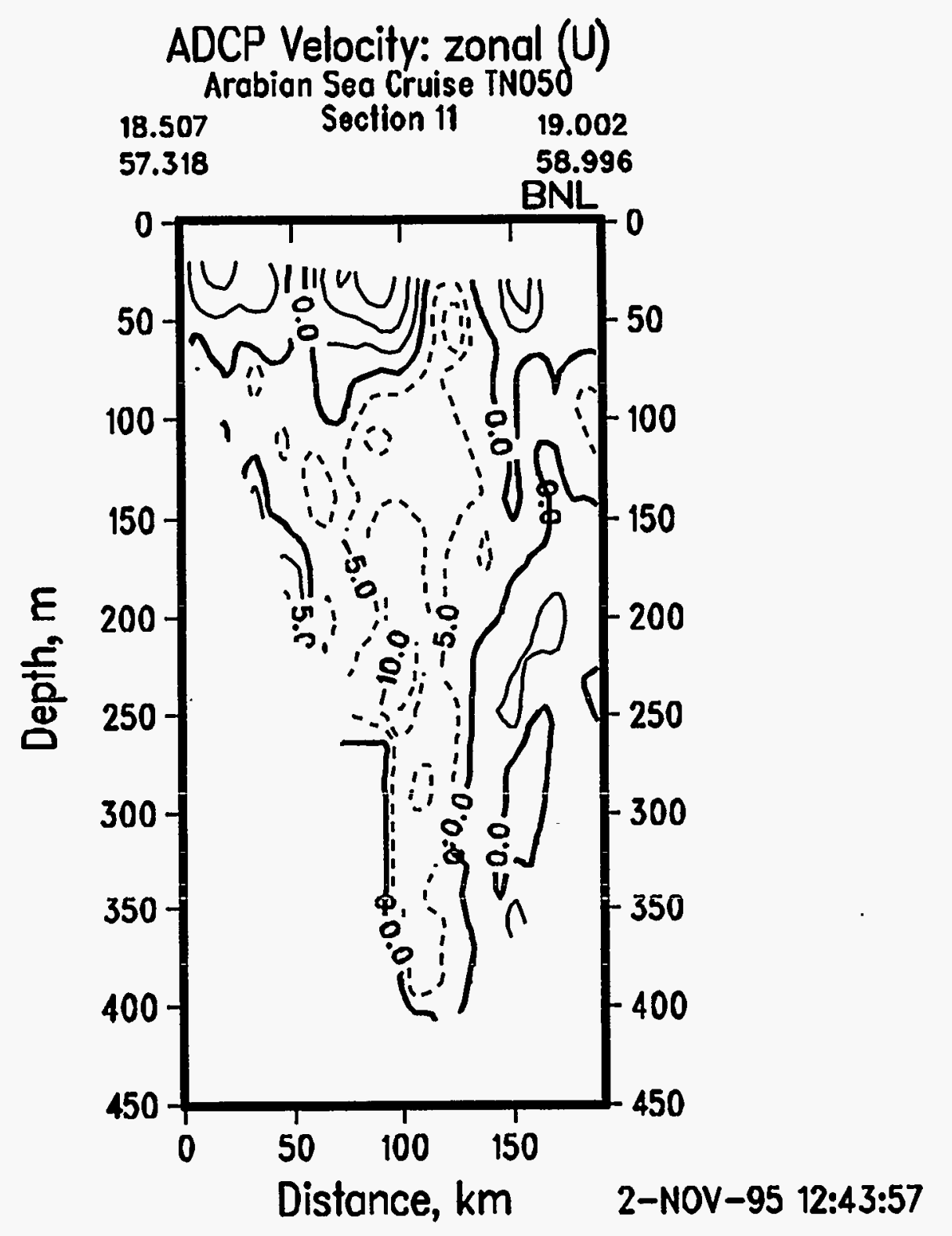




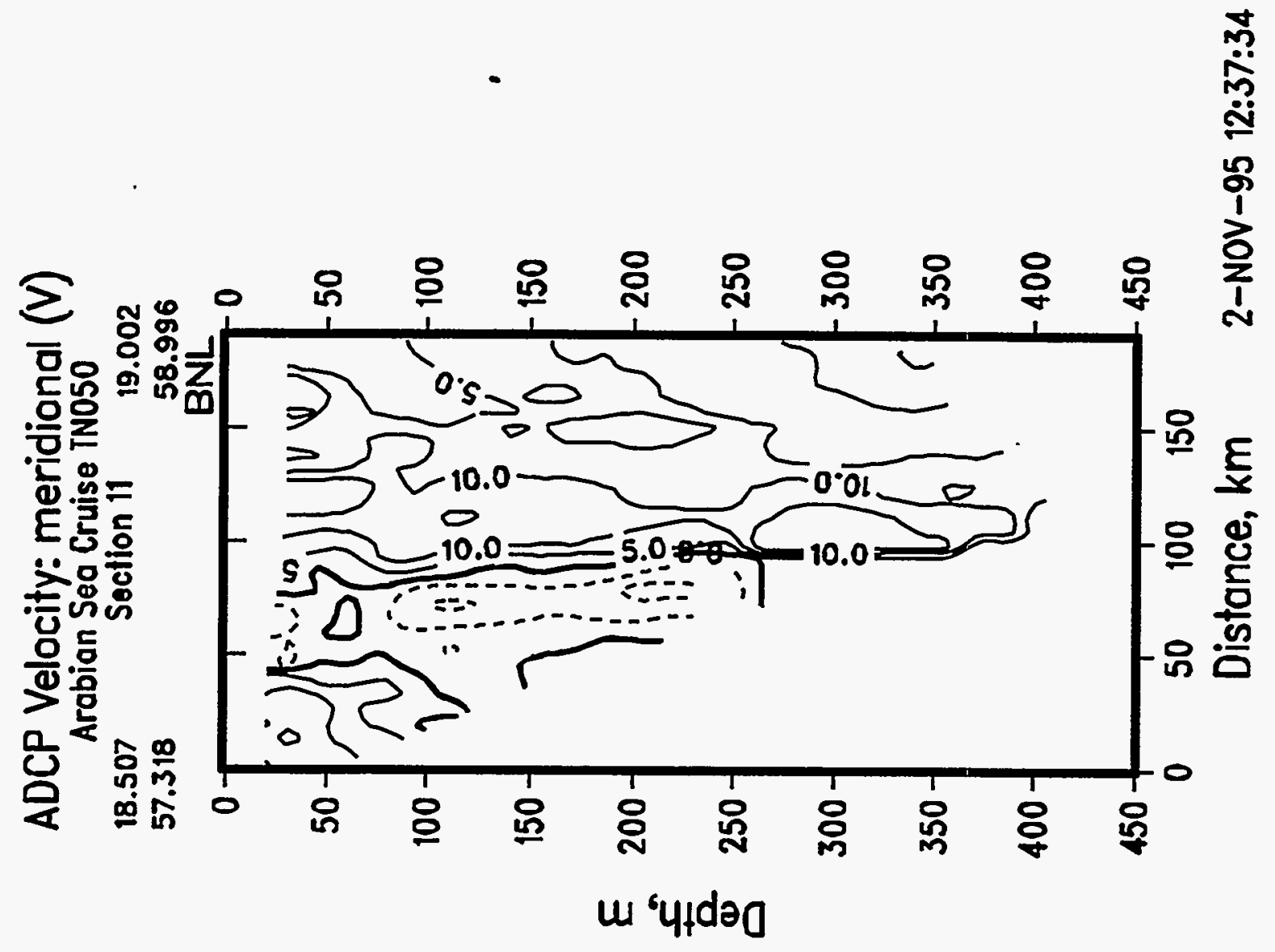




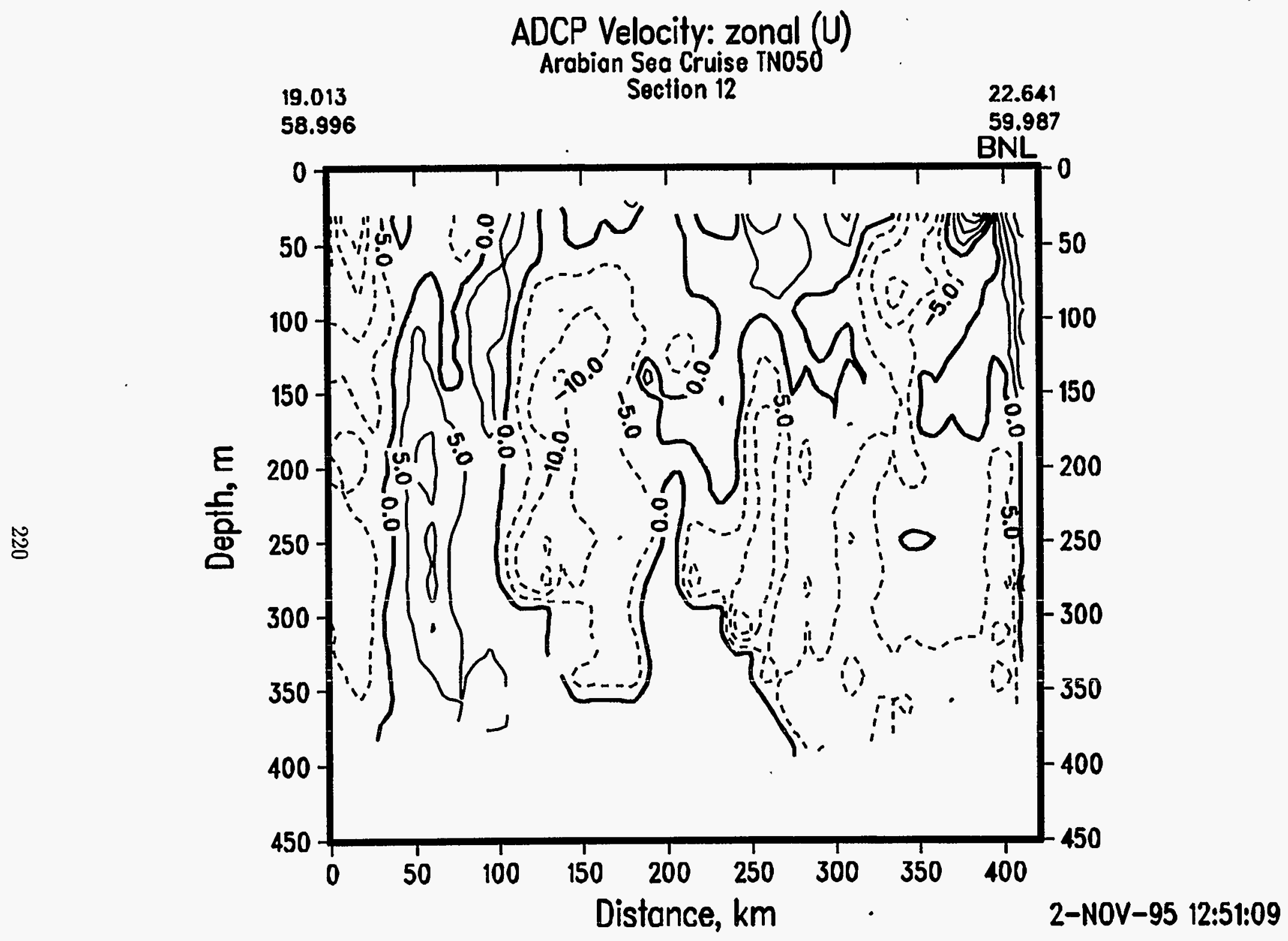




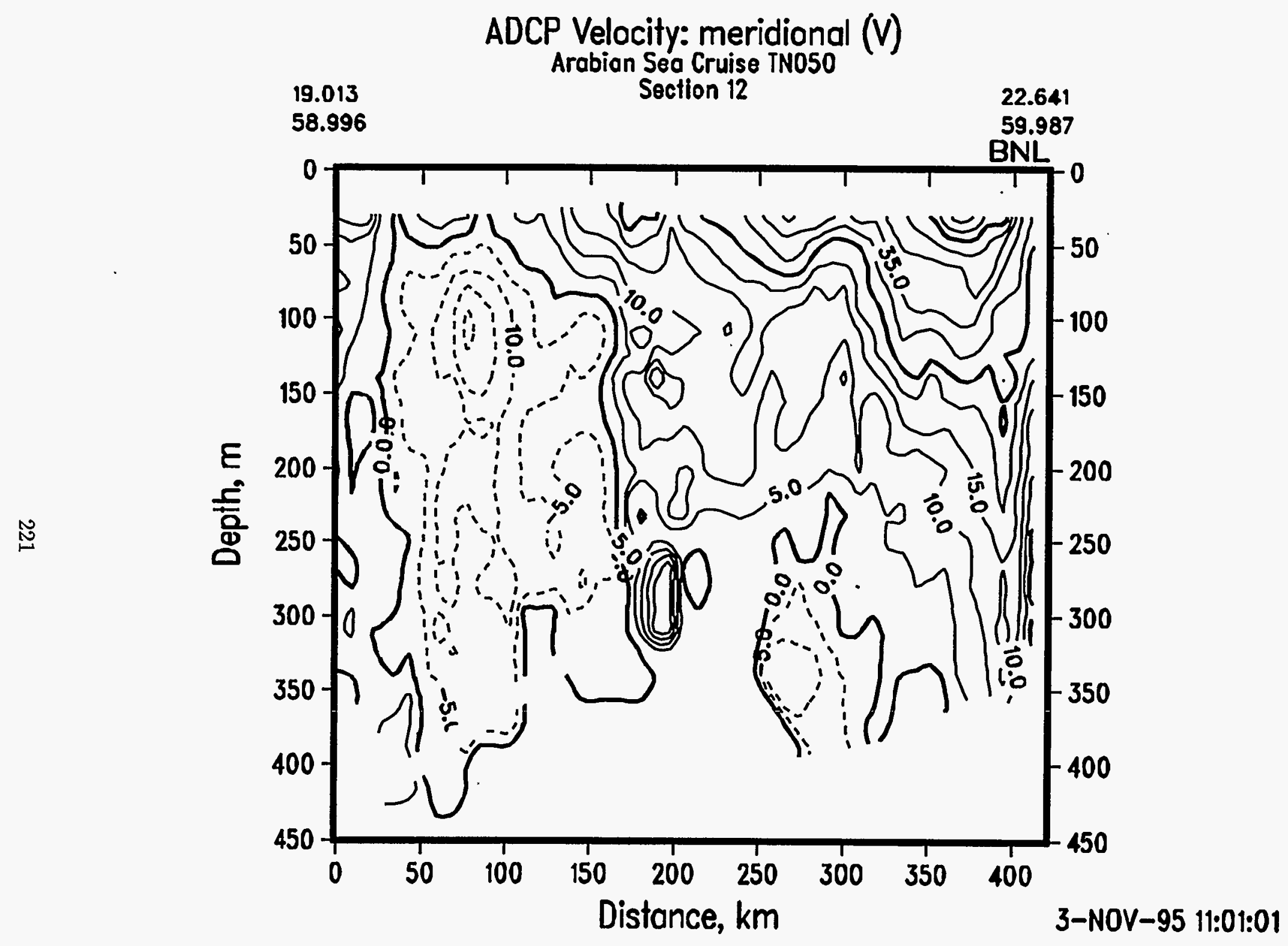




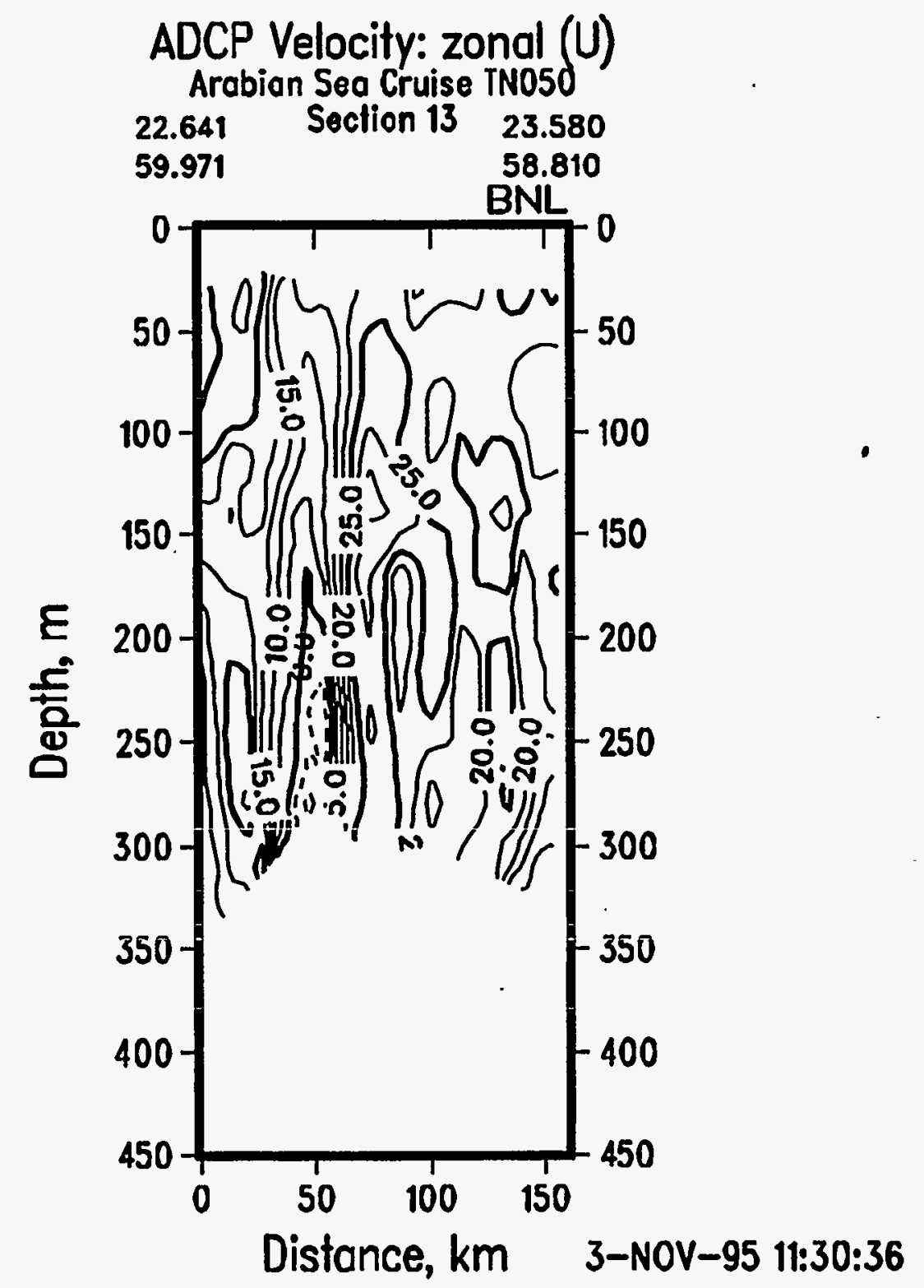




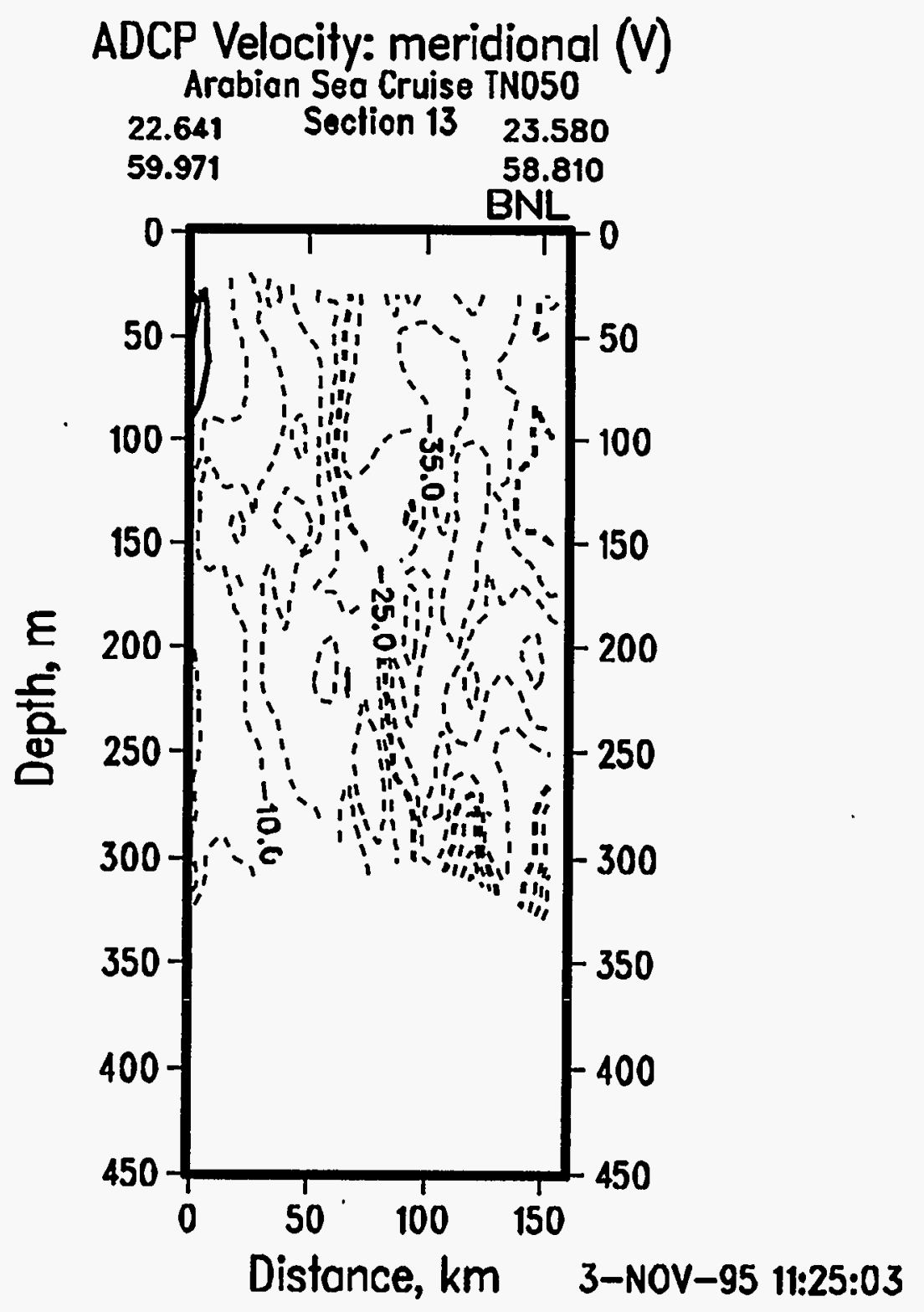

